\section{Small-Pore Zeolites: Synthesis and Catalysis}

\author{
Michiel Dusselier*, ${ }^{\dagger}$ and Mark E. Davis*, $*$ (1) \\ ${ }^{\dagger}$ Center for Surface Chemistry and Catalysis, KU Leuven, Celestijnenlaan 200F, 3001 Heverlee, Belgium \\ ${ }^{\ddagger}$ Chemical Engineering, California Institute of Technology, Mail Code 210-41, Pasadena, California 91125, United States
}

ABSTRACT: In the past decade or so, small-pore zeolites have received greater attention than large- and medium-pore molecular sieves that have historically dominated the literature. This is primarily due to the commercialization of two major catalytic processes, NOx exhaust removal and methanol conversion to light olefins, that take advantage of the properties of these materials with smaller apertures. Small-pore zeolites possess pores that are constructed of eight tetrahedral atoms $\left(\mathrm{Si}^{4+}\right.$ and $\left.\mathrm{Al}^{3+}\right)$, each time linked by a shared oxygen These eight-member ring pores (8MR) provide small molecules access to the intracrystalline void space, e.g., to NOx during car exhaust cleaning (NOx removal) or to methanol en route to its conversion into light olefins, while restricting larger molecule entrance and departure that is critical to overall catalyst performance. In total, there are forty-four structurally different small-pore zeolites. Fortyone of these zeolites can be synthesized, and the first synthetic zeolite (KFI, 1948) was in fact a small-pore material. Although the field of $8 \mathrm{MR}$ zeolite chemistry has expanded in

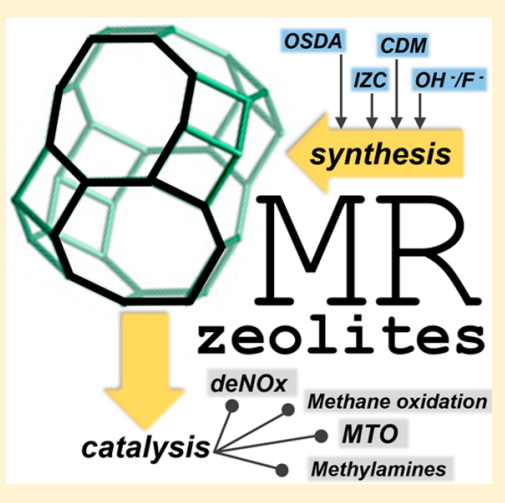
many directions, the progress in synthesis is framework-specific, leaving insights and generalizations difficult to realize. This review first focuses on the relevant synthesis details of all $8 \mathrm{MR}$ zeolites and provides some generalized findings and related insights. Next, catalytic applications where $8 \mathrm{MR}$ zeolites either have been commercialized or have dominated investigations are presented, with the aim of providing structure-activity relationships. The review ends with a summary that discusses (i) both synthetic and catalytic progress, (ii) a list of opportunities in the $8 \mathrm{MR}$ zeolite field, and (iii) a brief future outlook.

\section{CONTENTS}

1. Introduction

1.1. General Introduction to Zeolite Catalysts

1.2. 8MR Zeolites: Definitions and Scope of the Review

1.3. Introduction to the Use of $8 \mathrm{MR}$ Zeolites as Catalysts

2. Synthesis of 8MR Zeolites

2.1. Introduction to Different Strategies for Making 8MR Zeolites

2.2. Overview of Si/Al Ratios and Methods per Framework

2.3. Synthesis Details of 11 Significant Frameworks

2.3.1. AEI

2.3.2. AFX

2.3.3. CHA

2.3.4. DDR

2.3.5. ERI (and EAB)

2.3.6. GIS

2.3.7. KFI

2.3.8. LEV

2.3.9. LTA

2.3.10. RHO and Its New Family (PAU, MWF)

2.3.11. RTH

2.4. Summary Points of Zeolite Synthesis and Its Mechanisms

3. Catalysis with $8 \mathrm{MR}$ Zeolites

3.1. Introduction
3.2. Selective Catalytic Reduction (SCR or deNOx) for Exhaust Cleaning

3.2.1. Introduction to SCR and General Features of SCR with Zeolites
B

B

D

E

E

I

I I

L

M

$\mathrm{T}$

U

V

W

$X$

Z

$A D$

AE

AF

Al
3.2.2. Overview of Small-Pore Zeolite Catalysts for SCR of NOx

3.2.3. Cu-Zeolite Catalyzed SCR: The Impact of Topology

3.2.4. Fe-Zeolite Catalyzed SCR

3.2.5. Synthesis-Structure-Activity Observations

3.2.6. Conclusions from $\mathrm{NH}_{3}-\mathrm{SCR}$ of $\mathrm{NOx}$ with 8MR Zeolites

3.3. Partial Oxidation of Methane to Methanol

3.3.1. Introduction to Methane-to-Methanol with Transition Metal-Exchanged Zeolites

3.3.2. Small-Pore Cu-Zeolites for Methane Oxidation

3.3.3. Conclusions on Small-Pore Zeolites for Methane Oxidation

3.4. Olefin Generation: Methanol-to-Olefins (MTO) and Ethanol/Ethylene Conversion

3.4.1. History and General Chemistry of MTO

3.4.2. Overview and Specifics of Small-Pore Zeolite MTO

AO 
3.4.3. Key Structure-Activity Relations in Zeolite-Catalyzed MTO

3.4.4. Overarching Analysis of Small-Pore Zeolite Cavities for MTO

3.4.5. Conclusions of Small-Pore Cage-Based Zeolite-Catalyzed MTO

3.4.6. Olefin Generation from Ethanol or Ethylene Conversions: ETO and ETP

3.5. Methylamine Synthesis

3.5.1. Introduction to Zeolite-Catalyzed Methylamine Synthesis

3.5.2. Small-Pore Zeolites for Methylamine Synthesis from Methanol and Ammonia

3.6. Other Relevant Reactions

3.6.1. Cracking

3.6.2. Structure-Activity Relation of Al-Pairing in CHA for Dimethyl Ether Formation

4. Summary-Opportunities-Outlook

4.1. General Summary

4.2. Opportunities in Synthesis and Catalysis

4.3. Outlook

Author Information

Corresponding Authors

ORCID

Notes

Biographies

Acknowledgments

Abbreviations

References

\section{INTRODUCTION}

\subsection{General Introduction to Zeolite Catalysts}

Zeolites are a group of crystalline, microporous materials that are constructed from regular networks of alumina and silica tetrahedra $\left(\mathrm{TO}_{4}-\right.$ oxygen atoms bridge the tetrahedral atoms). ${ }^{1,2}$ These oxide networks, technically also known as tectoaluminosilicates, are often relatively open, through the presence of specific sub-2-nanometer pores and cages. Besides zeolites, that in the strict sense only have $\mathrm{Si}^{4+}$ and $\mathrm{Al}^{3+}$ in $\mathrm{T}$ atom positions, porous oxides with other elements that allow tetrahedral coordination, e.g., $\mathrm{P}^{5+}, \mathrm{Ti}^{4+}, \mathrm{Ge}^{4+}, \mathrm{Ga}^{3+}, \mathrm{Co}^{2+}$, or $\mathrm{Zn}^{2+}$, are known. The channels and voids allow for the intracrystalline transport, adsorption, and reaction of molecules and explain the use of the term molecular sieves for this broad class of inorganic materials. Currently, the diversity of existing crystalline molecular sieve topologies is documented in 235 frameworks. ${ }^{3}$ While some of these topologies are represented by vastly diverse compositions in the type of $\mathrm{T}$ atoms involved and their molar ratios, others are only represented by a single material. The former is illustrated by $\mathrm{CHA}$ (each unique framework topology is given a three letter code ${ }^{3}$ ), a framework encountered in the zeolite mineral chabazite, but also in synthetic silicoaluminophoshate (SAPO-34), aluminosilicate (synthetic zeolite SSZ-13) ${ }^{4,5}$ and more exotic versions (e.g., $\left.\mathrm{AlCoPO}_{4}{ }^{6}\right)$. An example of the latter is EEI, so far, only found as a high-silica zeolite (Figure 1).,8

The focus in the present work is placed solely on zeolite compositions. There, the generation of a negative charge, when $\mathrm{Al}^{3+}$ is isomorphically substituted for $\mathrm{Si}^{4+}$ in the oxide framework, dictates the need for a balancing cation such as $\mathrm{H}^{+}, \mathrm{Na}^{+}$, or $\mathrm{NH}_{4}^{+}$, or even divalent cations when two charges are in close proximity. This exchange capacity can be used to create catalytic sites inside the pores, leading to active site confinement. ${ }^{9}$ Zeolites are commercially employed in catalysis, adsorption (separation), and ion-exchange applications. Most catalytic uses are found in hydrocarbon (petrochemistry, refining) and environmental technology, ${ }^{10}$ while ion-exchange and sorption properties are respectively exploited in laundry detergent powders and adsorbents/desiccants. It is obvious that the size of the pores and the possible presence of additional cages or larger intersections influence the (organic) chemistry and catalytic applications that can result within. Typically, small-pore zeolites have pore sizes in the range of $0.30-0.45$ $\mathrm{nm}$, while medium-pore zeolite openings range from $0.45-0.60$ $\mathrm{nm}$ and large pore materials have their largest pores in the range from $0.60-0.80 \mathrm{~nm}^{11}$

Although the first synthetic zeolite was a small-pore material (vide infra), the catalytic application of zeolites was initially heavily focused on large-pore zeolites. Since the discovery of the synthetic form of faujasite in the 1960s, the large-pore zeolite Y (FAU), with supercages, has been exploited in the fluid catalytic cracking of oil, a large scale catalytic operation producing gasoline. ${ }^{12}$ Later the discovery of zeolite BEA and the introduction of MOR in catalytic processes fortified the role of large pore zeolites in petrochemistry, i.e., the catalytic upgrading of platform molecules from the refinery (e.g., transalkylation). With the advent of ferrierite (FER), MCM22 (MWW), and ZSM-5 (MFI), medium-pore zeolites found commercial application as well, e.g., in olefin isomerization (FER), refinery dewaxing or xylene isomerization (MFI), and ethylbenzene synthesis (MWW). ${ }^{10}$ Many of these classic hydrocarbon processes rely on shape-selective effects inside the specific voids. ${ }^{13}$ In the 1990s, a push for extra-large pore materials resulted in the synthesis of zeolites UTD-1 (DON) ${ }^{14}$ and CIT-5 (CFI), ${ }^{15}$ with pore sizes close to 1 and $0.8 \mathrm{~nm}$, respectively, as well as the generation of series of ordered mesoporous (alumino)silicates such as MCM-41. ${ }^{16}$ The new millennium brought about the search for catalytic processes dealing with alternative feedstocks and environmental remediation. Alternatives to crude oil have since been studied, with the goal of finding more sustainable (if efficient) routes to chemicals and materials, notably, from lignocellulosic biomass or (natural) gas. Dealing with biopolymer feedstock and its rather large sugar constituents ${ }^{17}$ has pushed zeolite development into mesopore-generation (e.g., hierarchical materials) as well as fueled the rise of Lewis acidic silicates such as SnBEA. $^{18-22}$ Thus, far, new zeolite structures have not been targeted in biomass conversion, but rather the goal has been to adapt commercial zeolite catalysts to new processes. ${ }^{9,23,24}$ On the other hand, the prospect of upgrading small-molecule feedstocks such as natural gas $\left(\mathrm{CH}_{4},{ }^{23} \mathrm{C}_{2} \mathrm{H}_{6}\right)$, syngas $(\mathrm{CO} /$ $\left.\mathrm{H}_{2}\right)$, ${ }^{26}$ and $\mathrm{CO}_{2}{ }^{27}$ and thereof derived platform molecules such as methanol and ethylene did stimulate the use and synthesis of small-pore zeolites in recent years. Together with the fast progress in catalytic environmental remediation, i.e., the use of $\mathrm{Cu}$-zeolites for the reduction of vehicle $\mathrm{NOx}$ emissions, these small-molecule conversions have triggered new synthetic strategies and allowed improved materials and even new zeolites to emerge.

\subsection{MR Zeolites: Definitions and Scope of the Review}

The 235 documented framework types thus present a diverse range of different pore and cavity systems with different potential uses. Considering only aluminosilicates (zeolites) and 


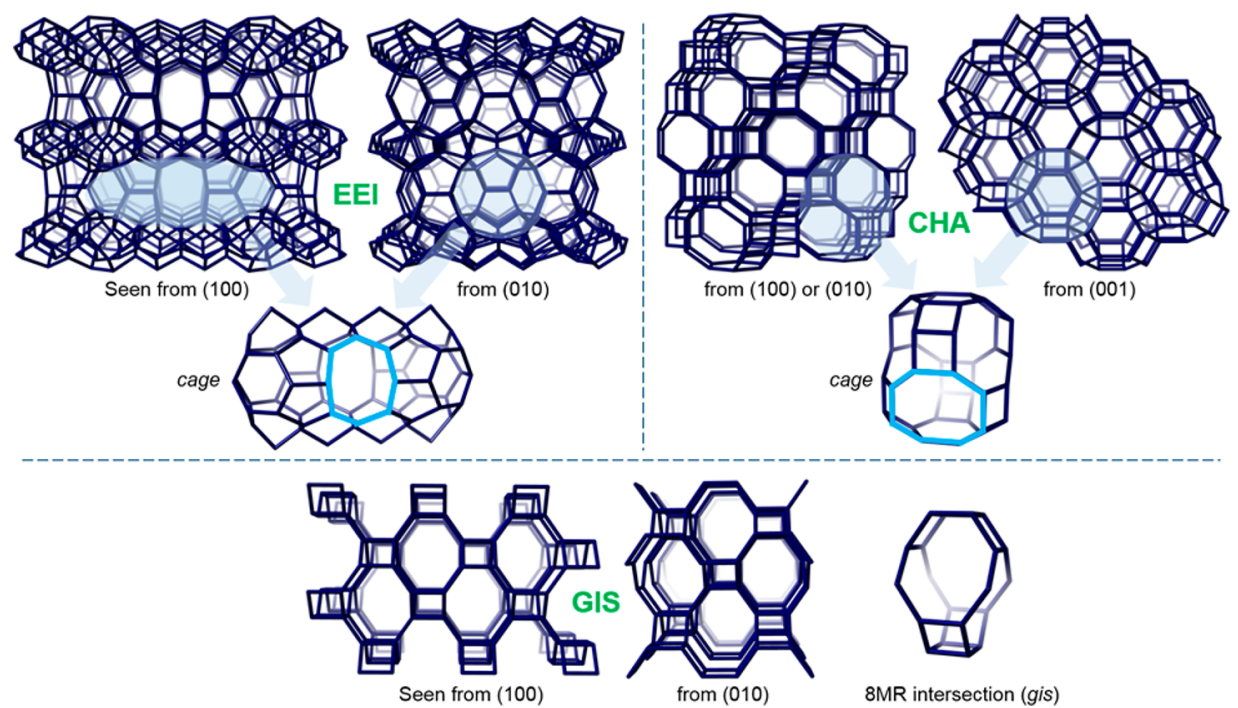

Figure 1. EEI and CHA frameworks with isolated cage and an exemplary 8MR-window (blue) and the GIS framework without cage. $\mathrm{O}$ atoms are represented by straight lines, and every corner is a $\mathrm{T}$ atom position (EEI is an example of the three letter codes designated by the International Zeolite Association (IZA) $)^{3}$.

Table 1. Complete List of All Known Forty-Four 8MR Zeolite Frameworks and Four 8MR Silicates ${ }^{a}$

\begin{tabular}{|c|c|c|c|c|c|c|c|c|c|}
\hline $\begin{array}{l}\text { IZA } \\
\text { code }\end{array}$ & Material name $^{b}$ & Pore $^{c}$ & Cage $^{d}$ & ref & $\begin{array}{l}\text { IZA } \\
\text { code }\end{array}$ & Material name & Pore & Cage $^{d}$ & ref \\
\hline $\mathrm{ABW}$ & Li-A(BW) & 8 & $x$ & 34 & LEV & Levyne, ZK-20, SSZ-17, Nu-3 & $8 \times 8$ & $\sqrt{ }$ & 35 \\
\hline AEI & SSZ-39 & $8 \times 8 \times 8$ & $\sqrt{ }$ & 36 & LTA & Linde type A, ITQ-29 & $8 \times 8 \times 8$ & $\sqrt{ }$ & 37 \\
\hline AFX & SSZ-16 & $8 \times 8 \times 8$ & $\sqrt{ }$ & 38,39 & LTJ & Linde type J & $8 \times 8 \times 8$ & $x$ & 40 \\
\hline ANA & Analcim $(\mathrm{t}) \mathrm{e}$ & irreg. & $x$ & 41 & LTN & Linde type $\mathrm{N}$ & $-e$ & $x$ & 42 \\
\hline ATT & RMA-3 & $8 \times 8$ & $x$ & 43 & MER & merlinoite, Linde type $\mathrm{W}$ & $8 \times 8 \times 8$ & $\sqrt{ }$ & 44 \\
\hline BCT & Svyatoslavite & 8 & $x$ & 45 & MON & Montesommaite & $8 \times 8 \times 8$ & $\times$ & \\
\hline BIK & Bikitaite & 8 & $x$ & 46 & MTF & MCM-35, UTM-1 & 8 & $\sqrt{ }$ & 47 \\
\hline BRE & Brewsterite, CIT-4 & $8 \times 8$ & $x$ & 48 & MWF & MCM-25 & $8 \times 8 \times 8$ & $\sqrt{ }$ & 51 \\
\hline CAS & & 8 & $x$ & 50 & NSI & $\mathrm{Nu}-6-(2)$ & $8 \mid 8$ & $\times$ & 49 \\
\hline $\mathrm{CDO}$ & UZM-25, MCM-65, RUB-37 & $8 \times 8$ & $\times$ & 52,53 & PAU & Paulingite, ECR-18 & $8 \times 8 \times 8$ & $\sqrt{ }$ & 54 \\
\hline $\mathrm{CHA}$ & Chabazite, K-G, SSZ-13, SSZ-62 & $8 \times 8 \times 8$ & $\sqrt{ }$ & 4,55 & PHI & Phillipsite, ZK-19 & $8 \times 8 \times 8$ & $x$ & 56 \\
\hline DDR & ZSM-58, Sigma-1 & $8 \times 8$ & $\sqrt{ }$ & 57,58 & RHO & Rho & $8 \times 8 \times 8$ & $\sqrt{ }$ & 59 \\
\hline $\mathrm{EAB}$ & TMA-E, Bellbergite (later) & $8 \times 8$ & $\sqrt{ }$ & 60,61 & RTH & SSZ-50 & $8 \times 8$ & $\sqrt{ }$ & 62 \\
\hline EDI & Edingtonite, K-F & $8 \times 8 \times 8$ & $x$ & $44,63,64$ & SAS & SSZ-73 & 8 & $\sqrt{ }$ & 65 \\
\hline EEI & ERS-18, SSZ-45 & 8 & $\sqrt{ }$ & 7,8 & SFW & SSZ-52 & $8 \times 8 \times 8$ & $\sqrt{ }$ & 66 \\
\hline EPI & Epistilbite & $8 \times 8$ & $x$ & 67,68 & THO & Thomsonite & $8 \times 8 \times 8$ & $x$ & 63 \\
\hline ERI & Erionite, UZM-12 & $8 \times 8 \times 8$ & $\sqrt{ }$ & 69,70 & TSC & Tschörtnerite & $8 \times 8 \times 8$ & $\sqrt{ }$ & \\
\hline ESV & ERS-7 & 8 & $\sqrt{ }$ & 71 & UFI & UZM-5 & $8 \times 8$ & $\sqrt{ }$ & 72,73 \\
\hline GIS & Gismondine, (Na-) P1 & $8 \times 8 \times 8$ & $x$ & 74 & YUG & Yugawaralite, Sr-Q & $8 \times 8$ & $x$ & $68,75,76$ \\
\hline GOO & Goosecreekite & $8 \times 8 \times 8$ & $x$ & & $\operatorname{ETL}^{f}$ & EU-12 & $8 \times 8 \mid 8$ & $\times$ & 77 \\
\hline IHW & ITQ-32 & $8 \times 8$ & $x$ & 78 & $\mathrm{IFY}^{g}$ & ITQ-50 & $8 \times 8 \times 8$ & $\sqrt{ }$ & 79 \\
\hline ITE & ITQ-3, Mu-14 & $8 \times 8$ & $\sqrt{ }$ & 80,81 & ITW $^{g}$ & ITQ-12 & $8 \times 8$ & $\sqrt{ }$ & 82,83 \\
\hline JBW & nepheline hydr. I & 8 & $x$ & 41 & $\mathrm{RTE}^{g}$ & RUB-3 & 8 & $\sqrt{ }$ & $84-86$ \\
\hline KFI & ZK-5 & $8 \times 8 \times 8$ & $\sqrt{ }$ & 87,88 & $\mathrm{RWR}^{g}$ & RUB-24 & $8 \| 8$ & $x$ & 89,90 \\
\hline
\end{tabular}

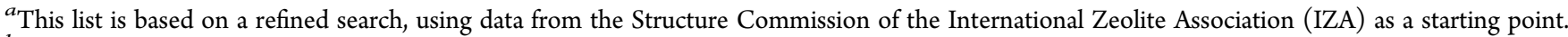
${ }^{b}$ Most prominent or first reported aluminosilicate members of the topology. Better-known, pure-silica representatives might exist (e.g., for DDR). Natural zeolites are recognized by their full name, and references for such zeolites are only given in case a synthetic route exists. " $X$ ” indicates intersecting channels, "I" indicates a parallel pore system, and "Il" indicates nonintersecting channels in multiple directions (considered a 1dimensional material). $8 \times 8 \times 8$ does not necessarily mean these channels run in perpendicular directions (i.e., along $a, b$, and $c$ ). ${ }^{d}$ Cage (Present: $\sqrt{ }$. Not-present: $\times$.) is defined here as an accessible void larger than the intersections of pores and being of sufficient size to allow for small organic molecule, e.g., methanol, adsorption. ${ }^{e} \mathrm{LTN}$ only has $6 \mathrm{MR}$ apertures and inaccessible cages. ${ }^{{ }}$Recently approved code by the IZA. ${ }^{g}$ Only reported in pure silica. IFY is obtained from all-silica LTA ITQ-29 by pressure-induced transformation. ITW is made in F-media using 1,3,4trimethylimidazolium cation. RTE and RWR come from topotactic transformation.

direct synthesis methods, rings of $\mathrm{T}$ atoms containing as few as $3\left(\mathrm{MEI}^{28}\right)$ and as much as (excluding larger ones where $\mathrm{T}$ atoms are not 4-connected) 14 members (CFI, SFH,
SFN) $)^{15,29,30}$ have been identified (the number of $\mathrm{T}$ atoms in the ring equals the number of oxygen atoms in the ring). In light of the above definitions and different catalytic scopes of 
small and large pore materials, the entrance to and exit from the intracrystalline void spaces have been defined. As such, 8membered ring $(8 \mathrm{MR}$, referring to $\mathrm{T}$ atoms, in fact 16 atoms are in the ring) structures are considered small-pore zeolites, while materials with openings limited by 10 - and 12-membered rings are defined as medium and large-pore zeolites, respectively. $^{31}$ Often, rings larger than 12 are denoted as extra-large pore materials. Medium, large, and extra-large pore materials can also contain smaller pores: LTL, e.g., has its 1dimensional $12 \mathrm{MR}$ channels intersected by $8 \mathrm{MR}$ openings.

Even though some large-pore zeolites behave like small-pore $8 \mathrm{MR}$ systems through intergrowth faulting of the main pore (e.g., 12MR GME, ${ }^{32}$ note that a fault-free version has just been reported $^{33}$ ), this review will only focus on the synthesis and applications of pure $8 \mathrm{MR}$ zeolites ( 8 being the largest ring size) for reasons provided below. Besides the $\mathrm{T}$ atom definition of pores, the pore connectivity as well as the occurrence of larger cavities is of major importance for applications. For example, EEI has a very large cage $(5.6 \times 19.8 \AA)$, that is only accessible through $8 \mathrm{MR}$ windows (Figure 1), as is the case for another $8 \mathrm{MR}$ zeolite, SFW. ${ }^{8} 8 \mathrm{MR}$ zeolites without cages also exist: a commercially used example is GIS, seen in Figure 1. Table 1 lists the forty-four known $8 \mathrm{MR}$ zeolites. Additionally, the list contains four pure-silicate $8 \mathrm{MR}$ molecular sieves. When expanding this list to other $\mathrm{T}$ atoms (e.g., common $\mathrm{PO}_{4}$ ), a total of seventy-six $8 \mathrm{MR}$ microporous materials can be found. ${ }^{3}$

Given the importance of the fit between molecules and pores, it is fairly obvious that $8 \mathrm{MR}$ zeolites will excel in applications dealing with smaller molecules and ions. ${ }^{91}$ Perhaps it is no coincidence that the discovery of the "molecular sieving" effect itself was done with an $8 \mathrm{MR}$ zeolite, $c f r$. Weigel and Steinhoff in 1924. They discovered the rapid adsorption of water, methanol, formic acid, and ethanol vapors on natural chabazite (CHA), while acetone, ether, or benzene vapors were not adsorbed. ${ }^{92}$ Today, over 90 years later, synthetic versions of $\mathrm{CHA}$ are produced at the kiloton-scale for use as methanol-toolefins (SAPO-34, mainly in China $)^{93}$ or NOx reduction catalysts (Cu-SSZ-13). ${ }^{94,95}$ Even though $8 \mathrm{MR}$ zeolites have been known for quite some time, it is only recently that the two significant commercial catalyst uses mentioned have occurred. These technologies have stimulated recent research into $8 \mathrm{MR}$ zeolites and molecular sieves. Given these events, the objective of this review is to provide a critical and comprehensive overview of the chemistry, synthesis, and catalytic applications of $8 \mathrm{MR}$ zeolites (strictly only aluminosilicates) from the early days (1940s) to the present. A classic historic and general account of hydrothermal zeolite synthesis (up to 2003) was presented by Cox and Cundy. ${ }^{96}$ Other comprehensive reviews in the field focus on one particular aspect of zeolite chemistry, such as more sustainable synthesis routes, ${ }^{97}$ new frameworks since 2007 (focused on structural information), ${ }^{98}$ catalytic applications for a specific group of substrates such as biomass, ${ }^{24}$ $\mathrm{C}-\mathrm{H}$ activation, ${ }^{99}$ or nitrogen containing exhaust gases. ${ }^{100,101}$ At this time, there is a brief overview on synthesis strategies for small pore molecular sieves by Moliner et al. ${ }^{31}$ Thus, our goal in the present review is to provide in-depth discussions on both the synthesis and catalytic applications of $8 \mathrm{MR}$ zeolites in order to highlight structure-property relationships for this increasingly important class of materials.

\subsection{Introduction to the Use of $8 \mathrm{MR}$ Zeolites as Catalysts}

From the early days of applied zeolite science, 8MR zeolites have been investigated for sorption and separation applica- tions. ${ }^{92}$ However, $8 \mathrm{MR}$ materials largely have been neglected as catalysts until recently (large and medium pore materials dominate in petrochemical applications). Since the discovery of the excellent olefin selectivities and yields using certain acidic $8 \mathrm{MR}$ molecular sieves during methanol conversion in the $1980 \mathrm{~s}^{102}$ and the remarkable stability and activity during redox reactions of transition metal-exchanged $8 \mathrm{MR}$ zeolites for $\mathrm{NOx}$ reduction in the 2000s, these zeolites have been extensively explored for catalytic conversions of small, often gaseous, molecules. Lately, there has been an increase in interest due to changes in cost/availability of gaseous feedstocks and emission legislation. ${ }^{103}$ An overview of prominent reactions where $8 \mathrm{MR}$ zeolites have been used is found in Figure 2.

Commercial applications (current and previous) of $8 \mathrm{MR}$ zeolites include materials that have the following topologies: CHA, EDI, ERI, GIS, LTA, MER, and RHO. ${ }^{10}$ Most of these materials are used for separations and sorption, while ERI, $\mathrm{CHA}$, and RHO also are exploited in catalytic applications. ERI was used as a hydrocracking catalyst in refineries, before its replacement by ZSM-5 (a 10MR-zeolite of the MFI topology). Specifically, ERI was used in the Selectoforming process, aimed at increasing the octane number of light naphtha by the shapeselective cracking of short linear alkanes while preserving the branched ones (section 3.6.1). ${ }^{104}$ Besides MTO, the reaction that is industrialized with SAPO-34 (CHA), the selective catalytic reduction (SCR) of NOx with Cu-SSZ-13 is now being exploited worldwide. The catalytic synthesis of methylamines (at one point, commercial based on large pore-zeolite MOR) has been performed with $8 \mathrm{MR}$ zeolite Rho (RHO) at the pilot stage. RHO was useful in order to exploit shapeselectivity and avoid the formation of trimethylamine, but it never reached the commercial stage. Two reactions related to MTO are the ethanol dehydration and the ethylene oligomerization-cracking processes (Figure 2). The former is not to be mistaken for the MTO-analogous ethanol-to-olefins route, as it can be performed through somewhat different reaction routes and conditions, as $\mathrm{C}-\mathrm{C}$ coupling is not per se needed (unless propylene is formed). Lastly, there is the partial oxidation of methane-to-methanol, with the use of $\mathrm{O}_{2}\left(\right.$ or $\left.\mathrm{N}_{2} \mathrm{O}\right)$ as oxidant. This reaction, discovered on $\mathrm{Cu}$-exchanged ZSM$5^{105,106}$ and later observed from other larger-pore materials, ${ }^{107}$ has recently also been reported with $\mathrm{Cu}$-exchanged $8 \mathrm{MR}$ zeolites by Lobo and co-workers. ${ }^{25}$ The similar nature of these catalysts with those used in SCR research warrants discussion that is provided below.

Although the CHA-materials dominate the industrial catalytic applications, numerous other $8 \mathrm{MR}$ materials have been explored for SCR, MTO, and methylamine synthesis, and sometimes, they yield better results with respect to the industrial standards. Here, after we thoroughly discuss the synthetic details of $8 \mathrm{MR}$ zeolites in the next section, this review will focus on selected catalytic data in order to demonstrate structure/activity relations of $8 \mathrm{MR}$ zeolites (section 3). Other applications, summarized below (provided for completeness), will not be discussed in detail.

While we limit our presentations to catalytic applications of $8 \mathrm{MR}$ zeolites, we mention the largest commercial applications of $8 \mathrm{MR}$ zeolites (volumetric scale) to inform readers that catalysis remains a growth area for these types of zeolites. The largest commercial applications for $8 \mathrm{MR}$ zeolites are still found in ion-exchange and sorption/separation. The use of zeolites $\mathrm{P}$ and A (GIS and LTA, respectively) in detergent-builders, e.g., to remove $\mathrm{Ca}^{2+}$ ions from aqueous solutions, is well-known. 


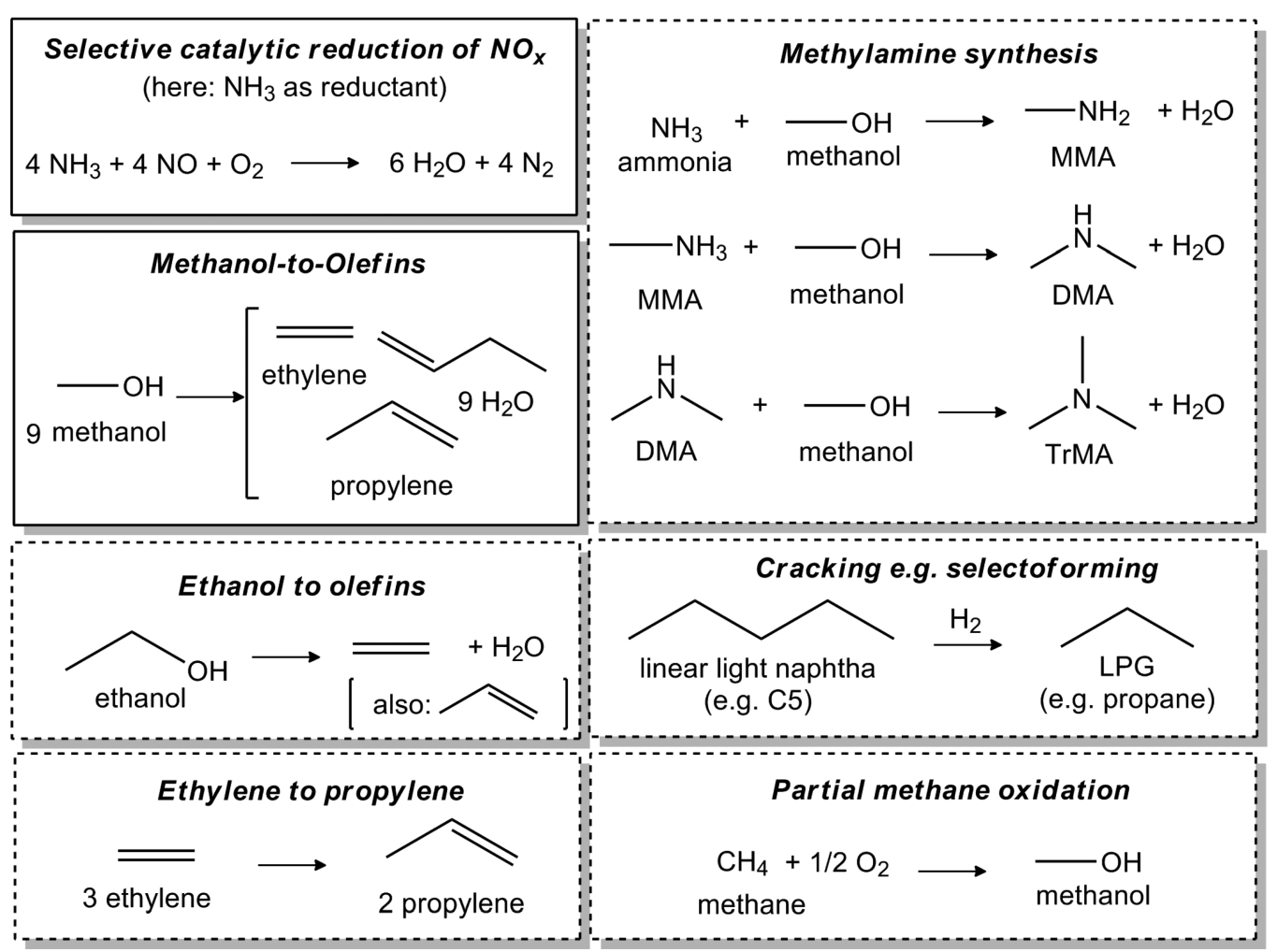

Figure 2. Reported important reactions with $8 \mathrm{MR}$ zeolites. Methanol to olefins and NOx reduction (solid lines) are commercially applied, at this time, using 8MR materials. The dashed boxes have only been investigated at small or pilot plant scale (amines) or have been shut down (Selectoforming). MMA, DMA, and TrMA, respectively, are mono-, di-, and trimethylamine. Methane oxidation can also use $\mathrm{N}_{2} \mathrm{O}$ as an oxidant.

Other common detergent-builders are the large pore materials zeolite $\mathrm{X}$ and Y. ${ }^{108}$ Also, $8 \mathrm{MR}$ zeolites (LTA) are often used as dessicants. Furthermore, in gas sorption and separation, $8 \mathrm{MR}$ zeolites are of major importance, due to their ability to discern between short chain alkanes and olefins, ${ }^{109}$ different light hydrocarbons, ${ }^{110,111} \mathrm{CO}_{2} / \mathrm{CH}_{4}{ }^{112} \mathrm{H}_{2} / \mathrm{N}_{2}$, and $\mathrm{CO}_{2} / \mathrm{N}_{2}{ }^{113}$ Often zeolite membranes are constructed in this context (LTA). ${ }^{114-116}$ Aside from these common applications, smallpore zeolites have been explored in all kinds of specialty devices and materials. ${ }^{117}$ Thin films of pure-silica CHA have been assessed in low-dielectric constant applications, ${ }^{118}$ while aluminous LTA has been applied in films for humidity sensors $^{119}$ and Ag-LTA in photoluminescent materials. ${ }^{120}$

\section{SYNTHESIS OF 8MR ZEOLITES}

\subsection{Introduction to Different Strategies for Making $8 \mathrm{MR}$ Zeolites}

Of the forty-four 8MR zeolites listed in Table 1, three are found as natural minerals only and no route for their synthesis exists to date (these lack an entry in the reference column in Table 1). For the remaining forty-one zeolites, a dedicated synthesis route, usually leading to a pure-phase product, exists. When analyzing the different routes to these $8 \mathrm{MR}$ aluminosilicates, a set of distinct synthetic approaches can be identified (Table 2). These methods will be explained one by one, from $A$ to $G$, in the following paragraphs. Then, in section 2.2, an overview of all synthetic $8 \mathrm{MR}$ zeolites is presented, with an indication of which methods have been reported for each framework. Specific examples and mechanistic insights of the use of these methods (other than those in the next paragraph) are found
Table 2. Distinguishable Routes for the Synthesis of $8 \mathrm{MR}$ Zeolites $^{a}$

\begin{tabular}{|c|c|c|}
\hline Code & Method & Typical example \\
\hline A & $\begin{array}{l}\text { Geothermal mimicking/high } \mathrm{T} \\
\text { approaches }\end{array}$ & $\begin{array}{l}\text { synthetic epistilbite } \\
\text { (EPI)/CAS }\end{array}$ \\
\hline B & Hydroxide media, alkali cation $\mathrm{SDA}^{b}$ & Linde type A (LTA) \\
\hline $\mathrm{C}$ & $\begin{array}{l}\text { Hydroxide media, OSDA (often with } \\
\text { alkali) }\end{array}$ & SSZ-13 (CHA) \\
\hline D & Interzeolite conversion $(\mathrm{IZC})^{c}$ & SSZ-39 (AEI) \\
\hline $\mathbf{E}$ & Charge density mismatch $(\mathrm{CDM})^{d}$ & UZM-5 (UFI) \\
\hline $\mathbf{F}$ & Fluoride media, OSDA & ITQ-32 (IHW) \\
\hline G & Topotactic condensation & CDS-1 (CDO) \\
\hline
\end{tabular}

${ }^{a}$ SDA: (inorganic) structure directing agent; OSDA: organic structure directing agent. ${ }^{b}$ OSDA-free, seed-assisted hydroxide methods are also included here, as these are mostly reported for $8 \mathrm{MR}$ zeolites that can be made in the absence of OSDA with strong alkali, e.g., CHA. RTH, not known from unseeded hydroxide media OSDA-free synthesis, is the exception to this. ${ }^{121}$ (This contrasts with a lot of high-silica, largepore zeolites (BEA, MFI), whose syntheses without OSDA were reported long after their discovery through the use of OSDAs.) ${ }^{c}$ Always with inorganic cations and/or OSDAs. ${ }^{d}$ Always with OSDAs.

throughout section 2.3, where all synthetic progress of the relevant $8 \mathrm{MR}$ zeolites is detailed per topology.

The first forays into zeolite synthesis were conducted by geothermal mimicking (Method A, Table 2), in an attempt to simulate the mineralization process found in the Earth's crust. This is mostly done by bringing mixtures of alkali, silica, and alumina (often glasses), with compositions close to that of the natural zeolites, to high pressures and temperatures. The pioneer of (classic) zeolite synthesis was Richard M. Barrer, who meticulously explored crystallization fields with different 
alkali cations and $\mathrm{Si} / \mathrm{Al}$ ratios. ${ }^{122}$ Soon, new zeolite recipes began emerging from his school in the 1940-50s and from research at Union Carbide (Linde type materials). Early on, several attempts were made to obtain synthetic chabazite, but the first synthetic $8 \mathrm{MR}$ zeolite prepared was likely analcite (ANA), a dense zeolite with little use for molecular sieving, dating back to $1882 .^{123,124}$ In 1948, while looking for synthetic chabazite, Barrer discovered the first synthetic zeolite with no natural counterpart, and he documented its chabazite-like behavior. $^{125}$ The zeolite later turned out to be an $8 \mathrm{MR}$ material with the KFI topology ${ }^{126}$ and thus analogous to the ZK-5 zeolite (in the meantime reported) and its structure (Mobil). ${ }^{8,127}$ Another 8MR milestone came in 1956, when R. M. Milton (later joined by Breck and co-workers) at Union Carbide demonstrated the synthesis of LTA (also not found in nature), with excellent ion-exchange properties. ${ }^{128-130}$ To this day, the production of this so-called zeolite $\mathrm{A}$ is one of the largest scale manufacturing processes of all synthetic zeolites, mainly due to its use as a detergent-builder. Several $8 \mathrm{MR}$ zeolites were discovered by these pioneers and others in their wake, by using different alkali as structure-directing agents in hydroxide media (Method B, Table 2): lithium-ABW (1951), potassium-EDI (K-F, 1956), rubidium-ATT (RMA-3, 2005), cesium-BIK (at Mobil, 1989), sodium-cesium-RHO (Rho, 1973), etc.

In 1961, Barrer introduced a new method to prepare zeolites by adding charged organic ammonium and alkylammonium species in the gels. ${ }^{131,96}$ This breakthrough effectively pioneered the use of organic structure directing agents (OSDAs) in zeolite synthesis (Method C, Table 2). LTA, for instance, was soon thereafter made in the presence of tetramethylammonium (TMA). ${ }^{132}$ The use of organic cations, typically bulkier per charge than classic alkali cations, revolutionized the synthesis field. Important was the realization that the larger organic cations required less aluminum to be built-in in the zeolite framework (countercharge), thus opening up the possibility of high-silica materials. Initially, only larger pore materials were discovered using OSDAs, such as the 10MR MFI and the 12MR-zeolites MWW and BEA. The first OSDA-directed 8MR zeolite was EAB (1970), containing a medium-large cage, made by using a combination of TMA and sodium cations. ${ }^{60}$ An excellent example of this strategy (Method C, Table 2) for $8 \mathrm{MR}$ zeolites is the synthesis of CHA-type zeolites that can now be prepared over a very wide range of $\mathrm{Si} / \mathrm{Al}$ ratios by using the large $N, N, N$-trimethyl-1-adamantyl-ammonium cation (ADAM) as OSDA. ${ }^{4}$ This method, invented by Zones and based upon stabilization of the large $\mathrm{CHA}$ cage by the organic, is industrially used to make the $8 \mathrm{MR}$ zeolite (SSZ-13) for exhaust cleaning. ${ }^{133} \mathrm{Up}$ to today, the use of new and complex OSDAs continues to lead to new zeolites ${ }^{134}$ or new recipes for known zeolites, the latter often with access to higher $\mathrm{Si} / \mathrm{Al}$ ratios. ${ }^{135,136}$ By means of illustration, the two OSDAs that can be used to prepare the EEI zeolite (Figure 1) are illustrated in Figure 3, along with the organic initially reported for SFW, an interesting zeolite related to $\mathrm{CHA}$, with a very large cage. The most recent example of Method C (OSDA/hydroxide media) is the synthesis of EU-12 by using choline ( $N, N, N$-trimethylethanolammonium), $\mathrm{Rb}^{+}$, and $\mathrm{Na}^{+}$(8MR-zeolite ETL, 2016). ${ }^{77}$

Barrer also introduced the use of a zeolite as sole source for making another zeolite, by studying the hydrothermal transformations of analcime in the presence of metal salts (yielding KFI with barium halides for instance). ${ }^{139}$ Dwyer and Chu presented the transformation of FAU, still in its growth

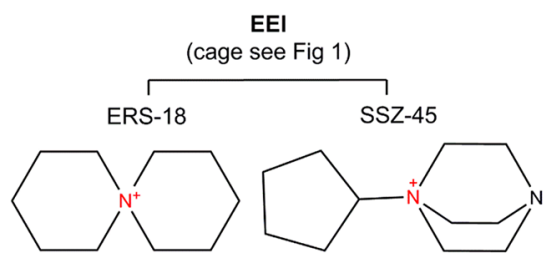

SFW

(SSZ-52)

Figure 3. OSDAs for making EEI (Figure 1) or SFW (Figure 10) zeolites in hydroxide media. The charged quaternary nitrogen atoms are marked in red. For SFW, more practical organics have been found recently, through computational OSDA design. The work of Deem et al. is a good example of this strategy. ${ }^{137,138}$

medium and considered metastable, into a MAZ-zeolite (ZSM4 , or Omega) in the presence of TMA at $100{ }^{\circ} \mathrm{C}$. Normally, the more dense zeolite P (GIS) is expected in the absence of TMA. Also, the MAZ zeolite appeared to nucleate on the surface of the dissolving FAU-crystal. ${ }^{140,141}$ Later, Zones reported an interesting series of experiments that involved the transformation of zeolite P (GIS) and Y (FAU) into a range of highsilica 8MR zeolites (LEV, CHA, AFX) by the addition of organocations, e.g., $\mathrm{ADAM}$, and by starting from actual dry zeolites. $^{142-144}$ Davis and co-workers later used (diluted) alkaline earths and successfully synthesized CIT $-4^{48}$ (synthetic BRE, use of seeds) and epistilbite (EPI) from zeolites P1 (GIS) and L (LTL). ${ }^{68}$ Due to peculiar differences between this method of interzeolite conversion (IZC) and classic hydroxide media reactions that use separate (and different) silica and alumina sources, we consider this a distinct method (Table 2, Method D). The Sano group reported a number of interesting IZC-based studies that yielded relevant $8 \mathrm{MR}$ zeolites such as AEI, CHA, and LEV, often from FAU precursors (see section 2.3 , with the respective frameworks). ${ }^{145,146}$ The observations that IZC often gives faster syntheses than identical recipes with traditional inorganic sources and that, sometimes, only IZC leads to a particular zeolite, e.g., AEI, have led to the idea that structural similarities (composite building units, cages, specific membered rings or other less-defined structures, e.g., ladders; collectively sometimes referred to as "nanoparts") between starting and product zeolites play, under the right conditions, a decisive role in the nucleation/growth of the new material (exemplified in Figure 4 for FAU to CHA). ${ }^{145,146}$ This is similarly asserted in seeded-synthesis. ${ }^{147}$

A new, creative approach to zeolite synthesis emerged from researchers at UOP in the 2000s, when Lewis et al. introduced the concept of charge density mismatch (CDM, Method E, Table 2). ${ }^{148}$ This approach (technically a variation on method C) is based on the creation of an initial mixture that is not able to crystallize because of a mismatch between the low charge density of the used OSDA and the high charge density of the potential aluminosilicate network (at low hydroxide content, often only sourced from the OSDA). Often, the inorganiccation free, mismatched mixture is a solution, rather than a gel in the case of alkali cations. Then, a second, crystallizationinducing, high charge density OSDA (often TMA or alkali cations) is added, but only in minute amounts. This OSDA cannot effectively dominate structure formation nor balance all $\mathrm{Al}$ present but triggers condensation. This forces the SDAs to work together. The classic example is the synthesis of $8 \mathrm{MR}$ UZM-5 (UFI, 2003) using tetraethylammonium (TEA) initially and TMA and $\mathrm{Na}^{+}$in a later stage. ${ }^{73,148}$

A game-changer in molecular sieve synthesis was the introduction of fluoride ions as mineralizing agent, traced 


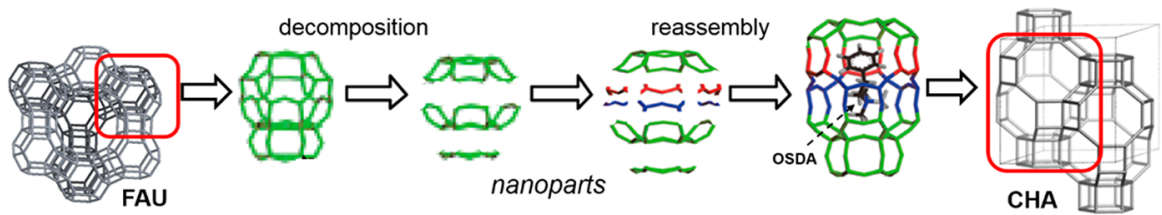

Figure 4. Cartoon illustrating the hypothesis that nanoparts are involved in the FAU-to-CHA IZC. Adapted from ref 145.

back to Flanigen and Patton in 1978. ${ }^{149}$ Typically, the more neutral synthesis media, often based on equimolar HF to $\operatorname{OSDA}\left(\mathrm{OH}^{-}\right)$addition, in the absence of alkali, prove successful to make less dense, high-silica zeolites and puresilicates (Method F, Table 2, Caution: HF is extremely corrosive). For several known $8 \mathrm{MR}$ zeolites, fluoride routes have been successfully explored as alternatives to hydroxide protocols: some with minor adaptations (e.g., CHA), some with largely different OSDAs (LEV). ${ }^{122}$ A few new $8 \mathrm{MR}$ zeolites, discovered and exclusively found in fluoride media, are ITQ-32 ${ }^{78}$ (IHW) and SSZ-73 ${ }^{65}$ (SAS). Their OSDAs and structures are seen in Figure 5. IHW is somewhat of a special

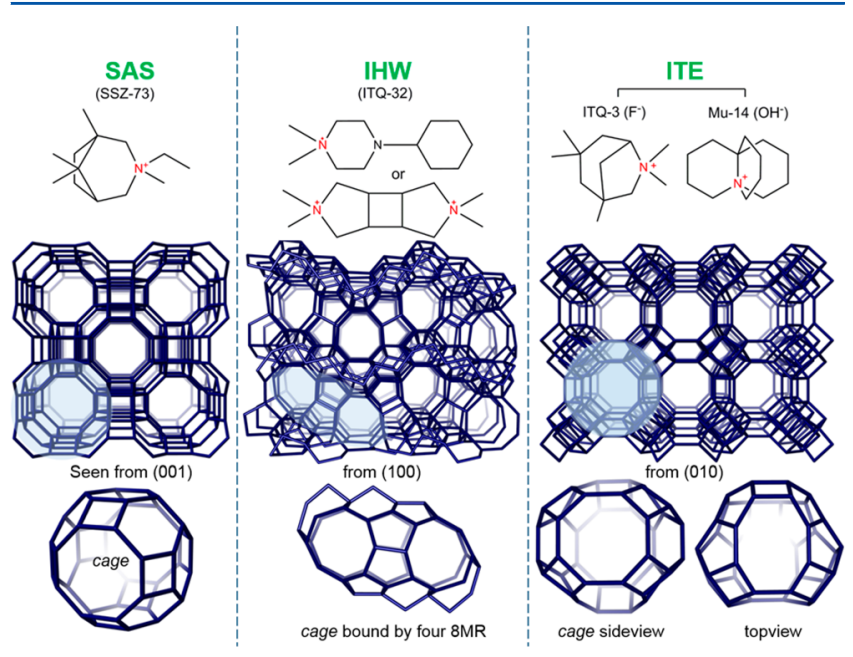

Figure 5. OSDAs used for SAS, IHW, or ITE (ITQ-3) zeolites in fluoride media. Mu-14 OSDA is shown for comparison, but not used in $\mathrm{F}^{-}$-media. For IHW, the double-charged OSDA promotes a large $\mathrm{Al}$ incorporation and yields ITQ-32 with $\mathrm{Si} / \mathrm{Al}$ ratios between 13 and 32, while the piperazine-derived OSDA (upper) leads to a higher $\mathrm{Si} / \mathrm{Al}$ (>300) material. $^{78}$ case, as it has 12-ring connections between the [100] channels, but there are no 12-ring channels, classifying it as an $8 \mathrm{MR}$ zeolite. A final example is zeolite ITE, originally discovered in pure-silica form, in low water fluoride media, but $\mathrm{Al}$ was also said to incorporate. ${ }^{150}$ Later, Valtchev et al. found a procedure to prepare Al-rich ITE in classic hydroxide gels, and their OSDA is remarkably different (Figure 5). ${ }^{80,81}$

It has been discovered that 2D-layered precursors could transform into 3D-frameworks upon high-temperature treatment (calcination) by the condensation of silanol groups in the layers that release water (topotactic condensation, Method G, Table 2). Marler and co-workers performed pioneering efforts in this synthetic area. Among the first zeolites prepared this way was FER, from the PREFER layer. ${ }^{151}$ Certain zeolites can (so far) only be made through the topotactic mechanism. The classic $8 \mathrm{MR}$ example is the synthesis of the CDO framework from the PLS-1 or RUB-36 or UZM-13 layers. In the case of $\mathrm{CDO}$, the layers also have a FER structure, but they are arranged in a different way due to the organic. ${ }^{152}$ These layers are synthesized hydrothermally and thus come stacked with organic moieties. PLS-1 is, for instance, made with TMA and $\mathrm{K}^{+}$cations in a silica, ${ }^{153}$ water, and dioxane mixture, while RUB36 and UZM-13 are made with diethyldimethylammonium cations. ${ }^{52,154}$ The latter two layers have been reported with $\mathrm{Al}$ incorporated, thus leading to zeolite versions of the CDO topology. ${ }^{155}$ Aluminosilicate $\mathrm{CDO}$ is also found in the isostructural MCM-65 zeolite. ${ }^{53,156,157}$ The topotactic conversion of RUB-36 to a silicate version of CDO is shown in Figure 6. A recent trend in material design is to take the layered precursors and pillar them with additional reagents, such as e.g. dimethyldichlorosilane, to obtain interlayer expanded materials. The connecting atoms are (mostly) not 4-fold coordinated in the framework (not strictly zeolites), but it can be an interesting route to introduce heteroatoms in the material for certain applications. ${ }^{158}$ In the context of creating $8 \mathrm{MR}$, the expansion concept is less useful, as the condensation of the classic layers (without expansion) usually creates at least an $8 \mathrm{MR}$.
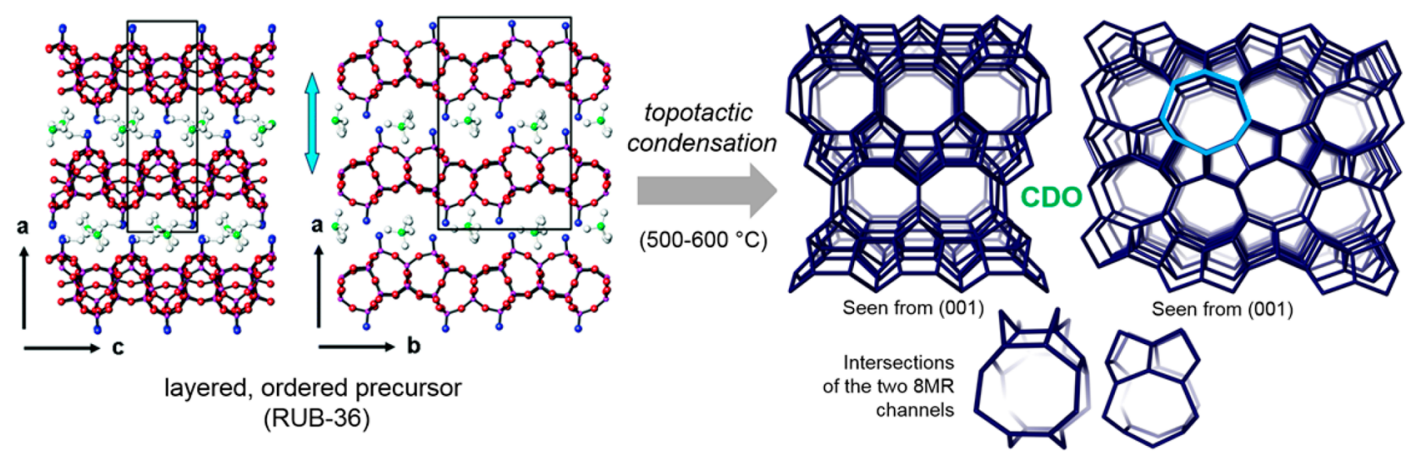

Figure 6. Topotactic conversion of RUB-36 layers to the $\mathrm{CDO}$ framework. Aluminum $\mathrm{T}$ atoms can be present in this conversion. Purple $=\mathrm{Si}$; red $=$ $\mathrm{O}$; blue = terminal oxygens. The OSDA here (green center = quaternary $\mathrm{N}$ ) is diethyldimethylammonium. The light blue arrow corresponds to 11.1 Å. Left part adapted from Marler et al., ref 152, with permission of The Royal Society of Chemistry. 
Table 3. Reported Methods and Si/Al Ranges for the Forty-One 8MR Synthetic Zeolites ${ }^{f}$

\begin{tabular}{|c|c|c|c|c|c|}
\hline $\begin{array}{l}\text { IZA } \\
\text { code }\end{array}$ & $\begin{array}{c}\text { Si/Al range } \\
\text { of the materials }\end{array}$ & METHOD ${ }^{b}$ & $\begin{array}{l}\text { IZA } \\
\text { code }\end{array}$ & $\begin{array}{c}\text { Si/AI range } \\
\text { of the materials }\end{array}$ & METHOD \\
\hline ABW & 1 & B, D & ITE & $17-35^{80}, 33-\infty^{81}$ & $C, F$ \\
\hline $\mathrm{AEI}$ & $5-25.5$ and 266 (Table 4$)$ & $C, D, F$ & JBW & 1 & B \\
\hline AFX & $3.7-16.7^{159}$ & C, D & $\mathrm{KFI}$ & $1.7-4.2$ & B, C, D \\
\hline ANA & $1.5-5$ & A, B, D & LEV & $1.9-49.0$ (Table 6) & B, C, D, F \\
\hline ATT & $3.5-3.9$ & B & LTA & $1-5.5,8.3-\infty$ (Table 7) & B, C, E, F \\
\hline $\mathrm{BCT}$ & 1 & A & LTJ & 1.08 & B \\
\hline $\mathrm{BIK}$ & $8.9-25$ & B & LTN & 1 & $\mathrm{~B}$ \\
\hline BRE & $2.9-3.0$ & D & MER & $1.5-3.6$ & B, C, D \\
\hline CAS & 5 & A & MTF & $20.8^{47}-\infty^{160}$ & C, G \\
\hline CDO & $19-78^{52}, 102-\infty^{155}$ & G & NSI & $12-\infty^{161}$ & G \\
\hline $\mathrm{CHA}$ & $1.15^{44}-\infty^{162}$ (Table 5) & B, C, D, F & MWF & $3.4^{51}-4.3^{163}$ & C \\
\hline DDR & $16^{164}-\infty$ & C & PAU & $2.9-3.7^{54,165}$ & C \\
\hline$E A B$ & $2.7-2.9$ & C & $\mathrm{PHI}$ & $2^{166}, 2.6^{167}, 1.5-3.1^{56}$ & B \\
\hline EDI & $1.32^{168}-1.5^{63}$ & $\mathbf{A}, \mathbf{B}, \mathbf{C}^{d}$ & $\mathrm{RHO}$ & $2.8-8$ & B, C, F \\
\hline $\mathrm{EEI}$ & $70.3^{7}$ and $>250^{8}$ & C & $\mathrm{RTH}^{\circ}$ & $6-59^{169}, 15-100^{62}$ & C, D, F, G \\
\hline EPI & 3 & A & SAS & $254(\mathrm{~s})$ & $F$ \\
\hline ERI & $2.8-5.5^{60,170}, 4.7-7.4^{70}$ & C, D, E & SFW & $8^{e}$ & C \\
\hline ESV & $8.1-8.4$ & C & $\mathrm{THO}$ & 1 & A \\
\hline ETL & 9.6 & C & UFI & $6-11^{171-172}$ & $E$ \\
\hline GIS & $1-3$ & A, B, C, D & YUG & \pm 3 & A, B, D \\
\hline IHW & $13-32,>300$ & $F$ & & & \\
\hline
\end{tabular}

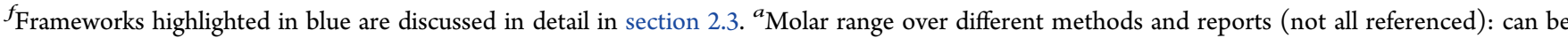
incomplete as this is a tentative attempt/estimate. When no continuous range is reported, or methods diverge too much, two ranges are given. (s) indicates that no $\mathrm{Si} / \mathrm{Al}$ was reported and that the $\mathrm{Si} / \mathrm{Al}$ ratio of the synthesis recipe is given. ${ }^{b}$ See Table 2: Method $\mathrm{A}=$ geothermal mimic or high $\mathrm{T}$ approaches (e.g., up to $1200{ }^{\circ} \mathrm{C}$ for $\mathrm{CAS}^{50}$ ); $\mathrm{B}=$ hydroxide media + alkali; $\mathrm{C}=$ hydroxide media + OSDA; $\mathrm{D}=$ interzeolite conversion; $\mathrm{E}=$ charge density mismatch; $\mathrm{F}=$ Fluoride media + OSDA; $\mathrm{G}=$ topotactic condensation. ${ }^{c} \mathrm{RTH}$ can also be made by seeding borosilicate, yielding products in the $\mathrm{Si} / \mathrm{Al} 35-57$ range ${ }^{121}$ and in pure-silica forms. ${ }^{173,174}{ }^{d}$ For EDI: metal-amine complex used alongside OSDA. ${ }^{e}$ Claimed: $6-25^{1 / 5}$

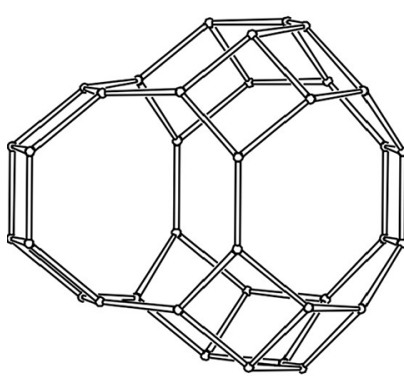

AEI $\left[4^{12} 6^{2} 8^{6}\right]$

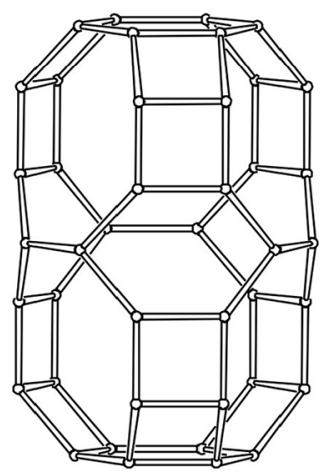

ERI $\left[4^{12} 6^{5} 8^{6}\right]$

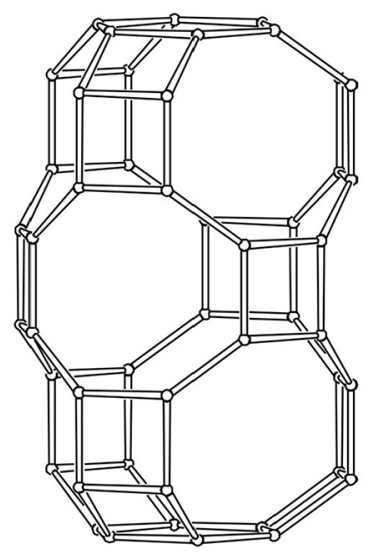

AFX $\left[4^{15} 6^{2} 8^{9}\right]$

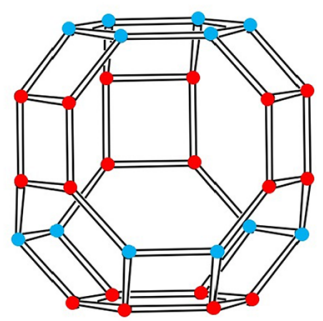

LEV

[4 $\left.4^{9} 6^{5} 8^{3}\right]$

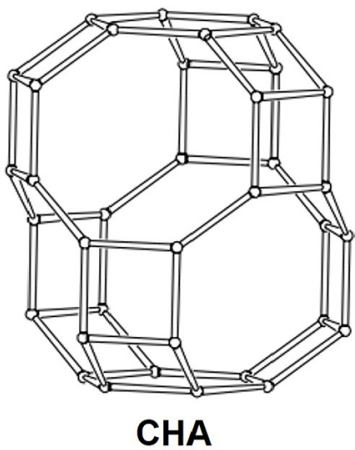

[4126 $\left.6^{2} 8^{6}\right]$

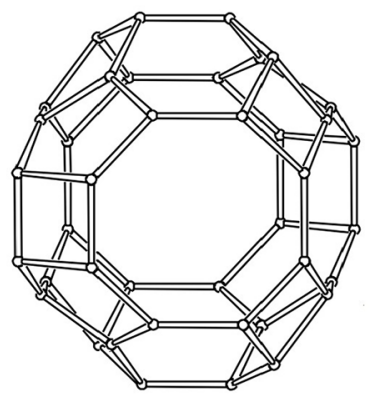

RTH [4658 $\left.5^{8} 6^{4} 8^{4}\right]$

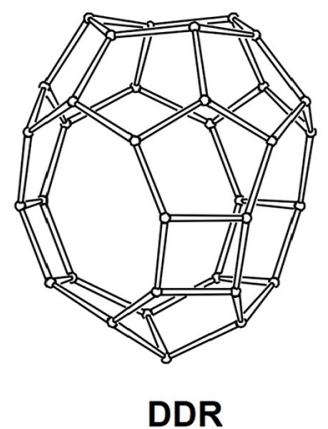

[4 $\left.4^{3} 5^{12} 6^{1} 8^{3}\right]$

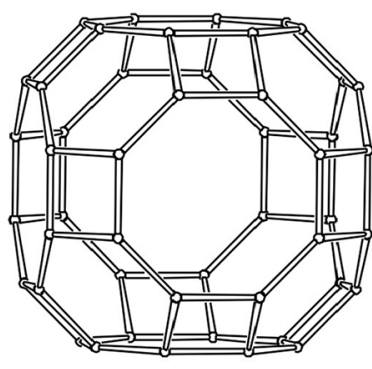

LTA, RHO, KFI

[4 $\left.4^{12} 6^{8} 8^{6}\right]$

Figure 7. Largest cages of the ten most relevant $8 \mathrm{MR}$ frameworks with their pore descriptors. Adapted from parts of the IZA Web site. ${ }^{3}$ Colors for LEV cage are discussed in section 2.3.8. 
Now that a concise overview of the generalized strategies for $8 \mathrm{MR}$ syntheses has been presented, we elaborate further on details for specific $8 \mathrm{MR}$ zeolites. Reviews on more generalized mechanisms of zeolite synthesis, applicable for all types of zeolites, can be found elsewhere and are focused on more classic zeolite synthesis $\left(\mathrm{OH}^{-}, \mathrm{OSDA}\right.$, alkali, $\left.\mathrm{F}^{-}\right)$, e.g., see Cundy and Cox. ${ }^{141}$

\subsection{Overview of Si/Al Ratios and Methods per Framework}

Table 1 lists all 8MR zeolites, while section 2.1 (Table 2) identifies a set of distinct routes for their synthesis. Table 3 shows which methods have been reported for each $8 \mathrm{MR}$ aluminosilicate. Additionally, the reported ranges of $\mathrm{Si} / \mathrm{Al}$ ratios that can be obtained by direct synthesis are shown (tentative). The $\mathrm{Si} / \mathrm{Al}$ range is often method-specific: for example, when a zeolite can be made in both $\mathrm{OH}^{-}$and $\mathrm{F}^{-}$media, $\mathrm{Si} / \mathrm{Al}$ ranges of materials made in the latter are often higher.

\subsection{Synthesis Details of 11 Significant Frameworks}

Based on the openness of topologies (2D-3D, cages), the amount of synthesis and application studies reported, and their (potential) catalytic relevance, we have selected the 11 most important $8 \mathrm{MR}$ zeolite frameworks and have detailed the progress on their synthesis. The aim is to (i) highlight interesting synthetic strategies or unique features of the synthetic approaches by concrete examples and (ii) develop links between topologies. These 11 topologies are highlighted in Table 3. Unsurprisingly, these are the ones where multiple methods of synthesis have been explored. Second, ten of these topologies have large cages, explaining their usefulness in catalysis and sorption (Figure 7). This review has no intention to draw or explain the structure of every topology in detail, and it refers the reader to the $\mathrm{IZA}^{3}$ and Zeomics resources. ${ }^{176}$ However, some structural features and important building units will be shown when useful to the discussion of the synthetic method. Zeolite P (GIS) is the only framework in the selected series without large voids, but this zeolite is often used in ionexchange to soften water.

2.3.1. AEI. 2.3.1.1. Structure and Implications. The AEI topology, as many others, was first encountered in aluminophosphate (AlPO-18) and SAPO-type compositions. ${ }^{177}$ The framework can be described entirely of d6r-building blocks ( $\mathrm{d} 6 \mathrm{r}=$ double $6 \mathrm{MR}=$ hexagonal prism $)$ without the need for any other composite building unit. Herein, we refer to such topologies as part of the "d6r-only" family. In AEI, these building units are linked by 4MRs, to form chains and eventually planes, with the d6r units all aligned in the same way (Figure 8). These planes are stacked along the $c$-axis, each with a $180^{\circ}$ rotation, and this leads to the asymmetric, pear-like cage with a sort of side-pocket (Figure 7 ). The cage has also been described as basket-shaped, although that expression fits the cage of $8 \mathrm{MR}$ zeolite ESV better. ${ }^{71}$ If the planes in Figure 8 are not rotated, but just stacked, the CHA-structure is obtained (vide infra).
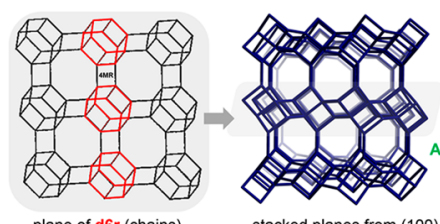

stacked planes from $(100)$
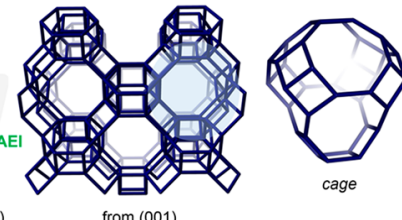

Figure 8. Building the AEI framework from linking d6r in chains to form planes, and stacking those planes.
Zones et al. discovered a recipe yielding the aluminosilicate version of AEI and named it SSZ-39. ${ }^{36}$ Wagner et al. noted that the zeolite formed with a range of organics (examples in Table 4 ) in mixtures with a medium $\mathrm{Si} / \mathrm{Al}$ ratio (15) and a lot of

Table 4. Chronologic Overview of Reported AEI-Zeolite Syntheses $\left(\right.$ Entry 1 = Oldest) ${ }^{e}$

\begin{tabular}{|c|c|c|c|c|c|c|c|c|c|}
\hline \multirow[t]{2}{*}{ E } & \multirow{2}{*}{ sources } & \multirow{2}{*}{ OSDA } & \multicolumn{4}{|c|}{$\begin{array}{c}\text { synthesis mixtures } \\
\text { composition relative to } \mathrm{Si}\end{array}$} & \multicolumn{2}{|c|}{ Product } & \multirow[t]{2}{*}{ ref } \\
\hline & & & Al & OSDA & $\mathrm{Na}^{+}$ & $\mathrm{H}_{2} \mathrm{O}$ & $\mu \mathrm{m}$ & Si/Al & \\
\hline 1 & \multirow{2}{*}{$\begin{array}{l}\mathrm{NH}_{4}-\mathrm{FAU} \\
(\mathrm{Si} / \mathrm{Al} 2.6) \\
+ \text { sodium } \\
\text { silicate }\end{array}$} & & 0.067 & 0.14 & 0.52 & 30 & - & 7.4 & 36.178 \\
\hline 2 & & & 0.02 & 0.14 & 0.52 & 30 & - & 25.5 & 36 \\
\hline $3^{a}$ & $\begin{array}{l}\mathrm{Al}\left(\mathrm{NO}_{3}\right)_{3} \\
+\mathrm{TEOS}^{\mathrm{a}} \\
\end{array}$ & & 0.0017 & 0.5 & $\begin{array}{l}0.6 \\
(\mathrm{HF})\end{array}$ & 4.9 & $1.5-2.5$ & 266 & 180 \\
\hline 4 & $\begin{array}{l}\text { steamed } \\
\mathrm{NH}_{4}-\mathrm{FAU} \\
\text { (Si/Al 2.6) } \\
\text { + sodium } \\
\text { silicate }\end{array}$ & & $\begin{array}{l}0.067 \\
0.033\end{array}$ & 0.17 & 0.40 & 40 & $0.5-1.0$ & $\begin{array}{l}7.4 \\
9.1\end{array}$ & 181 \\
\hline 5 & $\mathrm{H}-\mathrm{FAU}_{\mathrm{s}, \mathrm{a}}{ }^{\mathrm{b}}$ & & $\begin{array}{l}0.09 \\
0.063\end{array}$ & 0.2 & 0.05 & 5 & $0.4-0.6$ & $\begin{array}{l}11.1 \\
14.9\end{array}$ & 182 \\
\hline 6 & $\mathrm{H}-\mathrm{FAU}_{\mathrm{s}, \mathrm{a}}{ }^{\mathrm{c}}$ & TEP & 0.033 & 0.3 & 0.1 & 5 & 0.5 & 20.6 & 183 \\
\hline 7 & $\mathrm{H}-\mathrm{FAU}_{\mathrm{s}, \mathrm{a}}$ & DEDMP & 0.063 & 0.2 & 0.2 & 7.5 & $0.2-0.6$ & 12.0 & 183 \\
\hline 8 & \multirow{3}{*}{$\begin{array}{l}\text { steamed } \\
\mathrm{NH}_{4}-\mathrm{FAU} \\
(\mathrm{Si} / \mathrm{Al} 2.6) \\
+ \text { sodium } \\
\text { silicate }\end{array}$} & $\begin{array}{c}\text { cis/trans-3,5 = } \\
48 / 52\end{array}$ & 0.067 & 0.14 & 0.51 & 28 & $0.5-1$ & 6.2 & 184 \\
\hline 9 & & & 0.033 & 0.14 & 0.57 & 28 & - & 9.5 & 184 \\
\hline 10 & & $\begin{array}{c}\text { cis-3,5/cis-2,6 = } \\
50 / 50\end{array}$ & 0.033 & 0.14 & 0.57 & 28 & $0.5-1.0$ & 8.7 & 184 \\
\hline 11 & $\begin{array}{l}\mathrm{NH}_{4}-\mathrm{FAU} \\
+ \text { sodium } \\
\text { silicate }^{d}\end{array}$ & & 0.056 & 0.14 & 0.54 & 19 & - & 13.0 & 185 \\
\hline 12 & $H-F A U_{s . a}$ & cis/trans-3,5(?) & 0.094 & 0.2 & 0.2 & 15 & $0.3-0.4$ & 8.2 & 186 \\
\hline 13 & $\mathrm{H}-\mathrm{FAU}_{\mathrm{s}, \mathrm{a}}$ & $\begin{array}{l}\text { DEDMP + } \\
\text { TEP }\end{array}$ & 0.059 & $\begin{array}{l}0.14+ \\
0.06\end{array}$ & 0.1 & 5 & 0.2 & 14 & 187 \\
\hline 14 & $\mathrm{H}-\mathrm{FAU}_{\mathrm{s}, \mathrm{a}}$ & TEP & 0.090 & 0.1 & 0.1 & 5 & $0.04-0.05$ & 8.5 & 188 \\
\hline 15 & $\begin{array}{l}\text { H-FAU } \\
\text { +silica sol }\end{array}$ & cis/trans-3,5 (?) & 0.033 & 0.17 & 0.18 & 3.3 & $0.2-0.3$ & 16.4 & 189 \\
\hline
\end{tabular}

${ }^{e} \mathrm{E}=$ entry, DEDMP $=N, N$-diethyl-2,6-dimethylpiperidinium, TEOS = tetraethylorthosilicate, TEP = tetraethylphosphonium. Product crystal sizes are given in $\mu \mathrm{m}$, mostly from electron microscopy. ${ }^{a}$ Fluoridemedia synthesis ( $\mathrm{F} / \mathrm{Si}$ ratio is found in $\mathrm{Na}^{+}$-column) with addition of SSZ-39 seeds, made according to the Zones patent (first entry). DEDMP was also tested by Zones et al. in similar gels, yielding only zeolite SFF. ${ }^{190} b_{\mathrm{s}, \mathrm{a}}=$ steamed + acid-leached. ${ }^{c_{0}} \mathrm{NH}_{4} \mathrm{~F} / \mathrm{Si}$ was added, as well as $10 \mathrm{wt} \%$ of AEI-seeds. ${ }^{d}\left(\mathrm{NH}_{4}\right)_{2} \mathrm{SiF}_{6}$-treated, dealuminated FAU, LZ-210. ${ }^{144}$

hydroxide; the latter needed to solubilize the aluminum. ${ }^{36,178}$ They noted that in these cases, the inorganic gel composition can dominate over the organic/inorganic interactions and lead to cage-containing zeolites with even-membered ring constructions and small portals (e.g., AEI, AFX, CHA, SFW, ... vide infra). The even-membered rings ( $8 \mathrm{MR}, 6 \mathrm{MR}, 4 \mathrm{MR})$ are hypothesized to form more readily at high Al-substitution (than 5MR), because the strict alteration of $\mathrm{Si}$ and $\mathrm{Al}$ (Löwenstein's rule) can more easily avoid the unfavorable Coulombic interactions when two negatively charged alumina tetrahedra are close to each other (i.e., in the extreme case, $\mathrm{Si} / \mathrm{Al}=1$ can be obtained in a $6 \mathrm{MR}$ but never in a $5 \mathrm{MR}$ ).

2.3.1.2. AEI Zeolite Synthesis. Since this zeolite has proven merits in catalysis, ${ }^{179,181}$ a detailed discussion of its synthesis is warranted. Table 4 presents an overview of most of the reported AEI syntheses. 


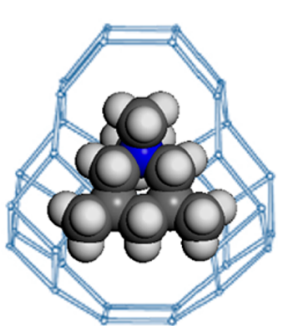

AEI: $-11.4 \mathrm{~kJ} / \mathrm{mol}$ $15.1 \mathrm{~T} / 1000 \AA^{3}$
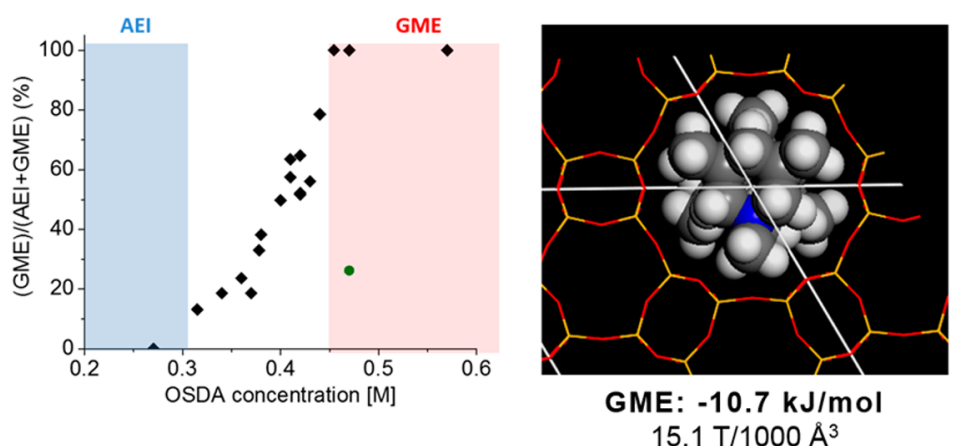

Figure 9. Competition from the ratios of reflections measured in PXRD between small-pore AEI and large pore GME zeolites as a function of the concentration of the $\mathrm{N}, \mathrm{N}$-dimethyl-cis-3,5-dimethylpiperidinium OSDA. The modeling energy and OSDA position for GME are accurate and found in ref 33. The energy for AEI is found in earlier work, ${ }^{192}$ without the optimal OSDA position documented: A simple cartoon showing one per cage (confirmed from various techniques) was made.

The original patent on SSZ-39 claims a set of different organics. Ten of these are effectively based on piperidine, with different, often methyl, substitutions on the ring and with the nitrogen quaternized by methyl or ethyl groups. The foremost examples are $N, N$-diethyl-2,6-dimethyl-, $N, N$-dimethyl-3,5dimethyl-, and $N, N$-dimethyl-2,6-dimethylpiperidinium (Table 4, entries 1, 4, and 9). Typically, these OSDAs, e.g., DEDMP in entry 1 , lead to SSZ-39 with a Si/Al ratio around 7.5 , in synthesis mixtures with $\mathrm{Si} / \mathrm{Al}$ ratios of 15 , with the help of a FAU zeolite as aluminum (and partial $\mathrm{Si}$ ) source. Evidently, the different $\mathrm{Si} / \mathrm{Al}$ ratios in the product and synthesis mixture reveal a low yield, as part of the silica remains unused. Another patented OSDA was based on an azoniabicyclononane (Table 4, Entry 2), and when tested in a $\mathrm{Si} / \mathrm{Al} 50$ mixture, a material was produced with a $\mathrm{Si} / \mathrm{Al}$ ratio of 25 (a value so far not attained for piperidinium-OSDAs in $\mathrm{OH}$-media). This is still the lowest Al-substitution reported in AEI zeolites made in hydroxide media. Later, Cao et al. claimed a route for AEI (with $\mathrm{Si} / \mathrm{Al}>200$ ) also using DEDMP in Al-deficient fluoride gels, based on using SSZ-39 seeds made in hydroxide media (Table 4, entry 3). However, Zones et al. published a thorough study investigating the role of a range of piperidinium-based OSDAs, also DEDMP, in fluoride media, but never obtained AEI. ${ }^{190}$

Moliner et al. reproduced the original synthesis of SSZ-39, in the context of deNOx catalysis, with the use of $N, N$-dimethyl3,5-dimethylpiperidinium (cis- and trans-3,5; unspecified isomer ratio, Table 4, entry 4). ${ }^{181}$ They noted the large impact of different sources on the success of making SSZ-39 in hydroxide media, and they showed that only a specific combination of a FAU zeolite precursor, also a member of the d6r-only family, and sodium silicate (as in Zones' patent) yielded SSZ-39. Later, Dusselier et al. showed that sodium silicate was replacable, e.g., by using TEOS or colloidal silica, as long as the FAU-zeolite Al-source was used, and the relatively high $\mathrm{OH}^{-}$and $\mathrm{Na}^{+}$contents remained. ${ }^{184}$ Dusselier et al. also investigated the influence of diastereo- and structural isomers of the tetramethylated-piperidinium OSDAs by using different cis/trans-3,5 mixtures (ranging from 48/52 to 98/2) and mixtures of these with $N, N$-dimethyl-cis-2,6-dimethylpiperidinium (cis-2,6). From an economic point of view, these 3,5- and 2,6-dimethylpiperidine-based molecules are important, since their precursor dimethylpyridines are among the most common commercially produced alkylated pyridines. ${ }^{184}$ The cis and trans isomers of the 3,5-form both arise during the hydrogenation of the aromatic ring, while for the 2,6-form, the cis- isomer dominates due to steric hindrance. Dusselier and coworkers showed specific conditions where SSZ-39 could be made, with cis-3,5, trans-3,5, or cis-2,6 isomers and, even tertiary, mixtures thereof (Table 4, entries 8-10). As the OSDA is often one of the decisive cost factors in commercial zeolite synthesis, these results are thus important, as mixtures (in line with the organic production) could be used instead of more expensive pure isomers. Although mixtures worked, the authors noted remarkable isomer-dependent trends for the AEI zeolite synthesis. A relative rate of formation trend was documented (in the studied conditions: trans-3,5 > cis-3,5 > cis-2,6). Second, it was shown that preferential incorporation existed (visible in ${ }^{13} \mathrm{C}$ MAS NMR and confirmed by zeolite dissolution), when isomers where presented in competition (trans-3,5 > cis-3,5 and cis-2,6 > cis-3,5 isomer). Recently, Shantz and co-workers deepened the isomer-study, confirming most of the findings and the trans-induced faster rate of formation, while also carefully analyzing the solid yields. Additionally, in $\mathrm{Si} / \mathrm{Al} 45$ synthesis suspensions, a small but clear increase in the $\mathrm{Si} / \mathrm{Al}$ ratio of the material is found when increasing the trans-isomer content. ${ }^{191}$ On a side note, recently it was found that when the concentration of water content of syntheses with pure cis-3,5 was lowered (in fact only going from $\mathrm{H}_{2} \mathrm{O}: \mathrm{Si} 35$ to 20 , in conditions like those of Table 4 entry 8 ), another zeolite formed. This zeolite, CIT-9, proved to be a fault-free GME. The concentrated cis-3,5 route thus ended a 40 -year search for a simple recipe to a porous version of this 12 $\times 8 \times 8$ topology. ${ }^{33}$ Although not a small-pore zeolite, this is informative in the light of targeting cage-based 8MR zeolites. The selectivity of the cis-OSDA for both GME and AEI, respectively in concentrated and dilute conditions, visualized in Figure 9, was suggested to be linked to the concentration of the OSDA in the syntheses. The cis-OSDAs were found in the 12MR channel of GME from molecular modeling, while for AEI, one OSDA per cage is found (Figure 9, left). The calculated energies for GME are most favorable when using two organics per unit cell, instead of less, implying OSDAs closely line up in the $12 \mathrm{MR}$ pore (Figure 9, right). It is likely that this type of structure-direction only occurs when the concentration in the synthesis suspension is high, while dilute conditions lead to AEI, with occlusion of one OSDA per cage.

In this context, the work of Schmidt et al. is intriguing, as it documented a computational search for the optimal OSDA for SSZ-39. Besides proposing a new OSDA from computation and successfully obtaining AEI aluminosilicate with that heavily 
substituted, asymmetrically quaternized piperidine (Table 4, entry 11), they reported the calculated stabilization energies of all reported N-based OSDAs for SSZ-39. ${ }^{185}$ In decreasing order, the values for DEDMP, azoniabicyclononane, $N, N$ dimethyl-2,6-dimethylpiperidinium, and $N, N$-dimethyl-3,5-dimethylpiperidinium (structures in Table 4) were -16.2, -14.9, -14.0 , and $-13.3 \mathrm{~kJ} / \mathrm{mol}_{\mathrm{Si}}$. Their new OSDA scored the highest value of $-16.9 \mathrm{~kJ} / \mathrm{mol}_{\mathrm{Si}}$. SSZ-39 synthesis with this organic led to a material with relatively high $\mathrm{Si} / \mathrm{Al}$ ratio of 13 . The energy difference between the 3,5- and the 2,6-isomer OSDAs is not deemed significant enough to explain the differences in rates and incorporation noted by Dusselier et al. Moreover, the calculations did not take into account cis/transisomerism. Usually, for a given framework, stabilization energy differences among OSDAs on the order of $2 \mathrm{~kJ} / \mathrm{mol}$ are significant to corroborate synthesis trends.

A new OSDA and set of conditions for AEI materials was reported by the Sano group, using tetraethylphosphonium hydroxide (TEP) and a FAU-zeolite as both $\mathrm{Si}$ and Al-source (Table 4, entry 5). This route, effectively an interzeolite conversion (method D in Tables 2 and 3), only worked well when a small amount of $\mathrm{NaOH}$ and specific dealuminated FAU zeolites ( $\mathrm{Si} / \mathrm{Al}$ ratios 11 and 17 ) were used. Remarkably, these synthesis-Si/Al ratios are similar to those used earlier in the mixtures with sodium silicate and an aluminous FAU zeolite. An issue with quaternized P-based organics is that during calcination, to remove the organic and empty the voids for application, often monomeric and condensed phosphorus species (e.g., oxides) remain in the solid. These P-species can alter the zeolite's properties. A P/Al ratio of 1.2 was indeed found after calcination of these AEI zeolites. Later, the group revisited their procedure, to investigate the $\mathrm{P}$-species in the zeolite, and demonstrated deNOx activity after $\mathrm{Cu}$-exchange. Using an excessive amount of seeds and by adding $\mathrm{NH}_{4} \mathrm{~F}$, a pure-phase material with $\mathrm{Si} / \mathrm{Al}=21$ was obtained using TEP (Table 4, entry 6). In the same work, the authors also successfully prepared SSZ-39 from interzeolite conversion with DEDMP (Table 4, entry 7). Although not highlighted in their work, this methodology is an easy route for SSZ-39, using classic (easy-to-remove) $\mathrm{N}$-based organics. ${ }^{183} \mathrm{The} \mathrm{Si} / \mathrm{Al}$ ratio of the starting and product zeolite in this IZC were 16 and 12 , respectively, suggesting a solid conversion yield near $75 \%$ (considering all $\mathrm{Al}$ incorporated in the new phase). Interestingly, the crystal sizes of the IZC-materials (entries 5-7) are somewhat smaller than those of the classic SSZ-39 zeolites, around $200-600 \mathrm{~nm}$ (vs $0.5-1.0 \mu \mathrm{m}){ }^{183}$ The materials prepared by TEP also seemed significantly more thermally stable, likely by phosphorus-modification. In a more recent report, the authors even proposed a mixed-OSDA strategy, using DEDMP and TEP together (Table 4, entry 13) to take advantage of an optimal, small amount of phosphorusmodification, to increase the hydrothermal stability. ${ }^{187}$

Martín et al. further studied IZC-methods for preparing SSZ39 from FAU (actual USY-zeolites, Table 4, entry 12). ${ }^{186}$ Notably, instead of DEDMP, ${ }^{183}$ they used the cis/trans-3,5 OSDA (ratio unknown). This improvement could be relevant, as a diethyl-quaternization step in OSDA synthesis (e.g., for DEDMP) is usually harder than a dimethyl one. The $\mathrm{Si} / \mathrm{Al}$ ratio of the starting and product zeolite were 10.5 and 8.2, respectively, indicating a high solid conversion yield. Interestingly, the authors also reported the addition of $\mathrm{Cu}$ tetraethylenepentamine to this synthesis, yielding Cu-SSZ-39 for SCR directly (without Cu-exchange afterward). ${ }^{186}$ The same authors also reported a modification of the TEPprocedure, using the $\mathrm{Si} / \mathrm{Al}=10.5 \mathrm{FAU}$-zeolite as source (Table 4, entry 14). ${ }^{188}$ They noted, compared to their work above in a similar synthesis with cis/trans-3,5, that the crystal sizes of the resulting zeolites were very small and in the range of $50 \mathrm{~nm}$. These zeolites are about an order of magnitude smaller than the TEP-zeolites reported earlier. The reason for this result is uncertain, although a faster nucleation rate, originating from an unknown interplay between the specific starting FAU zeolite and TEP is likely. Crystal sizes can be crucial to the performance in certain catalytic applications (see section 3.4.3.3). A recent AEI synthesis was also reported in this context, when Kubota and co-workers found medium-small crystallites (Table 4, entry 15) when using colloidal silica, an appropriate FAU-zeolite, and the cis/trans-3,5 OSDA (isomer ratio unknown). The concept in this report was to work with very low water content $\left(\mathrm{H}_{2} \mathrm{O} / \mathrm{Si}=3.3\right)$, and with specific alkaline ratios. The result, $300 \mathrm{~nm}$ small SSZ-39 particles, with a high $\mathrm{Si} / \mathrm{Al}$ of 16 , is remarkable and could be of use in catalysis. Additionally, an interesting and informative set of experiments was shown that involved different FAU precursors. For instance to obtain AEI in the conditions of entry 15, but with a more aluminous FAU ( $\mathrm{Si} / \mathrm{Al}=5.3$ instead of 10.3), the $\mathrm{NaOH}$ addition had to be increased to 0.24 (and the dilution, $\mathrm{H}_{2} \mathrm{O}: \mathrm{Si}$ to 5), to avoid MTW and FAU competition. ${ }^{189}$

2.3.1.3. AEI-Zeolite Conclusions. AEI presents an important set of materials due to the excellent performance in both SCR and MTO catalysis (sections 3.2, 3.4). In the last 3 years, remarkable progress in its hydrothermal synthesis has been reported. Some interesting observations, insights, and comments can be made:

(1) The $\mathrm{Si} / \mathrm{Al}$ ratios of the zeolite prepared in hydroxide media still have not risen above 20 (except for one patent entry). The question is whether this derives (i) from structure-specific limitations of the AEI framework itself, favoring more Al-incorporation or (ii) due to the lack of an OSDA that fits very well. The latter could be plausible, given that the patent entry made use of the relatively large azonia-OSDA.

(2) Since AEI and CHA are very similar structures and both are "d6r-only" members, it is worthwhile to note that the latter can be made in $\mathrm{OH}^{-}$-media up to $\mathrm{Si} / \mathrm{Al}=55$ by using the very well fitting ADAM OSDA (section 2.3.3), and that there is no structural limitation to even puresiliceous CHA materials ( $\mathrm{F}^{-}$-media). This argument is in favor of the possibility of creating AEI with higher ratios. On the other hand, creating highly siliceous cagecontaining zeolites in hydroxide media should also be approached from a charge balance perspective: in the ideal case, one OSDA occupies every large cage. AEI has $36 \mathrm{~T}$ atoms surrounding the cage (Figure 7 ), with each $\mathrm{T}$ atom shared over 3 cages, rendering the amount of $\mathrm{T}$ atoms per cage at 12 (the unit cell, having $48 \mathrm{~T}$ atoms and 4 full cages, confirms this count). ${ }^{184}$ This implies that the ideal AEI structure made with one OSDA per cage should include one aluminum for charge balancing, or thus have a $\mathrm{Si} / \mathrm{Al}$ ratio of 11 . The reported ratios in Table 4 seem to be centered around this value. Higher $\mathrm{Si} / \mathrm{Al}$ values in $\mathrm{OH}^{-}$-media entail the incorporation of charge-balancing siliceous defects (although these can anneal in calcination). Perhaps the structure of AEI does not allow the incorporation of such defects to the same 
extent as $\mathrm{CHA}$, considering for instance that AEI has three crystallographically different (although very similar) $\mathrm{T}$ atoms, while $\mathrm{CHA}$ has one.

(3) A multitude of OSDAs for aluminosilicate AEI have been reported. Notably, the heavily substituted piperidinium published by Schmidt et al. (entry 11, Table 4), with the largest stabilization energy for the cage, has not been tested in a range of conditions intended for creating higher silica materials. ${ }^{185}$ It should be.

(4) Not one AEI zeolite has been made without the presence of a FAU-zeolite. The FAU is used either as source for alumina, with silica added separately, or as only source in IZC. An exception here would be the fluoride-based method described in the patent, but there, AEI-seeds are used. To the best of our knowledge, aluminosilicate AEI is a unique case in this respect, certainly in the realm of $8 \mathrm{MR}$ zeolites. Since the source of alumina has so far always been a zeolite, there are indications that this influences the $\mathrm{Al}$-incorporation into the new zeolite and thus its $\mathrm{Si} / \mathrm{Al}$ ratio. Insights from the numerous IZC routes reported for CHA (see below, section 2.3.3.4) could be of use. Strikingly, CHA can be made without FAU-sources, but it seems to go faster if they are present (again pointing to the need for a good fitting OSDA for AEI). Both FAU and AEI are members of the d6r-only family (the only other 8MR-zeolite members are CHA, AFX, KFI, SAS, SFW, and TSC). It is likely that this structural similarity helps in forming the new zeolite during IZC (e.g., along the line of Figure 4, with 6MRnanoparts) or partial IZC. The hypothesis, preeminent in IZC literature, ${ }^{146}$ is that the new zeolite is formed faster (and selectively) through the reassembly of (nano)parts from the dissolving mother zeolite. It is also interesting to note the similarities to seeding and its benefits in classic synthesis. There, seeds sometimes completely disappear in the X-ray diffractogram in the first hours of the synthesis but still direct the crystallization to be faster or more selective, indicating that they do not completely dissolve to monomolecular $\mathrm{T}$ atoms. ${ }^{193}$

(5) Although the AEI zeolite can thus be made with a different range of organics (Table 4, Zones patent), the inorganic conditions are thought to predominate over the organic/inorganic interactions. Zones noted this, because these zeolites are formed in the presence of high $\mathrm{OH}^{-}$contents (i.e., $0.7 \mathrm{OH}^{-} / \mathrm{Si}$ ). ${ }^{178}$ This is thought to favor the occurrence of even-membered rings (AEI is built from 4, 6, and $8 \mathrm{MR}$ ), as well as being needed to solubilize the aluminum. In Table 4 , the $\mathrm{OH}^{-}$content can be calculated by simply adding the OSDA/Si and $\mathrm{Na} / \mathrm{Si}$ columns. ${ }^{178}$ Interestingly, most syntheses where FAU was used and another silica source was added indeed feature a high $\mathrm{OH} / \mathrm{Si}$, while the IZC routes use remarkably less hydroxide. Given the fact that a FAU zeolite is built from $4 \mathrm{MR}$ and $6 \mathrm{MR}$ (d6r), there is a good chance that the complete breakdown of the structure to monomolecular Al- and Si-precursors is not occurring, but rather to some (not necessarily well-defined) nanoparts. ${ }^{145,146}$ A possible reason why IZC routes need considerably less hydroxide for success (i.e., to inhibit other phases or amorphous solids) could be that the precursors-derived nanoparts with even-membered rings replace the role of a high-in-hydroxide medium favoring even-membered rings. Note that in the case of using FAU with additional silica, the $\mathrm{Si} / \mathrm{Al}$ of the product is more than doubled with respect to the starting zeolite (entries 1, 4, 8-10). Considering a d6r (with $12 \mathrm{~T}$ atoms) in a FAU precursor with three aluminums $(\mathrm{Si} / \mathrm{Al}$ $=9 / 3=3$ ), this entails theoretically replacing one (or two) aluminums by external silicons to obtain a $\mathrm{Si} / \mathrm{Al}=5$ (or 11). The use of a high hydroxide content in these FAU+silica syntheses is thus needed to mobilize aluminum, at least locally. The use of high hydroxide entails the coaddition of alkali $(\mathrm{Na})$ that does not help in creating high-silica materials $\left(\mathrm{Na}^{+}\right.$can easily balance charge in d6r cages). On the contrary, in the case of pure $\mathrm{IZC}$, the $\mathrm{Si} / \mathrm{Al}$ ratios of the product are always lower than that of the starting FAU (entries 5-7, 12-14), meaning that silica is being selectively dissolved during the transformation, and part of it stays in solution. There is thus less of a need for hydroxide-rich conditions since the aluminum does not need to be solubilized. These two types of synthesis, although leading to the same product and seemingly similar, are thus very different (!). There is of course a middle path, and in our opinion, this is embodied in the last entry in Table 4. Kubota and coworkers used an appropriate FAU source and a silica sol (instead of Na-silicate) and noted the crucial selection of both $\mathrm{NaOH}$ and water contents depending on the FAU used. Using less of a more aluminous FAU warranted higher hydroxide addition, but in a higher dilution, while using more of a siliceous FAU allowed the authors to use a lesser $\mathrm{NaOH}$ content in the gel. The latter also entailed heavily concentrating the solution to $\mathrm{H}_{2} \mathrm{O} / \mathrm{Si}=3.3$. ${ }^{189}$ We believe this is necessary to let the OSDA interact better with the FAU (note how these conditions start to resemble those of IZC, as these often rely on low water contents).

(6) Dusselier et al. found remarkable organic-sensitive trends in the isomer-study, although the inorganic conditions in these $\mathrm{OH}^{-}$rich syntheses are thought to dominate (comment 5). ${ }^{184} \mathrm{~A}$ likely explanation for these results is that the relative occurrence of kinetically competing phases (e.g., MOR) is altered by the different isomers. For instance in $\mathrm{Si} / \mathrm{Al}=15$ mixtures, the 2,6-isomer did not produce $\mathrm{AEI}$, while the 3,5-isomers did (in $\mathrm{Si} / \mathrm{Al}=$ 30 mixtures, both isomers did produce AEI). Similarly, cis-3,5 leads to GME in concentrated conditions. The kinetic competition of other phases clearly differs with the Al-content of the synthesis. The reason why IZC (could) overcomes this, is perhaps that the aluminum is not substantially solubilized, as is the case in the isomer studies using additional silica (corroborating comment 5).

(7) Crystal sizes could offer insights into the mechanisms governing AEI synthesis, as they are determined by the interplay between nucleation and crystal growth. The interaction of FAU precursors with the OSDA and the added $\mathrm{Na}^{+}$should mainly effect the former (e.g., nanosized synthesis by Martín et al). ${ }^{188}$

(8) The most recent synthesis by Kubota and co-workers seems relevant for catalytic purposes (also see comment $5)$, as Al-incorporation this low had never been reported for the perhaps most accessible $N, N$-dimethyl-3,5dimethylpiperidinium OSDA.

2.3.2. AFX. The first material reported with the AFX structure had a SAPO-composition. AFX is a member of the 
ABC-6 stacking family of structures. The ABC-6 pattern consists of planar hexagonal arrays of nonconnected $6 \mathrm{MR}$ that are translated horizontally and connected (stacked) vertically. Each planar layer is in an $\mathrm{A}, \mathrm{B}$, or $\mathrm{C}$ position, yielding repeating descriptions, e.g., ...AABBCCBB... for AFX (Figure 10). The

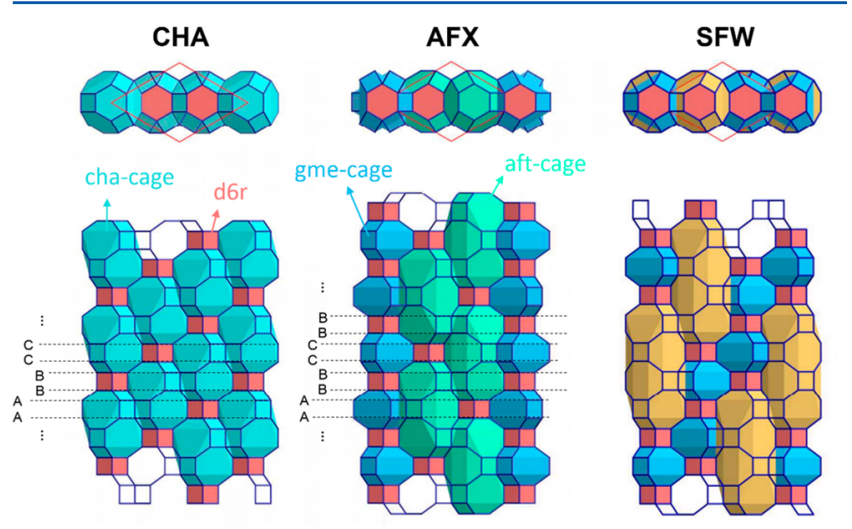

Figure 10. Structures of CHA, AFX, and SFW along [001] (top) and [110] (bottom). Adapted with permission from ref 66. Copyright 2013, American Chemical Society. Note how the "d6r-only" nature in ABC-6 zeolites is visible in the double repeat of each layer (e.g., AA). Yellow = very large SFW cage.

other $\mathrm{ABC}-6$ members in the $8 \mathrm{MR}$ zeolite family are $\mathrm{CHA}$, $\mathrm{EAB}, \mathrm{ERI}, \mathrm{LEV}$, and SFW. The ABC-6 pattern for AFX generates a large cage (aft composite building unit), resembling an extended version of the cage of CHA (Figure 7). Another way to build the AFX structure is by translating and connecting d6r units. As with AEI, AFX is a member of the d6r-only family. The only two other structures that belong to both the d6r-only and the ABC-6 families are CHA and SFW. The structural link between these three materials with expanding cages (Xie et al. ${ }^{66}$ ) provides an interesting case for relating synthesis and structure (Figure 10).

The zeolite version of AFX, named SSZ-16, was discovered by Zones using a 1,4-bis(1-azoniabicyclo[2.2.2] octane)butyl dibromide OSDA in hydroxide media, in the presence of $\mathrm{Na}^{+} \cdot{ }^{39,142}$ This OSDA consists of two quinuclidine units connected by their quaternary nitrogen atoms through a fourcarbon polymethylene bridge (Figure 11). The quinuclidine unit resembles 1,4-diazabicyclo[2.2.2] octane, better known as DABCO (structure in Figure 18, without the R-group of ERI OSDAs), but does not have a second $\mathrm{N}$ atom in the 4-position.

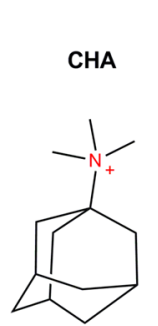

ADAM

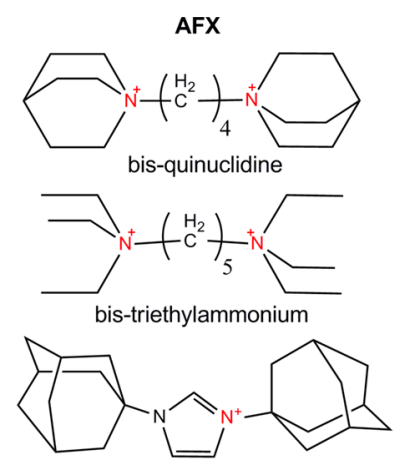

bis-ADAM-imidazolium

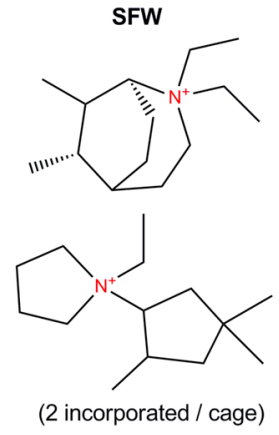

(2 incorporated / cage)
Figure 11. OSDA for CHA, AFX, and SFW (cages and structures in Figures 7 and 10) Only for SFW, two OSDAs per cage were found. $\mathrm{ADAM}=\mathrm{N}, \mathrm{N}, \mathrm{N}$-trimethyl-1-adamantylammonium.
A couple of other diquaternary OSDA (diquat) with fourcarbon bridges were also found to work and are based on connecting two ADAM, two DABCO, or even two triethylammonium units. ${ }^{38}$ Archer et al. used 1,3-imidazolium linked ADAMs for synthesizing SSZ-16 (not a diquat), ${ }^{194}$ while Lee et al. reported C5-bridged triethylammoniums ( $\mathrm{Et}_{6}$-diquat5). ${ }^{195}$ Figure 11 shows three of these SSZ-16 organics, along with the common OSDAs for CHA and SFW. The Si/Al range reported for AFX is narrow, from 3.7 to 17, suggesting that the d6r units in this zeolite have a preference for a specific amount of aluminum incorporation in $\mathrm{OH}^{-}$media: from 1 to 3 aluminums per $12 \mathrm{~T}$ atoms (=d6r unit). The $\mathrm{Si} / \mathrm{Al}$ ratio for the commonly used DABCO-, quinuclidine-, and triethylammonium-based diquats seems to be closer to 5 (or $2 \mathrm{Al}$ per d6r). ${ }^{38,164,195,196}$ The simplified $\mathrm{T}$ atom count per cage for charge balance estimates (as for AEI above and CHA below) is harder for AFX due to the presence of a second type of smaller cage (gme-unit, Figure 10), in spite of the structural similarity of the AFX cage and CHA-cage (1.5 $\times$ expansion).

The most siliceous AFX Si/Al (17) was reported using the monoquaternary bis-ADAM-imidazolium linked OSDA (Figure 11), ${ }^{159}$ likely due to the lower charge-over-size ratio of this organic. Aiming at lower $\mathrm{Si} / \mathrm{Al}$ ratios in the syntheses mixtures often gives competition with other $\mathrm{Na}^{+}$-rich phases that do not need to include organic. Given the d6r-only feature of AFX and the fact that the CHA zeolite, with structural similarity, can be made over the full range of $\mathrm{Si} / \mathrm{Al}$ ratios, there does not appear to be a thermodynamically-induced lower limit to $\mathrm{Al}$ incorporation. An all silica version of AFX should thus be able to form. The likely reason why no higher-silica versions of AFX have been made is that the stabilization energies of the reported OSDAs are not low enough, and perhaps most of these organics are too flexible. Considering that ADAM provides a very high stabilization of $-16.7 \mathrm{~kJ}$ per mole of $\mathrm{T}$ atoms in $\mathrm{CHA}$, its synthesis over a wider range of $\mathrm{Si} / \mathrm{Al}$ is less surprising. The trends in AFX and SFW (for the latter, -11.1 $\mathrm{kJ} / \mathrm{mol}$ is the lowest framework-OSDA stabilization encountered $^{137}$ ) seem to indicate that higher silica materials need to have a more specific OSDA-inorganic interaction, to be successfully synthesized in hydroxide media, or, in reverse, that these types of structures (ABC-6, d6r-only, cages) have a preferred $\mathrm{Si} / \mathrm{Al}$ compositional range, tentatively estimated from 2.6 (close to natural CHA) to 11. An interesting and detailed synthesis study using the bis-triethylammonium diquat was reported by Hrabanek et al., showing the importance of aging and inorganic sources for SSZ-16. The authors noted a strong influence of nucleation on particle size and, interestingly, isolated core-shell structures with amorphous silica inside an SSZ-16 shell, when fumed silica was used. ${ }^{197}$

Recently Martín et al. reported a new, IZC-based, route to AFX, with a large multicyclic Diels-Alder derived OSDA that also led to ERI in slightly different conditions (OSDA: see Figure 18). A very small synthetic window and the use of the right $\mathrm{FAU}(\mathrm{Si} / \mathrm{Al}=6)$ zeolite precursor led to $\mathrm{AFX}$ (i.e., $\left.\mathrm{OSDA} / \mathrm{Si}=0.2, \mathrm{NaOH} / \mathrm{Si}=0.1, \mathrm{H}_{2} \mathrm{O} / \mathrm{Si}=15\right)$. The $\mathrm{Si} / \mathrm{Al}$ range of the product, 5.2, is in line with previous SSZ-16 materials. The same conditions, save for changing $\mathrm{Na}^{+}$for $\mathrm{K}^{+}$, lead to ERI. ${ }^{198}$

2.3.3. CHA. 2.3.3.1. Synthetic Chabazite, SSZ-13, and Pure Silicas. As mentioned above and illustrated in Figures 7 and 10, the structure of CHA consists of symmetric, mediumsized cages obtained by stacking planes of nonconnected $6 \mathrm{MR}$ rings along an $\mathrm{AABBCC}$ sequence, or from d6r units. The latter 

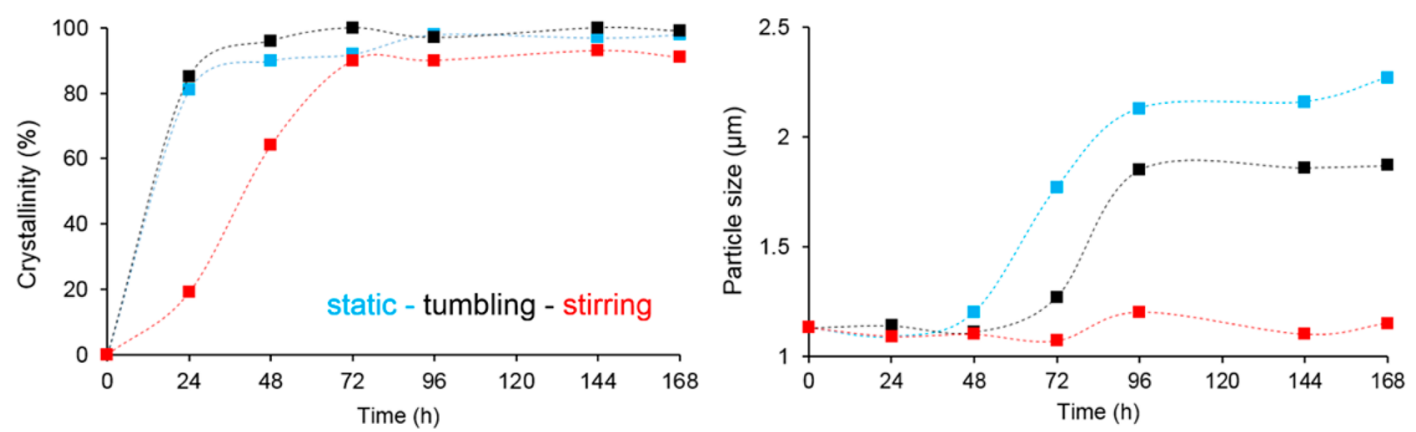

Figure 12. Crystallinity from PXRD (relative to the most crystalline sample from tumbling) and zeolite particle sizes from DLS, as a function of the synthesis time at $160{ }^{\circ} \mathrm{C} . \mathrm{Si} / \mathrm{Al}=50, \mathrm{H}_{2} \mathrm{O} / \mathrm{Si}=31, \mathrm{ADAM} / \mathrm{Si}=0.6$ ratios. Gels from TEOS and Al-hydroxide. Prepared with data from ref 206.

description resembles that of AEI (Figure 8), but for CHA, the planes of d6r units are stacked on top of each other along the $c$ axis, without prior rotation. CHA has only one unique $\mathrm{T}$ atom position. Since the early days, attempts were made to synthetically access CHA-zeolites, given the interesting sorption and sieving properties, discovered as early as 1924 on chabazite minerals. Barrer and Baynham obtained species K-G from potassium aluminosilicate gels. ${ }^{44} \mathrm{~A}$ standard recipe is now available to obtain this zeolite with $\mathrm{Si} / \mathrm{Al}$ ratio between 2 and 3 in classic hydroxide media ( $c f r$. Synthesis Commission of IZA) ${ }^{167}$ This recipe uses $\mathrm{Na}^{+} / \mathrm{K}^{+}$and $\mathrm{M}^{+} / \mathrm{Al}$ ratio of 0.085 , and 2.2, respectively, at $95{ }^{\circ} \mathrm{C}$, in a $\mathrm{Si} / \mathrm{Al} 2.6$ gel with a FAU-type zeolite as $\mathrm{T}$ atom source (in fact an organic-free IZC). ${ }^{199}$ Recipes with more classic sources are also known. A low-silica recipe using only $\mathrm{K}^{+}$with addition of $\mathrm{NH}_{4} \mathrm{~F}$ was reported recently. ${ }^{200}$

A breakthrough in CHA zeolite synthesis was realized by Zones in 1985, who demonstrated $\mathrm{Si} / \mathrm{Al}$ ratios well above those of the organic-free synthesis by using the large ADAM OSDA (Figure 11) in common hydroxide media. ${ }^{4}$ Zeolites with $\mathrm{Si} / \mathrm{Al}$ ratios higher than 10 are often required for catalytic applications, as they are more stable than their more aluminous counterparts at high temperatures or in steam-rich conditions. In synthesis mixtures with $\mathrm{Si} / \mathrm{Al}$ ratios below 55 , the zeolite can now readily be made with the according $\mathrm{Si} / \mathrm{Al}$ ratio in the material. Above that ratio, the hydroxide syntheses also starts to produce MWW, STT, and AFI-type zeolites. ${ }^{162,201,202}$ The large cages are ideally occupied by one ADAM molecule. By switching to fluoride media, Camblor and co-workers showed the possibility of making pure-silica CHA with ADAM. ${ }^{162}$ Typically, such a synthesis works in the absence of inorganic cations, and the amount of HF added neutralizes the amount of base generated by the addition of the OSDA in its hydroxide form $\left(\operatorname{ADAM}\left(\mathrm{OH}^{-}\right)\right)$. Furthermore, $\mathrm{F}^{-}$anions associate closely with the ADAM cation and counterbalance its charge so that the framework can be neutral, and pure-silica CHA can form. ${ }^{203}$ Zones' SSZ-13 discovery was very important for the application-relevant CHA topology, ${ }^{4}$ and it generally can be seen as a breakthrough for large cage-containing $8 \mathrm{MR}$ zeolites. Many materials, with useful Si/Al ratios, followed it: SSZ-16 (AFX), SSZ-45 (EEI), SSZ-50 (RTH), SSZ-52 (SFW), SSZ-73 (SAS), cfr. Table 3.

2.3.3.2. Alterations to the ADAM Recipe. Many variations to the Zones recipe have been reported. Eilertsen et al. detailed a recipe using ADAM, $\mathrm{NaOH}$, and $\mathrm{NaF}$ (in a 2:3:1 OSDA:Na:F molar ratio), from aluminum(hydr)oxide and fumed silica sources. ${ }^{202}$ This recipe appears to be a combination of fluoride and hydroxide-media and yields materials with $\mathrm{Si} / \mathrm{Al}$ ratios between 15 and 133 (in agreement with similar values in the gels). The particle sizes were generally in the $20 \mu \mathrm{m}$ range for the $\mathrm{Si} / \mathrm{Al}$ ratios under 40 and were much smaller, close to $4 \mu \mathrm{m}$, for the higher $\mathrm{Si} / \mathrm{Al}$ mixtures. In this context, Zones also patented a small crystallite aluminosilicate CHA, named SSZ62 , specifically with zeolite particles sizing between $0.05-0.1$ $\mu \mathrm{m}$, in the $\mathrm{Si} / \mathrm{Al}=10-25$ range. ${ }^{55}$ Common crystal sizes are 1 $\mu \mathrm{m}$ or larger for SSZ-13. The small crystals were obtained with classic ADAM and $\mathrm{NaOH}$ synthesis, but with a specific Alhydroxide gel (from easily soluble $\mathrm{Al}_{2} \mathrm{O}_{3}$ ) and precipitated amorphous silica, at a precise $\mathrm{H}_{2} \mathrm{O}: \mathrm{Si}$ ratio of 16 .

Usually, the unit cell of a zeolite contracts with decreasing $\mathrm{Al}$ incorporation, due to the larger bond length of $\mathrm{Al}-\mathrm{O}$ vs $\mathrm{Si}-\mathrm{O}$. The unit cell parameters of Eilertsen's SSZ-13 series with $\mathrm{Si} / \mathrm{Al}$ ranging from 15-133 were measured for both as-made and calcined materials. ${ }^{202}$ For as-made materials, the authors found an anisotropic contraction, with most unit cell shrinkage along the $a$-axis, while the $c$-axis parameter remained more or less constant. In the calcined materials, there was a large relaxation of strain (or expansion of the unit cell with increasing $\mathrm{Al}$ content) along the $c$-axis as well. Likely, the trend in the asmade materials can be linked to the orientation of the OSDA in the zeolite: the ADAM cation sits either parallel or antiparallel to the $c$-axis, as determined on pure-silica forms by Villaescusa et al. ${ }^{204}$ This arrangement could sterically prevent large shrinkages along the $c$-axis parameter of the unit cell in asmade higher silica materials. Interestingly, this would suggest that the structure direction with $\mathrm{ADAM}$ for $\mathrm{CHA}$ (and thus crystal growth) is more favorable at lower $\mathrm{Si} / \mathrm{Al}$ ratios; as for more siliceous materials the ADAM-cavity fit is less good. This could be one of the reasons why the competition of other zeolites is more profound at $\mathrm{Si} / \mathrm{Al}$ ratios $>55$ in $\mathrm{OH}^{-}$-media, although charge balancing is also key (vide infra).

In search for a single-parameter variation synthesis, Eilertsen et al. reported another series of CHA-zeolites made in fluoride media (ADAM:HF $=1$ ) and with $\mathrm{Si} / \mathrm{Al}$ ratios ranging from 20 to infinity. The particle sizes of the zeolites in this series (at 2$4 \mu \mathrm{m})$, as well as the surface areas, are more or less constant. For $\mathrm{Si} / \mathrm{Al}$ ratios larger than $100, \mathrm{Si} / \mathrm{F}$ ratios were around 12 , confirming the incorporation of about one $\mathrm{F}^{-}$-anion per OSDA in the materials, likely in the $\mathrm{d} 6 \mathrm{r}$ unit, as in pure-silica CHA ${ }^{204,205}$ Such series are very useful in application studies, as the impact of purely $\mathrm{Si} / \mathrm{Al}$-variation on, e.g., catalysis or sorption, can be studied, while every other property remains more or less constant. Structure-activity relations in such cases are more unambiguous.

Lillerud and co-workers also investigated the formation of SSZ-13, with a focus on the particle size (through the crystal 

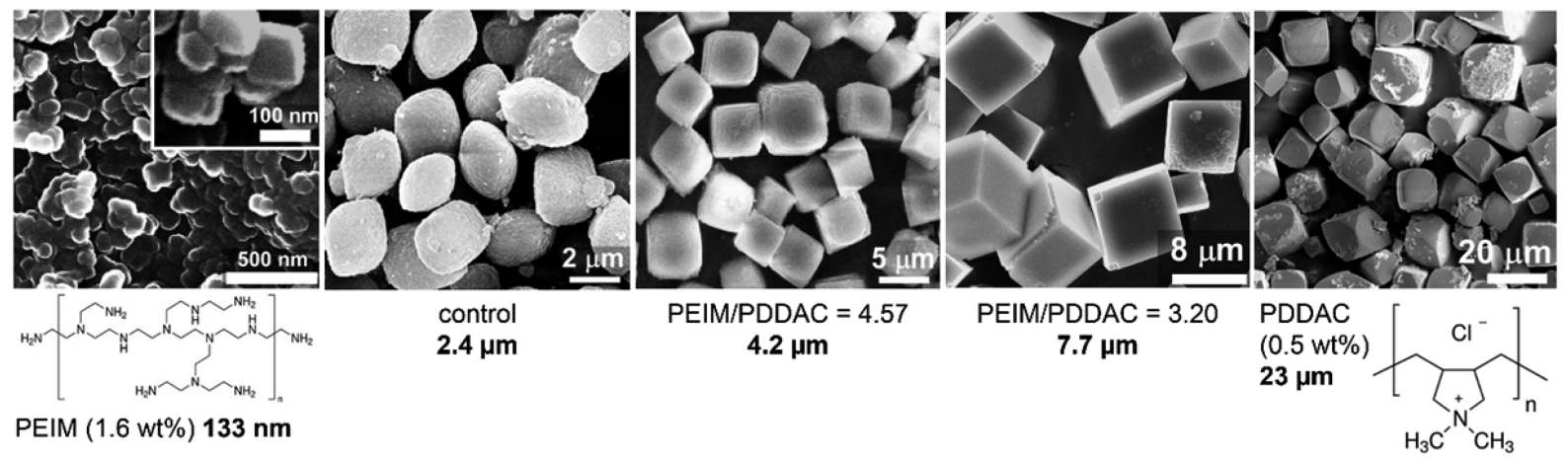

Figure 13. Size-tailored SSZ-13 zeolites by using polymer additives. Figure based on photographs by Kumar et al. in ref 207 . The average reported crystal size is given.

growth mechanism) in $\mathrm{Si} / \mathrm{Al}=50$ syntheses from $\mathrm{TEOS}$ and aluminum hydroxide. ${ }^{206}$ This $\mathrm{Si} / \mathrm{Al}$ ratio is close to the upper limit for hydroxide media syntheses. The influence of stirring versus tumbling versus static syntheses on particle size and crystallinity was tracked in time (Figure 12). It is important to note that the starting point for particle size from dynamic light scattering (DLS, right curve) at time zero corresponds to aggregates of clusters of silicon/aluminum/ADAM, sizing about one micron, obtained by aging the precursor solution under stirring for $24 \mathrm{~h}$ at room temperature. The final particle sizes for static synthesis were larger (as expected), but for stirring, no growth of the particles was seen. The growth of particles under tumbling or static conditions was not behaving in a linear manner, but rather with an induction period (sigmoidal) and mostly, the particles grew after reaching full crystallinity (compare left to right plots). The crystallization is also slower in the case of the strongest agitation (stirring). The crystallization process can hence be partly controlled, as is particle size.

The authors further noted a sigmoidal relation between the particle size and synthesis temperature for static conditions, a strange observation, since Arrhenius type behavior is to be expected for crystal growth rate. A third interesting series unexpectedly showed that diluting the synthesis mixtures led to increased particle sizes. Normally, the sizes are expected to be smaller because the growth rate depends on the concentration of reagents. A possible explanation could be a decreased nucleation rate due to the decreased alkalinity of the medium (giving less crystals growing larger). A final trend showed smaller particles when increasing the ADAM content. By combining parameter insights, the authors were able to prepare SSZ-13 particles sizing around 200-300 nm (DLS). The difference with small-crystal SSZ-62 zeolites is thus the more siliceous nature. $^{206}$

Rimer and co-workers reported an insightful study where remarkable control of the particle sizes was established (ranging from 0.1 to $20 \mu \mathrm{m}$ ) using zeolite growth-modifiers, and these results provided insights into the crystallization pathways. ${ }^{207}$ The systems of study were gels made from fumed silica and aluminum hydroxide with $\mathrm{Si} / \mathrm{Al}$ at 19 , and $\mathrm{Na} / \mathrm{Si}, \mathrm{ADAM} / \mathrm{Si}$, and $\mathrm{H}_{2} \mathrm{O} / \mathrm{Si}$ ratios at $0.2,0.1$, and 44 , respectively. This control ( 6 days at $180^{\circ} \mathrm{C}$ ) yields particles of around $2 \mu \mathrm{m}$ (in line with other reports discussed above), although a small fraction of 200 $\mathrm{nm}$ large cubic particles was always encountered. In a temporal analysis of their tumbling synthesis, they tracked the amorphous to crystalline transformation and noted a long induction period (where no crystals appear) of $40 \mathrm{~h}$ (compare to black curve in Figure 12) followed by a fast complete crystallization in under $10 \mathrm{~h}$. The induction period showed amorphous wormlike particles. The latter do not seem to decrease in size, indicating their consumption occurs by direct attachment rather than dissolution to soluble precursor species, and the reaction of those species with growing crystals. The latter is the classical mechanism for crystal growth, in layers, fitting to crystal habit and unit cell dimensions. Evidence for the attachment of larger amorphous precursors to growing crystals was mainly found from atomic force and electron microscopy, where features resembling the former amorphous particles were seen. On top, cryo-TEM showed the presence of tiny $(<10 \mathrm{~nm})$ particles near the growing crystals that were not found in solution. These surface-attached mini particles are hypothesized to be an intermediate stage during the structural rearrangement of the attached amorphous particles. Classical growth was also observed in AFM, but to a lesser extent and in a later stage, when the attachable particles become depleted. Based on these insights, the addition of several growth modifiers was tested. Remarkably, the addition of $1.6 \mathrm{wt} \%$ of polyethylenimine (PEIM, Figure 13) resulted in $130 \mathrm{~nm}$ large zeolite particles. Likely the neutral polymer prevents the attachment of the amorphous particles and aggregation. Similar effects were found for hexadecyl trimethyl ammonium bromide (CTAB). In reverse, adding cationic poly(diallyldimethylammonium chloride) or PDDAC (Figure 13) seemed to decrease nucleation time and enhance crystal growth, leading to crystals of $20 \mu \mathrm{m}$ in size (with some mesopores), likely by speeding up attachment. Combining the polymers gave access to crystal size control (overview, Figure 13).

The motivation to access smaller crystal sizes from synthesis derives from the higher external surface area such particles have and the shortening of the diffusion paths for reagent and product molecules. This sometimes ameliorates the performance of a zeolite in catalytic applications by overcoming diffusional limitations, coke formation, or low selectivities. The Corma and $\mathrm{Yu}$ groups further explored the merits of CTAB (growth modifier) addition, in a different way: ${ }^{208}$ after a classic SSZ-13 synthesis mixture ( $\mathrm{Si} / \mathrm{Al} 20, \mathrm{Na} / \mathrm{Si}$ 0.2, ADAM/Si 0.2; $\mathrm{H} 2 \mathrm{O} / \mathrm{Si} 44$ ) had been in the oven at $160{ }^{\circ} \mathrm{C}$ for 1 day, CTAB was added, at a $\mathrm{CTAB} / \mathrm{Si}$ ratio of 0.12 . After 9 more days, this resulted in aggregated SSZ-13, with a bulk $\mathrm{Si} / \mathrm{Al}$ ratio of 17 , sizing in the 50-200 $\mathrm{nm}$ range. This material displayed interparticle mesoporosity in $\mathrm{N}_{2}$-adsorption in addition to its $0.2 \mathrm{~cm}^{3} / \mathrm{g}$ of microporosity. Leaving the classic gel uninterrupted for 6 days instead, gave classic SSZ-13 with Si/Al = 15 and particles sizing $1.5-2.5 \mu \mathrm{m}$, with $0.25 \mathrm{~cm}^{3} / \mathrm{g}$ of 
microporosity. More defect sites and a lower framework incorporation of $\mathrm{Al}$ were however noted for the nano-SSZ-13. Lastly, the Sano group also reported control over the particle sizes in their interzeolite conversions (section 2.3.3.4).

In analogy to Eilertsen's 15-133 series, Hensen and coworkers also added $\mathrm{NaF}$ in hydroxide media, but in a $4: 3: 2$ OSDA:Na:F molar ratio, for a Si/Al 20 synthesis (and 0.2 $\mathrm{ADAM} / \mathrm{Si}$ ). ${ }^{209}$ Remarkably, a bimodal distribution in the micropore range was observed for the material, as next to the cage-average micropore calculated at $0.54 \mathrm{~nm}$, a micropore in the range of 4.6-7 $\AA$ seemed present. Additional evidence was found in the occurrence of tiophene diffusion in the bimodal samples, as well as by a much faster uptake of $n$-butanol and isobutanol in sorption experiments. It was hypothesized that Faddition favors the particle attachment mechanism of nonclassical growth, as described above by Rimer and coworkers, ${ }^{207}$ and results in additional micropores at the boundaries of the particles attached to the growing zeolites.

Another technical alteration used to obtain SSZ-13 consists of a fast continuous-flow synthesis, as presented by Okubo and co-workers. ${ }^{210}$ The method consists of adding seeds, hence avoiding the slow nucleation phase, which then grow without thermal lag while quickly moving in a tubular reactor heated at $210{ }^{\circ} \mathrm{C}$ (in e.g., a 10 min synthesis). The crystal growth rate was enhanced by selecting the right $\mathrm{Al}$-source, which proved to be $\mathrm{Al}(\mathrm{OH})_{3}$. This solid has a low solubility and was hypothesized to hamper the formation of an amorphous aluminosilicate with the colloidal silica. The amorphous aluminosilicate phase is thought to decrease crystal growth rates. In such systems, the clogging of the tubular reactor is to be overcome.

2.3.3.3. Other OSDAs for CHA and Mesoporous Recipes. Since the synthesis of ADAM is expensive, alternative OSDAs have been highly sought after. Cao et al. reported the use of $N, N, N$-dimethylethylcyclohexylammonium hydroxide as OSDA for high silica CHA (Figure 14). ${ }^{211}$ Using very low water

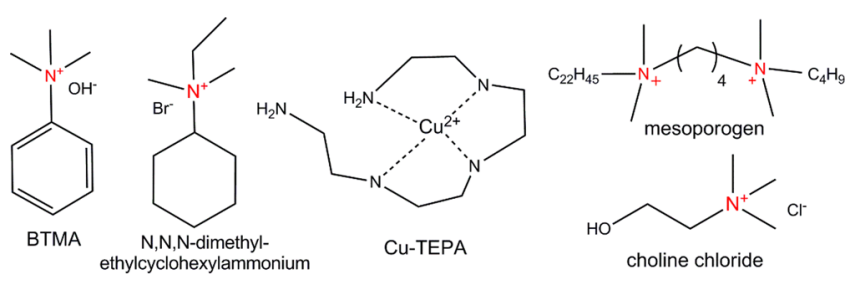

Figure 14. Alternative OSDAs for CHA. BTMA $=N, N, N-$ trimethylbenzylammonium, TEPA $=$ tetraethylenepentamine.

content $\left(\mathrm{H}_{2} \mathrm{O} / \mathrm{Si}=6.4\right)$ and keeping the ratios of $\mathrm{Na}^{+}$and OSDA/Si at 0.1 and 0.2 , this method yields CHA-zeolites (in competition with MTW) at $150{ }^{\circ} \mathrm{C}$ with $\mathrm{Si} / \mathrm{Al}$ ratios around 54 . Wang et al. further explored this recipe in a solvent-free approach using the bromide form of this OSDA (Figure 14). ${ }^{212}$ After grinding the solid precursors (sodium metasilicate, aluminum sulphate, solid silica gel, OSDA), the mixture was reacted at $180{ }^{\circ} \mathrm{C}$. The ratios of $\mathrm{Na}^{+}$and OSDA to Si were 0.4 and 0.1 here, and the obtained CHA-zeolites, in high yield, had limited $\mathrm{Si} / \mathrm{Al}$ ratios, ranging from 5 to $10^{212}$

Ren et al. reported the use of a metal complex for directing CHA-synthesis. ${ }^{213}$ They noted that a $\mathrm{Cu}^{2+}$-amine complex (TEPA, Figure 14) had similar size properties as the CHA-cage. Using dilute gels $\left(\mathrm{H}_{2} \mathrm{O} / \mathrm{Si}=200\right)$ from silica sol and sodium aluminate, with both $\mathrm{Na} / \mathrm{Si}$ and $\mathrm{Cu}-\mathrm{TEPA} / \mathrm{Si}$ ratios around 0.1 ,
$\mathrm{Cu}-\mathrm{CHA}$-zeolites were obtained at $140{ }^{\circ} \mathrm{C}$, with $\mathrm{Si} / \mathrm{Al}$ ratios in the range of 4 to 7.5. After calcination, the $\mathrm{Cu}$-containing material could directly be used for SCR of $\mathrm{NOx}$ with $\mathrm{NH}_{3}$. Corma and co-workers later reported a one-pot recipe for $\mathrm{Cu}$ SSZ-13 based on using both Cu-TEPA and ADAM, in both hydroxide and fluoride media. ${ }^{214}$ Using mixtures allows one to obtain higher $\mathrm{Si} / \mathrm{Al}$ ratios in the solids and a better control of the $\mathrm{Cu}$ loadings.

Another synthesis using the addition of a second organic to ADAM was reported by Zones, with $N, N, N$-trimethylbenzylammonium (BTMA, Figure 14). He showed that combinations of 1:1 up to 1:7 (ADAM:BTMA) could direct to the SSZ-13 structure from fumed silica and $\mathrm{Al}_{2} \mathrm{O}_{3}$, as well as combinations of ADAM and $N, N, N$-triethylbenzylammonium (up to $1: 3$ ). No characterization of the products was given. ${ }^{215}$ Sano and coworkers later succeeded in making $\mathrm{CHA}$-zeolites by only using BTMA hydroxide by making use of the IZC method (Table 2, method D). ${ }^{216} \mathrm{IZC}$ has been thoroughly investigated for $\mathrm{CHA}$, in both the presence and absence of organic cations or seeds (see section 2.3.3.4).

Rather unexpected, $\mathrm{Xu}$ et al. were able to use choline chloride (Figure 14) in gels from sodium aluminate and colloidal silica and obtain CHA-zeolites. ${ }^{217}$ These gels had 0.2 choline/Si ratios and importantly, unknown amounts of seeds of SSZ-13, made with ADAM. The claimed materials had limited $\mathrm{Si} / \mathrm{Al}$ ratios between 3.3 and 8.7. The authors assumed that 2 choline (chloride) units clustered in the large CHA cage, although the thermogravimetric analysis showed a weight loss of only $9.6 \%$ linked to the organic $\left(\right.$ choline $\left.=104 \mathrm{~g} \cdot \mathrm{mol}^{-1}\right)$. In classic SSZ-13 synthesis using ADAM, the weight loss equals around $20 \%$, due to one organic cation, weighing $194 \mathrm{~g} \cdot \mathrm{mol}^{-1}$, decomposing per cage.

Hensen and co-workers reported on the direct synthesis of mesoporous SSZ-13 by using, in addition to ADAM, a mesoporogen with two cationic heads (Figure 14). ${ }^{218,219}$ The same molecule was also used by Ryoo et al. for creating nanosheet MFI. ${ }^{220}$ This meso-SSZ-13, with $\mathrm{Si} / \mathrm{Al}=17$, had $0.21 \mathrm{~cm}^{3} / \mathrm{g}$ of mesoporosity on top of a normal amount of microporosity. A combination of this strategy with the Fassisted bimodal microporous SSZ-13 synthesis (above) was recently demonstrated, resulting in trimodal hierarchical SSZ$13 .^{221}$

Tatsumi and co-workers reported the synthesis of CHA zeolites without organic nor starting zeolite sources, but with the addition of large amounts (20 wt \%) of classically prepared (using ADAM) seeds. In this manner, they were able to synthesize CHA from amorphous gels (fumed silica, sodium aluminate, or $\mathrm{Al}$-isopropoxide) using $\mathrm{Na}^{+}$with $\mathrm{K}^{+}$or $\mathrm{Cs}^{+}$alkali. The $\mathrm{K}^{+}$materials had $\mathrm{Si} / \mathrm{Al}$ ratios below 4 (a bit higher than the classic OSDA-free recipe from FAU zeolite ${ }^{199}$ ) but interestingly, with Cs, a ratio of 5.2 could be attained. A time series at $170{ }^{\circ} \mathrm{C}$ indicated at least partial dissolution of the seeds, as a fully amorphous diffractogram appeared after $1 \mathrm{~h}$. The synthesis was complete in $24 \mathrm{~h}$, and longer times led to other phases appearing. 193

2.3.3.4. Interzeolite Conversions (IZC). The IZC of FAU to $\mathrm{CHA}$ was already schematized in Figure 4. Table 5 lists most of the IZC routes that have led to CHA zeolites. As mentioned, the standard recipe for OSDA-free, high-alumina $\mathrm{CHA}$ is based on the transformation of a FAU-zeolite at $95{ }^{\circ} \mathrm{C}$ with $\mathrm{Si} / \mathrm{Al}=$ 2.6 (Table 5, entry 1). ${ }^{199}$ The FAU in this procedure, as described by the Synthesis Commission ${ }^{167}$ contained a little bit of $\mathrm{Na}^{+}$, but the main element needed for $\mathrm{CHA}$ is $\mathrm{K}^{+}$. Ji et al. 
Table 5. Overview of CHA-Zeolite Syntheses by Interzeolite Conversion ${ }^{a}$

\begin{tabular}{|c|c|c|c|c|c|c|c|c|}
\hline \multirow[b]{2}{*}{$\mathbf{E}$} & \multirow[b]{2}{*}{ starting zeolite $^{b}$} & \multirow[b]{2}{*}{$\mathrm{Si} / \mathrm{Al}$ reag. } & \multicolumn{3}{|c|}{ synthesis mixtures composition relative to $\mathrm{Si}$} & \multirow[b]{2}{*}{$\mathrm{T}, \mathrm{t}\left({ }^{\circ} \mathrm{C}, \mathrm{h}\right)$} & \multirow[b]{2}{*}{ Si/Al prod. } & \multirow[b]{2}{*}{ ref } \\
\hline & & & $\mathbf{M}^{+}\left(\mathrm{OH}^{-}\right)$ & $\operatorname{OSDA}\left(\mathrm{OH}^{-}\right)$ & $\mathrm{H}_{2} \mathrm{O}$ & & & \\
\hline 1 & $(\mathrm{Na}, \mathrm{H})-\mathrm{FAU}$ & 2.6 & $0.84\left(\mathrm{~K}^{+} / \mathrm{Na}^{+}: 12\right)$ & & 43 & 95,96 & 2.16 & 167 \\
\hline 2 & $\mathrm{NH}_{4}-\mathrm{FAU}_{s, \mathrm{a}}{ }^{c}$ & 6.0 & $1.1\left(\mathrm{~K}^{+}\right)$ & & 44 & 100,96 & 2.4 & 222 \\
\hline 3 & $\mathrm{NH}_{4}-\mathrm{FAU}^{d, d}$ & 2.7 & $1.37\left(\mathrm{~K}^{+} / \mathrm{Na}^{+}: 18\right)$ & & 58 & 95,96 & 2.1 & 223 \\
\hline 4 & $\mathrm{Na}-\mathrm{FAU}$ & 2.7 & $1.67\left(\mathrm{~K}^{+} / \mathrm{Na}^{+}: 3.5\right)$ & & 58 & 95,96 & 1.6 & 223 \\
\hline 5 & $\mathrm{Na}-\mathrm{GIS}^{e}$ & $3.0^{e}$ & $0.68\left(\mathrm{Na}^{+}\right)$ & $0.11 \operatorname{ADAM}\left(\mathrm{I}^{-}\right)$ & 25 & 130,144 & $7.5^{e}$ & 143 \\
\hline 6 & $\mathrm{H}-\mathrm{FAU}_{\mathrm{s}, \mathrm{a}}$ & 21 & $0.1(\mathrm{NaCl})$ & 0.2 ВTMA & 5 & 120,504 & 16.9 & 216 \\
\hline 7 & H-FAU ${ }_{s, \mathrm{a}}$ CHA-seeds $2 \%$ & 22 & $0.1(\mathrm{NaCl})$ & 0.2 ВТМА & 5 & 125,168 & 18.2 & 224 \\
\hline 8 & H-FAU ${ }_{s, \mathrm{a}}$ CHA-seeds $2 \%$ & 16 & $0.1\left(\mathrm{Na}^{+}\right)$ & 0.2 BTMA & 5 & 125,168 & 14.7 & 224 \\
\hline 9 & H-FAU $\mathrm{s}_{\mathrm{s}, \mathrm{a}}$ CHA-seeds $2 \%$ & 81 & $0.1(\mathrm{NaCl})$ & 0.2 BТМА & 5 & 125,168 & 21.3 & 224 \\
\hline 10 & H-FAU ${ }_{s, \mathrm{a}}$ CHA-seeds $10 \%$ & 97 & & 0.3 ВТМА & 5 & 125,168 & 18.6 & 224 \\
\hline 11 & H-FAU ${ }_{s, \mathrm{a}}$ CHA-seeds $2 \%$ & 23 & $0.1\left(\mathrm{Na}^{+}\right)$ & $0.2 \mathrm{ADAM}$ & 5 & 125,48 & 19 & 225 \\
\hline 12 & H-FAU ${ }_{s, \mathrm{a}}$ CHA-seeds $2 \%$ & 114 & $0.1\left(\mathrm{Na}^{+}\right)$ & $0.2 \mathrm{ADAM}$ & 5 & 125,48 & 67 & 225 \\
\hline 13 & $\mathrm{H}-\mathrm{FAU}_{\mathrm{s}, \mathrm{a}}$ & 10.5 & $0.2\left(\mathrm{Na}^{+}\right)$ & 0.2 TEA & 5 & 160,72 & 8.5 & 226 \\
\hline 14 & H-LEV & 9 & $3\left(\mathrm{Na}^{+}\right)$ & & 80 & $125,1.5$ & 2.8 & 227 \\
\hline
\end{tabular}

${ }^{a} \mathrm{E}=$ entry. $\mathrm{M}^{+}\left(\mathrm{OH}^{-}\right)$refers to alkali added and can be more than one (added with ratio given). If another anion is used instead of $\mathrm{OH}^{-}$, this is mentioned in brackets. The same is valid for the OSDA column. ${ }^{b}$ Mostly, if FAU is mentioned, this is either zeolite Y or a treated version of Y. s,a $=$ steamed and acid washed, for leaching out aluminum. If this is in the case of FAU, these zeolites are better known as USY (ultrastable Y). ${ }^{c} \mathrm{CBV} 712$ of Zeolyst. ${ }^{d} \mathrm{CBV}$ 300: contains some Na. ${ }^{e}$ Not strictly an IZC, as sodium silicate is added, rendering the Si/Al synthesis ratio $+/-16$. These conditions resemble a lot of those in Table 4 for AEI.

recently confirmed this result, albeit with a more siliceous starting zeolite (Table 5 , entry 2 ). ${ }^{222}$ Both products were very similar. Van Tendeloo et al. reported a similar conversion from $\mathrm{NH}_{4}^{+}$-FAU (entry 3). ${ }^{223}$ Interestingly, these authors also exchanged the starting FAU with $\mathrm{Na}^{+}, \mathrm{K}$, or $\mathrm{H}^{+}$prior to the conversions in the $\mathrm{KOH}$ solution, and they noted similar CHA formation, albeit with a little variation in the $\mathrm{Si} / \mathrm{Al}$ ratios (e.g., Table 5, entry 4). In the same report, Van Tendeloo demonstrated the synthesis of three other $8 \mathrm{MR}$ zeolites from the same $\mathrm{NH}_{4}-\mathrm{FAU}$ : ABW, MER, and ANA. They did this by respectively using $\mathrm{LiOH}, \mathrm{RbOH}$, or $\mathrm{CsOH}$, instead of $\mathrm{KOH}$ for CHA, all at mild conditions. ${ }^{223}$

Groundbreaking work in the context of IZC with organics was published by Zones and Van Nordstrand in the late 1980s. Following the success of using ADAM for SSZ-13, they explored different zeolites as alumina source for making different (higher silica) zeolites with the addition of OSDA. ${ }^{142-144}$ The work began when they noticed the intermediate production of zeolite P (GIS) in the hydrothermal synthesis of SSZ-13. The ADAM organic seemed not to interfere with the first transformation of sodium silicate and $\mathrm{Al}_{2}\left(\mathrm{SO}_{4}\right)_{3}$ into GIS, via aluminosilicate oligomerization and gel formation. Then, as witnessed by monitoring both the $\mathrm{pH}$ and the relative mass of solids formed in time (compared to reactions without organic, only forming GIS), the uptake of ADAM by the solid phase and its gradual transformation to SSZ-13 occurred. ${ }^{143}$ The CHA-phase was also more siliceous than the GIS-phase, indicating that all alumina was already in the solid GIS-phase, while silica was added from solution. No $\mathrm{Al}^{3+}$ was thus detected in solution at any point. The authors then made $\mathrm{Na}$-GIS $(\mathrm{Si} / \mathrm{Al}=3)$ and dried it prior to reacting it with added sodium silicate, $\mathrm{NaOH}$, and ADAM. This successfully led to SSZ-13, and while the $\mathrm{Si} / \mathrm{Al}$ ratio went up to 7.5 , the weight of zeolite more than doubled (Table 5, entry 5). Zones later reported a study using the same ingredients, but zeolite FAU instead of GIS, again with sodium silicate. ${ }^{144} \mathrm{~A}$ range of effects originating from modifications on the starting FAU was shown. They noted that the surface chemistry of FAU had a profound impact on its conversion. For instance, steamed
FAU samples were much slower in reacting, but if the aluminum at the surface after steaming was acid-removed, they reacted much faster. Silylation also inhibited the reactivity of certain FAU zeolites. Importantly, in all these conversion, there is no new product formation without an increase in mass for the solid phase. Given the additional silica source, these first reports cannot be considered pure IZC, but they provided valuable insights into the use of different FAU zeolites and the dynamics of converting the zeolite in the high hydroxide crystallization field. Another important insight was that no amorphous phase was produced during the process, and SSZ13 formed during the breakdown of the parent FAU.

The Sano group has reported excellent results using real IZC (without added silica) for non-8MR frameworks (such as BEA, RUT, ...; for an overview see ref 145), but they also managed to demonstrate some for CHA. They were able to transform FAU zeolite into high-silica CHA-materials using BTMA (Figure 14) as the OSDA (Table 5, entry 6). ${ }^{216}$ Typically, this IZC is conducted in low water conditions, similar to the IZC results reported for AEI (Table 4). The CHA-zeolite could only be made from FAU precursors with $\mathrm{Si} / \mathrm{Al}$ ratios in the 21-23 range, and, as expected, it could not form from amorphous (gel) precursors with this OSDA. This latter result is in line with data from the Zones patent that combined $\mathrm{ADAM}$ and BTMA to get SSZ-13 from fumed silica and $\mathrm{Al}_{2} \mathrm{O}_{3}$, while noticing that the presence of (at least one-seventh) ADAM was unconditional. ${ }^{215}$ The solid yield of this IZC was not reported, and it could be a bottleneck, although, considering the Alcontent in starting and product zeolite, a maximum yield of about $80 \%$ can be derived. This preliminary calculation assumes the full consumption of the $\mathrm{AlO}_{4}{ }^{5-}$ tetrahedra and, thus, no leftover dissolved aluminum in the synthesis mixture. The studies from Zones and Van Nordstrand suggest this to be correct. $^{143}$ The Sano group later added CHA-seeds to their IZC methods and widened their good results: the synthesis could be reduced to 7 days (Table 5, entry 7 ), and the synthesis reported a solid yield of $92 \%{ }^{224}$ Using $\mathrm{NaOH}$ instead of $\mathrm{NaCl}$ with seeds allowed a wider set of starting FAU zeolites ( $\mathrm{Si} / \mathrm{Al}$ wise) to be used. However, the $\mathrm{Si} / \mathrm{Al}$ ratio in the products varied only 

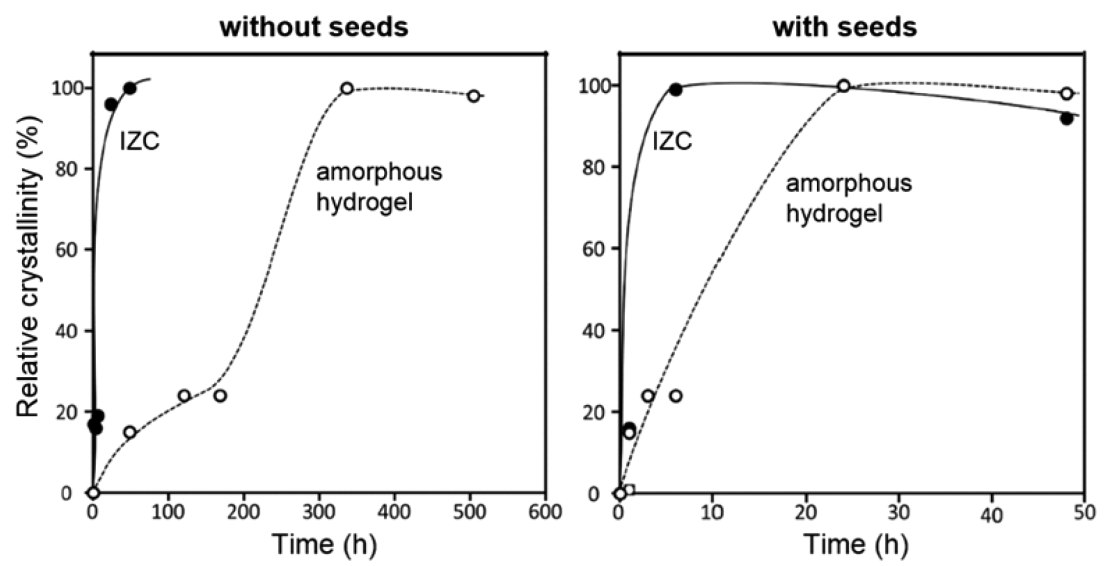

Figure 15. Crystallization curves for CHA-zeolites from $\mathrm{Si} / \mathrm{Al}=35$ mixtures at $125^{\circ} \mathrm{C}$, in the case of IZC (from FAU) and from an amorphous hydrogel (from fumed $\mathrm{SiO}_{2}$ and $\mathrm{Al}(\mathrm{OH})_{3}$ ). Figure adapted with permission from Takata et al. ref 225. Copyright 2016 Elsevier.

within a limited range, up to a maximum of 21.3 (Table 5, entries 8-9). Although $\mathrm{Na}^{+}$was not essential, it required more organic and more seeds without its presence (viz. Table 5 entry 10). The unseeded IZC materials sized in the $1 \mu \mathrm{m}$ range, while for the seeded materials, in the presence of $\mathrm{Na}^{+}$, crystallites were much smaller, around 100-200 nm. Those prepared with more seeds and without $\mathrm{Na}^{+}$were even smaller.

The Sano group also explored their IZC reactions using ADAM. Significant differences with the previous BTMA route were the shorter time needed for complete crystallization and the possibility of obtaining higher $\mathrm{Si} / \mathrm{Al}$ ratios in the resulting materials (Table 5, entries 11 and 12, compared to 7 and 10). $\mathrm{CHA}$ crystal sizes were in the $100 \mathrm{~nm}$ range (compare for instance to the nanosized SSZ-13s described in section 2.3.3.2). Interestingly, the rates of crystallization were compared from use of classic amorphous gels and IZC, in both the absence and presence of seeds (Figure 15). Without seeds (left curves), IZC was remarkably faster than the more classic synthesis from amorphous precursors. However, one should note that the crystallization times for the amorphous gels are excessive here, even for a classic synthesis and much longer than those listed in Figure 12 (also from amorphous precursors). The reason for this could be the low organic content, low temperature, and unusually high concentration (lower water content) for these kinds of amorphous gels ( $\mathrm{ADAM}: \mathrm{Si}=0.2, \mathrm{H}_{2} \mathrm{O} / \mathrm{Si}=5$ ). These features however do not diminish the remarkably fast performance of IZC under these conditions with less organic. With seeds, the differences are smaller, although IZC reaches full crystallinity at only $6 \mathrm{~h}$, versus $24 \mathrm{~h}$ for the amorphous gel (Figure 15). The authors suggest that the enhanced crystallization rate of IZC derives from locally ordered aluminosilicate species (nanoparts) formed by the partial decomposition of the starting FAU zeolite (Figure 4). As mentioned earlier, both FAU and CHA are d6r-only members, so there definitely exists a structural similarity between the IZC starting and product zeolite in this case (same as AEI above). In a way, the often positive effect of adding seed crystals in more classic syntheses also partially relies on this phenomenon. How seeds interact with the zeolite precursor during IZC remains a good research question. A second question is the role of the starting zeolite's Al-content, in all of the above, as this is often a decisive factor in IZC, whether or not a phase can form.

Recently, Corma and co-workers discovered that the common OSDA TEA, in its hydroxide form, could also lead to CHA-zeolites when starting from a FAU zeolite (Table 5, entry 13). These conditions closely resemble those reported by the same group for AEI-zeolite (Table 4, entry 12) and the product materials had similar $\mathrm{Si} / \mathrm{Al}$ (8.5). The reflections of this $\mathrm{CHA}$ in the diffractogram had somewhat different intensities (relative to each other) and broader widths than those known for classic SSZ-13. The yield from this synthesis is high, micropore volumes were normal, and the zeolites sized $0.1-0.2$ $\mu \mathrm{m}$. Moreover, TEA is a commercial and cheap OSDA, available at the large scale, due to, among other applications, its use for zeolite BEA synthesis. Zeolite BEA was logically the main competing phase, but the combination of TEA and the zeolitic source of $\mathrm{Si}$ and $\mathrm{Al}$, with its structural similarity to the product, favored CHA in a narrow range of conditions. ${ }^{226}$ The findings of Martín et al. should be further investigated to see whether they can lead to $\mathrm{CHA}$ zeolites with larger $\mathrm{Si} / \mathrm{Al}$ ratios (as, e.g., up to 20 was attained for IZC using BTMA).

Often, IZC series progress from more open structures with lower framework densities (say FAU) to more dense structures (CHA). The use of OSDA can of course reverse this trend and create more open structures, even in IZC. Large inorganic cations can effect such transformations as well, and the first IZC ever (Barrer) was that of dense ANA to more open KFI (see section 2.1). Sano and co-workers discovered a way to synthesize CHA from the more dense LEV structure without OSDA (Table 5, entry 14). ${ }^{227} \mathrm{LEV}$, similar to CHA, is also an ABC-6 zeolite (section 2.3.8 vs Figure 10 for $\mathrm{CHA}$ ). In the mixtures (rich in $\mathrm{NaOH}$ ), the authors witnessed the transformation of LEV to amorphous to CHA to ANA. In analogous amorphous starting gels, such intermediate (and thus kinetically controlled) growth of a CHA phase was never found. The CHA zeolite produced, however, had a low pore volume and too much aluminum to be of practical use. Additionally, LEVzeolites are not commercially accessible.

Finally, Goel et al. also demonstrated IZC of FAU to CHA without OSDA, through the use of seeds and $\mathrm{NaOH}^{228}$ Tatsumi and co-workers have previously demonstrated seeding for CHA in amorphous gels. ${ }^{193}$ The product CHA in the seeded-IZC report had amorphous phase cocrystallized next to it. This phase influences the $\mathrm{Si} / \mathrm{Al}$ ratio of the measured bulk sample and likely explains the low micropore volume $(<0.1$ $\mathrm{cm}^{3} / \mathrm{g}$ ).

The above IZC syntheses for making CHA (specifically Table 5, entries 6-13) present significant results, especially if an alternative to the use of ADAM is desired. FAU (and USY) zeolites are among the cheapest available due to their large- 
scale use in catalytic cracking processes. Given a high-value application for the CHA-materials and considering that the aluminum content and pore volume are adequate for application (respectively $15-20$ and $0.29 \mathrm{~cm}^{3} \cdot \mathrm{g}^{-1}$ ), the IZC recipe using BTMA has the potential to be commercially feasible, next to the ADAM recipe. Moreover, a comparative study suggested that the acid-stability of the IZC BTMA materials was higher than that of the classic ADAM zeolites from amorphous gels with $\mathrm{Si} / \mathrm{Al}$ ratios around $15 .{ }^{229}$ The CHA-zeolites made with TEA seem promising as well, although the $\mathrm{Si} / \mathrm{Al}$ product range is a bit limited.

2.3.3.5. Insights into the Al-Distribution in CHA Zeolites. The CHA topology is d6r-only, so the distribution of $\mathrm{Al}$ in $\mathrm{d} 6 \mathrm{r}$ units (constructing the entire framework; or the distribution in $6 \mathrm{MR}$ even) is representative of the entire framework. Second, it is important to note that, as proposed by Barthomeuf, there is a maximum density of $\mathrm{Al}$ atoms in a zeolite beyond which the formation of $-\mathrm{Al}-\mathrm{O}-\mathrm{Si}-\mathrm{O}-\mathrm{Al}-$ (next nearest neighbor (NNR) aluminums) becomes a certainty. For CHA, based on the topological density, this limit is near a $\mathrm{Si} / \mathrm{Al}$ ratio of 7.230 When such NNR-pairs are found in one face of a flat 6MR, or two $\mathrm{Al}$-atoms are across of each other in that ring (both shown in the inset of Figure 16, left), they are known to exchange
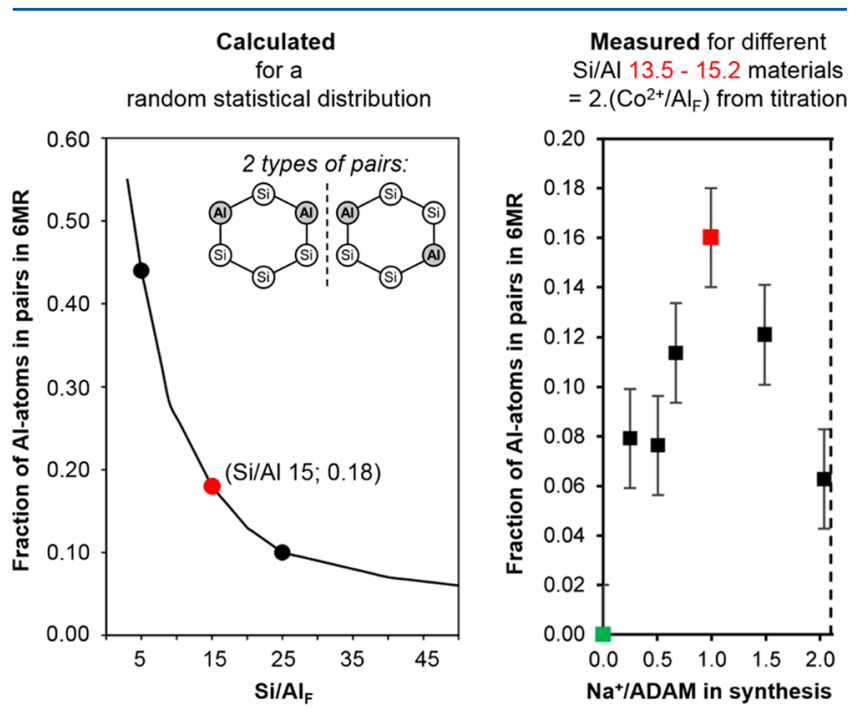

Figure 16. Control over Al-distribution in terms of pairs/isolation in CHA. Left: the theoretical abundance (in fraction of the Al-atoms) of the two types of Al-pairs (inset) in 6MRs in a random distribution, varying with the framework $\mathrm{Si} / \mathrm{Al}$ ratio. Right: the fraction of $\mathrm{Al}$ in pairs measured by $\mathrm{Co}^{2+}$ titration for a set of $\mathrm{Si} / \mathrm{Al} 15$ materials made with different $\mathrm{Na} / \mathrm{ADAM}$ ratios in the synthesis gels, at fixed total cationic charge $\left[\left(\mathrm{Na}^{+}+\mathrm{ADAM}\right) / \mathrm{Al}=7.5\right]$. The random distribution value can be attained through synthesis (red square), as can the $100 \%$ isolated case (green square). Higher $\mathrm{Na} / \mathrm{ADAM}$ ratios give MORzeolite competition. Adapted with permission from ref 233. Copyright 2016 American Chemical Society.

divalent ions very well. ${ }^{196}$ Bates et al. showed that the energy difference for divalent cation exchange (of relevance to redox catalysis, e.g., $\mathrm{Cu}^{2+}$ in SCR, see section 3.2) on two framework $\mathrm{Al}$-atoms in a $6 \mathrm{MR}$ (e.g., Figure 28) was much more favorable than in the 4MR or 8MR of CHA. ${ }^{231}$ Bates et al. then theoretically calculated the number of such 6MRs (with exactly two aluminums) occurring per framework aluminum, based on a random Al-distribution and Löwenstein's rule in an ideal CHA framework, for a given Si/Al ratio (Figure 16, left). Their curve predicted a density of $22 \%$ of these $6 \mathrm{MR} \mathrm{Al}$-pairs for a $\mathrm{Si}$ / $\mathrm{Al}=5$ CHA-zeolite (normalized on total Al-content) or, translated, a fraction of $44 \%$ of the $\mathrm{Al}$ occurring in such pairs. By extension, this random distribution relation should be valid for all other d6r-only members, since the way these d6r-units connect in space should not matter for the statistical model. ${ }^{231}$ Earlier, Akporiaye et al. attempted to model experimental ${ }^{29} \mathrm{Si}$ NMR spectra of different CHA-zeolites (with maximum $\mathrm{Si} / \mathrm{Al}$ at 7.6) by specific ordered $\mathrm{Al}$ distributions as well as by random distributions. They found the random distribution to fit best for their two highest $\mathrm{Si} / \mathrm{Al}$ materials (5.2-7.6). Although this result does not prove randomness, the inadequate description by several ordered configurations is suggestive. ${ }^{232}$

A groundbreaking insight in Al-distribution in CHA-zeolites was recently reported by Di Iorio and Gounder, who studied the distribution in terms of isolation or pairing in relation to synthesis methods. ${ }^{233}$ They focused on the Al-pairs mentioned above (inset Figure 16, left), while using $\mathrm{Al}(\mathrm{OH})_{3}$ and colloidal silica in hydroxide media and developed an accurate method to quantitate these pairs (known to stabilize extra-framework divalent cations). ${ }^{233}$ The method is based on taking twice the saturation capacity from the $\mathrm{Co}^{2+}$-ion exchange isotherm, with verification by diffuse reflectance $\mathrm{UV}$-vis spectroscopy, $\mathrm{Cu}^{2+}$ exchange, and selective titration of the remaining $\mathrm{H}^{+}$. The Coexchange work of Dědeček and co-workers for other frameworks (MFI, BEA, ...) is instrumental in this context. ${ }^{234-236} \mathrm{Di}$ Iorio et al. thus conducted a series of syntheses to study the influence of the organic ADAM vs inorganic $\mathrm{Na}^{+}$cations. One of the striking conclusions was that when $\mathrm{Si} / \mathrm{Al}=15$ materials were made in the absence of $\mathrm{Na}^{+}$(and the specific inorganic sources) no pairs occurred (green square, Figure 16, right). This perfect isolation of each aluminum is likely related to the incorporation of one charged ADAM cation per cage. As each cage has $36 \mathrm{~T}$ atoms shared over 3 cages, or thus 12 full $\mathrm{T}$ atoms, a $\mathrm{Si} / \mathrm{Al}$ ratio of 11 would then equal one aluminum incorporated (negative framework charge) per OSDA per cage. Thus, it would present the ideal case of charge neutrality in the absence of inorganic cations and fluoride anions. Although one ADAM per cage is often analyzed in SSZ-13 syntheses, framework anionic defects (e.g., deprotonated silanols) likely interfere with this ideal ratio, allowing less $\mathrm{Al}$ to be incorporated in hydroxide media or thus higher $\mathrm{Si} / \mathrm{Al}$ ratios, when only ADAM is used. Di Iorio et al. obtained CHA (with $\mathrm{Si} / \mathrm{Al}=26)$ from a $\mathrm{Si} / \mathrm{Al}=30$ synthesis, and even hydroxide materials in the $\mathrm{Si} / \mathrm{Al}=50$ regions are feasible. Attempts to crystallize $\mathrm{CHA}$ from higher $\mathrm{Si} / \mathrm{Al}$ synthesis mixtures in $\mathrm{OH}^{-}$ media, as mentioned above, do not succeed. In contrast to the isolated $\mathrm{Al}$ case when only ADAM was used (green square, Figure 16), the use of both $\mathrm{Na}^{+}$and $\mathrm{ADAM}$ in a $1 / 1$ ratio led to a number of Al-pairs (red square, Figure 16, right) in line with the statistically predicted number for random distribution (red dot, Figure 16, left). Intermediate values (between 0-1) of the $\mathrm{Na}^{+} /$ADAM ratio (or thus cationic charge density) confirmed this observation and offer one a limited control over the desired amount of pairing (up to the statistical random occurrence) for a given $\mathrm{Si} / \mathrm{Al}$ ratio. The authors demonstrated this for $\mathrm{Si} / \mathrm{Al}=$ 15 and 25 materials. At ratios higher than 1, the number of pairs again decreased. Explaining these results is difficult, although it was noted that above a certain ratio, competing zeolites occurred (dashed line in Figure 16). A likely explanation for the influence of the cationic charge density on the number of pairs (maximal when $\mathrm{Na}^{+} / \mathrm{ADAM}=1$ ) was given, based on the more favorable stabilization of an $\mathrm{Al}$ - 
(charge)-pair by both the quaternary ammonium head of the OSDA and a $\mathrm{Na}^{+}$cation in close vicinity (of the same 6MR), compared to when they are further apart (not balancing a pair). The case where they are further apart would entail a larger disruption of the nonpolar contacts between the apolar adamantyl group of ADAM and the siliceous network, on the other side of the OSDA. This would be in line with the reported orientation of $\mathrm{ADAM}$ in $\mathrm{CHA}$, i.e., along the $c$-axis or length of the cage. This result suggests that the polar head of ADAM points up to a $6 \mathrm{MR}$, while an additional $\mathrm{Na}^{+}$resides in the d6r that $6 \mathrm{MR}$ is part of. A recent update by Gounder and co-workers showed that the use of Al-isopropoxide in the synthesis was able to yield up to $44 \%$ of $\mathrm{Al}$ in pairs, for a $\mathrm{Si} / \mathrm{Al}$ $=14$ material (contrary to $20 \%$ in the theoretical curve, Figure 16 , left), indicating that statistical pairing is exceeded. ${ }^{237}$ The pairing series was also used in catalytic test reactions (section 3.6).

As reported above, Corma and co-workers used ADAM in combination with $\mathrm{Cu}$-TEPA to obtain $\mathrm{Cu}-\mathrm{SSZ}-13$ in one pot. ${ }^{214}$ Interestingly, they noted different deNOx activities for materials from the $\mathrm{F}^{-}$and $\mathrm{OH}^{-}$-preparation routes, in spite of similar heteroatom substitution, $\mathrm{Cu}$ loading, and particle sizes. This suggests a strong influence of the preparation on the materials. Perhaps, this is related to differences in the Al-pairing or siting, influencing the $\mathrm{Cu}$-speciation. The Co-titration method could thus be of use here, in case $\mathrm{Cu}$ can be fully removed before Co-exchange.

2.3.3.6. CHA-Zeolite Conclusions. CHA is, arguably, the most interesting $8 \mathrm{MR}$ zeolite from a synthesis point of view, due to its industrial relevance, the vast body of literature, its structure with large cages, and its compositional flexibility (from highly aluminous to pure-silica). Some insights/ observations are

(1) CHA is a member of both the d6r-only and ABC-6 families. The only other two members of both structural families are AFX and SFW, and they present a series with expanding, structurally related cages and similar synthesis conditions.

(2) $\mathrm{CHA}$ can be made without organic, using $\mathrm{K}^{+} / \mathrm{Na}^{+}$ mixtures in very aluminous compositions or with the help of OSDAs, most commonly ADAM, in more siliceous to even pure-silica forms. Unlike for AEI, there is a great flexibility for different kinds of $\mathrm{T}$ atom sources in the ADAM-route.

(3) It is clear that the ADAM/CHA-cage pair has a highly favorable host/guest interaction. This is evidenced from molecular modeling, the large conditional flexibility $\left(\mathrm{F}^{-}\right.$, $\left.\mathrm{OH}^{-}, \mathrm{IZC}, \ldots\right)$ and the high structural specificity, certainly when compared to, e.g., tetra-alkylated ammonium or piperidinium-based OSDAs. Few other molecular sieves are stabilized well by ADAM, the largepore silicate AFI being a known exception. ${ }^{238}$ The competition with other phases in $\mathrm{OH}^{-}$-media, for instance, only occurs in mixtures with $\mathrm{Si} / \mathrm{Al}>55$. Strong-structure direction is, however, still not the same as true templating. ${ }^{91,192}$

(4) Based on the charge balance and counting cages, the ideal $\mathrm{Si} / \mathrm{Al}$ ratio of a defect-free SSZ-13 is 11 , assuming one ADAM per cage and no sodium in the synthesis (cfr. AEI). The same calculation for AFX and SFW networks is more difficult due to the additional presence of other smaller cages (Figure 10).
(5) The demonstrated control over particle size in CHA syntheses is rather exceptional in the $8 \mathrm{MR}$ zeolite literature. The use of growth-modifiers and insights into the particle attachment mechanism should be further explored for different $\mathrm{Si} / \mathrm{Al}$ ratios within $\mathrm{CHA}$ (e.g., lower ratios are used in SCR, higher in MTO, viz. sections 3.2 and 3.4) and for other frameworks. Lessons learned for CHA could be transferable to zeolites with structural similarity based on 6MR (ABC-6: LEV, ERI, $\mathrm{EAB}, . .$.$) or d6r (AEI, AFX, KFI, SFW, SAS).$

(6) IZC is a successful method for CHA-synthesis, and materials with $\mathrm{Si} / \mathrm{Al}$ ratios ranging from 2 to 67 have been reported (Table 5). This upper limit is even higher than in common hydroxide media synthesis. The role of structural similarity between starting (FAU) and product zeolite can assist in the construction of the latter and possibly plays a structure-directing role. Recall that even the OSDA-free standard recipe relies on using an aluminous FAU-zeolite. Hard proof of the nanoparts hypothesis is still lacking, but due to ample reports focusing on CHA, the FAU-to-CHA IZC presents an ideal case for deeper investigation. The role of $\mathrm{Al}$ mobility/solubility should however not be forgotten.

(7) The work of Gounder and coauthors in preparing and characterizing the amount of Al-pairs (potentially of use as divalent cation exchange sites) is instructive. It shows that the random Al-distribution, e.g., entailing $16 \%$ of the $\mathrm{Al}$-atoms occurring in pairs for $\mathrm{Si} / \mathrm{Al}=15$, is obtained if the $\mathrm{Na} / \mathrm{ADAM}$ ratio in the synthesis is fixed at 1 for specific amorphous inorganic sources. Lower ratios lead to less pairs, and sodium-free synthesis leads to fully isolated $\mathrm{Al}$-centers in the zeolite. This presents a first proof of a degree of control over the pairing from synthesis in $8 \mathrm{MR}$ literature. It is imperative that the Aldistributions resulting from other CHA-synthesis protocols (detailed in this review) are characterized (Cotitration). Equally so, the protocol could be easily verified for other "d6r-only" materials, given that the statistical model for random pairing is based on the $\mathrm{Al}$-occurrence in $6 \mathrm{MRs}$ (Figure 16, left)

2.3.4. DDR. The framework DDR is known since its puresilica form (deca-dodecasil 3R) was prepared by Gies using 1adamantylamine. ${ }^{239}$ In addition to RTH, it is one of the few "relevant" $8 \mathrm{MR}$ zeolites that contain 5MR. Since the pioneering effort of Gies, a great deal of work has been performed on puresilica DDR, especially in the context of sorption and gasseparation (i.e., $\mathrm{CH}_{4} / \mathrm{CO}_{2}{ }^{240}$ propylene/propane ${ }^{241}$ ). These pure-silica (nonzeolite) syntheses are out of the scope of this review. The first aluminosilicate DDR, ZSM-58, was patented by Valyocsik, ${ }^{58}$ while Stewart et al. reported the similar Sigma-1 zeolite. $^{57}$

ZSM-58 is made using so-called methyltropinium (Figure 17) in classic gels containing $\mathrm{Na}^{+}$, and it typically has high $\mathrm{Si} / \mathrm{Al}$ ratios; originally from 31 to $111 .^{58}$ Several groups later reported samples with higher and lower Si/Al ratios (178 and 18). ${ }^{242,243}$ In similar gels, with $\mathrm{Si} / \mathrm{Al}$ ratios specifically at 30 and $\mathrm{OH} / \mathrm{Si}$ ratios around $0.1-0.17$, Stewart et al. found that using the free amine, 1-adamantylamine (Figure 17), also worked for DDR formation, giving the zeolite Sigma-1. Competing zeolites in $\mathrm{OH}^{-}$-richer media were mordenite and ZSM-5 (both also containing $5 \mathrm{MR}$ ). Interestingly, using $\mathrm{Si} / \mathrm{Al}$ ratios lower than 30 gave a competitive formation of LEV zeolite $(\mathrm{Nu}-3$, see section 2.3.8), while less alumina favored Sigma-2 formation 


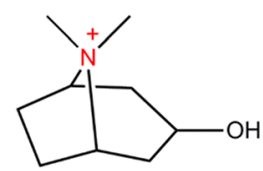

$\mathrm{N}$-methyltropinium

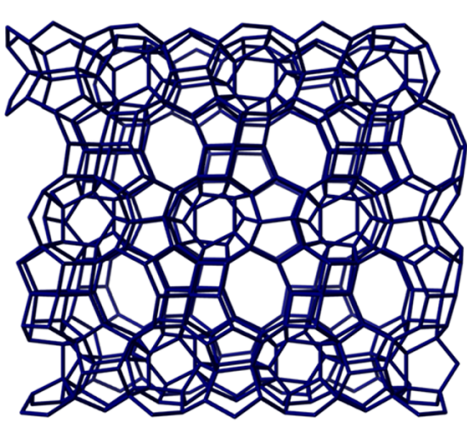

Seen from $(100)=(110)=(010)$

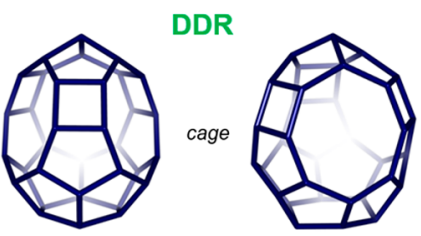

bound by three 8 MR (2 views)

Figure 17. Reported OSDAs for aluminosilicate DDR synthesis and the DDR structure.

(SGT). The material produced by Stewart and co-workers had a $\mathrm{Si} / \mathrm{Al}$ ratio near 50 , but later, Lobo and co-workers and Jeon et al. managed to obtain Sigma-1 zeolite with $\mathrm{Si} / \mathrm{Al}$ ratios of 16. ${ }^{244,164}$ Given that the all-silica version of DDR exists, the $\mathrm{Si} /$ $\mathrm{Al}$ ratios of reported DDR-zeolites thus range from 16 to infinity.

Recently, Yarulina et al. studied Sigma-1 and ZSM-58 in close comparison, while assessing the impact of seeding on defect formation and MTO performance (for in depth catalytic discussion, see section 3.4.3). ${ }^{245,246}$ The authors conveniently showed how the use of seeds with specific sizes $(0.08,0.5$, and $2.5 \mu \mathrm{m}$, respectively, from ball-milling) can produce Sigma-1 zeolites with controlled and uniform sizes $(0.5,2.5$, and $4.6 \mu \mathrm{m}$, respectively). The particle size of ZSM-58 in this study, made for comparison, was ca. $1 \mu \mathrm{m}$.

2.3.5. ERI (and EAB). Erionite is a naturally occurring zeolite with $\mathrm{Si} / \mathrm{Al}$ ratios close to 3 . This zeolite is a member of the ABC-6 family, as is the closely related EAB zeolite (Table 3, stacking sequences in Figure 18). Interestingly, EAB, with the cage in Figure 18 and also a $\mathrm{Si} / \mathrm{Al}$ ratio near 3, was first discovered using TMA and only later found in a mineral composition (see Table 1). Natural erionite was used as a shape-selective cracking catalyst in the past (section 1.2, and 3.6.1), and this fueled the need for synthetic recipes. Aiello and Barrer reported the first synthetic ERI, with a similar composition to that of natural erionite using $\mathrm{Na}^{+}$and TMA cations. They noted that the TMA cations had to be residing in the large cage of the structure (Figure 7), since the other voids (the $d 6 r$ and can-units, Figure 18) are too small to host TMA. Likely, more than 1 TMA was found per cage. The large cages are connected and construct an open 3D-network of $8 \mathrm{MR}$ pores, unlike in $\mathrm{EAB}$, where gme-cavities connect the larger cages, and a $2 \mathrm{D}$-network results. Meier reported that in EAB synthesis, the TMA cation occupies the gme-cavities (previously shown to be a good fit). ${ }^{61}$ The framework densities of EAB and ERI are 16 and $16.1 \mathrm{~T}$ atoms/1000 $\AA^{3}$, respectively.

While $\mathrm{EAB}$ forms in mixtures with the $\mathrm{Si} / \mathrm{Al}$ ratio at 6.8 and the $\mathrm{Na}^{+}$and $\mathrm{TMA}^{+}$to $\mathrm{Si}$ ratios at about $0.5,{ }^{61}$ making pure ERI with TMA is more difficult. Often, intergrowths with the closely related OFF zeolite (large pore material) are obtained. ${ }^{247}$ Rubin and Rosinski patented a method for synthetic ERI, with $\mathrm{Si} / \mathrm{Al}$ ratios around 4 , based on adding BTMA (also used for making CHA through IZC, Figure 14) to $\mathrm{Na}^{+}$- and $\mathrm{K}^{+}$containing $\mathrm{Si} / \mathrm{Al}=14$ mixtures. $^{248}$ Later, OFF intergrowths were also detected in this material. ${ }^{249}$ Occelli et al. reported an interesting synthesis based on DABCO derivatives (Figure 18). ${ }^{170}$ Ironically these authors first labeled their material as an ERI/OFF mixture, but later, through electron diffraction, they showed that it was in fact phase-pure ERI after all, with the $\mathrm{Si}$ / $\mathrm{Al}$ ratio around 5 . $^{249}$

A breakthrough for synthetic ERI was presented in the 2000s, by using the charge density mismatch approach (method E, Table 2). ${ }^{69,148,250}$ This route offers access to more siliceous ERI, known as UZM-12, so far, up to $\mathrm{Si} / \mathrm{Al}$ 7.4. The CDM approach is often seen as a two-step procedure. For ERI, first, a mix of $\mathrm{SiO}_{2}$, Al-butoxide, and TEA $\left(\mathrm{OH}^{-}\right)$is made, with a $\mathrm{Si} / \mathrm{Al}$ ratio of 16 and a high TEA/Si of 0.8 . This mixture does not induce crystallization or solid formation, not even after 28 days. $^{70}$ After digestion overnight, Miller et al. added the crystallization-inducing solution, consisting of a large diquat (e.g., $\mathrm{Me}_{6}$-diquat-6, Figure 18) and some $\mathrm{KCl}$ (diquat/ $\mathrm{Al}=2$ and $\mathrm{K} / \mathrm{Al}=4)$, and incubated at $125^{\circ} \mathrm{C}$ for 7 days. This leads to a pure ERI-zeolite with $\mathrm{Si} / \mathrm{Al}$ at 5.7. Hong and co-workers incubated similar solutions, but with the diquat and $\mathrm{KCl}$ added right from the start, with similar ERI formation results. ${ }^{70}$ They
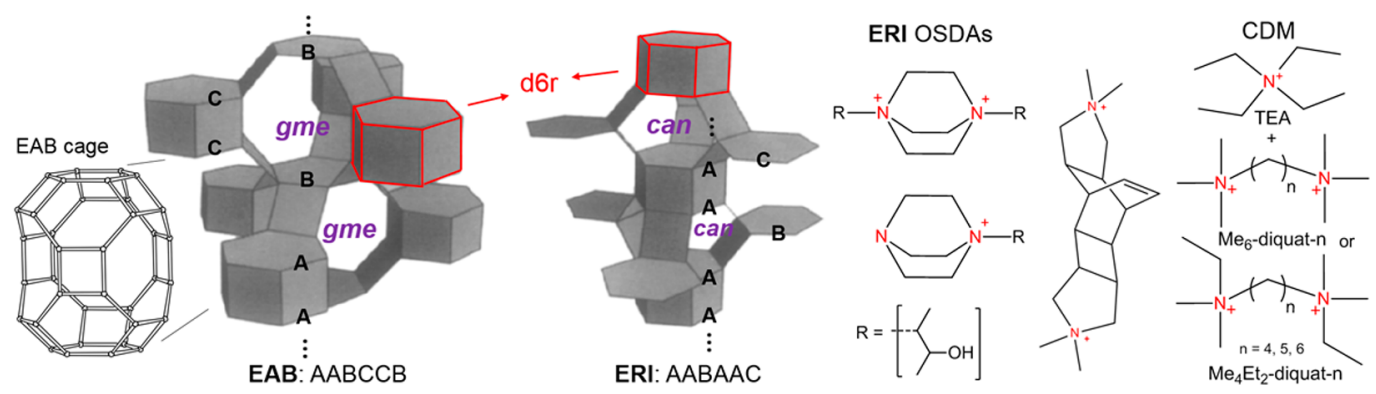

Figure 18. ABC-6 stacking sequence of ERI and EAB. Middle figures adapted from Meier and Groner. ${ }^{61}$ Note that both structures have d6r (where two layers are repeated), but they cannot be exclusively formed by that composite building unit. Reported classic DABCO-derived OSDAs for ERI on the left (for DABCO, remove R-groups and the charge), the large Diels-Alder derived OSDA in the middle, and the cooperative CDM OSDAs on the right. Diquats are the crystallization-inducing organics for UZM-12. 

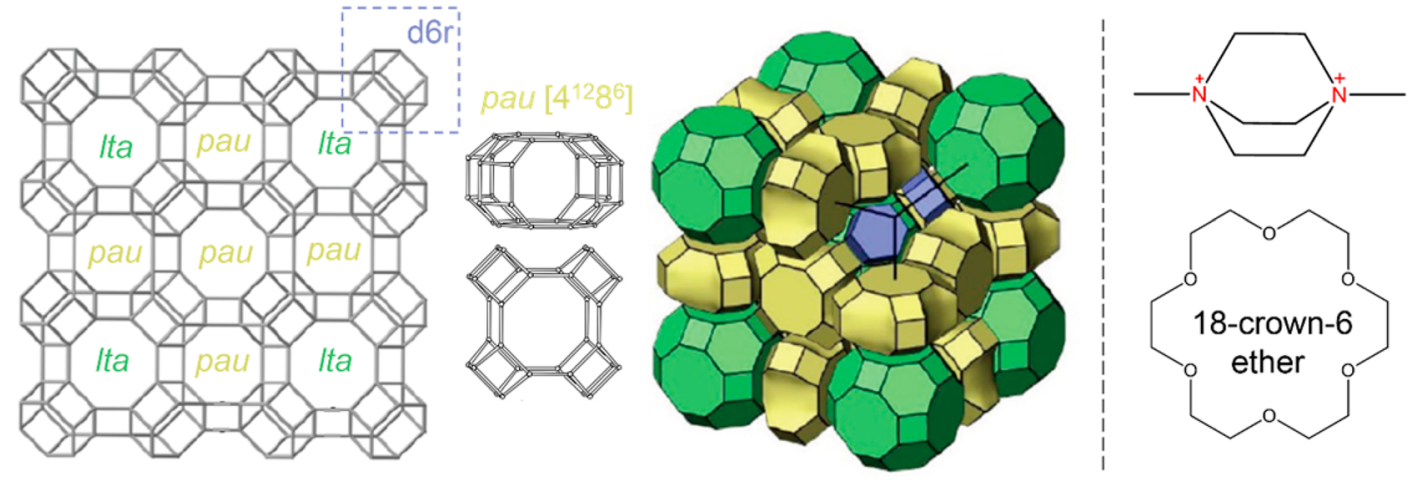

Figure 19. Left: the structure of KFI as built from chains of d6r units (blue), with its pau (yellow) and lta cages (green). Right: OSDAs reported for KFI: methyl-diquaternized DABCO (up) and crown-ether (down). Left: 2D-network adapted from the IZA; ${ }^{3}$ 3D-network adapted with permission from Remy et al. ${ }^{112}$ Copyright 2013 American Chemical Society. Compare left to Figure 8 for AEI and CHA.

also noted that diquats (with 6 different kinds of end-groups) that were either too short or long $(n=3$ or 7$)$ did not yield ERI. These authors also computed the stabilization energies of the diquats in the large ERI cage. They found that the differences between TEA and the diquats were sufficiently large to assume that TEA only acted as a CDM OSDA (preventing the initial mixture from condensing). Strikingly, since a large range of diquats worked in this approach, it is safe to suggest the structurally nonspecific role of these organics, thus as crystallization OSDAs, rather than fitting perfectly. The cation incorporation for the $\mathrm{Me}_{6}$-diquat- $6 \mathrm{ERI}$ for instance, was estimated at (diquat $\left.{ }_{1.6} \mathrm{TEA}_{0.1} \mathrm{~K}_{2.1} \mathrm{H}_{0.9} \mathrm{H}_{2} \mathrm{O}_{10.3}\right)-\left[\mathrm{Al}_{6.3} \mathrm{Si}_{29.7} \mathrm{O}_{72}\right]$, clearly in excess for the diquat with respect to TEA. ${ }^{70}$ It is interesting to note that the recipes from Occelli et al, using DABCO derivatives (Figure 18), are not far off from the CDM recipes in terms of gel composition, with the exception that, instead of TEA, $\mathrm{Na}^{+}$was used.

Finally, in 2017, Martín et al. reported a new IZC route to ERI, based on a large multicyclic Diels-Alder derived OSDA (Figure 18, middle of OSDAs) and the use of the right FAU $(\mathrm{Si} / \mathrm{Al}=6)$ zeolite precursor (OSDA $/ \mathrm{Si}: 0.2, \mathrm{KOH} / \mathrm{Si}: 0.1$, $\left.\mathrm{H}_{2} \mathrm{O} / \mathrm{Si}: 5-15\right)$. The same OSDA also led to AFX zeolite (section 2.3.2). ${ }^{198}$ An intergrowth of ERI and LEV is also know in the patent literature, i.e., SSZ-105. ${ }^{251}$

2.3.6. GIS. Zeolite $P$ is the synthetic analogue of gismondine (and some other very related mineral structures). It was discovered as $\mathrm{Na}-\mathrm{P}$ by Barrer and his colleagues. ${ }^{252}$ The cageless zeolite presents a medium-dense structure (i.e., $16.4 \mathrm{~T}$ atoms per $1000 \AA^{3}$ compared to 19.2 for dense ANA, and 15.1 for CHA), with channels running in three dimensions. The structure is (unusually) flexible and has good inorganic ionexchange properties. ${ }^{253}$ The latter is the reason for its commercial application at the kiloton scale, in a form also known as maximum aluminum $\mathrm{P}$ or MAP. ${ }^{108,254}$ Its ionexchange performance is sometimes attributed to the small crystallite sizes with large external surface areas. ${ }^{255}$

Barrer and co-workers discovered this zeolite using inorganic components alone. It is a common phase observed in sodiumrich, highly alkaline aluminosilicate gels heated to around 100 ${ }^{\circ} \mathrm{C}$, and therefore, it is often encountered as an impurity in zeolite synthesis containing both sodium and OSDA. An example of this is the synthesis of AEI, where relatively high $\mathrm{OH} / \mathrm{Si}$ and $\mathrm{Na} / \mathrm{Si}$ ratios prevail. GIS-zeolite impurities can often easily be removed via acid-washing, e.g., with $\mathrm{HCl}$, while the OSDA-filled AEI zeolite is acid-stable. ${ }^{184}$ Structural elucidation of GIS was performed by Baerlocher and Meier, ${ }^{74}$ and even a TMA-directed, so-called high-silica $P$, was documented by them. TMA appeared to be occluded, and the $\mathrm{Si} / \mathrm{Al}$ was $3 .^{256}$ In the early days of zeolite synthesis, obtaining highly crystalline samples with $\mathrm{Si} / \mathrm{Al}$ ratios of 1 was difficult. Moreover, different types of zeolite $\mathrm{P}$ were found, with different crystal habits. Hansen et al. clarified these issues (discerning between zeolite $\mathrm{P} 1(\mathrm{Si} / \mathrm{Al} \pm 1.6), \mathrm{P} 2(\mathrm{Si} / \mathrm{Al} \pm 2.2)$, and high-silica $\mathrm{P}$ ) and investigated the relation between chemical composition and crystal structure. ${ }^{253}$ Albert et al. managed to obtain well-crystallized $\mathrm{Na}-\mathrm{P}$-zeolites with $\mathrm{Si} / \mathrm{Al}$ ratio at unity (MAP), from equimolar sodium aluminate and silicate mixtures, with added $\mathrm{NaOH}$ at $100{ }^{\circ} \mathrm{C}$ for 5 days (likely, the commercial recipe is similar, but with shorter crystallization times). They refined the structure of their aluminous $\mathrm{NaP}$, as well as its Ca-exchanged form $(\mathrm{CaP})$, hereby confirming the GIS net and discussing the close structural relationship between synthetic P-zeolites and gismondine. ${ }^{257,258}$

The IZA recipe for zeolite $\mathrm{P}(\mathrm{Si} / \mathrm{Al}=1.2)$ is based on a long 60 day procedure at $85{ }^{\circ} \mathrm{C}$ using kaolinite clay as the source of both $\mathrm{T}$ atoms in a NaF-rich medium $(\mathrm{F} / \mathrm{Si}=2.4){ }^{259}$ Gismondine type zeolites have also been prepared via hydrothermal, high-pressure (geomimicking) conditions by Ghobarkar and Schaf. These authors synthesized a lot of $8 \mathrm{MR}$ zeolite in this way (e.g., EDI, EPI, ANA, THO, see method A in Table 3). At 1000 bar, and temperatures near $250{ }^{\circ} \mathrm{C}$, gismondine type minerals could be prepared from the glass $4 \mathrm{CaO}-4 \mathrm{Al}_{2} \mathrm{O}_{3}-8 \mathrm{SiO}_{2}{ }^{67}$

As mentioned (sections 2.3.3.4), zeolite $\mathrm{P}$ has been used as an $\mathrm{Al}$-source in partial interzeolite conversions, leading to $\mathrm{CHA}$ (and LEV, see later). The opposite direction, i.e., IZC leading to GIS, is also known. Subotic and co-workers studied the transformation of zeolite A (LTA) into P (GIS). ${ }^{260}$ In this transformation, the authors thought it was more likely that the P-nucleation happened in the solution, rather than on the zeolite A's surface and thus that zeolite A and P existed as discrete particle systems during all stages of the transformation. IZC in this case clearly contrasts with that of other more siliceous zeolites (e.g., CHA or LEV), probably due to the highly alkaline $(\mathrm{NaOH})$ conditions.

The more recent zeolite $\mathrm{P}$ work focuses on morphology control ( $\mathrm{Si} / \mathrm{Al}$ dependent), ${ }^{261}$ the use of different, cheaper, $\mathrm{T}$ atom sources (e.g., fly ash), or alternative methods (e.g., microwave, sonochemistry). ${ }^{262,263}$ Sharma et al. noted a Na-P1 synthesis where the zeolite seemingly exhibits spherical morphologies, composed of a large number of nanocrystalline particles $(40-100 \mathrm{~nm})$, rendering the zeolite mesoporous. ${ }^{264}$ 
Table 6. Overview of Notable LEV-Zeolite Synthesis Conditions

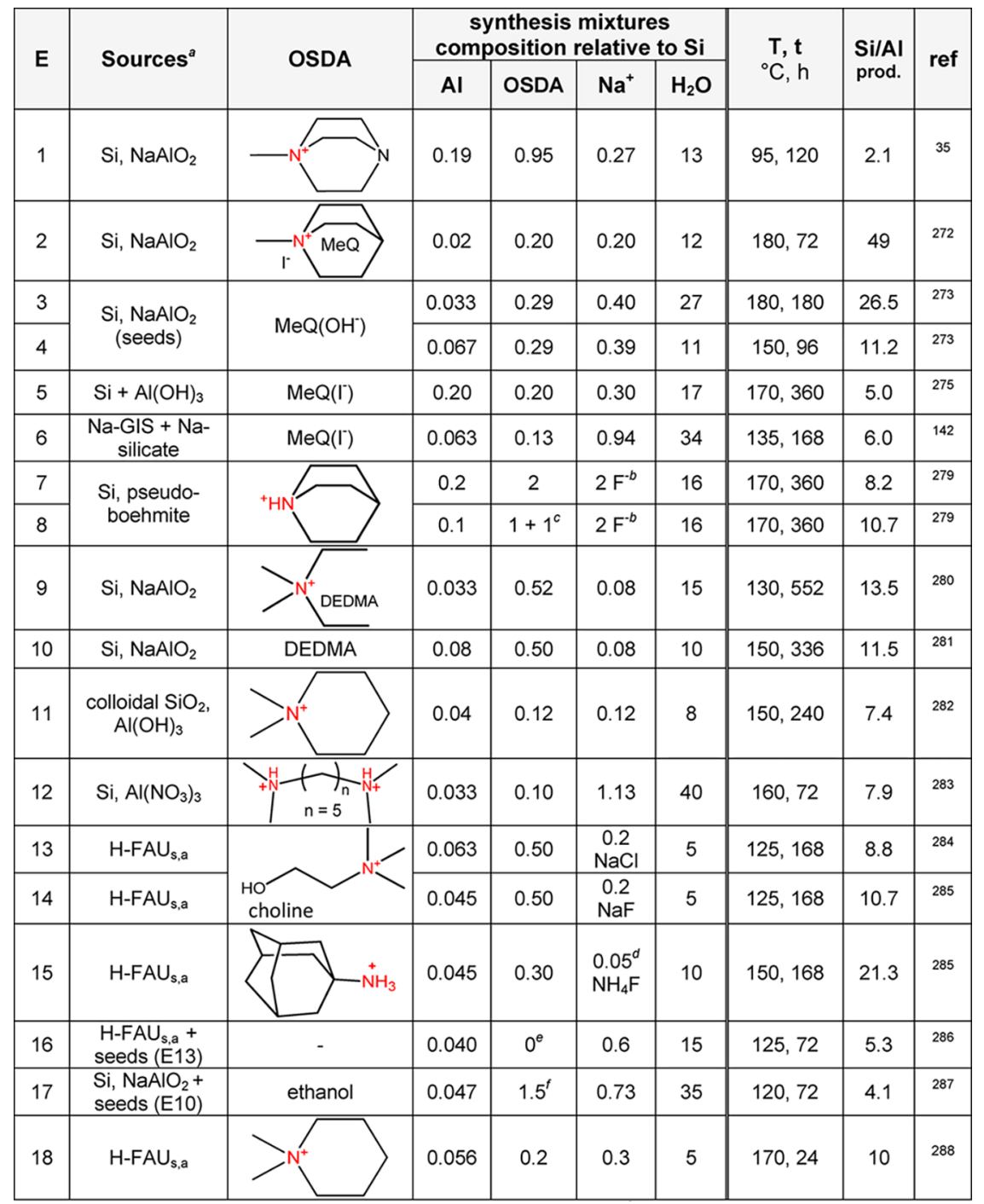

${ }^{a} \mathrm{Si}$ indicates silica sol or fumed silica. Quaternary amines (OSDA) and $\mathrm{Na}^{+}$in/from hydroxide form unless otherwise mentioned. s.a. $=$steamed and acid-leached. ${ }^{b}$ Near neutral fluoride media synthesis without $\mathrm{Na}^{+}$, with HF $(\mathrm{F} /$ amine $=1) .{ }^{c}$ Methylamine and seeds added. ${ }^{d} \mathrm{No} \mathrm{Na}^{+}$used. ${ }^{e} \mathrm{Note}$ that the seeds $(17 \%)$ contained choline, as they were made according to entry $13 .{ }^{f} 1-2$ ethanol to Si used, on top of $5 \%$ seeds made according to reference from entry 10 , with $\mathrm{Si} / \mathrm{Al} 9.8$, calcination unsure.

Goel et al. have looked into incorporating metal clusters in the small-pore zeolite, by blending (organic amine or ammonia ligated) metal precursors into the synthesis. Interestingly, metal-containing zeolite ANA (dense 8MR zeolite) was obtained by the IZC of a metal-containing GIS. ${ }^{265}$

The relevance of MAP is evident, given its industrial application. However, pure-phase syntheses of GIS zeolites with $\mathrm{Si} / \mathrm{Al}$ ratios higher than 3 have not been encountered in our search. It might however be important to look for highly siliceous or even pure silica GIS phases, as these could have beneficial properties for small-molecule separation $\left(\mathrm{CO}_{2} / \mathrm{CH}_{4} /\right.$ $\mathrm{H}_{2}$ e.g.). The synthesis of such GIS materials will be especially challenging, as it does not resemble the high-silica approaches for cage-based $8 \mathrm{MR}$ zeolites, e.g., applied to CHA or LEV, where organics are incorporated easily. Even lessons from LTA synthesis (section 2.3.9), that for a long time had the same limitations to its $\mathrm{Si} / \mathrm{Al}$ range (max. 3), do not seem relevant here.
2.3.7. KFI. Barrer encountered the first KFI zeolite using Basalts and synthetic analcime (also other minerals and gels) as $\mathrm{T}$ atom source at around $200{ }^{\circ} \mathrm{C} .{ }^{125} \mathrm{He}$ recognized it as being the first synthetic zeolite with no natural counterpart and noticed its $8 \mathrm{MR}$ behavior by comparing it to chabazite. Structure elucidation and the first presentation of the very relevant framework were presented by Meier and Kokotailo, with Mobil's ZK-5 zeolite (different synthesis). ZK-5 was among the first zeolites prepared with an OSDA in hydroxide media. ${ }^{88,127,266}$ The structure of KFI can be built from the large ( $\alpha$-cage) lta-composite building unit, a large cuboctahedron, also found in LTA and RHO (Figure 7). These large cages are linked to each other by their $6 \mathrm{MR}$, effectively forming d6r units (Figure 19). In contrast, to obtain LTA, the large cages are linked by their $4 \mathrm{MR}$ (in $\mathrm{d} 4 \mathrm{r}$ ), and by sharing their $8 \mathrm{MR}$, while in $\mathrm{RHO}$, they are exclusively linked by their $8 \mathrm{MR}$ (via d8r, Figure 23 below). ${ }^{127}$ Given the KFI description based on lta-cages, linked by $\mathrm{d} 6 \mathrm{r}$, the remaining space is filled by paucages ( 2 projections of this building unit in Figure 19). In the 

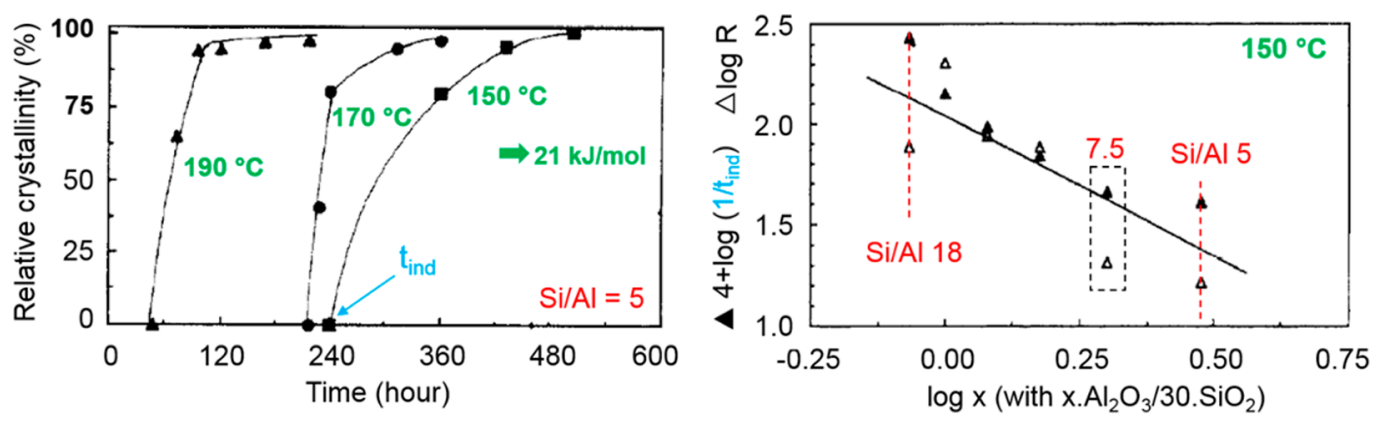

Figure 20. Left: crystallization curves for LEV with $\mathrm{MeQ}\left(\mathrm{I}^{-}\right)$in the conditions of Table 6, entry 5 at different temperatures. Using induction time ( $t_{\text {ind }}$ in hours) as a measure for nucleation rate and the linear slope of the relative crystallinity ( $\mathrm{R}$, in change/day) for the crystallization rates, the plot on the right can be constructed for $\mathrm{Si} / \mathrm{Al}=5$. Right: logarithmic nucleation and growth rate as a function of the Al-content. The nucleation curve is translated to fit both plots in one frame. Based on data and figures from Tuoto et al. ${ }^{275}$

light of $8 \mathrm{MRs}$, the latter is an interesting unit, as it is composed of two types of 8-rings, one set of these being near planar. Interestingly, the entire KFI structure can also be constructed from only d6r units. As with AEI and CHA, the d6r units can be visualized ordered in chains that form planes (Figure 19, left), which lead to the large cavities by stacking.

Given the clear structural links between KFI, RHO, and LTA, based on the large cage and with KFI being a member of the "d6r-only" family, the synthesis of KFI presents an interesting case. Kerr reported ZK-5 using the methylated diquat of DABCO (Figure 19) in the presence of $\mathrm{Na}^{+}$, and these materials had $\mathrm{Si} / \mathrm{Al}$ ratios between 2.0-2.5. Later, ZK-5 was produced by Robson, in a more straightforward, organic-free way, using $\mathrm{K}^{+}$as principal cation and $\mathrm{Cs}^{+}$as cocation (with or without $\mathrm{Na}^{+}$). Robson's KFI zeolites had $\mathrm{Si} / \mathrm{Al}$ ratios below 3.5. ${ }^{87}$ The latter recipe was recently confirmed by Ji et al. yielding $\mathrm{Si} / \mathrm{Al}=3.1$, in an attempt to evaluate dealuminated KFI in methanol conversion. ${ }^{267} \mathrm{~A}$ higher-silica KFI was claimed by Verduijn, using a mix of $\mathrm{Sr}^{2+}$ and $\mathrm{K}^{+}$, typically in gels with $\mathrm{Si} / \mathrm{Al}$ ratios near 5 . The actual ratios of the materials were often close to 3.5. ${ }^{268}$ When insufficient $\mathrm{Sr}^{2+}$ is added $\left(\mathrm{Sr}^{2+} / \mathrm{Si}<\right.$ 0.0025 ), the gels typically lead to the one-dimensional $12 \mathrm{MR}$ zeolite LTL. Interestingly, Verduijn noticed that decreasing the alkalinity was found to slightly increase the $\mathrm{Si} / \mathrm{Al}$ ratios and also that the addition of trace $\mathrm{Ba}^{2+}$ helped as well: a gel containing $\mathrm{K}^{+} / \mathrm{Si}, \mathrm{Sr}^{2+} / \mathrm{Si}$, and $\mathrm{Ba}^{2+} / \mathrm{Si}$ ratios of $0.36,0.01$, and 0.0005 , respectively, yielded $\mathrm{KFI}$ with $\mathrm{Si} / \mathrm{Al}=4.2$, at $150{ }^{\circ} \mathrm{C}$. Chatelain et al. reported an interesting variation of the $\mathrm{Sr}^{2+}$ recipe, by using an additional organic crown-ether (Figure 19) in the gel and the same amounts of $\mathrm{K}^{+}$and $\mathrm{Sr}^{2+}$. The crown ether was found to speed up the crystallization of KFI, slightly decreasing the $\mathrm{Al}$ incorporation $(\mathrm{Si} / \mathrm{Al}=4.0)$. One crown-ether was incorporated per unit cell in the product, in the lta-cage. In a reverse strategy for aluminum and in the context of $\mathrm{CO}_{2}$ adsorption, Remy et al. proposed a recipe for low-silica KFI, achieving $\mathrm{Si} / \mathrm{Al}$ ratios near 1.7 , based on using $\mathrm{Li}^{+}, \mathrm{Na}^{+}, \mathrm{K}^{+}$, and TMA cations. ${ }^{112}$ This recipe somewhat resembles another entry by Barrer, who combined $\mathrm{Li}^{+}, \mathrm{Cs}^{+}$, and TMA to obtain KFI. ${ }^{269}$

The structure of KFI, the first synthetic zeolite and also the first example of interzeolite conversion, is a promising one: as Meier pointed out, the zeolite has two independent 3D-pore systems based on $8 \mathrm{MRs}$ and large, useful cages. ${ }^{127}$ For gasseparation and adsorption, KFI has been reported to some extent, but its use as a catalyst is largely unexplored. The latter is explained by the fact that, strikingly, a zeolite version of the framework with $\mathrm{Si} / \mathrm{Al}>5$ has never been reported. Methods to postsynthetically remove $\mathrm{Al}$ have been evaluated, but a synthetic recipe leading to more stable $\mathrm{KFI}$ zeolites with $\mathrm{Si}$ / $\mathrm{Al}$ ratios in the range of $10-50$ would be a game-changer. Given the recent progress in making high-silica and even puresilica LTA in fluoride media, based on stabilizing the large $\alpha$ cages (see below ${ }^{37,135,172}$ ), the synthesis of the KFI framework could be revisited in high-silica gels, using similar OSDAs. A second approach to KFI could focus on IZC methods starting from FAU, as reported for CHA and AEI. Given the systematic relationship between KFI and the structures of these two d6ronly frameworks (planes of d6r), as pointed out by Lillerud, ${ }^{270}$ new synthesis routes to KFI might be found in modified CHA or AEI-conditions. The most difficult part will be to stabilize the larger lta-cages. In this context, the SAV-topology deserves mention: this framework, also constructed from d6r planes and chains and with a relatively large cage, has only been reported in metalloaluminophosphate composition (not a zeolite), using azamacrocycles. The latter are similar to crown-ethers (Figure 19), but with nitrogen instead of oxygen and with additional methyl groups on the nitrogens. ${ }^{271}$ Exploring these or similar OSDAs in conditions known to crystallize zeolites CHA or AEI (LTA, KFI) could be an option.

2.3.8. LEV. LEV, known from minerals (Table 1-3), is another member of the ABC- 6 family, with stacking sequence AABCCABBC. LEV has some d6r units, but cannot exclusively be built from them. LEV has one of the smaller cages of the 8MR zeolites (Figure 7).

Kerr claimed the first synthetic LEV by using monomethylated DABCO (Table 6, entry 1), and he obtained highly aluminous products ( $\mathrm{Si} / \mathrm{Al}$ from 1.9 to 2.7 ) that closely resemble the natural levyne. Short and Whittam patented $\mathrm{Nu}-3$, a more siliceous form of $\mathrm{LEV}$, with $\mathrm{Si} / \mathrm{Al}$ ratios ranging up to 50 by using $N$-methylquinuclidium as OSDA (MeQ, Table 6, entry 2). ${ }^{272}$ Casci et al. further investigated $\mathrm{Nu}-3$ formation (Table 6, entry 3-4) with MeQ. Although structurally similar to $\mathrm{DABCO}$, the MeQ molecule is not able to lead to LEV in the conditions of Kerr, and vice versa, the DABCO OSDA did not lead to $\mathrm{Nu}-3$ in Casci's conditions. ${ }^{273}$ Later, Stewart also patented $\mathrm{Nu}-3$ made from 1-adamantylamine (not in table). ${ }^{274}$ Adamantylamine is known from DDR synthesis (section 2.3.4).

Tuoto et al. presented a thorough study on the crystallization of LEV from classic gels, with the MeQ OSDA in its iodide form. ${ }^{275}$ They studied nucleation and crystallization rates for different $\mathrm{Si} / \mathrm{Al}$ starting ratios ranging from 5 to 25 (e.g., Table 6 , entry 5), as well as for different temperatures. This range is more aluminous than that in Casci's work, ${ }^{273}$ and the $\mathrm{Al}$ incorporation matched the content in the synthesis mixtures well. The crystallization curves for $\mathrm{Nu}-3$ at $\mathrm{Si} / \mathrm{Al}=5$ (Figure 
20, left) allowed for the calculation of an (apparent) activation energy that is around $21 \mathrm{~kJ} / \mathrm{mol}$ for both nucleation and crystal growth (thermally activated, Arrhenius). This energy for the crystallization is on the low side, as for example Thompson's review showed a range of $45-80 \mathrm{~kJ} \mathrm{~mol}^{-1}$ to be common for a variety of molecular sieves. ${ }^{276}$ Values in the latter range would be indicative of control (limitation of rate) by the surface reaction rather than by diffusion from precursors of the gel or solution to the crystal surface. Given the low value for LEV found by Tuoto et al., the question arises whether their data shows diffusion-limited growth rates. Such low values could suggest that larger condensed particles (amorphous precursors) have to transport to the surface and attach to the growing crystal, rather than monomolecular $\mathrm{T}$ atom precursors or small oligomeric species. ${ }^{167,207}$ Next, these authors investigated the influence of the amount of aluminum on both rates, and they expressed this in linear plots with logarithmic variables (Figure 20, right). The higher Al-content of the gel or the process of incorporating more $\mathrm{Al}$ in the frameworks, had a strong negative effect on the rates of crystallization and nucleation (i.e., longer induction times).

The authors also performed a thermogravimetric analysis (TGA) to find proof that $\mathrm{MeQ}$ associated with negatively charged silica defects, i.e., $\mathrm{Si}-\mathrm{O}^{-}$or siloxy groups, ${ }^{277}$ at high $\mathrm{Si} /$ $\mathrm{Al}$ ratios (next to compensating $\mathrm{Al}$-framework charge). For $\mathrm{Si} /$ $\mathrm{Al}=5$, a uniform decomposition zone for the organic was found in TGA, but for lower Al-incorporations, a second decomposition temperature emerged, in conjunction with an improper charge balance indicating the formation of $\mathrm{SiOM}$ or $\mathrm{Si}(\mathrm{OM})_{2}$ (with $\mathrm{M}$ being $\mathrm{MeQ}^{+}, \mathrm{Na}^{+}$or $\mathrm{H}^{+}$). The latter was confirmed by ${ }^{29} \mathrm{Si} \mathrm{NMR}$ and mass spectrometry, as well as by calcination, where the defect groups disappeared upon dehydration. ${ }^{275}$ The authors also analyzed the $\mathrm{MeQ}, \mathrm{Na}$, and $\mathrm{Al}$ contents per unit cell, but no calculation related to $\mathrm{MeQ}$ occlusion in cages was given. We performed a count of the number of (individual) $\mathrm{T}$ atoms per cage for LEV in two ways. The unit cell possesses 6 full cages for $54 \mathrm{~T}$ atoms or on average 9 "full" $\mathrm{T}$ atoms per cage. ${ }^{196}$ This value is also possible to obtain from counting the $\mathrm{T}$ atoms surrounding the cage and taking into account their degree of sharing over cages: $30 \mathrm{~T}$ atoms form the lev-cage, but by viewing a 3D-model, one can discriminate between $\mathrm{T}$ atoms that are part of the d6r units (red in Figure 7) and those that are part of singular 6MR (the ABC-6 sequence can be useful here). The latter (blue in Figure $7,12 / 30 \mathrm{~T}$ atoms) are shared over 4 cages, while the remaining $18 \mathrm{~d} 6 \mathrm{r}$-T atoms are shared over 3 cages, thus adding up to 9 full $\mathrm{T}$ atoms per cage. Considering one $\mathrm{MeQ}$ per cage, this would indicate that $\mathrm{Si} / \mathrm{Al}=8$ ratios $(8 \mathrm{Si}+1 \mathrm{Al})$ are ideal for not having defects. Interestingly, Tuoto et al. analyzed $5.8 \mathrm{MeQ}$ molecules per unit cell, perfectly matching the 5.8 aluminums per unit cell for their material with $\mathrm{Si} / \mathrm{Al}$ ratio of 7.5. More aluminous materials incorporated more $\mathrm{Na}^{+}$(no defects), while less aluminous ones had more or less the same amount of $\mathrm{Na}^{+}$ (but with increasing defect sites). The balance $\mathrm{MeQ} / \mathrm{Al}$ was only 1 in the $\mathrm{Si} / \mathrm{Al}=7.5$ case. Taking into account our analysis and those for AEI and CHA above, it appears that there is an ideal $\mathrm{Si} / \mathrm{Al}$ ratio for the $\mathrm{MeQ}$ (Nu-3) LEV-type material. An interesting open question is whether this influences or causes the slower rates of nucleation and growth in the more aluminous case (e.g., Figure 20, right, $\mathrm{Si} / \mathrm{Al}=7.5$ ), considering, e.g., that building defects entail less condensation reactions and less strain. This analysis is illustrated in Figure 27 in section 2.4.
Using $\mathrm{MeQ}$ as well, Zones and co-workers reported the formation of $\mathrm{Nu}-3$ starting from zeolite P (GIS) and soluble sodium silicate (Table 6, entry 6). ${ }^{142}$ Recall that these authors also used this type of gel-free system to obtain $8 \mathrm{MR}$ zeolites CHA (Table 5, entry 5) and AFX from the same GIS. Interestingly, Chan et al. presented a follow-up study where the GIS-to-LEV transformation was monitored by electron microscopy, as all changes take place without GIS transforming into an amorphous phase. ${ }^{278}$ The nucleation of the LEV was found to occur at the surface of the disappearing GIS crystals (solution/solid interface), but no evidence of phase-intergrowth was found in electron diffraction. The authors suggested a role for the organic as a phase-transfer reagent at this interface due to the rate-enhancement effect of the organic. Keeping Tuoto's low activation energies for LEV crystal growth in mind, this role could be plausible. The resulting zeolites' $\mathrm{Si} / \mathrm{Al}$ values are quite low, i.e., doubled versus the starting GIS (additional sodium silicate is added). Whether this is limited by the high solubility of silica in these hydroxide rich systems (Table 6, entry 6) or our above hypothesis that the MeQ-zeolite has a tendency for low $\mathrm{Si} / \mathrm{Al}$ ratios around 8 (or lower based on $\mathrm{Na}^{+}$) remains to be seen.

Caullet et al. prepared LEV in fluoride media by using the free amine quinuclidine (Table 6 , entry 7 , drawn with proton as the $\mathrm{p} K_{\mathrm{a}}$ is 11 , and the synthesis neutral). ${ }^{279}$ They noted that the obtainable $\mathrm{Si} / \mathrm{Al}$ ratio in the materials was very limited (between 8 and 11) and that only $0.6-1.3 \mathrm{~F}^{-}$-anions were incorporated per unit cell (along with 6 quinuclidiniums (ammonium)). Pure-silica LEV, with coincorporation of one Fanion per OSDA, can thus not be made in this manner. The authors also added methylamine to some synthesis and noted that, in its presence, a part of the OSDA incorporated was in situ formed $\mathrm{MeQ}$ (entry 8).

Researchers from Mobil reported zeolite ZSM-45, also of the LEV-topology, by using choline chloride, metal-organic complexes ${ }^{289}$ such as $\left[\mathrm{Co}\left(\mathrm{C}_{5} \mathrm{H}_{5}\right)_{2}\right]^{+}$or, notably, diethyldimethylammonium as organic additive (DEDMA, Table 6, entry 9). The latter organic was claimed to lead to LEV in mixtures with $\mathrm{Si} / \mathrm{Al}$ ratios between 5 and 40, while lower or higher values led to formation of FAU or MTW-type zeolites, respectively. ${ }^{280}$ Yamamoto et al. confirmed this recipe and presented a structural analysis of this LEV-analogue in a synthesis where product and gel roughly had the same $\mathrm{Si} / \mathrm{Al}$ ratio (Table 6, entry 10). ${ }^{281}$ Notably, they found that the ethyl groups of the occluded OSDA were allocated to build a 5-membered organic ring (4-carbon, 1 nitrogen). They then briefly also demonstrated successful LEV syntheses with the $\mathrm{N}, \mathrm{N}$-dimethylpyrrolidinium, and $N, N$-dimethylpiperidinium cations (i.e., respectively using the 5-membered ring and an organic with one additional carbon in the ring). The latter had already been reported for $\mathrm{LEV}$, by $\mathrm{Xu}$ et al., who showed $\mathrm{Si} / \mathrm{Al}$ ratios ranging from 3.4 to 10.6 in the materials, even though some gels had much higher ratios (Table 6, entry 11, chloride form). ${ }^{282}$

Hong and co-workers discovered that the aliphatic diquat (or protonated di-tertiary amine in this case) $\mathrm{Me}_{4}$-diquat-5 (bromide form, Table 6, entry 12) could lead to LEV in a very narrow range $(\mathrm{Si} / \mathrm{Al}$ in gel $=20-30) .{ }^{283}$ This group had already successfully used other diquats for $8 \mathrm{MR}$ zeolites (see AFX and ERI). The narrow range of conditions and the high $\mathrm{OH}^{-}$and $\mathrm{Na}^{+}$contents demonstrate the inorganic domination in this synthesis. Strikingly, the $\mathrm{Si} / \mathrm{Al}$ of this aluminosilicate LEV, again, is close to 8 . Moreover, elemental analysis showed around 3 diquats per unit cell, which seemed plausible from ${ }^{13} \mathrm{C}$ 
NMR and stabilization energy calculations considering one organic spanning 2 cages. The authors rightfully noted that the diquat in this case plays a structurally nonspecific space-filling role, as it is also known to lead to NON, MTW, and MOR in similar inorganic-dominated gels. This is similar to the role of such diquats in ERI synthesis (CDM).

Besides the partial IZC mentioned above for LEV from GIS (added silica, entry 6), the Sano group reported the synthesis of LEV from FAU-zeolites, in both hydroxide and fluoride media. They found that choline hydroxide as organic worked well, and they noticed highly microporous LEV forming from zeolites with $\mathrm{Si} / \mathrm{Al}$ ratios of $16-22$ (not higher, Table 6, entry 13). ${ }^{284}$ From TGA, seven decomposing cholines per unit cell were counted and the $\mathrm{Si} / \mathrm{Al}$ ratio was (again) close to 8. Amorphous precursor syntheses did not lead to LEV-crystallization. FAU belongs to the d6r-only family, while LEV contains a decent number of d6r, on top of free $6 \mathrm{MR}$ connected through $4 \mathrm{MR}$ and $8 \mathrm{MR}$. A time-resolved PXRD study showed the disappearance of all FAU reflections, before LEV reflections appeared from the X-ray-amorphous mixtures. Later, the same group investigated this transition in fluoride (-containing) media, using 1-adamantylamine or choline hydroxide (Table 6, entry $14-15) .{ }^{285}$ Using choline hydroxide, $\mathrm{Na}^{+}$was necessary to obtain crystalline LEV and it should be noted that these syntheses contain more $\mathrm{OH}^{-}$(from OSDA) than $\mathrm{F}^{-}$anions. From adamantylamine (no hydroxide), the conditions were more flexible, were $\mathrm{Na}^{+}$-free, and worked over a larger $\mathrm{Si} / \mathrm{Al}$ range. Recall that Stewart patented this OSDA for Nu-3 in classic hydrothermal systems. ${ }^{274}$ The 1-adamantylamine products were in close relation to the starting FAU, i.e.,1329 in the obtained zeolites (Table 6, compare entries 14-15). The 1-adamantylamine-containing synthesis thus inferred high yields. Another striking difference with the choline catalyzed IZC was that the FAU zeolite did not disappear with 1adamantylamine before LEV reflections were seen. A very recent IZC details the use of $N, N$-dimethylpiperidinium hydroxide as OSDA for obtaining nanosized LEV particles (e.g., $35 \mathrm{~nm}$ in entry 18). Comparable synthesis from amorphous sources yielded $80 \mathrm{~nm}$ crystals, while a similar recipe with choline hydroxide (cfr, entry 13-14) led to larger $220 \mathrm{~nm}$ sized zeolites. Nanosized LEV materials in the range of $\mathrm{Si} / \mathrm{Al}=10-30$ can be accessed with this new IZC route. ${ }^{288}$

Finally, two organic-free, seed-assisted methods for LEV synthesis have been reported (Method B, Table 2). First, the Sano group succeeded in transforming FAU $(\mathrm{Si} / \mathrm{Al}=25)$ in the presence of a large amount, 17 wt \% based on silica, of uncalcined, choline hydroxide containing seeds $(\mathrm{Si} / \mathrm{Al}=10.7$, made according to entry 13). ${ }^{286}$ The resulting zeolite had a low $\mathrm{Si} / \mathrm{Al}$, and the yield was around $20 \%$ (entry 16 ). Interestingly, the authors note that the LEV had a silica enriched core and Alenriched shells. Likely, the core stems from partially dissolved, more siliceous seeds onto which the new zeolite has grown. All choline in the seeds was recovered in the final zeolite. When calcined seeds were used, no LEV was formed, indicating that the seeds are more stable when containing the organic. ${ }^{286} \mathrm{~A}$ second OSDA-free method was reported by Zhang et al., using 5 wt \% of LEV-seeds from a DEDMA synthesis (likely calcined) and ethanol (Table 6, entry 17). The ethanol suppressed the competing MOR-zeolites, and the resulting LEV had a low $\mathrm{Si} / \mathrm{Al}$ ratio of 4 . Solid yields were not mentioned and the pore volume of the Na-containing zeolite was very low. ${ }^{287}$

In conclusion, $\mathrm{LEV}$ is an appealing $8 \mathrm{MR}$ zeolite, and even though the structure is known from aluminous natural minerals
$(\mathrm{Si} / \mathrm{Al}=2)$, its synthetic aluminosilicate counterparts are always synthesized with the use of an OSDA (despite of some OSDA-derived seeded synthesis). When comparing all representative entries in Table 6, it is clear that a lot of syntheses lead to $\mathrm{LEV}$ with $\mathrm{Si} / \mathrm{Al}$ ratio around 8 , and a link with the cage-based organic incorporation has been suggested. The best OSDA for making these zeolites over the broadest Alcontent range is the methyl-quinuclidinium cation. So far, the highest $\mathrm{Si} / \mathrm{Al}$ ratio reported still dates back to the first patent using said organic. ${ }^{272}$ The abundance of $6 \mathrm{MR}$ in the structure could matter in the IZC conversion routes starting from FAU but is yet to be proven. Recent mechanistic studies concerning the crystallization mechanisms of LEV and other cagecontaining zeolites (CHA, LTA, and UFI) are discussed in section 2.4 .

2.3.9. LTA. 2.3.9.1. Introduction and Pioneering Syntheses. LTA is the best-known $8 \mathrm{MR}$ zeolite. Its use as a universal drying agent (desiccant) in gases and polar or nonpolar liquids and an ion exchanger and adsorbent for organics is widespread (domestic, industrial, academic). Consider for instance that zeolites $3 \mathrm{~A}, 4 \mathrm{~A}$, and $5 \mathrm{~A}$ are all commercially available LTA varieties, that effectively have different practical pore openings of 3,4 , and $5 \AA$, because they are exchanged with either $\mathrm{K}^{+}, \mathrm{Na}^{+}$, or $\mathrm{Ca}^{2+}$, respectively. The cubic structure of the zeolite is easily recognizable and harbors the large lta (or $\alpha$ )-cage (Figure 7). Theses cages partially connect with each other through $\mathrm{d} 4 \mathrm{r}$ units, as well as by sharing their $8 \mathrm{MR}$. The common building unit arising from this organization is the sodalite (sod-) cage, and the structure is more easily visualized by connecting sod-cages through $\mathrm{d} 4 \mathrm{r}$ (Figure 21). Recall that in KFI and RHO, the lta-cages connect through d6r and d8r units, respectively (Figures 19,23, and 24).

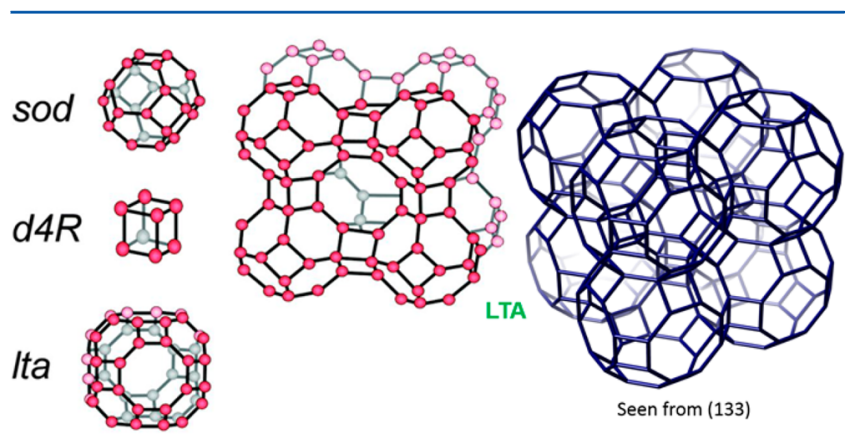

Figure 21. Structure of LTA with its three composite building blocks (red). Adapted from Conato et al., ref 290 with permission of The Royal Society of Chemistry. (Compare to Figure 23, section 2.3.10). The blue structure shows LTA built from eight lta (or $\alpha$-) cages.

The pioneering synthesis of LTA led to the zeolite called "Linde type A". A standard procedure is now available for this material that has a $\mathrm{Si} / \mathrm{Al}$ ratio of 1 (Table 7 , entry 1 ). Since the discovery, researchers have attempted to make LTA type materials with higher $\mathrm{Si} / \mathrm{Al}$ ratios. As reported by $\mathrm{Kerr}, \mathrm{Si} / \mathrm{Al}$ ratios near 1.5 were attained by using the TMA cation in conjunction with $\mathrm{Na}^{+}$(ZK-4 material, Table 7, entry 2). Entry 3 presents the very similar IZA-recipe for ZK-4. Later, Mobil researchers also reported zeolite alpha, with $\mathrm{Si} / \mathrm{Al}$ ratios near 3. ${ }^{291}$ The standard IZA recipe for that form of LTA differs from the original one. Essentially, the OSDA added per $\mathrm{Si}$ is much lower in the IZA-recipe for a strikingly higher Al-content, while the gels are richer in sodium (compare Entries 4 and 5 in Table 7). Kühl et al. also reported a method leading to LTA with $\mathrm{Si}$ / 
Table 7. Overview of Notable LTA-Zeolite Synthesis Conditions

\begin{tabular}{|c|c|c|c|c|c|c|c|c|c|}
\hline \multirow{2}{*}{ E } & \multirow{2}{*}{$\begin{array}{c}\text { material } \\
\text { name I } \\
\text { approach }\end{array}$} & \multirow{2}{*}{ OSDA } & \multicolumn{4}{|c|}{$\begin{array}{c}\text { synthesis mixtures } \\
\text { composition relative to } \mathrm{Si}\end{array}$} & \multirow{2}{*}{$\begin{array}{l}\mathrm{T}, \mathrm{t} \\
{ }^{\circ} \mathrm{C}, \mathrm{h}\end{array}$} & \multirow{2}{*}{$\begin{array}{l}\text { SilAl } \\
\text { prod. }\end{array}$} & \multirow{2}{*}{ ref } \\
\hline & & & Al & OSDA & $\mathrm{Na}^{+a}$ & $\mathrm{H}_{2} \mathrm{O}$ & & & \\
\hline 1 & Linde type $A$ & - & 1.03 & - & 3.29 & 66 & 99,4 & 1 & 167 \\
\hline 2 & ZK-4 & $+\overline{T M A}$ & 0.49 & 2.03 & 0.72 & 75 & 100,24 & 1.4 & 132 \\
\hline 3 & ZK-4 & TMA & 0.51 & 2.11 & 0.79 & 82 & 100,32 & 1.4 & 167 \\
\hline $4^{b}$ & zeolite alpha & TMA & 0.09 & 0.89 & 0.09 & 15 & 78,144 & 3 & 291 \\
\hline 5 & zeolite alpha & TMA & 0.20 & 0.48 & 0.21 & 12 & 90,30 & 3 & 167 \\
\hline 6 & UZM-9 & $\begin{array}{c}\text { TEA + DEDMA } \\
\text { + TMA }\end{array}$ & 0.12 & $\begin{array}{l}0.4+0.1 \\
+0.06\end{array}$ & 0.06 & 14 & 98,240 & 5.5 & 148 \\
\hline 7 & ITQ-29 ${ }^{C}$ & & $0.02^{e}$ & $\begin{array}{c}0.25+ \\
0.25\end{array}$ & $\begin{array}{l}0.5 \\
F^{-}\end{array}$ & 3 & 135,120 & 47 & 37 \\
\hline 8 & $\begin{array}{l}\text { as entry } 7 \\
\text { different seed }\end{array}$ & $\begin{array}{c}\text { TMA + } \\
\pi-\pi-\text { complex }\end{array}$ & d & $\begin{array}{c}0.25+ \\
0.25\end{array}$ & $\begin{array}{l}0.5 \\
F^{-}\end{array}$ & 4.5 & 135,168 & $\begin{array}{l}110- \\
440\end{array}$ & 294 \\
\hline 9 & $\begin{array}{l}\text { as entry } 7 \\
\text { FAU + seeds }\end{array}$ & $\begin{array}{c}\text { TMA + } \\
\pi-\pi-\text { complex }\end{array}$ & $0.02^{e}$ & $\begin{array}{c}0.25+ \\
0.25\end{array}$ & $\begin{array}{l}0.5 \\
\mathrm{~F}^{-}\end{array}$ & 2 & 135,120 & 63 & 295 \\
\hline 10 & \multirow{2}{*}{$\begin{array}{l}\text { pure Si-LTA } \\
\text { seeds }\end{array}$} & & 0.05 & $\begin{array}{l}0.05+ \\
0.45\end{array}$ & $\stackrel{0.5}{\mathrm{~F}^{-}}$ & 5 & 125,216 & 12 & 135 \\
\hline 11 & & & 0.01 & $\begin{array}{l}0.05+ \\
0.45\end{array}$ & $\begin{array}{l}0.5 \\
F^{-}\end{array}$ & 5 & 125,168 & 42 & 135 \\
\hline 12 & no seeds & $\begin{array}{c}\text { TMA + } \\
\text { DM3(4MB) }\end{array}$ & 0.02 & $\begin{array}{c}0.02+ \\
0.50\end{array}$ & $\begin{array}{c}0.49 \\
F^{-}\end{array}$ & 5 & 175,72 & 56 & 172 \\
\hline 13 & seeds & $\begin{array}{c}\text { TMA + } \\
\mathrm{DM} 3(4 \mathrm{MB})\end{array}$ & 0.13 & $\begin{array}{l}0.10+ \\
0.50\end{array}$ & $\begin{array}{c}0.49 \\
F^{-}\end{array}$ & 5 & 175,11 & 8.3 & 172 \\
\hline 14 & no seeds & & 0.01 & $0.01+0.50$ & $\begin{array}{c}0.49 \\
F^{-}\end{array}$ & 5 & 175,72 & - & 172 \\
\hline 15 & HOU-2 & - & 0.43 & - & 0.56 & 10 & 65,24 & 2.1 & 290 \\
\hline $16^{f}$ & metal/LTA & & 1.18 & 0.12 & 3.76 & 65 & 100,12 & 1 & 296 \\
\hline
\end{tabular}

${ }^{a} \mathrm{Na} / \mathrm{Si}$, unless other element is explicitly mentioned; then element/Si ratio is tabulated, e.g., $\mathrm{F} / \mathrm{Si} .{ }^{b} \mathrm{Calculated}$ from example 1 of the original patent, assuming use of pure $\mathrm{NaAl}_{2} \mathrm{O}_{3}$ where stated sodium aluminate. ${ }^{c}$ Seeded with 10 wt $\%$ pure-silica LTA. Two such OSDAs can form a $\pi-\pi$-complex; see Figure $22 .{ }^{d} 1,5$, or $10 \mathrm{wt} \%$ of LTA $(\mathrm{Si} / \mathrm{Al}=2)$ seeds added, giving $\mathrm{Si} / \mathrm{Al}$ of 110,267 , or $440 .{ }^{e} 10 \mathrm{wt} \%$ of $\mathrm{FAU}(\mathrm{Si} / \mathrm{Al}=2.5)$ added, and 5 wt $\%$ of ITQ-29 seeds. ${ }^{f_{0}} 011 \mathrm{Pt} / \mathrm{Si}$ was also added. The organic is said to lose its methyl groups by hydrolysis, associate with $3 \mathrm{Na}^{+}$cations, and complex with the metal giving $\mathrm{Pt}\left(\mathrm{Na}_{3}-\mathrm{OSDA}-\mathrm{SH}\right)_{4}$.

$\mathrm{Al}$ ratios ranging between 1 and 2.25 using (eventually intercalated) phosphates (claimed to complex Al-atoms during the synthesis). ${ }^{292}$

2.3.9.2. Toward Higher Si/Al Ratios. The Si/Al ratios of classic LTA zeolites $(<3)$ are not high enough to ensure a good performance in acid-catalyzed reactions. This is due to the low hydrothermal stability and low hydrophobicity. Given the large voids and highly open 3D structure, LTA should be an interesting catalytic sieve, if $\mathrm{Si} / \mathrm{Al}$ ratios higher than 10 are achievable.

Moscoso et al. filed a patent in 2002 for the synthesis of LTA through the CDM approach. ${ }^{293}$ The charge density mismatch approach seems to work well for small pore-zeolite synthesis, since next to LTA, ERI and UFI zeolites can been made that way (Tables 2 and 3: method E).

The first CDM paper describes how to find the right, frustrated (CDM) precrystallization mixtures. ${ }^{148}$ These mixtures stay solutions even after long times at higher temperatures, due to the charge density mismatch between the relatively high $\mathrm{Al}$-content (high charge density potential framework) and the (low charge density) CDM OSDA (ideally tetrapropylammonium or TEA, in mixtures with $\mathrm{Si} / \mathrm{Al} \leq 10$ at $\mathrm{OH} / \mathrm{Si} \geq 0.8)$. Then, by adding the right amount of TMA or $\mathrm{Na}$ (higher charge density), matching occurs and the crystallization is induced. LTA was encountered in a TEAmismatched mixture $(\mathrm{Si} / \mathrm{Al}=8, \mathrm{TEA} / \mathrm{Si}=1)$ upon adding TMA and $\mathrm{Na}$ (both 0.5 per $\mathrm{Al}$ ) and 8 days at $125{ }^{\circ} \mathrm{C}$. The conditions closely resembled that to make UZM-5 (at $150{ }^{\circ} \mathrm{C}$, 4d), the new zeolite topology discovered via CDM (UFI, Table 3). Further optimization led to a mismatch mixture containing both TEA and DEDMA (this OSDA was encountered in Table 6 as well for LEV), crystallized by adding $\mathrm{Na}$ and TMA ([Na +TMA $] / \mathrm{Al}=1$, Table 7 , entry 6). The material had a high $\mathrm{Si} /$ $\mathrm{Al}$ ratio of 5.5 (high for a $\mathrm{OH}^{-}$-media derived LTA), and all three organics were found to be incorporated. ${ }^{148}$ A detailed charge density model was recently proposed, focusing on UFI and LTA. The authors noted that the crystallization inducing cations (and heat) attack the CDM barrier, while the driving 

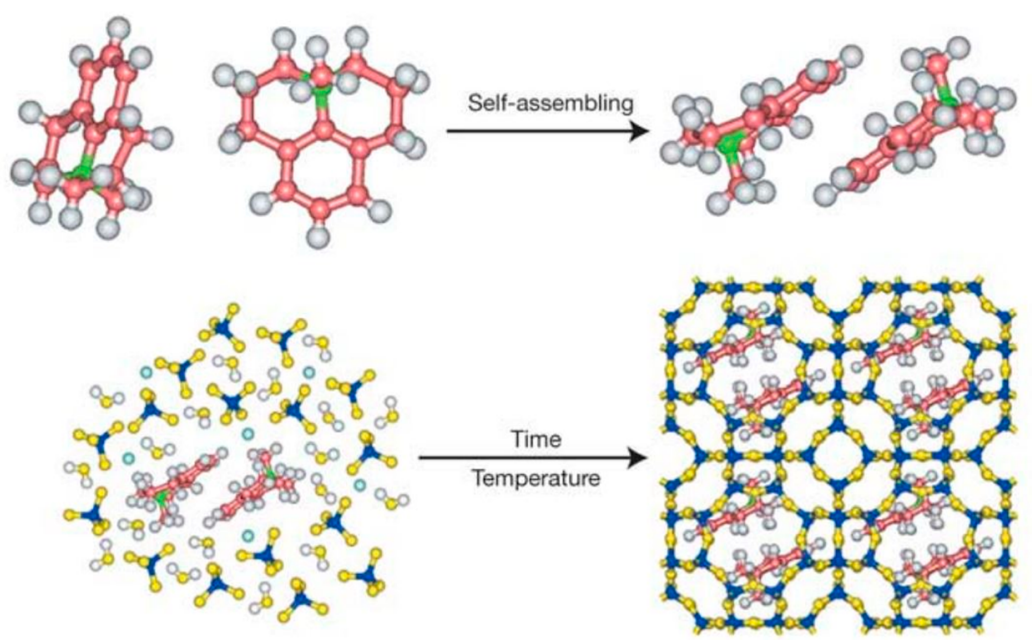

Figure 22. Formation of ITQ-29 (LTA) from the supramolecular self-assembly of 4-methyl-2,3,6,7-tetrahydro-1H,5H-pyrido [3.2.1-ij] quinolinium iodide. Atom colors: green $=\mathrm{N}$, red $=\mathrm{C}$, blue $=\mathrm{T}$ atoms, yellow $=\mathrm{O}$, white $=\mathrm{H}$. For aluminosilicate, TMA needs to be added, that presumably occupies the sod-cage in the center (not shown). Note how the lta-cages are connected in this view, compared to that in Figures 21 and 23. Reproduced with permission from ref 37. Copyright 2004 Nature Publishing Group.

force for solid formation from a frustrated mixture is the Coulombic stabilization associated with the charged zeolite framework. ${ }^{297}$ The mechanism of LTA formation via this route, in comparison to UFI, was studied in detail by Hong and coworkers, as discussed in section 2.4. ${ }^{297,298}$

A second breakthrough for LTA was presented by Corma et al. in 2004, when they prepared so-called ITQ-29, in fluoride media syntheses. Although mostly pointing to germanosilicate and pure-silicate versions of LTA, the authors also showed an aluminosilicate LTA by using TMA in conjunction with a large supramolecular OSDA complex of two identical large aromatic $\pi-\pi$-stacked cations (Figure 22). That moiety self-assembles in solution and incorporates in the large cage. ${ }^{37}$ The synthesis was heavily seeded (Table 7, entry 7) and yielded a material with a $\mathrm{Si} / \mathrm{Al}$ ratio of 47 .

Valtchev and co-workers further investigated the selfassembly approach, focusing on aluminosilicates. ${ }^{294}$ They proposed a reproducible recipe for high-silica LTA by adding nanocrystalline aluminous LTA seeds $(\mathrm{Si} / \mathrm{Al}=2$, made according to ref 299) — still containing TMA—to the fluoride media synthesis (Table 7, entry 8). The seeds dissolved, and the aluminum was incorporated into the growing crystals. Highly siliceous LTA's thus obtained could be used for new seeded synthesis ( $1 \mathrm{wt} \%$ being enough). The lowest $\mathrm{Si} / \mathrm{Al}$ ratio in this approach was 110. Very recently, Moteki and Lobo expanded this approach by using FAU crystals as Al-source in fluoride media, still with the self-assembled complex OSDAs leading to LTA zeolites with $\mathrm{Si} / \mathrm{Al}$ ratios ranging from 63 to 420 (Table 7, entry 9). ${ }^{295}$ As with the aluminous LTA seeds, it was shown that the FAU-crystals dissolved in the early stages, prior to LTA formation. It should be mentioned that germanosilicate ITQ-29 seeds were added there. This method of using FAU crystals as Al-source in low-water fluoride media gels was also demonstrated for CHA. ${ }^{295}$ Note that (i) the synthesis of aluminosilicate LTA with the self-assembling OSDAs has never succeeded without seeds (Entries 7-9); (ii) the use of Kryptofix $\mathrm{K} 222\left(\mathrm{C}_{18} \mathrm{H}_{36} \mathrm{O}_{6} \mathrm{~N}_{2}\right)$, a large crown-ether, for (germano)silicate ITQ-29 has also been reported, but not for aluminosilicate ${ }^{300}$ and; (iii) many recipes with other organics are known for other LTA sieve compositions (e.g., $\left.\mathrm{AlPO}_{4}\right)^{301,302}$
A third breakthrough in widening the $\mathrm{Si} / \mathrm{Al}$ ratios of LTA was reported by Davis and co-workers. ${ }^{135}$ The use of 1,2dimethyl-3-(4-methylbenzyl)imidazolium (DM3(4MB)) and a small amount of TMA in fluoride media offers an LTA-recipe with flexibility in the aluminum incorporation (Table 7, entries 10-11). As such, Boal et al. demonstrated seeded syntheses yielding LTA with $\mathrm{Si} / \mathrm{Al}$ ratios ranging from 12 to 42 . This almost closes the gap in the prior $\mathrm{Si} / \mathrm{Al}$ range, as up until then, no aluminosilicate LTA had been reported with ratios in the range between 5.5 (CDM method) and 47 (self-assembled OSDA). It was also possible to obtain pure-silica LTA, with either seeds or TMA added. The robustness of the method was shown by germanosilicate and titanosilicate LTA syntheses. TGA showed two OSDA molecules in the lta-cage, and this was supported by molecular modeling. A stabilization energy of $-16.9 \mathrm{~kJ}$ per mol Si, for 2 OSDAs per unit cell, was found. The energies for the supramolecular stacked OSDA were also calculated and averaged at $-13.03 \mathrm{~kJ} /(\mathrm{mol} \mathrm{Si})$. A bit later, Jo et al. reported the same OSDA for LTA synthesis (entries 1213), as well as a modified version with a fluoro group (entry 14). ${ }^{172}$ The syntheses with the same OSDA were conducted at higher temperature, and no seeds were needed for similar results as the earlier report (compare to entries 11-12). Using seeds, a material with intermediate Al-content was obtained $(\mathrm{Si} / \mathrm{Al}=8.3$, entry 13$)$.

2.3.9.3. Other LTA Syntheses. The Rimer group interestingly reinvestigated the synthesis of LTA without organic with the help of kinetic (ternary) phase diagrams, as often used in the early days of zeolite discovery. ${ }^{290}$ Remarkably, they found a region in the diagram, using classically composed mixtures of colloidal silica, $\mathrm{NaOH}$, and sodium aluminate, where LTA zeolites with $\mathrm{Si} / \mathrm{Al}$ ratios near 2 formed. The narrow region dictated a $\mathrm{Si} / \mathrm{Al}$ ratio in the mixtures between 2.3 and 4.0 and a $\mathrm{Si} / \mathrm{OH}$ ratio between 1.8 and 2.5 (e.g., Table 7, entry 15). When compared to the classic OSDA-free LTA synthesis (entry 1 ), the $\mathrm{Si} / \mathrm{Al}$ ratio of the product is doubled. When compared to the ZK-4 syntheses (entries 2-3), one can see that the conditions are not greatly different, but-while ignoring the presence of TMA and its $\mathrm{OH}^{-}$- the $\mathrm{NaOH}$-derived $\mathrm{Si} / \mathrm{OH}$ ratios are crucially lower, at 1.4 and 1.3 , respectively, for entries 2 and 3 in Table 7. The authors also noted that the size of the 
Si-precursor colloids greatly mattered, as smaller ones produced FAU and fumed silica produced amorphous materials in the same conditions. The (right type of) colloids are said to lead to the assembly of amorphous core-shell precursors with silicarich insides and alumina-rich shells. ${ }^{303}$ The authors recently investigated the role of heterogeneous aluminosilicate precursors in the sol-gel system during LTA nucleation. They put forward some interesting observations pointing to the role of core-shell particles containing entrained solvent, in a seemingly macroscopic homogeneous "gel". The particles give rise to microscopic domains with very different spatial $\mathrm{Si}$ and $\mathrm{Al}$ distributions. The degree of heterogeneity influences the nucleation via the rate of silica release into the $\mathrm{Al}$-rich environments (e.g., shell). Confinement effects, indicating that zeolite formation inside the amorphous precursor particles is energetically less favored than on the outside, were hypothesized. $^{304}$ The synthesis of nanocrystal LTA has also been reported. ${ }^{305}$

There have been a lot of developments in the direct synthesis of mesoporous zeolites (opposed to popular postsynthetic methods ${ }^{306,307}$ ), for overcoming mass-transfer limitations. Xiao et al. showed the use of mesoscale cationic polymers for this purpose, $^{308}$ while Ryoo and co-workers reported the concept by using organosilane surfactants as mesopore-generating agents (mesoporogen, also see section 2.3.3.3 for CHA) in hydrothermal zeolite synthesis. Interestingly, the cationic polymer used by Xiao is the same as that used by Rimer and co-workers as growth-modifier to control the crystal sizes of CHA-zeolites (PDDAC). LTA was included in the pioneering effort by Ryoo. ${ }^{309}$ In follow-up work focusing on LTA (classic $\mathrm{NaA}$ ), it was shown that mesopore generation happened fully disordered, for instance evidenced by generating Pt-nanowires in the mesopores and visualizing these with TEM. The openness of the mesopores was probed with ${ }^{129} \mathrm{Xe}-\mathrm{NMR}$. The additional use of triblock copolymers for mesoporeexpanding was also shown. ${ }^{310}$ Hasan et al. demonstrated the use of (nonsilane) surfactant $\mathrm{CTAB}$ to obtain mesopores in $\mathrm{NaA}$ (again, also used in the CHA growth-modifier study). ${ }^{311} \mathrm{~A}$ different approach to LTA mesoporosity was shown by the Tsapatsis team, hydrothermally growing LTA zeolite inside 3Dordered carbon templates with imprinted mesopores. ${ }^{312}$ Another entry in the literature expanded the concept of using organofunctionalized silica precursors (or seeds) (1) $^{313}$ to obtain an ordered mesoporous LTA. ${ }^{314}$ Even the synthesis of hollow core-shell LTA zeolite crystals has been reported. ${ }^{315}$ The reader is referred to recent reviews ${ }^{316-318}$ on the topic of synthesizing hierarchical zeolites, a large and active field, with many entries for LTA.

Finally, an interesting synthesis of LTA was reported by Iglesia and co-workers, who showed a strategy to encapsulate metal particles in the zeolite during their hydrothermal synthesis. The added metal precursor was stabilized by mercaptosilane ligands, preventing metal (hydr)oxide precipitation. Meanwhile, it was suggested that the trialkoxysilane side of the organic, thought to be balanced by $3 \mathrm{Na}^{+}$cations after hydrolysis, promoted $\mathrm{T}$ atom condensation. ${ }^{296}$ The precursor to the encapsulated metal-sulfur complex is seen in Table 7 (entry 16) along with the gel composition, that shows a quite high Al-content. The authors focused on the properties of the encapsulated metal particles in the zeolite, but not on the synthesis. The amount of organic incorporated per unit cell from TGA would for instance be a good measure to see the degree of complex incorporated and to verify if it has a structure-directing role rather than being encapsulated during a classic zeolite A synthesis. The cluster sizes also indicate that the migration of metal atoms had to have occurred, if the metal-sulfur complexes were encapsulated in a 1 per cage fashion, as schematized in the work. ${ }^{296}$ The authors further explored this context, replacing mercaptosilanes with amines. ${ }^{319}$ For instance, LTA synthesis was shown by adding $\mathrm{NH}_{3}$ complexed $\mathrm{Pt}$ or ethylenediamine-complexed $\mathrm{Pd}$ to an aging gel. At this point, these results are in line with the pioneering work of Davis and co-workers in the 1980s that effectively demonstrated Rh- and Ru-containing LTA zeolites. ${ }^{320-322}$ Even earlier, the need for metal precursors to be present during zeolite crystallization was recognized, e.g. in FAU zeolite synthesis. $^{323}$

\subsubsection{LTA-Zeolite Conclusions.}

(1) LTA is a valuable topology, and its high-alumina zeolite members are commercially available and implemented at a large scale.

(2) So far, hydroxide media syntheses have not produced LTA with $\mathrm{Si} / \mathrm{Al}$ ratios above 5.5. The latter was obtained by a clever tuning of the charge densities (cation addition sequence) to obtain cooperative OSDA behavior (CDM). The mechanism of this synthesis is discussed later (part 2.4).

(3) TMA is an important organic for LTA: it is the main OSDA for ZK-4 and zeolite alpha, but it is also added in the CDM method, as well as in the fluoride routes accompanying more complex OSDAs. TMA is known to stabilize sod-cages.

(4) LTA can be built entirely from d4r-units. It has been noted that pure-silica $4 \mathrm{MRs}$ in $\mathrm{d} 4 \mathrm{r}$ units are traditionally hard to obtain due to reasons of strain $(\mathrm{Si}-\mathrm{O}-\mathrm{Si}<\mathrm{Si}-$ $\mathrm{O}-\mathrm{Al}$ ). It can thus be hypothesized that every $4 \mathrm{MR}$ needs at least one $\mathrm{Al}$-atom to be energetically more stable and thus form more readily (than pure-silica $4 \mathrm{MR})$. This dictates a minimum of 2 aluminums per $\mathrm{d} 4 \mathrm{r}$ (per $8 \mathrm{~T}$ atoms) to obtain the minimal strain relief for every $4 \mathrm{MR}$ of the cube. Knowing that LTA can be built from only $\mathrm{d} 4 \mathrm{r}$ units and that this unit is the most demanding one from a structural point of view, this implies that the $\mathrm{Si} / \mathrm{Al}$ ratio to just minimally relieve strain is at most 3. Maximal strain relief would entail the incorporation of $2 \mathrm{Al}$ atoms per $4 \mathrm{MR}$, as is the case in Linde type $\mathrm{A}(\mathrm{Si} / \mathrm{Al}=1)$ material. The highest reported value of $\mathrm{Si} / \mathrm{Al}$ that one can attain in $\mathrm{OH}^{-}$media without organics is 2 , lending credibility to this structure/charge/ strain perspective. The relation between $\mathrm{d} 4 \mathrm{r}$ strain and (in)organic charge balancing in more siliceous CDMzeolites should be informative for future syntheses in $\mathrm{OH}^{-}$-media.

(5) The new organic proposed by the Davis group gives access to LTA zeolites with $\mathrm{Si} / \mathrm{Al}$ ratios of 8.3 to infinity, but only in $\mathrm{F}^{-}$-media. The success is due to the stabilization of the large lta-cage by two OSDAs, in combination with the fluoride ion incorporating in the $\mathrm{d} 4 \mathrm{r}$, aiding in its stabilization. ${ }^{135}$ It has been concluded that the $\mathrm{d} 4 \mathrm{r}$ units are virtually impossible to make in pure-silica composition in the absence of $\mathrm{F}^{-}$-ions. ${ }^{203,324}$ The need for seeds and some TMA still reflects the challenging nature of constructing LTA with less aluminum, even in fluoride media. 
(6) It is interesting that no IZC conversions have been reported with LTA as the product. This is even more remarkable considering that the common FAU source can be entirely constructed from sod-cages. That no FAU-to-LTA IZC has been noted could be an argument in favor of the (partial) d6r (6MR) nanopart hypotheses in other reported FAU IZC syntheses (to AEI, CHA, $\mathrm{LEV}, \ldots .$.$) .$

2.3.10. RHO and Its New Family (PAU, MWF). Zeolite Rho was discovered by Robson et al. and reported in 1973. ${ }^{325}$ This zeolite contains the large lta (or $\alpha$ )-cages (Figure 7), and these cages are connected by the $8 \mathrm{MR}$ portals to form $\mathrm{d} 8 \mathrm{r}$ units and by sharing a $6 \mathrm{MR}$. The structure, built from the lta and $\mathrm{d} 8 \mathrm{r}$ tiles, was predicted by Meier and Kokotailo while figuring out the structure of KFI (ZK-5). ${ }^{127}$ Figure 23 (and Figure 24 below) shows the connection mode of the lta-cages in RHO, along with that for zeolites LTA and KFI.

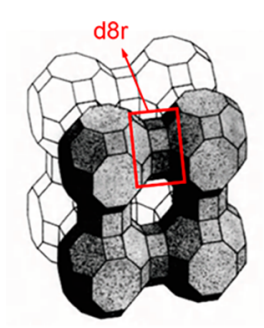

RHO

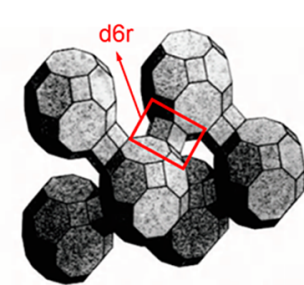

KFI

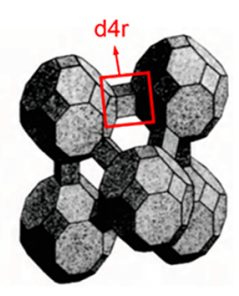

LTA
Figure 23. Connection mode of the lta-cages in the RHO, KFI and LTA structures. Adapted from ref 127. The lta-cages in LTA also connect via sharing 8MRs (not shown, see e.g., Figure 22).

Rho was discovered by replacing part of the $\mathrm{NaOH}$ in a typical LTA synthesis with $\mathrm{CsOH}$, at about $0.12 \mathrm{Cs}^{+}$/ $\left(\mathrm{Cs}^{+}+\mathrm{Na}^{+}\right)$. This ratio needs to be somewhat precise as trace $\mathrm{Cs}^{+}$leads to FAU contaminations, and too much $\mathrm{Cs}^{+}$to $\mathrm{CHA}$. The $\mathrm{Cs}^{+}$is believed to direct the formation of the $\mathrm{d} 8 \mathrm{r}$ units and thus the linking mode of the $\alpha$-cages. The classic Rho recipes lead to $\mathrm{Si} / \mathrm{Al}$ ratios near $2.9 .^{59,267}$ This recipe was recently confirmed as a starting point $(\mathrm{Si} / \mathrm{Al}=2.8)$ for a steaming study. ${ }^{267}$ Burkett and Davis were the first to try 18 -crown-6 ether (and 15-crown-5) in gels with $\mathrm{Cs}^{+}$present and the $\mathrm{Si} / \mathrm{Al}$ ratio at $5 .{ }^{326}$ They noticed RHO formation and a small incorporation of the ether from weight analysis. Chatelain and co-workers systematically investigated this synthesis and noted excellent RHO formation in the presence of the ether, obtaining $\mathrm{Si} / \mathrm{Al}$ ratios of around 4 (instead of $<3$ without) in gels with $0.36 \mathrm{Na} / \mathrm{Si}, 0.06 \mathrm{Cs} / \mathrm{Si}$, and $\mathrm{Si} / \mathrm{Al} 5$ at $110^{\circ} \mathrm{C} .{ }^{327}$ The ether is occluded in about half of the lta-cages of RHO (two cages per unit cell). A perspective summarizes the use of macrocycles (oxa-, oxa-aza-, as well as pure aza- (N-containing) macrocycles) in the synthesis of microporous materials. ${ }^{328}$ From an application point-of-view, it is interesting to note that OSDA-free Rho is known to be flexible and undergoes phasechanges with temperature, owing to the deformation of the $8 \mathrm{MR}$ windows, which diminishes the sorption capacity. The crown-ether-RHO had an increased sorption capacity, and no structural changes were noted. Typically, protonated Rho shrinks upon heating, and a gradual decrease of the unit cell's aparameter was recorded while heating from 30 to $250{ }^{\circ} \mathrm{C}$. The different behavior of the crown-ether RHO zeolite seems a direct consequence of the lower Al content. Recently, a new synthesis for RHO was presented by Liu et al. using the PDDAC cationic polymer, remarkably, in the absence of $\mathrm{Cs}^{+} .329$ The polymer, already encountered here as growth-modifier for CHA (Figure 13) and mesoporogen for LTA, led to zeolite Rho, but with the classic Si/Al ratios of $2.8 .^{329}$

In 2017, $\mathrm{Ke}$ et al. reported a breakthrough synthesis for RHO-zeolites, as $\mathrm{Si} / \mathrm{Al}$ ratios up to 8 were achieved. ${ }^{330}$ The synthesis strategy consists of using a presynthesized complex made from a mixture with well-balanced $\mathrm{Na}^{+}, \mathrm{Cs}^{+}$, and 18crown-6 ether ratios. This complex is said to be a supramolecular sandwich, where two ethers interact with one $\mathrm{Cs}^{+}$. The complex is hypothesized to stabilize the large $\alpha$-cage of RHO during synthesis, and this was corroborated by TGA analysis, from which 2 ethers per cage were calculated. It is interesting to compare the Cs/ether ratios of this approach, around 0.45 , to those in the work of Chatelain et al. where a value of 1.2 , thus in excess of $\mathrm{Cs}^{+}$, is used. Clearly, this is crucial in the formation of the complex and the structure direction. $\mathrm{Ke}$ et al. also performed SCR with the new high-silica RHO zeolites (section 3.2).

In 2015, the Hong, Zou, and Wright groups reported on a complex family of related zeolites with embedded isoreticular structures and expanding unit cells, based on RHO, and in a further expansion PAU. ${ }^{51}$ While elucidating the structure of zeolite ZSM-25, patented back in 1981, they noticed the structural similarity of its strong reflections to those of PAU (Table 1) and RHO. ZSM-25, now framework code MWF, is an $1 \times$ expanded version of PAU, constructed from the same 7 tiles (colored tiles, see Figure 24), but with its a-parameter of the unit cell expanded by $10 \AA$. PAU itself is a doubly expanded version of $\mathrm{RHO}$ and the $1 \times$ expansion of a (so far notsynthesized) theoretical member of the family (RHO-G2, already predicted by Vaughan et al. in $\left.1999^{54}\right)$. The first synthetic PAU, named ECR-18, was reported by Vaughan as well. PAU is a very intriguing structure, and it has a very high

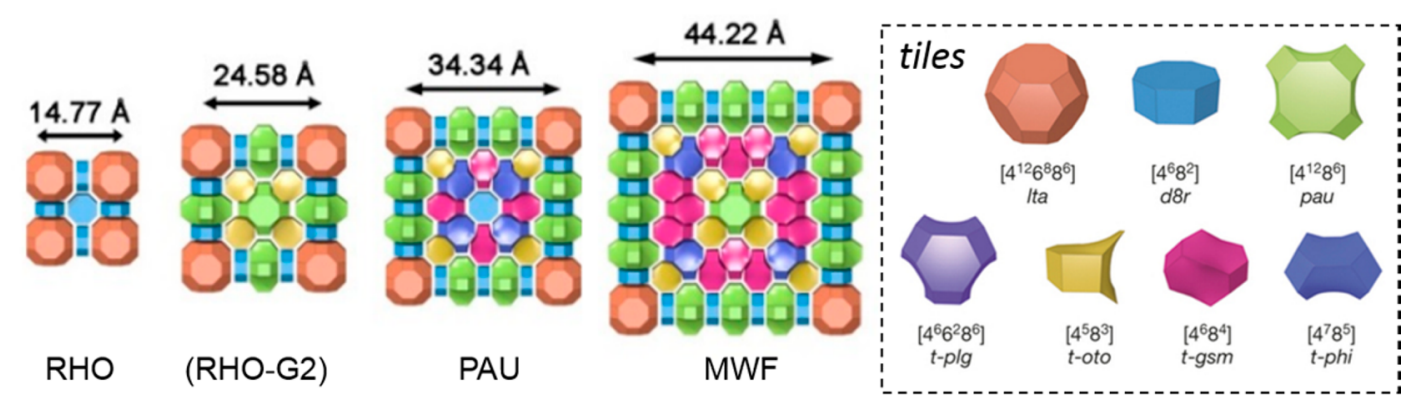

Figure 24. Four first members of the RHO family and the tiles to construct them. Figure adapted with permission, from ref 51 . Copyright 2015 , Nature Publishing group. 
free volume of almost 50\%. This derives from the fact that there are no smaller inaccessible cages (such as e.g., d6r) in the structure. The introduction of TEA $(0.29 / \mathrm{Si})$ in the $\mathrm{K}^{+} / \mathrm{Na}^{+}$gel with $\mathrm{Si} / \mathrm{Al}=4.5$ is essential, and the crystallization field is narrow. The product, having $\mathrm{Si} / \mathrm{Al}$ of 3.6 , shows interesting thermogravimetric analysis, as a distinction could be made between TEA degrading from pau-cages (also note pau-cages in KFI, Figure 19) and TEA from $\alpha$-cages. The distinction was based on profiles of TEA-Rho and TEA-MER (merloinite), another $8 \mathrm{MR}$ zeolite built from pau-cages and $\mathrm{d} 8 \mathrm{r}^{54}$ In an interesting side note, Camblor and co-workers reported a recipe for synthetic MER with increased $\mathrm{Si} / \mathrm{Al}$ ratios (from 2 up to $3.8)$, by adding TEA to the $\mathrm{K}^{+}$-rich $(\mathrm{Si} / \mathrm{Al}=5)$ gels (the principle Barrer and Denny first put forward $\left.{ }^{131}\right){ }^{465}$

Guo et al. clearly represented the expansion relation between RHO, PAU, and MWF (Figure 24), and based on this, they calculated even more complex members, PST-20 and PST-25 (not shown). The classic recipes for synthetic PAU and MWF both use a combination of TEA and $\mathrm{Na}^{+}$, while additionally $\mathrm{K}^{+}$ is used for PAU. Based on the increasing numbers of $t$-oto, $t$ $g s m$, and $t$-phi cages in the expanding series (Figure 24) and the fact that these cages are found in certain zeolites made with bivalent cations, the authors added alkaline earth cations to the mix. With $\mathrm{Sr}^{2+}$, a more complex member of the series was synthesized (PST-20, not shown). ${ }^{51}$ Although rationalizing the needs of the different (secondary building units) cages/tiles in the structure in terms of stabilizing cations can thus be rewarding, one may not underestimate the role of trial and error in synthetic experimentation. The synthesis mechanism of PAU, MWF, and PST-20, in this isoreticular expansion series, was recently investigated. This leads to a hypothesis where nucleation starts with the construction of lta-cages and plg-tiles, that connect via shared $8 \mathrm{MRs}$ along the diagonals of the cubic unit cell. This is then followed by the stepwise construction of the remaining tiles in Figure 24 (right), with the exception of pau and $d 8 r$, which form in the end, along the edges of the cubic cell. ${ }^{331}$

In conclusion, given the interest in high-silica $\mathrm{RHO}$ from a catalysis point-of-view (section 3.2, i.e., methylamine synthesis, $\mathrm{SCR}^{330} \mathrm{MTO}^{267}$ ), its synthesis should be revisited, in the search for zeolites with $\mathrm{Si} / \mathrm{Al}$ ratios in excess of 8 . Although this upper barrier has only recently been moved, further progress, e.g., along the lines of stabilizing the lta-cage in high-silica LTA materials, seems plausible, especially considering the absence of $d 4 r$ units in the structure.

2.3.11. RTH. The RTH framework was discovered as a borosilicate (RUB-13) by Gies and co-workers using polymethylated piperidine and ethylenediamine. Lee and Zones reported a complex OSDA that directed the synthesis toward aluminosilicate RTH zeolites in a range of gels with large $\mathrm{Si} / \mathrm{Al}$ variation (15 to pure-silica). The organic cation $\mathrm{N}$ ethyl-N-methyl-5,7,7-trimethylazoniumbicyclo-[4.1.1] octane (Figure 25, left) showed a high specificity for RTH, and subtle changes to the substitutions on the ring altered the product selectivity. The resulting $\mathrm{Si} / \mathrm{Al}$ ratios of the materials, named SSZ-50, were not divulged but likely evolved in trend with the gels. $^{62}$ Tatsumi and co-workers later reported an organic-free method for zeolitic RTH, by seeding deboronated RUB-13 and carefully tuning water and $\mathrm{NaOH}$ content. ${ }^{121,332}$ This route is quite unique in the fact that high-silica materials were obtained $(\mathrm{Si} / \mathrm{Al}=37-57)$, an uncommon result for this kind of organicfree, seeding synthesis (e.g., see 12MR BEA literature).
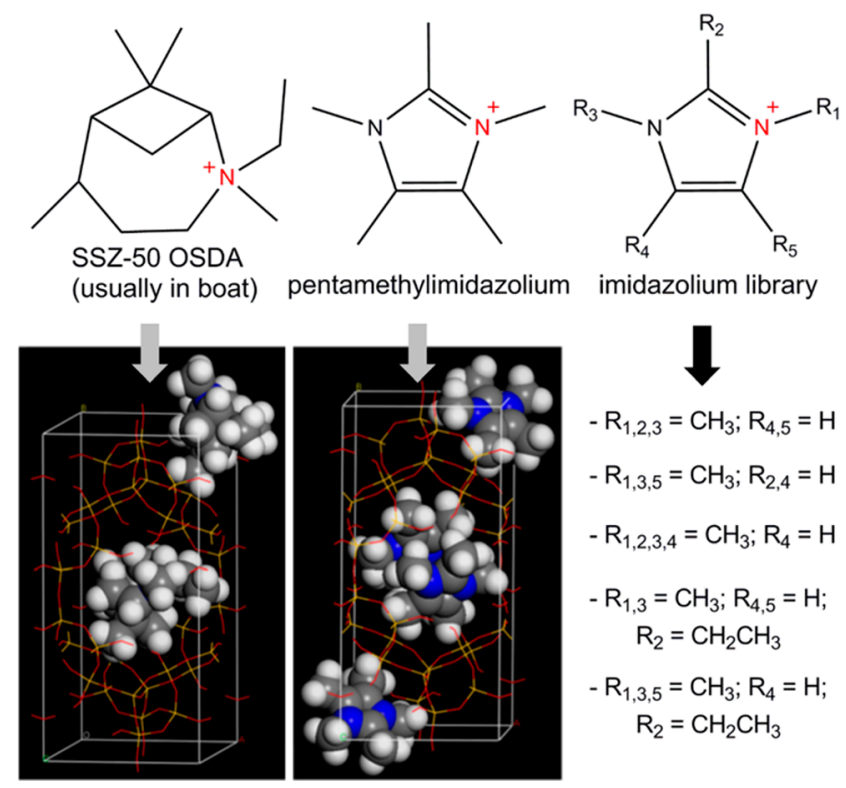

- $\mathrm{R}_{1,2,3}=\mathrm{CH}_{3} ; \mathrm{R}_{4,5}=\mathrm{H}$

$-\mathrm{R}_{1,3,5}=\mathrm{CH}_{3} ; \mathrm{R}_{2,4}=\mathrm{H}$

$-\mathrm{R}_{1,2,3,4}=\mathrm{CH}_{3} ; \mathrm{R}_{4}=\mathrm{H}$

$-\mathrm{R}_{1,3}=\mathrm{CH}_{3} ; \mathrm{R}_{4,5}=\mathrm{H}$;

$\mathrm{R}_{2}=\mathrm{CH}_{2} \mathrm{CH}_{3}$

$-\mathrm{R}_{1,3,5}=\mathrm{CH}_{3} ; \mathrm{R}_{4}=\mathrm{H}$;

$\mathrm{R}_{2}=\mathrm{CH}_{2} \mathrm{CH}_{3}$

Figure 25. Reported OSDAs for RTH zeolites. Molecular modeling data adapted from ref 136 . The right modeling result involves 2 OSDAs per cage.

Schmidt et al. recently reported a new OSDA-route for RTH, in both hydroxide and fluoride media in 2014 (method $\mathrm{C}$ and F, Table 3). ${ }^{169}$ The relatively simple OSDA is pentamethylimidazolium (Figure 25), known previously to lead to pure-silica STW in fluoride media. ${ }^{333}$ The organic leads to RTH materials with $\mathrm{Si} / \mathrm{Al}$ ratios varying between 6 and 59 in hydroxide gels and 7-27 in fluoride media. Quite uncommonly, the most siliceous materials were obtained in hydroxide media. In a further expansion of the work, Schmidt reported a range of imidazolium cations (Figure 25) that also lead to RTH. ${ }^{136}$ Although no widening of the $\mathrm{Si} / \mathrm{Al}$ range with this library was reported, some synthesis recipes were interesting, as they use an ultrastable Y (USY) zeolite as the only source of T atoms (a FAU IZC). A FAU zeolite with a $\mathrm{Si} / \mathrm{Al}$ ratio of 15 led to different $\mathrm{RTH}$-zeolites $(\mathrm{Si} / \mathrm{Al}=9-14)$ in the presence or absence of seeds, with some of the imidazoliums, and exclusively either with or without seeding for others. The library of cations could be useful, as some of these are certainly cheaper to produce than others. From a synthesis point of view, the pentamethylated one proved the most versatile in terms of inorganic conditions. This was also confirmed by calculating and comparing the interaction energies of the organics with RTH (based on 4 OSDAs per unit cell, or two per cage): the pentamethylimidazolium attained the most favorable, lowest value of $-20 \mathrm{~kJ} \mathrm{~mol}_{\mathrm{T} \text { atom }}{ }^{-1}$. This compared positively to the original SSZ-50 OSDA, that attained values of only $-11 \mathrm{~kJ}$ $\mathrm{mol}_{\mathrm{T} \text { atom }}{ }^{-1}$. Figure 25 shows the modeled positions of both OSDAs in the cage of RTH (cage also seen in Figure 7).

Very recently, Jo et al. also reported on the use of the 1,2,3trimethylimidazolium OSDA for RTH synthesis (included in Figure 25), in somewhat different conditions and in the context of $\mathrm{deNO}_{x}$ and $\mathrm{CO}_{2}$ sorption. ${ }^{324}$ The material only formed in gels with $\mathrm{Si} / \mathrm{Al}$ ratio of 10 (or somewhat lower) and, in contrast to the Schmidt data, did not form when seeds were added to higher silica syntheses. This difference could derive from the use of different sources, as Schmidt used mesoporous FAU zeolites at higher $\mathrm{Si} / \mathrm{Al}$ ratios. ${ }^{136}$ The authors also presented evidence in favor of 2 OSDAs per cage, and they even 
investigated the arrangement of the cations through Rietveld refinement. It was concluded that the rings of both ions reside in the cage parallel to each other, with the three methyl groups pointing to opposite directions of the parallel axis. ${ }^{324}$ It should be noted however that the pentamethylated version (Figure 25) also easily incorporates (likely) in a pair, not to say there can be no favored arrangement when two trimethylated imidazoliums are present.

Finally, the Davis group reported an unexpected discovery, when Schmidt et al. noticed a layered precursor during a puresilica attempt at HEU synthesis in fluoride media using a diquaternary OSDA (Figure 26). ${ }^{334}$ They discovered the pure-

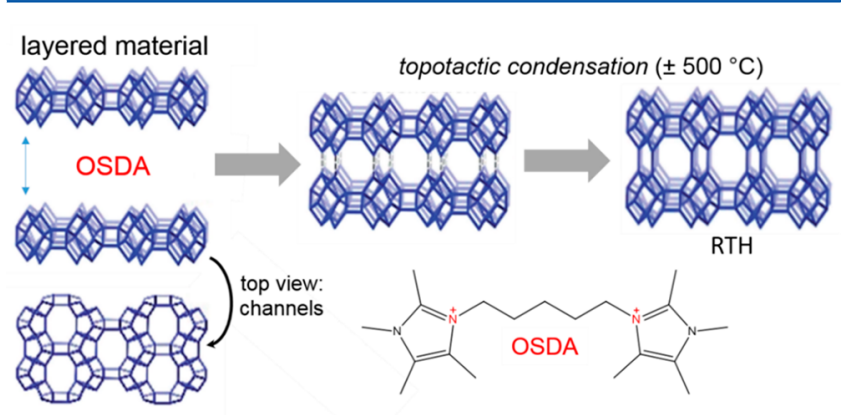

Figure 26. Topotactic conversion of the RTH layer to pure silica RTH. Based on work of Schmidt et al. ${ }^{174}$

silica RTH-layer: the first 2D-layer with small pores (8MR) perpendicular to the surface of the layer (Figure 26). The layers are only half a unit cell thick, and since the $8 \mathrm{MR}$ pore-system is already present before topotactic condensation, the layered material could be interesting on its own for application. The distance between the layers is $11.8 \AA$, similar to the RUB-36 materials (Figures 6 and 26).

The synthesis of RTH is a case worth studying, not only because of its interesting features for application (unique cage), but especially because it is a zeolite with a wide compositional flexibility in terms of $\mathrm{Al}$-incorporation, perhaps related to its $5 \mathrm{MRs}$. The fact that it can be made with $\mathrm{Si} / \mathrm{Al}$ ratios in the sub10 range as well as in pure-silica form is encouraging. ${ }^{169}$ This indicates that there might be opportunities for new zeolite formation in gels with $\mathrm{Si} / \mathrm{Al}$ ratios between 5 and 30, given that the structural influence of $\mathrm{Al}$-cations is diminished in that range relative to the low silica-gels (that easily favor e.g., LTA, RHO, KFI). Moreover, since the unveiling of the easy pentamethylimidazolium route to RTH and the unique RTH-layer, the opportunities to tailor RTH to application, with heteroatoms for example, are ample. ${ }^{174}$

\subsection{Summary Points of Zeolite Synthesis and Its Mechanisms}

From the survey of $8 \mathrm{MR}$ syntheses presented, there are a number of points that merit discussion:

(1) It is remarkable that certain zeolites have not yet been synthesized over a wider range of $\mathrm{Si} / \mathrm{Al}$ ratios (cf. ranges in Table 3), particularly given their interesting cage structure for applications, e.g., MTO (section 3.4). Especially high $\mathrm{Si} / \mathrm{Al}$ ratios seem to be elusive for a lot of $8 \mathrm{MR}$ zeolites (e.g., $>8$ for RHO, $>5$ for KFI), although the four pure-silica sieves from Table 1 have not yet been reported with aluminum either. Obviously, there are multiple explanations for this observation including the argument that not enough trials were conducted or no suitable OSDA has been identified. Another main reason is probably due to a structure-induced lower limit to $\mathrm{Al}$ incorporation (i.e., a maximum $\mathrm{Si} / \mathrm{Al}$ ), dictated by strain

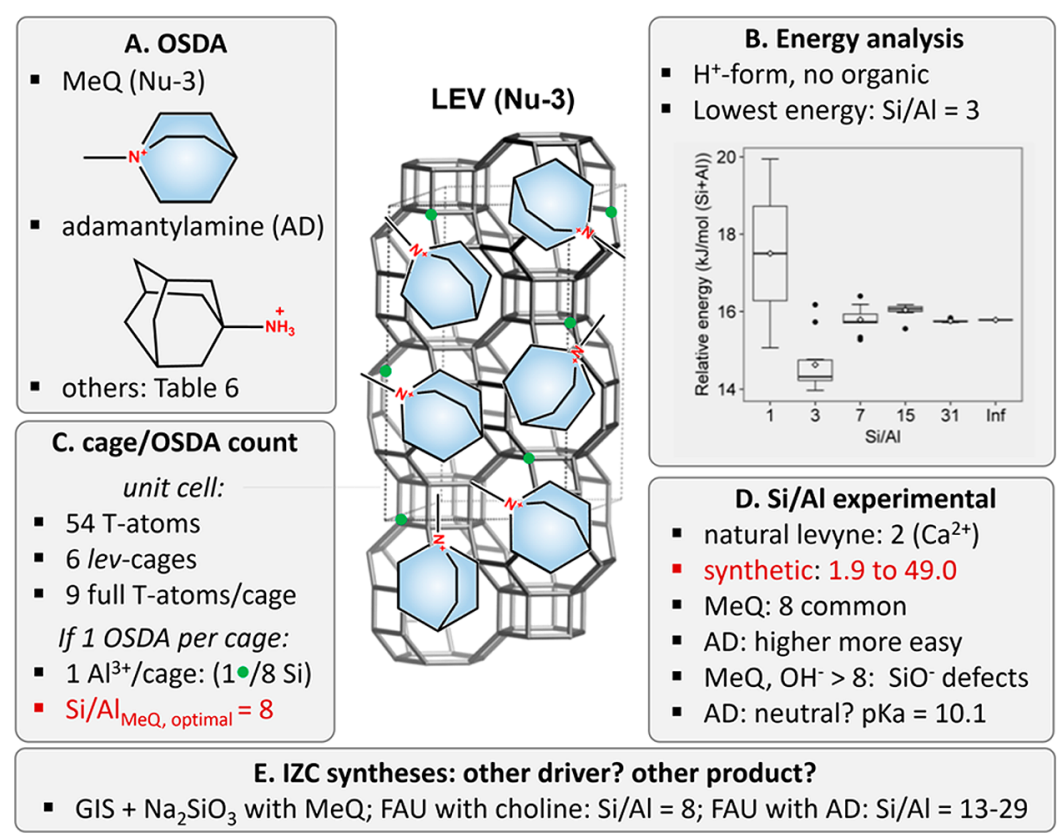

Figure 27. Summary of synthesis considerations for cage-containing small-pore zeolites in terms of product $\mathrm{Si} / \mathrm{Al}$ ratios, illustrated here for LEV, tentatively shown here defect-free with $\mathrm{MeQ}$ incorporated in each of its cages and $\mathrm{Al}$ represented by a green dot. (A) OSDAs are always crucial to attaining high $\mathrm{Si} / \mathrm{Al}$ ratios. (B) Energy analysis for LEV: the bold bar inside the box indicates the median, while the diamond indicates the mean. Plot reproduced with permission from ref 335 . Copyright 2016, American Chemical Society. (C) Calculation of optimal Si/Al for a given zeolite in $\mathrm{OH}^{-}$media synthesis with quaternary ammoniums based on the number of OSDAs per cage (TGA, elemental analysis), $\mathrm{T}$ atoms per cage, and cages per unit cell. (D) Some experimental Si/Al ratios for LEV. (E) Role of IZC to LEV and its $\mathrm{Si} / \mathrm{Al}$ ratios. 
in small cages, composite building blocks, or simply $4 \mathrm{MR}, 5 \mathrm{MR}$, and 6MRs. The role of $\mathrm{d} 4 \mathrm{r}$ in LTA synthesis is a good example (see 2.3.9.4). It is very likely that on top of structure-direction by alkali and cage-stabilization effects, this strain, and similar structure-related effects, have a real contribution in the overall thermodynamics or kinetics of phase-formation.

In this context, the computational energy analysis of aluminosilicate zeolites across a wide range of frameworks and $\mathrm{Si} / \mathrm{Al}$ ratios, by Okubo and co-workers, is highly relevant. ${ }^{335}$ First, the work found similar linear relationships between framework energies and their $\mathrm{T}$ atom density, compared to previous pure-silica computation. More interesting in this context was the comparison of relative framework energies of different $\mathrm{Si} / \mathrm{Al}$ ratios $(1,3,7,15,31, \infty)$ within one zeolite topology (as well as 10 different Al-distributions, i.e. where does $\mathrm{Al}$ sit, for $\mathrm{Si} / \mathrm{Al} \mathrm{3,} \mathrm{7,} 15$ and 31). The data set suggests that the relative thermodynamic stability and the existence of preferential Al-sites rely not only on topology but also on composition (Al-content). For a given framework, an energetically favorable $\mathrm{Si} / \mathrm{Al}$ ratio, e.g., 3 for LEV (see Figure 27B), is calculated. Note that these calculations assume proton countercations, rendering it more likely that these energy differences arise intrinsically from the structure. Other examples include MFI, where $\mathrm{Si} / \mathrm{Al}=31$ and pure-silica were most favorable, while for $\mathrm{FAU}, \mathrm{Si} / \mathrm{Al}=3$ was lowest in energy. For $8 \mathrm{MR}$ zeolites CHA, KFI, LTA, RHO, and RTH minima (the means) were found at $\mathrm{Si} / \mathrm{Al}=1,31,3,1$, and 31, respectively. Comparing $\mathrm{CHA}$ and KFI, both can be exclusively built from d6r units, revealing that the energy analysis is very different. LTA, RHO, and KFI, all containing $\alpha$-cages, also differ substantially. The Aldeficient optimum for RTH can be rationalized from its 5MR-content, as such zeolites are often more siliceous and the lowest $\mathrm{Si} / \mathrm{Al}$ for $\mathrm{RTH}$ found synthetically is indeed 6. It is difficult to link the analysis for KFI to synthesis results, as the highest $\mathrm{Si} / \mathrm{Al}$ ratio accessible is around 4. The use of OSDAs and/or small alkali cations that direct zeolite formation in real syntheses, where metastable intermediates or end-products are often kinetically controlled, renders comparison of synthesis outcomes to the calculations with $\mathrm{H}^{+}$countercations difficult. However, the data can suggest an equilibrium zeolite product and provide some energetic clues into a zeolite's formation with certain Al-content. Of course, for those topologies for which they exist, the Al-content of natural minerals could be used in the same manner, i.e. thermodynamic minima in the presence of inorganic cations and time. Synthetic zeolites with high content of OSDA, such as SSZ-13, and most cage-containing smallpore zeolites are stabilized differently.

(2) It is clear that the synthesis of most, if not all, catalysisrelevant $8 \mathrm{MR}$ zeolites proceeds through the use of an OSDA to access higher $\mathrm{Si} / \mathrm{Al}$ ratios, e.g., Figure 27A in $\mathrm{OH}^{-}$media for LEV (Method C in Table 2). Properties of good OSDAs have been documented. ${ }^{336,337}$ The $\mathrm{Si} / \mathrm{Al}$ ratio via geomimicking and alkali-cation approaches in hydroxide media is always limited (method A, B). OSDAs are also crucial in the CDM approach, in Fmedia (method E, F), as well as in all relevant IZC syntheses (i.e., not highly alkaline IZC, method D). The rare cases where OSDA-free syntheses lead to products with intermediate $\mathrm{Si} / \mathrm{Al}$ ratios (e.g., 5-10) always rely on large additions of seeds made via OSDA-routes.

It is obvious that the synthesis of a zeolite with an OSDA relies on the space-filling interaction between the organic and the framework, which translates to fitting in the cage for most small-pore zeolites (Figure 7). Furthermore, the OSDAs for $8 \mathrm{MR}$ zeolites are mostly charged (quaternary ammonium, phosphonium), with the exception of a couple of $\mathrm{pH}$-dependent amines, and this positive charge needs to be balanced, during synthesis, either with framework charge based on isomorphic Al-substitution or a siloxy-defect, or a free $\mathrm{F}^{-}$-anion. The $\mathrm{Si} / \mathrm{Al}$ range of the product is thus influenced by the OSDA in two ways: (i) the OSDA/ framework energy and (ii) the overall charge balance that needs to be neutral. The first, experimentally, shows that OSDAs with a really good space-fit (often confirmed from pure-silica molecular modeling) allow for a broad range of $\mathrm{Si} / \mathrm{Al}$ products within one topology. Two examples here are ADAM for $\mathrm{CHA}$ and pentamethylimidazolium for RTH (two per cage); the latter e.g. allows for $\mathrm{Si} / \mathrm{Al}=6-59$ products in hydroxide media. Whether or not these molecules are true templates is up to the reader, ${ }^{338}$ but bear in mind that ADAM can also lead to AFI and STT, e.g. when inorganic conditions change or overrule the organic stabilization. Generally, excellent fits between OSDAs and cages can be identified if the organic can direct to a given topology in both $\mathrm{OH}^{-}$ and $\mathrm{F}^{-}$-media. The charge balance (ii) entails that if a charged OSDA is occluded in a cage, in $\mathrm{OH}^{-}$-media, at least one aluminum should result in the unit cell, per (organic-capable) cage. Lower Al-incorporation should not be possible unless silicon based defects are built-in, while lower $\mathrm{Si} / \mathrm{Al}$ ratios are possible only when other smaller cations (TMA or $\mathrm{Na}^{+}$) are coincorporated.

(3) Based on charge balancing and counting the atoms surrounding a cage, it should be possible to predict an ideal (maximum) $\mathrm{Si} / \mathrm{Al}$ ratio for which no siloxy defects are needed, for every cage-based zeolite-framework made in hydroxide media and with organic cations occluded in the cages. This defect-free ratio has been calculated for CHA, AEI, and LEV above and is illustrated in Figure $27 \mathrm{C}$ for LEV. To what extent the formation of a zeolite and more specifically its Al-content is influenced by the absence or presence of defects in a given OSDA/zeolite/ $\mathrm{Si} / \mathrm{Al}$ system remains unknown. The effect could be both thermodynamically, e.g., certain defects produce less or more strain on the lattice, or kinetically driven; that is, their rate of formation could be different as for example defect-sites require less condensation reactions, or it could be driven by both. It is interesting to note that certain zeolites have ordered defects, e.g., pure silica ITQ-39 (-ITN). ${ }^{339}$

(4) The prior analysis, predicting an optimal $\mathrm{Si} / \mathrm{Al}$ in the absence of smaller cations and defects, and the properties of an excellent OSDA, able to lead to high $\mathrm{Si} / \mathrm{Al}$ ratios, imply that syntheses direction by a well-fitting organic overrule constraints by defect formation. OSDAs that fit less well, e.g. $N, N, 3,5$-tetramethylpiperidinium for AEI (Figure 9) or MeQ for LEV (Figure 27), do not allow free choice of the $\mathrm{Al}$-content in the product. Strikingly, 
the $\mathrm{Si} / \mathrm{Al}$ ratios of different syntheses along these lines end up near the one predicted from cage-counts (e.g., Table 4, Table 6). This infers that defect formation in the synthesis of cage-containing zeolites with organics is indeed further away from the equilibrium. In these kinds of synthesis, the inorganic constituents and external conditions play a larger role, such as for instance the starting inorganic $\mathrm{T}$ atom sources, temperature, and agitation. Interzeolite conversion and the CDM approach (Table 2, method D, E), often leading to new recipes for existing zeolites with organics that do not perfectly fit a given cage, fortify this point. Examples of IZC in this case are the use of TEA for CHA, choline for LEV, and most AEI syntheses, while CDM examples include LTA and ERI. Effectively, this means that it can still be rewarding to explore common or reported OSDAs in unusual conditions. Unusual here could be related to the content and stoichiometry of the recipe, e.g., two cations cooperating (CDM); the source of $\mathrm{T}$ atoms (e.g., zeolite), or the external conditions (flow, ....). ${ }^{210}$ Exemplary here is the discovery of $12 \mathrm{MR}$-zeolite GME with the same OSDA as that for AEI with conditions only differing in water content (Figure 9). ${ }^{33}$

(5) In light of constructing $8 \mathrm{MR}$ zeolites, the work by Hong and co-workers on the mechanism of formation of $\mathrm{LTA}^{297,298} \mathrm{UFI}^{72} \mathrm{LEV}$, and $\mathrm{CHA}^{340}$ sheds an interesting perspective. Through the use of time-resolved multinuclear liquid and solid-state NMR, and other techniques, the authors propose that the large cages of these structures form first, with OSDA incorporated (e.g., $\alpha$-cage for UFI and LTA; cha-cage; lev-cage), before they connect through smaller units, e.g. d6r or shared 8MRs. For LEV, the linking of lev-cages is hypothesized to occur in pairs by sharing an $8 \mathrm{MR}$, before these pairs in turn link together forming the $\mathrm{d} 6 \mathrm{r}$ and the LEV framework (center in Figure 27). Although plausible, these studies focus on one composition and fixed conditions. The influence of the starting $\mathrm{Si} / \mathrm{Al}$ ratio on these mechanisms would be interesting in light of the predicted optimal $\mathrm{Si} / \mathrm{Al}$ ratios deduced from charge/cage counts (e.g., 8 for LEV). If the synthesis of cage-based small-pore zeolites begins with the construction of the large OSDA-precluded cages, rather than smaller building blocks, focus should be put on the charge balance. We surmise here that such a scenario would favor the incorporation of one $\mathrm{Al}$-per cage, maximum $\mathrm{Al}$ dispersion (isolation rather than pairing), and $\mathrm{Si} / \mathrm{Al}$ ratios near or below the optimum from cage-counts. Extending these studies with $\mathrm{Si} / \mathrm{Al}$ variation, as well as different inorganic sources, might yield clues into the $\mathrm{Si}$ / $\mathrm{Al}$ question.

(6) Interzeolite conversion is a relatively unexplored route for zeolite synthesis. Many aspects of IZC remain unclear, because the crystalline source material can interact with all constituents of the synthesis mixture in more than one way. The sol-gel mechanisms likely do not occur in a lot of IZCs. Even though poorly understood, the trial and error approach has yielded good results, and the benefits of the IZC route should be generally accepted by now. The nanoparts idea remains a hypothesis, and if proven, will likely be very conditional and framework specific. Two major types of IZC can be distinguished, those with very high alkaline cation concentrations (OSDA-free) and those with OSDA, and a lot less mineralizing power. The latter are considered true IZC, since in the case of the former (e.g., FAU to ABW, CHA, MER, ANA), ${ }^{223}$ the zeolite likely only functions as $\mathrm{T}$ atom source that completely breaks down, and no clear benefits of using the zeolite in terms of phase selectivity exist. True IZC, and everything in between, uses lower $\mathrm{OH} / \mathrm{Si}$ ratios and OSDAs, often to yield surprising results.

(7) Fluoride media syntheses (Route F, Table 2) are not really on the forefront in $8 \mathrm{MR}$ zeolites, except in a couple of case where pure silica or very high $\mathrm{Si} / \mathrm{Al}$ ratios are desired (Table 3). The exception is LTA, where two breakthroughs, leading to catalytic innovation (see section 3.2 ), rely on $\mathrm{F}^{-}$: the supramolecular complex and the DM3 $(4 \mathrm{MB})$ syntheses. $\mathrm{F}^{-}$is needed to stabilize the siliceous $\mathrm{d} 4 \mathrm{r}$ units. Few $8 \mathrm{MR}$ zeolites have a high hydrophobicity, since few have been made in the very high $\mathrm{Si} / \mathrm{Al}$ range (e.g., 100+) and/or can be made according to a fluoride route. Striking counterexamples are the synthesis of EEI, DDR, and CHA, possible in high $\mathrm{Si} / \mathrm{Al}$ ratios, in $\mathrm{OH}^{-}$-media (Figure 1, Table 3). The not-straightforward translation of OSDA effects from $\mathrm{OH}^{-}$- to $\mathrm{F}^{-}$-media, and vice versa, can be partially explained by the charge/cage perspective. Since $\mathrm{F}^{-}$ anions can neutralize the OSDA charge locally, pure silica nets can be formed defect-free (and more hydrophobic). Therefore, the (perceived) drive toward the "ideal" Al-content per unit cell from cage-counts is absent in fluoride media, and the space-filling role (i) of the OSDA is much more important. OSDAs with less tight fits (see above) often do not produce the zeolite in fluoride media. Although $\mathrm{F}^{-}$-mediated syntheses are more challenging at the large scale, innovation surrounding Lewis acidic Sn-BEA zeolites is lowering industrial barriers for zeolites to come. ${ }^{341}$

(8) Next to the Al-content discussion, a second important observation is the nonexistence of aluminosilicate versions of certain $8 \mathrm{MR}$ molecular sieves with interesting structures. The ABC- 6 molecular sieves AFT and SAT or the d6r-only SAV-structure are examples. For germanosilicates, the reason is often the increased stability of structural units (4MR) due to Ge-inclusion in the ring (in fluoride media). These positive effects do not occur in aluminosilicate formation. Why certain $\mathrm{AlPO}_{4}$ and SAPO-sieves have not translated to aluminosilicate versions is more difficult to understand. Why do OSDAs for many (M)A(1)PO syntheses never direct the corresponding zeolite? Differences in mechanisms of structure-direction at acidic (AlPO) vs basic (zeolite) synthesis conditions could be one reason. For one, the use of charged amines (due to neutral/acidic $\mathrm{pH}$ and amine $\mathrm{p} K_{\mathrm{a}}$ values near 10) in AlPO synthesis does not translate easily to zeolitic $\mathrm{OH}^{-}$-media, since the highly basic mineralizing environment renders the amines neutral. It thus seems that the charge of the OSDA outweighs its space-filling role in a lot of (M)A(l)PO syntheses. 


\section{CATALYSIS WITH 8MR ZEOLITES}

\subsection{Introduction}

As outlined in section 1.3, small-pore zeolites have been commercialized for a number of applications. Here, a concise overview of the key catalytic reactions where small-pore zeolites show promise or have been commercialized is presented. These applications are exhaust cleaning, partial oxidation of methane, olefin generation (MTO and ethylene/ethanol conversion), and methylamine synthesis. Additionally, a brief overview of a few other reactions is provided at the end of this section. Unlike section 2, this section does not provide an exhaustive discussion for every reaction and its mechanism but rather highlights the specific issues when using different small-pore zeolites and pinpoints recognized, structure-activity relations. For more details on each topic, the reader is referred to reaction-specific and detailed existing reviews in every subsection. Note that zeotypes such as SAPOs are often also used for these reactions but are deliberately not discussed here, in order to keep the focus on aluminosilicates.

\subsection{Selective Catalytic Reduction (SCR or deNOx) for Exhaust Cleaning}

3.2.1. Introduction to SCR and General Features of SCR with Zeolites. In the 1980s, Iwamoto et al. discovered the high activity and stable performance of $\mathrm{Cu}^{2+}$-exchanged ZSM-5 (medium-pore MFI zeolite) for NO decomposition. ${ }^{342}$ Since then, zeolite catalysts have been prominently featured in emission control literature, and the SCR of NOx with ammonia (or urea) is now one of the dominant technologies. The term deNOx, often used to refer to SCR, suggests that both NO and $\mathrm{NO}_{2}$ can be present in exhaust gases, and both need remediation. The largest fraction in diesel exhaust is NO, thus leading to the most standard chemical reaction of SCR (seen in Figure 2), converting $\mathrm{NO}$ into $\mathrm{N}_{2}$ and $\mathrm{H}_{2} \mathrm{O}$, with the aid of the ammonia reductant and $\mathrm{O}_{2} \cdot{ }^{343}$ Oxygen-gas free versions can also be written, e.g., when $\mathrm{NO}_{2}$ is present in significant amounts and " $4 \mathrm{NO}+\mathrm{O}_{2}$ " is replaced with " $2 \mathrm{NO}+$ $2 \mathrm{NO}_{2}$ " in Figure 2. This is also known as the fast SCR reaction. $^{344}$

Cu-ZSM-5 (MFI) has been at the forefront since the beginning, although its low hydrothermal stability above 700 ${ }^{\circ} \mathrm{C}$ (in the presence of steam), its lower activity in the lower temperature region, as well as its tendency to hydrocarbon adsorption (fouling), has motivated the search for more stable zeolite hosts. Small-pore zeolites ${ }^{4,55}$ provide an answer here, as they inhibit larger hydrocarbons from entering the cages. Bull et al. reported SCR with $\mathrm{Cu}-\mathrm{SSZ}-13$, and they noted a comparably high SCR activity, a better hydrothermal stability, and less hydrocarbon poisoning than other Cu-zeolites tested before (large pore BEA, medium-pore MFI). ${ }^{345}$ Others were also on this approach, ${ }^{346}$ e.g., researchers at Ford. ${ }^{103,347}$ Peden and coworkers demonstrated early on that the hydrothermally aged version of this catalyst outperforms BEA, MFI, and Yzeolites. ${ }^{348}$ A swift commercialization followed, and in 2010, $\mathrm{Cu}-\mathrm{SSZ}-13$ could be found as an emission control catalyst in on-road diesel automotive exhaust aftertreatment systems. ${ }^{344}$ $\mathrm{Cu}-\mathrm{SSZ}-13$ based SCR is a genuine and inspiring success story of small-pore zeolite chemistry. Note that the classic gasoline engine aftertreatment system is based on the "three-way catalysts" in catalytic convertors and has been commercial for over 30 years (reducing $\mathrm{CO}, \mathrm{NO}$, and hydrocarbons). ${ }^{100}$ This type of system does not work well on lean-burn engine operation, as is the case when oxygen/fuel ratios are high, e.g., in diesel vehicle engines, hence the need for $\mathrm{Cu}$-zeolites or other catalytic systems for these situations. Cu-zeolites were preferred over $\mathrm{V} / \mathrm{Ti}$ systems or Fe-zeolites, due to their lower dependence on feed gas $\mathrm{NO}_{2}$ for low temperature deNOx (fast vs standard SCR mentioned above). ${ }^{103}$

The literature on SCR with Cu-SSZ-13 and Cu-SAPO-34 has grown large since 2010. A couple of recent review articles $^{95,100,344}$ clearly describe the state-of-the-art in this field. The mechanism of SCR, at the level of the active Cu-site, is not completely known. For the standard SCR, the role of the redox chemistry of copper is still under scrutiny. Paolucci et al. demonstrated that zeolites exchanged with isolated $\mathrm{Cu}^{2+}$, contain both $\mathrm{Cu}^{+}$and $\mathrm{Cu}^{2+}$ ions during $200{ }^{\circ} \mathrm{C} \mathrm{SCR}^{349} \mathrm{~A}$ catalytic cycle based on their work is found in Figure 28, showing the $6 \mathrm{MR}$ (half of the d6r) of the CHA framework with two aluminum atoms across from each other (e.g., Figure 16).

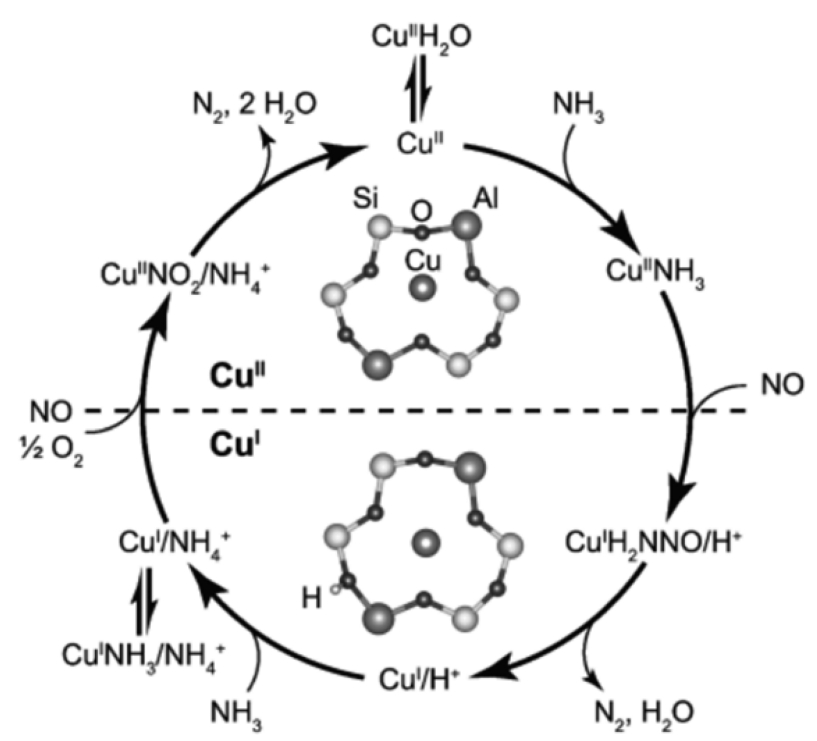

Figure 28. Suggested cycle for Cu-SSZ-13 at $473 \mathrm{~K}$ in the standard SCR. The dotted line separates oxidized $\mathrm{Cu}$ (top) from reduced (bottom) halves of the redox cycle. Reproduced with permission from ref 349. Copyright 2014 Wiley.

Details of the mechanistic, kinetic, and cation-siting aspects of SCR based on Cu-SSZ-13 catalysts are not presented here, and the reader is referred to the above-mentioned reviews, as well as expert contributions. ${ }^{133,350-355}$ A recent review in this journal also focuses on converting $\mathrm{N}$-containing exhaust gases with zeolites. ${ }^{101}$ The next section provides an overview of the different $8 \mathrm{MR}$ zeolite hosts reported for SCR and compares the impact of topology vs CHA (Table 8). After that, selected synthesis-structure-activity relations are detailed.

3.2.2. Overview of Small-Pore Zeolite Catalysts for SCR of NOx. Assessing SCR activity often seeks to find the range of temperature where conversion is close to $100 \%$ (Table 8 ), and working conditions resemble those of an exhaust (wet). Generally, a $\mathrm{N}_{2}$-balance stream, rich in $\mathrm{O}_{2}$ (e.g., 5-14\%) containing some water (e.g., 2-10\%, labeled as W, "wet conditions", vs D, dry) and a couple of 100 ppm's of NO and $\mathrm{NH}_{3}$, is used as reactants (often $500 \mathrm{ppm}$ of both). Selectivity is also important, as $\mathrm{NO}_{2}$ and $\mathrm{N}_{2} \mathrm{O}$ have to be avoided in favor of $\mathrm{N}_{2}$. Cu-SSZ-13 leads to significantly less $\mathrm{N}_{2} \mathrm{O}$ and $\mathrm{NO}_{2}$ (e.g., less than 5 and $10 \mathrm{ppm}$, respectively, over the entire 
Table 8. List of the 8MR-Framework Zeolites Tested in SCR of NOx with $\mathrm{NH}_{3}$

\begin{tabular}{|c|c|c|c|c|c|c|c|c|c|}
\hline \multirow[b]{2}{*}{ Top. ${ }^{a}$} & \multicolumn{7}{|c|}{ Practical numerical example $b$} & \multirow[b]{2}{*}{ Performance $^{e}$} & \multirow[b]{2}{*}{ remarks } \\
\hline & Material & $\mathrm{Si} / \mathrm{Al}$ & $\mathbf{M}$ & $\mathbf{M} / \mathbf{A l}$ & $\begin{array}{l}\mathrm{NO} / \mathrm{NH}_{3} / \mathrm{H}_{2} \mathrm{O}^{c} \\
\quad(\mathrm{ppm} / \mathrm{D}, \mathrm{W})\end{array}$ & $\begin{array}{c}\text { T-range } \\
\left({ }^{\circ} \mathrm{C}\right)^{d}\end{array}$ & $\mathbf{R}^{b}$ & & \\
\hline \multirow[t]{3}{*}{ CHA } & SSZ-13 & 9.0 & $\mathrm{Cu}$ & 0.18 & $500 / 500 / \mathrm{D}$ & $\begin{array}{l}\text { F: } 200-500 \\
\text { A: } 200-500\end{array}$ & 244 & ++++ & $\begin{array}{l}\text { Commercial. Many reports. Excellent } \\
\text { catalyst. }\end{array}$ \\
\hline & & 12 & $\mathrm{Cu}$ & 0.20 & $350 / 350 / \mathrm{W}$ & $\begin{array}{l}\text { F: } 175-550 \\
\mathrm{~A}^{d}:-(\text { Figure } 31)\end{array}$ & 356 & & $\mathrm{~A}^{d}$ : above $80 \%$, Figure 31. \\
\hline & & 12 & $\mathrm{Fe}$ & 0.20 & $350 / 350 / \mathrm{W}$ & $\begin{array}{l}\text { F: } 360-500 \\
\text { A: - }\end{array}$ & 357 & +++ & See Figure 31. \\
\hline \multirow[t]{2}{*}{ AEI } & SSZ-39 & 9.1 & $\mathrm{Cu}$ & 0.32 & $500 / 530 / \mathrm{W}$ & $\begin{array}{l}\text { F: } 270-550 \\
\text { A: } 220-450\end{array}$ & 181 & ++++ & $\begin{array}{l}\text { A Cu-SSZ-13 under same aging, was } \\
\text { less stable }\end{array}$ \\
\hline & & 8.0 & $\mathrm{Fe}$ & 0.1 & $50 / 60 / \mathrm{W}$ & $\begin{array}{l}\text { F: } 350-550 \\
F: 400-500\end{array}$ & 358 & +++ & one-pot synth has good aged activity \\
\hline \multirow[t]{2}{*}{ AFX } & SSZ-16 & 4.5 & $\mathrm{Cu}$ & 0.23 & $500 / 500 / D$ & $\begin{array}{l}\text { F: } 200-500 \\
\text { A: } 200-400\end{array}$ & 244 & +++ & Good SCR, decent aging \\
\hline & & 5.2 & $\mathrm{Fe}$ & 0.1 & $50 / 60 / \mathrm{W}$ & $\begin{array}{l}\text { F: } 550 \\
\text { A: n.r. }\end{array}$ & 198 & ++ & Removal of $\mathrm{Na}^{+}$needed \\
\hline \multirow[t]{2}{*}{$\mathrm{ERY}^{f}$} & $\begin{array}{l}\text { Sigma-1 } \\
f\end{array}$ & $\begin{array}{l}16 \\
5.2\end{array}$ & $\begin{array}{l}\mathrm{Cu} \\
\mathrm{Cu}\end{array}$ & $\begin{array}{l}0.14 \\
0.3^{h}\end{array}$ & $\begin{array}{l}500 / 500 / \mathrm{D} \\
500 / 530 / \mathrm{W}\end{array}$ & $\begin{array}{l}\text { F,A: } 300-350 \\
\text { F: } 500-550 \\
\text { A: - }\end{array}$ & $\begin{array}{l}244 \\
198\end{array}$ & $\begin{array}{l}+ \\
+\end{array}$ & $\begin{array}{l}\text { A worse than } \mathrm{F} \text {, but } \max = \\
\text { A: } \max 45 \% \text { at } 300{ }^{\circ} \mathrm{C}\end{array}$ \\
\hline & & 5.2 & $\mathrm{Fe}$ & 0.1 & $50 / 60 / \mathrm{W}$ & $\begin{array}{l}\text { F: - } \\
\text { A: n.r. }\end{array}$ & & + & F: $\max 65 \%$ at $500{ }^{\circ} \mathrm{C}$ \\
\hline KFI & ZK-5 & $4^{g}$ & $\mathrm{Cu}$ & 0.38 & $500 / 500 / W$ & $\begin{array}{l}\text { F: } 250-500 \\
\text { A: } 300-450\end{array}$ & 359 & +++ & $\mathrm{Cu} / \mathrm{Al}$ in aging important \\
\hline LEV & $\mathrm{Nu}-3$ & 8 & $\mathrm{Cu}$ & 0.08 & $500 / 500 / D$ & $\begin{array}{l}\text { F: } 250-400 \\
\text { A: } 250-300\end{array}$ & 244 & ++ & A worse than $\mathrm{F}$, but $\max =$ \\
\hline LTA & & 16 & $\mathrm{Cu}$ & 0.58 & $500 / 500 / \mathrm{W}$ & $\begin{array}{l}\text { F: } 260-475 \\
\text { A: } 275-500\end{array}$ & 172 & ++++ & Aged at $750{ }^{\circ} \mathrm{C}$ \\
\hline RHO & & 7 & $\mathrm{Cu}$ & $0.1^{i}$ & $500 / 500 / \mathrm{W}$ & $\begin{array}{l}\text { F: } 250-500 \\
\text { A: n.r. }\end{array}$ & 330 & / & Too few data to judge \\
\hline RTH & SSZ-50 & 10 & $\mathrm{Cu}$ & n.r. & $500 / 500 / \mathrm{W}$ & $\begin{array}{l}\text { F: } 200-430 \\
\text { A: - }\end{array}$ & 324 & ++ & A: $\max 70 \%$ at $360{ }^{\circ} \mathrm{C}$ \\
\hline UFI & PST-7 & 11 & $\mathrm{Cu}$ & 0.44 & $500 / 500 / \mathrm{W}$ & $\begin{array}{l}\text { F: } 260-500 \\
\text { A: - }\end{array}$ & 172 & ++ & $\begin{array}{l}\text { A condition same as LTA. } 70 \% \text { at } \\
330{ }^{\circ} \mathrm{C}\end{array}$ \\
\hline
\end{tabular}

${ }^{a_{\text {Top. }}}=$ topology. ${ }^{b} \mathrm{R}=$ reference. The table is by no means complete and entries were selected for allowing the broadest, most accurate comparison. ${ }^{c} \mathbf{D}$ points to dry reactant flows, $\mathbf{W}$, points to deliberately adding $\mathrm{H}_{2} \mathrm{O}$ to the SCR feedstock (wet, realistic). $\mathrm{O}_{2}$ is also present. ${ }^{d}$ Range where NO conversion in standard SCR is still $\geq 90 \%$, often estimated from graphs with connected data points. F indicates fresh catalyst, while A means after hydrothermal aging (high T steaming, often different conditions). - indicates that conversion was always below $90 \%$, see remarks column. n.r.: not reported. ${ }^{e}$ Performance relative vs all entries and benchmark SSZ-13. ${ }^{f}$ ERI/OFF intergrowth known as ZSM-34 also patented for SCR; see ref 360. Erionite would not be an accurate material name here. ${ }^{g} 3.7$ from synthesis, after $\mathrm{Cu}$ procedure and calcination, $4.2 .{ }^{h}$ Estimated for 2.8 wt $\%$. ${ }^{i}$ Estimate.

temperature range (T-range), on $350 \mathrm{ppm}$ of NO feedstock) than $\mathrm{Cu}$-beta and $\mathrm{Cu}-\mathrm{ZSM}-5 .{ }^{348}$

3.2.3. Cu-Zeolite Catalyzed SCR: The Impact of Topology. After performing a $\mathrm{Cu}$-cation siting study for both zeolites, ${ }^{196}$ CHA and AFX were investigated thoroughly by Fickel et al., noting that both were excellent catalysts when compared to ZSM-5. ${ }^{244}$ Different behavior for SCR is mostly found after a hydrothermal treatment (e.g., $750{ }^{\circ} \mathrm{C}, 5 \%$ water feed). There, Cu-SSZ-13 and Cu-SSZ-16 excelled versus $\mathrm{Cu}-$ ZSM-5, but also between them, differences were notable: while the CHA zeolite still performed near identical SCR, the AFX material loses its activity at temperatures over $350{ }^{\circ} \mathrm{C}$. In the same study, LEV and DDR-zeolites were assessed, but these had lower activity (especially DDR), evidenced from the operation window in Table 8. The authors concluded that the dimensionality of DDR and LEV (2D) was likely to blame for the reduced SCR activity. Furthermore, it was suggested that during the dealumination process, under hydrothermal aging, $\mathrm{Al}(\mathrm{OH})_{3}$, with an estimated $0.5 \mathrm{~nm}$ diameter, needs to exit the framework in order to cause structural trouble. Small-pore windows, such as those constricting CHA and AFX cages, prevent this, and thus $\mathrm{Al}$-species stay inside the pore where they were originally dislocated. At lower temperatures, realumination could occur. ${ }^{244} \mathrm{~A}$ further finding by Chen and co-workers noted that for large pore $\mathrm{BEA}$, a destructive $\mathrm{Cu} / \mathrm{Al}_{2} \mathrm{O}_{3}$ interaction induces framework collapse above $800{ }^{\circ} \mathrm{C}$, but this interaction is minimized by pore-size in CHA.,361 Evidenced from the fact that since 2010 about 200 publications have been reported containing the term "Cu-SSZ-13" in a topic search (Web of Science, 10/10/2017), remarkable focus has been placed in the catalytic community on SCR with the CHAzeolite. It is worth noting that a typical commercial sample has a $\mathrm{Si} / \mathrm{Al}$ ratio around 17 and a $\mathrm{Cu}$ loading of 2.8 wt \% (BASF), corresponding to a $\mathrm{Cu} / \mathrm{Al}$ ratio of 0.5 , or, charge-based at least, stoichiometric exchange. ${ }^{362}$

A truly excellent SCR topology was identified by Moliner et al.; AEI. SSZ-39 proved to have an good activity over a broad T-range and a very high hydrothermal stability. ${ }^{181}$ In their study, a comparison to a SSZ-13 with higher $\mathrm{Si} / \mathrm{Al}=12$ and similar Cu-loading clearly showed the benefit of SSZ-39. The 
stability of SSZ-39 in hydrothermal steaming conditions was also verified later by Dusselier et al. in an MTO study (section 3.4) where dealumination by steaming was pursued (and in the presence of $\mathrm{Cu}^{2+}$, the framework held up well). ${ }^{179}$ The second SCR study for AEI was conducted on IZC materials made with the tetraethylphosphonium OSDA from the Sano group, compared to the N-based DEDMP cation (Table 4 entries 6-7). Although NO conversion was lower for the P-zeolites, the thermal stability of the $\mathrm{Cu}$-free hosts in calcination was a bit better for the P-containing materials. After hydrothermal steaming, the P-based zeolite also seemed to have an increased $\mathrm{NO}$-conversion (for $\mathrm{P} / \mathrm{Al}=0.2$, e.g.), while that of the more classic material decreased a little, although these steaming times were short ( 1 and $4 \mathrm{~h}$ at $\left.900{ }^{\circ} \mathrm{C}\right)$. The NO conversion however decreased with increasing $\mathrm{P} / \mathrm{Al}$ ratio, suggesting that only a small amount of P-modification could be beneficial. ${ }^{183}$ A similar effect (small amount of P-modification from synthesis, not postsynthesis) was observed for the dual-template AEI (Table 4 entry 13). ${ }^{187}$ Martín et al. reported SCR on their SSZ-39 made with their efficient IZC synthesis method using $\mathrm{N}, \mathrm{N}$-dimethyl3,5-dimethylpiperidinium (Table 4, entry 12) and compared them to the P-containing OSDA materials and an SSZ-39 prepared with both the piperidinium and $\mathrm{Cu}$-tetraethylenepentamine (Cu-TEPA) present. ${ }^{186}$ The latter is known as a one-potapproach that allows the loading of $\mathrm{Cu}$ in situ during synthesis. Here, the P-containing material underperformed versus the others, and a lower hydrothermal stability was noted for the Pbased material after steaming at $750{ }^{\circ} \mathrm{C}$. The P-content of the material here however was not reported. The two other $\mathrm{Cu}-$ SSZ-39 materials were stable during steaming (from PXRD) and behaved similarly, i.e., excellent SCR (e.g., at 500/500/W, F: $250-490{ }^{\circ} \mathrm{C}$ and A: $260-450{ }^{\circ} \mathrm{C}$, for the postsynthetic $N, N-$ dimethyl-3,5-dimethylpiperidinium based zeolite, compared to Table 8).

RTH, assessed by Jo et al., showed a good fresh performance, but this activity did not stay after hydrothermal aging. ${ }^{324}$ Gounder and co-workers investigated the kinetic and structural changes after SCR on AEI, CHA, and RTH zeolites. ${ }^{363}$ When comparing rates, in standard SCR $\left(\mathrm{Cu}, 250{ }^{\circ} \mathrm{C}\right)$, AEI and $\mathrm{CHA}$ performed similarly, before and after aging. $\mathrm{RTH}$, however, had $2-3 \times$ lower rates and zero activity after hydrothermal aging. After aging, the RTH framework is still intact (XRD) and porous (physisorption), inferring that the structural changes for the worse happen to the $\mathrm{Cu}$-sites. The study thus confirms the positive role of $\mathrm{d} 6 \mathrm{r}$ containing zeolites in terms of protecting the active $\mathrm{Cu}$ species during hydrothermal aging. Furthermore, the lower "fresh" activity for SCR in RTH is likely caused by the $2 \mathrm{D}$ nature of its pore system with constrained, asymmetric $8 \mathrm{MR}$ windows. These likely limit access, rendering the RTH framework to behave as a 1D SCR catalyst.

Martín et al. tested new IZC routes to ERI and AFX based on large dicationic OSDAs, in both $\mathrm{Cu}$ and Fe-forms. Notably, ERI was not a good SCR catalyst, as high-temperatures were needed for the fresh catalyst and aging deteriorated the performance heavily. ${ }^{198}$ AFX had already been studied by Fickel et al., but not in wet conditions. At 500/530/W (compared to Table 8), the fresh Cu-SSZ-16 catalyst achieved over $90 \% \mathrm{NO}$ conversion in a temperature range from 350 to $550{ }^{\circ} \mathrm{C}$, while the aged zeolite only went up to $80 \%$ at $300-350{ }^{\circ} \mathrm{C}$. The difference with the dry SCR data from Table 8 logically suggests that deNOx under more realistic, wet conditions is more difficult for AFX, although comparing across reports is difficult (Cu-loading, GHSV, ...).
Zeolites containing the large lta-cavity were also studied for SCR, by different groups (KFI, RHO, UFI, LTA). The team of Hong and co-workers assessed both UFI and LTA frameworks, made with benzylimidazolium-based cations (e.g., Table 7, Entries $10-13$ for synthesis and Table 8 for SCR data). ${ }^{172}$ Especially LTA stood out, and high activity was found initially and retained after hydrothermal aging tests up to $750{ }^{\circ} \mathrm{C}$. At $850{ }^{\circ} \mathrm{C}$, activity was mostly gone, but this was true for benchmark CHA and MFI as well. A direct comparison to SSZ13 with the same $\mathrm{Si} / \mathrm{Al}$ ratio, after $750{ }^{\circ} \mathrm{C}$ aging, showed a clear pattern of LTA outperforming CHA. The authors continued their work and found that for a perfectly exchanged LTAzeolite, even better stability and SCR activity after aging occurred. Figure 29 compares data from different LTA and $\mathrm{CHA}$ zeolites, before and after a severe $900{ }^{\circ} \mathrm{C}$ aging. The severity of the aging is known to destroy a lot of the SSZ-13 activity. Yet, LTA, with the right amount of $\mathrm{Cu}$, is highly stable. This is likely the best hydrothermal aged SCR catalyst reported to date. Figure 29, part a, shows that having an overexchange,
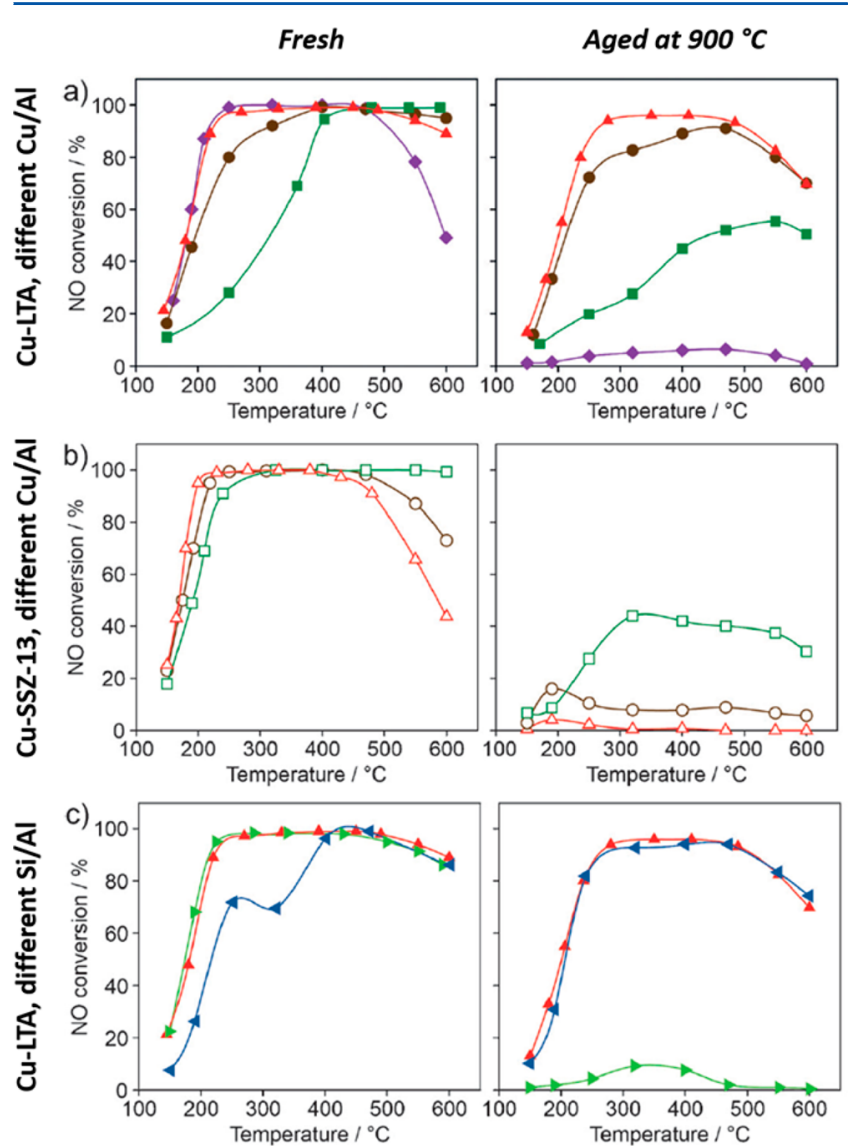

Figure 29. Performance in SCR for Cu-LTA, compared to Cu-SSZ-13. $\mathrm{NO}$ conversion as a function of temperature over the (left) fresh and (right) $900{ }^{\circ} \mathrm{C}$-aged forms of: (a) Cu-LTA-16-0.14 (square), Cu-LTA16-0.32 (dot), Cu-LTA-16-0.48 (triangle) and Cu-LTA-16-0.65 (rhombus). (b) Cu-SSZ-13-16-0.15 (green), Cu-SSZ-13-16-0.34 (brown), and Cu-SSZ-13-16-0.49 (red). (c) Again Cu-LTA-16-0.48 (red triangle), this time with Cu-LTA-11-0.48 (green), Cu-LTA-230.50 (blue). Reaction conditions: 500/500/W, (as in Table 8), while hydrothermal aging was performed under flowing air containing $10 \%$ $\mathrm{H}_{2} \mathrm{O}$ at $900{ }^{\circ} \mathrm{C}$ for $12 \mathrm{~h}$. The last two values of the catalyst identification correspond to the $\mathrm{Si} / \mathrm{Al}$ and $\mathrm{Cu} / \mathrm{Al}$ ratios of the catalysts, respectively. Adapted with permission from ref 364. Copyright 2017 Wiley. 
(a)

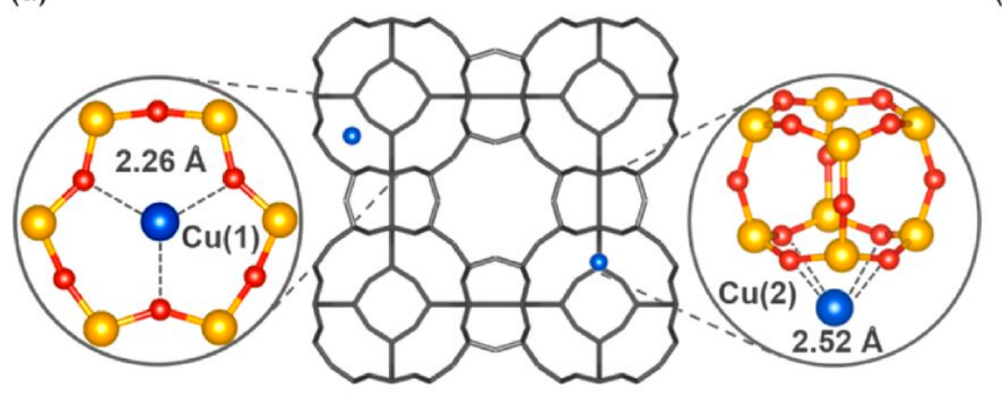

(b)

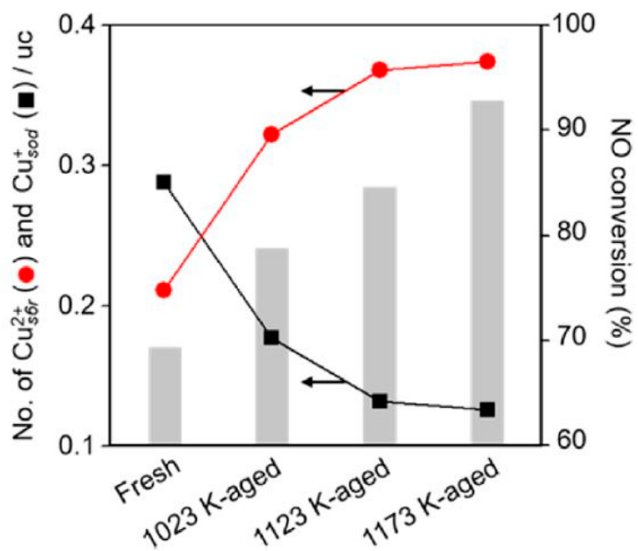

Figure 30. Cu-LTA SCR site proposal and catalytic conversions after aging (a) Structure of the fresh, dry Cu-LTA-23-0.50 catalyst with 2 different sites labeled as $\mathrm{Cu}(1)$ and $\mathrm{Cu}(2)$. Colors: red, $\mathrm{O}$; blue, $\mathrm{Cu}$; yellow, $\mathrm{Si}$; $\mathrm{Al}$ is not represented in this figure. (b) Numbers of $\mathrm{Cu}$ ions at single-6MR (-) and $\mathrm{Cu}$ ions inside sod-cages ( $)$ per unit cell of Cu-LTA-23-0.50 vs hydrothermal aging temperature. The NO conversions at $320{ }^{\circ} \mathrm{C}$ (viz. dip in Figure 29c) of fresh and aged catalysts are given as a bar diagram. Reproduced with permission from ref 365 . Copyright 2017 American Chemical Society.

Fresh:

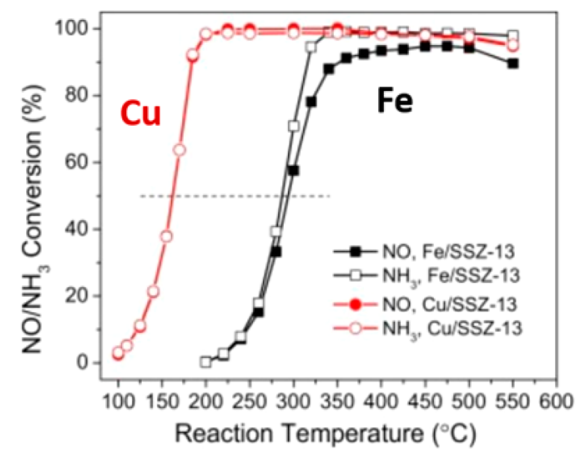

After hydrothermal aging $\left(800^{\circ} \mathrm{C}\right.$ in flowing air with $10 \%$ of water):
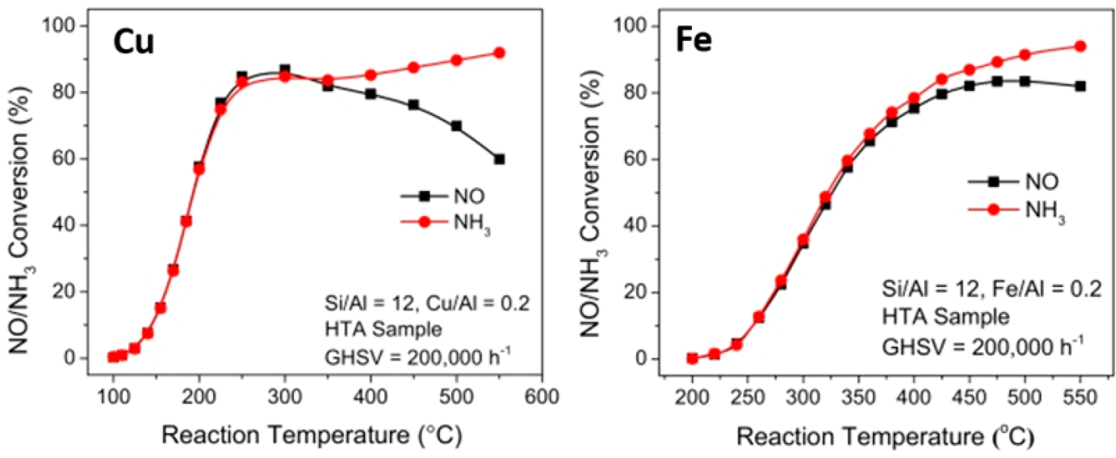

Figure 31. Comparing $\mathrm{Cu}$ and Fe-SSZ-13 in standard, wet SCR before (fresh) and after hydrothermal aging. Conditions in inset. Adapted with permission from ref 356. Copyright 2015 Elsevier.

e.g., $\mathrm{Cu} / \mathrm{Al}$ of 0.65 , is deleterious for the SCR performance of the LTA after the high-temperature aging. Yet, values close to 0.4-0.5 Cu/Al, render LTA zeolites stable against aging and still highly performing from 250 to $550{ }^{\circ} \mathrm{C}$. The most stable SSZ-13 material tested (series b, Figure, 29) has a lower $\mathrm{Cu} / \mathrm{Al}$ ratio (of 0.15), rather than a higher. For SSZ-13, it was already known that higher $\mathrm{Cu} / \mathrm{Al}$ ratios are not always optimal for surviving the aging, as for example $\mathrm{Cu} / \mathrm{Al} 0.28$ vs 0.35 already caused a large difference after aging in the dry SCR runs by Fickel et al. on $\mathrm{Si} / \mathrm{Al}=6$ materials. $^{244}$ The optimal SSZ-13 catalyst fails to attain even $50 \%$ of $\mathrm{NO}$ conversion after high temperature aging. Finally, three different $\mathrm{Si} / \mathrm{Al}$ ratios of LTA, with optimal exchange near 0.5 were tested as well, clearly showing that the improved SCR effect only holds true for the least aluminous materials ( $\mathrm{Si} / \mathrm{Al}=16$ and 23 , Figure 29c). Rietveld refinement indicated that $\mathrm{Cu}^{2+}$ ions were located only at the center of single-6MR, and it was surmised that they serve not only as active center but also as a dealumination suppressor. $^{364}$

Interestingly, the low temperature $\mathrm{SCR}$ with $\mathrm{Si} / \mathrm{Al}=23$ materials (thus with the least amount of $\mathrm{Cu}$, see Figure 29 part c, blue, from left to right) improved upon aging, hinting at stabilization or relocation of low-temperature active sites during the aging, rendering them more active. The same authors studied this phenomenon in-depth, and they demonstrated that it originates from the migration of $\mathrm{Cu}^{+}$ions present inside the 
sod-cages (against $\mathrm{d} 4 \mathrm{r}$ windows) to vacant single-6MR during the hydrothermal aging (Figure 30). The sod-cages could be seen as a useful catalyst reservoir releasing active sites during SCR.

Cu-KFI for SCR was patented by Reichinger et al.; ${ }^{366}$ while recently, a thorough study was published by Kim et al. ${ }^{359}$ Low temperature activity and decent performance are two excellent features of $\mathrm{Cu}-\mathrm{KFI}$. The aged performance was tested for two Cu-loadings, and the highest one prevailed (shown in Table 8). The report directly compared to SSZ-13, with the latter yielding a slightly better performance. However, one should keep in mind that this KFI-zeolite is made without OSDA and thus, potentially, very cheap. ${ }^{359}$ Further testing in more stringent conditions, longer aging, and repeated cycles is due. The other lta-cage containing zeolite, RHO, has not been tested adequately. Cu-RHO was briefly tested for SCR by Ke et al., in the light of their new synthesis with the Cs-crown-ether complex leading to rho materials with higher $\mathrm{Si} / \mathrm{Al}$ ratios. However, no aging experiments were given, rendering SCR assessment rather difficult. ${ }^{330}$ Given the interesting findings of the Hong group for LTA, high $\mathrm{Si} / \mathrm{Al}$ RHO zeolites could yield surprising results. Finally, of note is that a few of the small-pore zeolites, i.e., ERI, LEV, CHA, and DDR, were already included in the list of tested materials featured in a patent by Andersen et $\mathrm{al}^{2,346}$

3.2.4. Fe-Zeolite Catalyzed SCR. The above discussion clearly highlights the extraordinary performance of CHA, AEI, LTA, and KFI-zeolites in copper-based SCR. A few of the 8MR zeolite materials have also been investigated using $\mathrm{Fe}$ cations as active centers, i.e., CHA, AEI, AFX, and ERI. Fe-SSZ-13 was assessed by Peden and co-workers. ${ }^{357}$ Later, a comparison of reaction kinetics with $\mathrm{Fe}$ - and $\mathrm{Cu}$-based zeolite was made. ${ }^{356}$ Fresh Fe-SSZ-13 was on average less active than the $\mathrm{Cu}$-version in standard SCR under wet conditions (see Figure 31 comparing both zeolites, in fresh and aged conditions). Although a serious drop in activity ensued for the Fe-version after aging, it interestingly retained more activity than the $\mathrm{Cu}$ material above $500{ }^{\circ} \mathrm{C}$. A full discussion of Fe-species, their loading effects, and transformation, in SSZ-13, is found in further work by the Peden group. ${ }^{367,368}$

Fe-SSZ-39 was assessed by Martín et al. (entry in Table 8), and a one-pot method for introducing $\mathrm{Fe}$ into the small-pore material was presented. Ferric nitrate was added to the $N, N$ dimethyl-3,5-dimethylpiperidinium OSDA-based IZC synthesis. ${ }^{358}$ The classic SSZ-39, postsynthetically exchanged via ferrous sulfate, was also compared, but it performed worse than the one-pot zeolite after aging. Clearly, the way of introducing $\mathrm{Fe}$ matters, especially since $\mathrm{Fe}$ needs to be carefully ionexchanged. Fe-ERI and Fe-AFX were briefly looked into by Martín et al. as well (Table 8), but no aging was performed, and the feedstock ppm concentration of $\mathrm{NO}$ was low, compared to the work with Fe-SSZ-13. ${ }^{198}$

3.2.5. Synthesis-Structure-Activity Observations. Since the detailed study of SCR entails testing many different conditions (e.g., aging and hydrothermal stability), and the dynamic nature of the active site of the classic catalyst is still under elucidation, it is understandable that few true synthesisstructure-activity relations have been reported (opposed to for example MTO, see section 3.4). The greatest number of structure-activity relations has been detailed for Cu-SSZ-13, and the reader is referred to the above-mentioned reviews in this context. Not often do these studies rely on synthetic variation other than $\mathrm{Si} / \mathrm{Al}$ ratios, that is easily varied in SSZ-13, and $\mathrm{Cu}$-content $(\mathrm{Cu} / \mathrm{Al}){ }^{369}$ On the other hand, $\mathrm{CHA}$ zeolites made via new synthetic routes (e.g., see Table 5 or Figure 14), such as Corma and co-workers' TEA-based $(\mathrm{Si} / \mathrm{Al}=8)$ material, ${ }^{226}$ or the solvent-free $\mathrm{CHA}$ zeolite $(\mathrm{Si} / \mathrm{Al}=5)$ made with $N, N, N$-dimethylethylcyclohexylammonium (Figure 14) of the Xiao group, ${ }^{212}$ are often tested in SCR, to see if the material can match the activity of a classic SSZ-13.

Interestingly, the way $\mathrm{Cu}$ (or $\mathrm{Fe}$ ) is introduced into the zeolite can offer a synthetic challenge.

Beale and co-workers compared the classic ion-exchange route versus a chemical vapor deposition (CVD) based ionexchange. ${ }^{370}$ The latter is performed using a setup where precursor salt and zeolite are in close contact (glass-wool) and heated in an inert flow at $250{ }^{\circ} \mathrm{C}$. The CVD method yielded only half the $\mathrm{Cu}$-loading as the classic wet exchange, and its SCR was abysmal. While the copper sites were found for the CVD material and they were like those obtained from ion exchange-i.e., the $\mathrm{Cu}^{2+}$ center on the outside of the d6r subunits of the CHA structure (e.g., see Fickel et al., ${ }^{196}$ but note that these are dry, nonworking condition coordinated species) - a secondary inactive $\mathrm{CuAlO}_{2}$-like phase was present. Another solid-state ion-exchange method at higher temperature did yield active SCR catalysts. ${ }^{371}$

The approach by Ren et al., concerning the use of a $\mathrm{Cu}$ TEPA complex for directing CHA-synthesis, delivers $\mathrm{Cu}$ as active SCR site to the cages. ${ }^{213}$ The SCR activity of the fresh sample on a $1000 / 1000 / \mathrm{D}$ feedstock was above $90 \% \mathrm{NO}$ conversion in the zone of $175-450{ }^{\circ} \mathrm{C}$, for a Si/Al ratio of 4 and, concomitantly, a high Cu-loading (9.5 wt \%). The coupling between $\mathrm{Cu}$ loading and $\mathrm{Si} / \mathrm{Al}$ through synthesis, in the first report, shows a reduced degree of freedom in choosing $\mathrm{Cu}$ and $\mathrm{Al}$ content separately. However, later, the group reported $\mathrm{Cu}$-content control and better SCR features. ${ }^{372}$ Martinez-Franco et al. followed in this path but combined ADAM with $\mathrm{Cu}$-TEPA, that allowed more control over $\mathrm{Si} / \mathrm{Al}$ and $\mathrm{Cu} /(\mathrm{Si}+\mathrm{Al})$ ratios and obtained decent $\mathrm{SCR}$ performance and good hydrothermal stability. ${ }^{372}$ Martín followed the same strategy for AEI, yielding "one-pot” Cu-SSZ-39, mentioned above. ${ }^{86}$ In an interesting side-note, Yamada et al. focused on bead-milling SSZ-16 zeolites and then subjecting them to postmilling crystallization, rending $<100 \mathrm{~nm}$ large crystals. These showed faster and more homogeneous (in the crystal) ion-exchange, due to accessibility, when subjected to $\mathrm{Cu}^{2+}$, but no SCR was reported. ${ }^{373}$

The effect of morphology and particle sizes in SSZ-13 was investigated, following three modified synthesis procedures, based on ADAM as OSDA. ${ }^{362}$ More classic $>1 \mu \mathrm{m}$ zeolites were compared to 450 and $260 \mathrm{~nm}$ sized particles. The latter, based on longer aging in the synthesis, already show mesoporosity in physisorption, deriving from interparticle adsorption. The SCR performance of the different-sized zeolites, with similar $\mathrm{Si} / \mathrm{Al}$ and $\mathrm{Cu} / \mathrm{Al}(0.15)$ ratios, was very similar. This is attributed to the extraordinary stability of the $\mathrm{Cu}$ ion-framework $\mathrm{Al}$ pairs, against steaming, independent of particle size. This method could however help in depositing more Cu-SSZ-13 active species, on SCR setups based on washcoated layers of zeolite upon a support. Access to thinner (from smaller zeolite particles), more active layers there could improve mass and heat transport.

Finally, a mesoporous SSZ-13 was studied, that was based on desilication by base leaching. Using the mildest leaching conditions $(0.1 \mathrm{M} \mathrm{NaOH})$, microporosity was somewhat reduced $\left(0.36\right.$ to $\left.0.23 \mathrm{~cm}^{3} \cdot \mathrm{g}^{-1}\right)$, and mesopores were created 
$\left(0.23 \mathrm{~cm}^{3} \cdot \mathrm{g}^{-1}\right) . \mathrm{Si} / \mathrm{Al}$ and $\mathrm{Cu} / \mathrm{Al}$ ratios of this material and the parent (nondesilicated) were similar, but the treated materials showed a remarkable improvement in the low temperature SCR regime (1000/1000/D), e.g,. a 2-fold increase in NO conversion at 150 and $250{ }^{\circ} \mathrm{C}$ (said to derive from improved accessibility). ${ }^{374}$

3.2.6. Conclusions from $\mathrm{NH}_{3}-\mathrm{SCR}$ of $\mathrm{NOx}$ with $8 \mathrm{MR}$ Zeolites. Small-pore zeolites are essential to lean-burn diesel engine exhaust cleaning catalyst technology. Cu-SSZ-13 is already commercial, and its performance is linked to its excellent stability under hydrothermal conditions. Detailed studies to understand the full mechanistic aspects and catalytic cycle of this system are still published regularly. The discovery of the SSZ-13 zeolite ${ }^{4}$ thus led to great progress in exhaust cleaning technology. The CHA zeolite is however made with ADAM, and this OSDA is quite costly. The excellent SCR performance has thus motivated researchers to look for alternative $\mathrm{CHA}$ synthesis recipes, and in turn brought great innovation in the synthesis field.

Apart from CHA, AEI is an excellent topology for SCR as well, and studies unraveling its performance are underway. Similarities in CHA and AEI performance and stability have led many to hypothesize that desirable properties are derived from the d6r-only nature of the frameworks. For the AFX zeolite, also d6r-only, decent SCR performance was noted. The effect of the size of the cavity, large in AFX, could be a topic of future research (this is for instance crucial in MTO chemistry, section 3.4.3). When considering the other d6r-only topology with related but even larger cavities (see Figure 10), i.e., SFW, interesting structure-activity relations could be unraveled. Synthetic access to SFW-zeolites is not straightforward, but recently a new route has been detailed. ${ }^{66,137}$ At this time, an SCR study on SFW is lacking.

Finally, a very recent breakthrough in small-pore zeolite based SCR warrants a highlight. New synthetic access to LTAzeolites with $\mathrm{Si} / \mathrm{Al}$ ratios in the range of $11-50^{135,172}$ has led to the discovery of an unprecedentedly active and stable SCR catalyst, based on full $\mathrm{Cu}$ exchange $(\mathrm{Cu} / \mathrm{Al} 0.5)$ and a remarkable stability in steaming up to $900{ }^{\circ} \mathrm{C}$ (Figure 29). The LTA framework lacks d6r units, but single-6MR are present, e.g., the faces of the sod-cavity, and these were found to be active cation hosting sites (centered in the single-6MR, inside the large lta-cavity). Furthermore, time will tell if the synthesis of this material is cost-effective (fluoride route) and a potential competitor for $\mathrm{Cu}-\mathrm{SSZ}-13$. It is worth noting that KFI, also constructed using only d6r building blocks, has lta-cages as well. A first SCR assessment proved to be promising, but synthetic access to KFI with $\mathrm{Si} / \mathrm{Al}$ ratios significantly larger than 4 is lacking. This is remarkable given the fact that KFI (ZK-5) was the first synthetic zeolite (Barrer).

\subsection{Partial Oxidation of Methane to Methanol}

3.3.1. Introduction to Methane-to-Methanol with Transition Metal-Exchanged Zeolites. Panov et al. reported the decomposition of $\mathrm{N}_{2} \mathrm{O}$ at low temperature using $\mathrm{Fe}$ exchanged ZSM-5 in 1990 with release of $\mathrm{N}_{2}$. The oxygen was deposited onto the catalyst to form a highly reactive oxygen-Fe. Subsequently contacting the oxidized material with methane at room temperature resulted in the production of an adsorbed methanol precursor. ${ }^{375}$ Recently, the active $\mathrm{Fe}$-site for this reaction was reported in the form of an $\alpha$-Fe $\mathrm{Fe}^{\mathrm{II}}$ against a single-6ring of for example BEA. ${ }^{376}$
In 2005, Groothaert et al. documented the first activity for methane partial oxidation to methanol with $\mathrm{O}_{2}$ on $\mathrm{Cu}$ zeolites. ${ }^{106}$ The structure of the $\mathrm{Cu}$-active complex was supposedly elucidated in 2009 by researchers in Stanford and Leuven. ${ }^{377}$ The accepted catalytic cycle, featuring a dimeric copper species (mono(- $\mu$-oxo-)-dicopper), is seen in Figure 32.

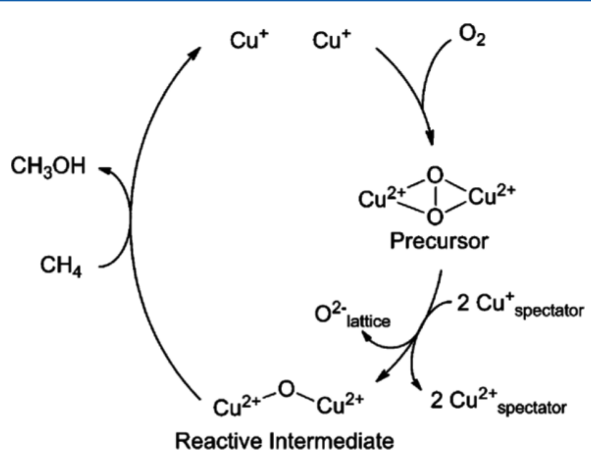

Figure 32. Proposed reaction cycle on Cu-ZSM-5 for $\mathrm{O}_{2}$ activation and $\mathrm{CH}_{4}$ hydroxylation. Reproduced with permission from ref 378 . Copyright 2010 American Chemical Society.

After activation in $\mathrm{O}_{2}$, the active site is formed, which can then react with a subsequent feed of $\mathrm{CH}_{4}$. After stoichiometric reaction, a strongly adsorbed partially oxidized methane product is formed and the site is deactivated, requiring reactivation with $\mathrm{O}_{2}$. The adsorbed product can be recovered as methanol by liquid extraction or steaming. ${ }^{378} \mathrm{~A}$ review by Vanelderen et al. points out the biomimetic links between such $\mathrm{Cu}$-zeolites and $\mathrm{Cu}$-methane monooxygenases. ${ }^{105}$

Besides MFI, a plethora of medium and large pore $\mathrm{Cu}$ zeolites have been proposed for this reaction, notably MOR ${ }^{107,379}$ An overview on the coordination chemistry of copper in zeolite shows that $\mathrm{Cu}^{2+}$ preferentially coordinates in 6MR (as in some SCR-zeolites), with 1, 2, or $3 \mathrm{Al} \mathrm{T}$ atoms. ${ }^{380}$ Some of these species then autoreduce under inert atmosphere at high temperature, to $\mathrm{Cu}^{+}$, before the reaction with $\mathrm{O}_{2}$ to form the active dimer (Figure 32).

In the context of feedstock shifts in the chemical industry (e.g., shale gas) and a general revival in $\mathrm{C}-\mathrm{H}$ activation, ${ }^{381}$ the field of methane oxidation with transition metal ion-exchanged zeolites has expanded rapidly in the last three years. Not only have breakthroughs been reported in terms of methanol extraction $^{382}$ or even reactivation with steam, ${ }^{383}$ efforts have also been directed to turn the stepwise stoichiometric reaction into a catalytic one. ${ }^{384}$ The latter report for instance details a gas-phase process for continuous methanol production, flowing a mixture of $\mathrm{CH}_{4}, \mathrm{H}_{2} \mathrm{O}$, and $\mathrm{O}_{2}$ over $\mathrm{Cu}-\mathrm{ZSM}-5$ at $210{ }^{\circ} \mathrm{C}$, with good selectivity, and (a still very low) $\mathrm{CH}_{3} \mathrm{OH}$ production rate of $0.88 \mu \mathrm{mol} \cdot \mathrm{g}$ cat $^{-1} \cdot \mathrm{h}^{-1}$. Note that a catalytic liquid phase methane oxidation process using $\mathrm{Fe}-\mathrm{ZSM}-5$ with $\mathrm{H}_{2} \mathrm{O}_{2}$ as oxidant has been known for a longer time, but so far, no smallpore zeolites have been reported for this case. ${ }^{385}$

It was only in 2015 that the first small-pore zeolites (Table 9) exchanged with $\mathrm{Cu}$ were reported for gas-phase methane oxidation, as pioneered by the Lobo group. ${ }^{25}$ Several reports have surfaced since, but still only a select number of topologies have been tested (Table 9). For a comparative series of medium- and large pore zeolites, the reader is referred to a recent critical assessment, ${ }^{386}$ as well as an in-depth review in this journal. ${ }^{99}$ 
Table 9. List of 8MR-Framework Zeolites Tested in Partial Oxidation of Methane

\begin{tabular}{|c|c|c|c|c|c|c|c|c|}
\hline Top. $^{a}$ & Material & $\mathrm{Si} / \mathrm{Al}^{b}$ & $\mathbf{M}$ & $\mathbf{M} / \mathbf{A l}$ & Oxidant & $\mathrm{MeOH}$ production $(\mu \mathrm{mol} / \mathrm{g} \text { cat })^{c}$ & ref & Activity remarks \\
\hline MFI & ZSM-5 & 11.5 & $\mathrm{Cu}$ & 0.34 & $\mathrm{O}_{2}$ & 16 & 25 & Benchmark \\
\hline CHA & SAPO-34 & $6^{b}$ & $\mathrm{Cu}$ & 0.6 & $\mathrm{O}_{2}$ & 15 & 25 & Low vs zeolite \\
\hline AEI & SSZ-39 & 10 & $\mathrm{Cu}$ & 0.26 & $\mathrm{O}_{2}$ & 36 & 25 & High, $0.09 \mathrm{MeOH} / \mathrm{Cu}$ \\
\hline AFX & SSZ-16 & 6.5 & $\mathrm{Cu}$ & 0.34 & $\mathrm{O}_{2}$ & 39 & 25 & Low, $0.05 \mathrm{MeOH} / \mathrm{Cu}$ \\
\hline $\mathrm{CHA}$ & SSZ-13 & 12 & $\mathrm{Cu}$ & 0.35 & $\mathrm{O}_{2}$ & 31 & 25 & Medium, $0.06 \mathrm{MeOH} / \mathrm{Cu}$ \\
\hline CHA & SSZ-13 & 15.8 & $\mathrm{Cu}$ & 0.84 & $\mathrm{O}_{2}$ & 30 & 387 & \\
\hline $\mathrm{CHA}$ & SSZ-13 & 12 & $\mathrm{Cu}$ & 0.4 & $\mathrm{O}_{2}$ & 45 & 388 & \\
\hline $\mathrm{CHA}$ & SSZ-13 & 12 & $\mathrm{Cu}$ & 0.4 & $\mathrm{~N}_{2} \mathrm{O}$ & 35 & 388 & \\
\hline $\mathrm{CHA}$ & SSZ-13 & 12 & $\mathrm{Cu}$ & 0.5 & $\mathrm{O}_{2}$ & $107^{d}$ & 389 & Very high: $0.2 \mathrm{MeOH} / \mathrm{Cu}$ \\
\hline $\mathrm{CHA}^{e}$ & SSZ-13 & 13.8 & $\mathrm{Cu}$ & 0.5 & $\mathrm{O}_{2}$ & $16 \mu \mathrm{mol} \cdot \mathrm{g}^{-1} \cdot \mathrm{h}^{-1}$ & 384 & catalytic \\
\hline $\mathrm{CHA}^{f}$ & SSZ-13 & 12 & $\mathrm{Cu}$ & 0.4 & $\mathrm{~N}_{2} \mathrm{O}$ & $55 \mu \mathrm{mol} \cdot \mathrm{g}^{-1} \cdot \mathrm{h}^{-1}$ & 388 & catalytic \\
\hline
\end{tabular}

${ }^{a_{\text {Top. }}}=$ topology. ${ }^{b}(\mathrm{Al}+\mathrm{P}) / \mathrm{Si}$ in the case of silicoaluminophosphate. ${ }^{c}$ Three-step cycle reaction, with oxidation temperature at $450{ }^{\circ} \mathrm{C}$ and reaction temperature $\left(\mathrm{CH}_{4}\right.$ step $)$ at $200{ }^{\circ} \mathrm{C}$. ${ }^{d}$ Oxidation temperature of $500{ }^{\circ} \mathrm{C}$. ${ }^{e}$ Flow mode at $260{ }^{\circ} \mathrm{C}$ with activation at $550{ }^{\circ} \mathrm{C} .{ }^{f}$ Flow mode at $300{ }^{\circ} \mathrm{C}$. Here, rates are reported.
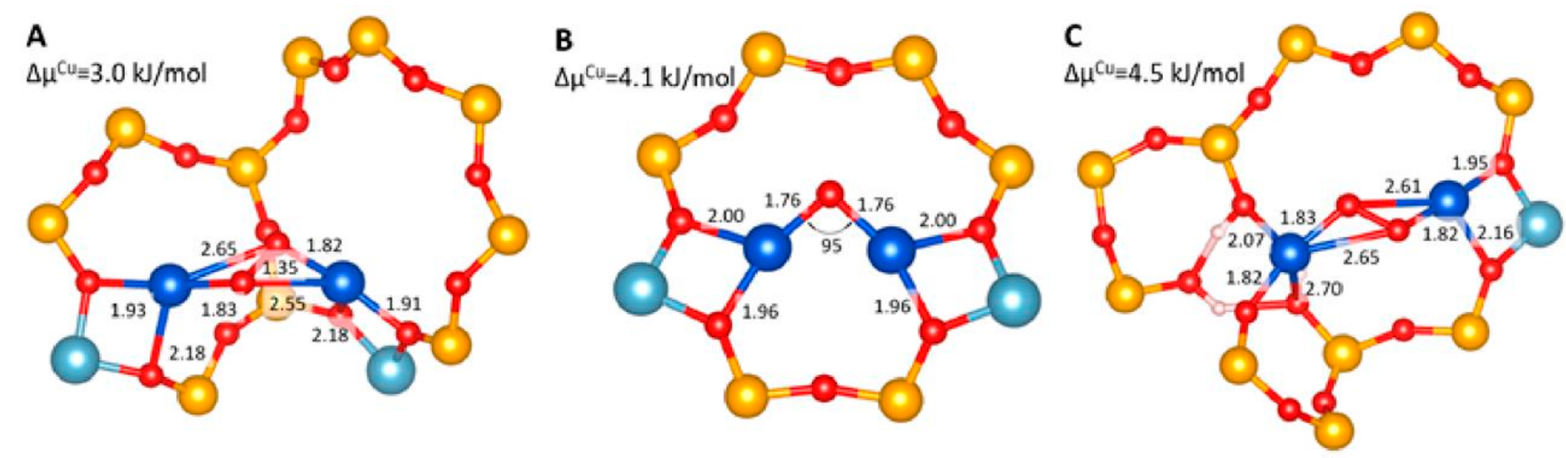

Figure 33. Three different structures of possible active sites in $\mathrm{Cu}-\mathrm{SSZ}-13$ within $5 \mathrm{~kJ} \mathrm{~mol}^{-1}$ of a $[\mathrm{CuOH}]^{+}$site in the zeolite: $\mathrm{A}$ and $\mathrm{C}$ are peroxo $\left[\mathrm{Cu}_{2} \mathrm{O}_{2}\right]^{2+}$ species while $\mathrm{B}$ is a mono-( $\mu$-oxo) dicopper(II). Colors: red, O; blue, $\mathrm{Cu}$; yellow, $\mathrm{Si}$; marine, $\mathrm{Al}$; $\mathrm{H}$, white. Bond distances are given in $\AA$. Reproduced with permission from ref 390. Copyright 2017 American Chemical Society.

3.3.2. Small-Pore Cu-Zeolites for Methane Oxidation. Wulfers et al. assessed AEI, AFX, and CHA versus MFI and SAPO-34 for methane oxidation following the three-step activation, reaction, extraction cycle. The three small pore, d6r-based zeolites performed similarly, and about 30-40 $\mu \mathrm{mol}$ methanol per gram of catalyst was obtained, as compared to only $16 \mu \mathrm{mol} \cdot \mathrm{g} \mathrm{cat}^{-1}$ for a ZSM-5. The small-pore zeolite results give methanol per $\mathrm{Cu}$ ratios between 0.03 (an aluminous CHA, not in Table 3) and 0.09 (AEI). It has been noted that the active sites of these copper-containing small-pore zeolites could be the same as those active for the decomposition of NO in SCR. ${ }^{25}$ Park et al. confirmed the value for CHA, but higher $\mathrm{Si} / \mathrm{Al}$ and $\mathrm{Cu} / \mathrm{Al}$ ratios were used (Table 9) ${ }^{387}$ Later, the Lobo group also found the system to work with $\mathrm{N}_{2} \mathrm{O}$ instead of $\mathrm{O}_{2}{ }^{388}$ Moving from a consecutive to a real catalytic system is clearly a necessity if this process is ever to be viable. RomanLeshkov and co-workers broke ground in that respect, using $\mathrm{O}_{2}$ in flow conditions, and with several types of zeolites. The rates with $\mathrm{Na}-\mathrm{Cu}$-SSZ-13 attained $16 \mu \mathrm{mol} \cdot \mathrm{g}^{-1} \cdot \mathrm{h}^{-1}$. ${ }^{384}$ Ipek et al. investigated expanding the $\mathrm{N}_{2} \mathrm{O}$-activated cycle into a catalytic process for Cu-SSZ-13 as well, noting similar rates at $260{ }^{\circ} \mathrm{C}$ $\left(19 \mu \mathrm{mol} \cdot \mathrm{g}^{-1} \cdot \mathrm{h}^{-1}\right)$, and up to $55 \mu \mathrm{mol} \cdot \mathrm{g}^{-1} \cdot \mathrm{h}^{-1}$ at $300{ }^{\circ} \mathrm{C}$ (Table 9). ${ }^{388}$ Ipek et al. also launched a full scale investigation into the nature of the Cu-sites in SSZ-13 and SSZ-39 and showed that trans- $\mu$-1,2-peroxo dicopper(II), that is, $\left[\mathrm{Cu}_{2} \mathrm{O}_{2}\right]^{2+}$, and mono( $\mu$-oxo) dicopper(II), that is, $\left[\mathrm{Cu}_{2} \mathrm{O}\right]^{2+}$, likely form on these $\mathrm{Cu}$-zeolites (with $\mathrm{Cu} / \mathrm{Al}=0.4-0.48, \mathrm{Si} / \mathrm{Al}=10-12$ ), as seen in Figure 33.
The thermodynamically optimized structures need at least one $\mathrm{Cu}$-cation on the $8 \mathrm{MR}$ of SSZ-13 (Figure 33). Aluminous SSZ-13 zeolites have a higher percentage of bare $\mathrm{Cu}^{2+}$ on $\mathrm{d} 6 \mathrm{r}$ $6 \mathrm{MR}$ windows, containing two $\mathrm{Al}$-atoms (e.g., see Figure 16). These bare sites seem inactive for methanol formation, while $\mathrm{Cu}^{2+}$ ions on $8 \mathrm{MR}$ windows are believed to lead to $\mathrm{Cu}_{x} \mathrm{O}_{y}$ active species. ${ }^{390}$ Studt and co-workers recently performed a DFT study, suggesting that monocopper species are also active sites for partial methane oxidation in $8 \mathrm{MR}$ zeolites. The suggested $\left[\mathrm{Cu}{ }^{\mathrm{II} O H}\right]^{+}$active site was said to provide an additional route for methane activation in zeolites in addition to the known multicopper sites. ${ }^{391}$ Pappas et al. studied the $\mathrm{Cu}-$ SSZ-13 in great detail, uncovering structure-activity relations and allowing them to optimize methanol formation: up to 107 $\mu$ mol.g cat ${ }^{-1}$ was found using a long high temperature $\mathrm{O}_{2}$ activation (Table 9). After four cycles, $125 \mu \mathrm{mol} \cdot \mathrm{g}^{-1}$ was even obtained, related to the water-assisted movement of the metal during the extractions, to (more) active positions. Bare $\mathrm{Cu}^{\mathrm{II}}$ species on $6 \mathrm{MRs}$ were indeed excluded as active sites, while $\left[\mathrm{Cu}^{\mathrm{II}} \mathrm{OH}\right]^{+}$species, also inactive, are identified as precursors to the methane converting site. A positive linear structure-activity correlation was found between activity and the reducibility of the $\mathrm{Cu}$ center. ${ }^{389}$

3.3.3. Conclusions on Small-Pore Zeolites for Methane Oxidation. While $\mathrm{Cu}$ - and Fe-zeolites have been known for quite some time to possess activity for methane oxidation after activation with $\mathrm{O}_{2}$ or $\mathrm{N}_{2} \mathrm{O}$, the use of the first small-pore zeolites in these types of reactions was reported in 2015 and, thus far, only with $\mathrm{Cu}$. Only a few topologies have been tested, 


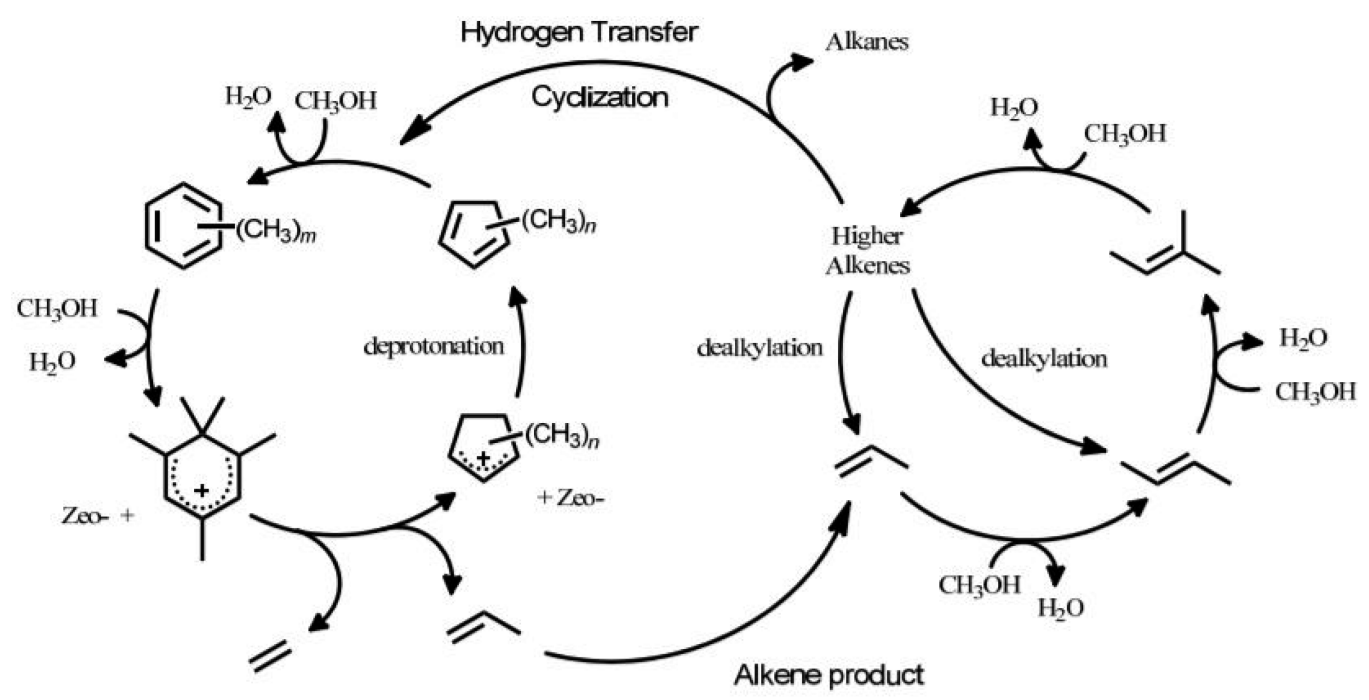

Aromatic Cycle

Alkene Cycle

Figure 34. Dual-cycle mechanism in MTO. Reprinted with permission from ref 403. Copyright 2016 Elsevier.

and most of the focus has been placed on CHA, where the active sites have now been more clearly defined. There is a large opportunity for improvement in this area, especially when considering that the $\mathrm{Si} / \mathrm{Al}$ ratios needed for this reaction are similar to the ones in SCR where hosting the same transition metals plays a crucial role. However, the active site requirements to the zeolite framework seem to be different (e.g., $\mathrm{Al}$ in d6r, 8MR, ...). Drawing parallels between the SCR literature, large-pore methane oxidation reports, and the identity of the active site (precursors) in SSZ-13 will undoubtedly lead to new insights and active small-pore zeolite catalysts for this reaction (and likely new types of active sites).

\subsection{Olefin Generation: Methanol-to-Olefins (MTO) and Ethanol/Ethylene Conversion}

3.4.1. History and General Chemistry of MTO. The MTO reaction is an industrially viable way to produce light olefins $(\mathrm{C} 2-\mathrm{C} 3-\mathrm{C} 4)$ at temperatures around $350{ }^{\circ} \mathrm{C}$. Typically, MTO requires a solid acid catalyst such as a zeolite or a silicoaluminophosphate (zeotypes). The MTO reaction evolved from the methanol-to-gasoline process, as discovered in the 1970s by the Mobil researchers Chang and Silvestri. ${ }^{392,393}$ Serendipity was involved, as the researchers were looking for routes to make highly branched alkanes from methanol and isobutane. The latter molecule did not convert, but methanol did and gave a mixture of aromatics and isoalkanes with Cnumbers not larger than C11. ${ }^{394}$ In the 1980s, the first plant was commissioned in New Zealand, to produce gasoline from natural gas, through intermediate methanol production. The selectivity to light olefins (MTO) was remarkably improved when UOP researchers discovered SAPO-34, the silicoaluminophosphate of the small-pore CHA topology. Nowadays, MTO, focused on making ethylene and propylene, offers an industrially viable alternative route to olefins from nonpetroleum sources, such as biomass, natural gas, and coal. The intermediate methanol is often produced via syngas through $\mathrm{Cu} / \mathrm{ZnO} / \mathrm{Al}_{2} \mathrm{O}_{3}$ catalyst technology. ${ }^{395,396}$ A large number of industrial and academic research groups have contributed to the understanding and advancement of MTO over the years, and informative reviews on the subject are available..$^{93,102,394,397-399}$ In recent years, several large scale commercial units have been built in China, mainly based on SAPO- $34,{ }^{93}$ but also a ZSM-5-based (medium sized porezeolite MFI) operation is reported. ${ }^{394}$

MTO can be considered in four consecutive steps. ${ }^{400}$ First, the dehydration of methanol yields dimethyl ether (DME), methanol, and water in equilibrium. Second, an induction time is present, on fresh catalysts, and only few olefins are produced. Internally, intermediate species start to accumulate, and the first $\mathrm{C}-\mathrm{C}$ bond formation occurs. The third step involves high yield production of olefins, i.e., actual MTO, and a so-called hydrocarbon pool mechanism is dominant in most of the materials. The fourth step describes the deactivation by coking inside the zeolite.

In SAPO-34 a hydrocarbon pool of alkylbenzenes is present, and these intermediates dominate the pathway of olefin formation. ${ }^{401}$ An active pool can consist of benzene and naphthalene aromatics that are substituted with methyl groups (mostly more than one). The organic pool together with the inorganic acid forms a hybrid reaction hub for adding $\mathrm{C} 1$ species (methanol, dimethyl ether, ...) that then transform, forming ethyl and propyl side groups that lead to olefin expulsion. Other mechanisms can also lead to olefin generation during the third phase, such as the methylation of olefins, with chain lengths increasing, followed by cracking of the longer olefins into ethylene and propylene. This route can be considered independent of the pool pathway and is often thought to be present to some extent as the minor reaction path. Dual-cycle mechanisms combining the methylation and hydrocarbon pool have also been proposed. ${ }^{402}$ Figure 34 shows the dual-cycle, as it conveniently displays both major paths. ${ }^{403}$

A lot of mechanistic research has recently focused on elucidating the first $\mathrm{C}-\mathrm{C}$ bond formation, either on ZSM-5 or SAPO-34. ${ }^{404-406}$ MTO is a very interesting reaction to study since it involves a whole range of classic (as well as less common) hydrocarbon chemistries: isomerization, alkylation, hydrogen transfer, ${ }^{407}$ cracking, (de)protonation, homologation and oligomerization, and cyclization and aromatization. The study of MTO has certainly helped to understand other vital hydrocarbon conversions. Overviews of MTO chemistry, often centered on SAPOs, are available. ${ }^{93,394,408}$ 
Table 10. Complete List of 8MR-Framework Zeolites Tested in MTO and General Assessment

\begin{tabular}{|c|c|c|c|c|c|c|c|c|c|}
\hline \multirow[b]{2}{*}{ Top. ${ }^{a}$} & \multirow[b]{2}{*}{ Typical behavior $^{b}$ and advantages } & \multicolumn{6}{|c|}{ Practical numerical example ${ }^{c}$} & \multirow[b]{2}{*}{$\begin{array}{l}\text { Per- } \\
\text { formance }\end{array}$} & \multirow[b]{2}{*}{ Drawbacks } \\
\hline & & Material $^{d}$ & $\mathrm{Si} / \mathrm{Al}$ & $\underset{\left({ }^{\circ} \mathrm{C}\right)}{\mathrm{T}}$ & $\begin{array}{l}\text { WHSV } \\
\left(h^{-1}\right)\end{array}$ & $\begin{array}{c}\mathrm{S}_{\text {alkenes }}^{e} \\
\mathrm{C} 2 / 3 / 4(\%)\end{array}$ & $\mathbf{R}^{c}$ & & \\
\hline \multirow[t]{2}{*}{ CHA } & \multirow[t]{2}{*}{ Benchmark, cheap, tunable C2/C3. } & SAPO-34 & n.r. & 450 & 1.5 & $40 / 40 /-^{g}$ & & \multirow[t]{2}{*}{++++} & \multirow[t]{2}{*}{ Hydrothermal stability } \\
\hline & & & $0.12^{g}$ & 400 & 1.3 & $42 / 37 / 15$ & 179 & & \\
\hline \multirow[t]{3}{*}{ CHA } & \multirow[t]{3}{*}{ High activity, commercial in $\mathrm{SCR}^{h}$} & \multirow[t]{3}{*}{ SSZ-13 } & 50 & 475 & 0.5 & $61 / 25 /-$ & 415 & \multirow[t]{3}{*}{++++} & \multirow{3}{*}{$\begin{array}{l}\text { Heavy and fast coke } \\
\text { formation }\end{array}$} \\
\hline & & & 55 & 400 & 1.3 & $48 / 37 / 11$ & 416 & & \\
\hline & & & 67 & 325 & 0.5 & $39 / 49 /-$ & 201 & & \\
\hline AEI & $\begin{array}{l}\text { selective for } \mathrm{C} 3+\mathrm{C} 4 \text {. High activity, } \\
\text { long lifetime }\end{array}$ & SSZ-39 & $62^{i}$ & 400 & 1.3 & $17 / 48 / 20$ & 179,188 & ++++ & Steaming was needed ${ }^{i}$ \\
\hline AFX & Low activity vs CHA & SSZ-16 & 16.7 & 400 & 1.3 & $23 / 31 /-$ & 159 & ++ & $\begin{array}{l}\text { Large coke species, short } \\
\text { lifetime }\end{array}$ \\
\hline $\mathrm{CDO}$ & Main product DME & RUB-37 & 204 & 400 & 1.3 & $2 / 4 /-$ & 413 & + & Alkanes, few olefins \\
\hline \multirow[t]{2}{*}{ DDR } & \multirow[t]{2}{*}{$90 \%$ yield of $\mathrm{C} 2+\mathrm{C} 3 \mathrm{few}$ paraffins } & ZSM-58 & 55 & 400 & 2.0 & $30 / 38 / 12$ & 417 & \multirow[t]{2}{*}{++++} & \multirow{2}{*}{$\begin{array}{l}\text { Fast coking of strongest } \\
\text { acid sites }\end{array}$} \\
\hline & & Sigma-1 & 50 & 400 & 1.0 & $27 / 47 / 11$ & 418 & & \\
\hline ERI & Initial high selectivity to olefins & $\mathrm{UZM}-12$ & 6.5 & 350 & 0.67 & $29 / 41 / 10$ & 70 & ++ & Fast deactivation \\
\hline ESV & Low activity, some DME & ERS-7 & 8.1 & 400 & 1.3 & none & 413 & n.a. & No olefins \\
\hline ITE & Selective to $\mathrm{C} 3$ & ITQ-3 type & 18.1 & 400 & 1.3 & $18 / 40 / 17$ & 419 & ++ & Short lifetime \\
\hline KFI & Interesting $\mathrm{C} 3+\mathrm{C} 4$ selectivity & ZK-5 & $17^{i}$ & 400 & 1.3 & $21 / 34 / 21$ & 267 & ++ & Steaming needed \\
\hline \multirow[t]{2}{*}{ LEV } & \multirow[t]{2}{*}{$\mathrm{C} 2$ as main olefin. } & SSZ-17 & 16.8 & 400 & 1.3 & $43 / 31 /-$ & 159 & \multirow[t]{2}{*}{++} & \multirow[t]{2}{*}{ C5 olefins and DME } \\
\hline & & $\mathrm{Nu}-3$ & $30^{j}$ & 400 & 1.0 & $37 / 24 / 7$ & 418 & & \\
\hline \multirow[t]{2}{*}{ LTA } & \multirow[t]{2}{*}{ Interesting C4 selectivity } & ITQ-29 & 42 & 400 & 1.3 & $24 / 25 / 24$ & 135 & \multirow[t]{2}{*}{++} & \multirow[t]{2}{*}{ Fast deactivation } \\
\hline & & UZM-9 & 5.1 & 350 & 0.7 & $20 / 45 / 18$ & 420 & & \\
\hline \multirow[t]{2}{*}{ MTF } & \multirow[t]{2}{*}{ Main product $\mathrm{DME}$} & UTM-1 & 45 & 475 & 0.5 & $4 / 3 /-$ & 415 & \multirow[t]{2}{*}{ n.a. } & \multirow[t]{2}{*}{ No olefins } \\
\hline & & MCM-35 & 31.7 & 400 & 1.3 & none & 413 & & \\
\hline SFW & Low activity vs CHA & SSZ-52 & 6.1 & 400 & 1.3 & $35 / 35 / 8$ & 419 & ++ & Similar to AFX \\
\hline $\mathrm{RHO}$ & Interesting $\mathrm{C} 3+\mathrm{C} 4$ selectivity & Rho & $23^{i}$ & 400 & 1.3 & $21 / 40 / 21$ & 267 & + & Fast deactivation, needs \\
\hline & & Rho & 3.5 & 400 & 1.0 & $31 / 29 /-$ & 421 & & steaming \\
\hline RTH & Selective to $\mathrm{C} 3+\mathrm{C} 4$. Medium-high & SSZ-50 & 17 & 400 & 1.3 & $15 / 47 / 21$ & 169 & +++ & Medium lifetime \\
\hline & activ. & Al-TTZ-1 & 41 & 400 & 1.0 & $23 / 45 /-$ & 121 & & \\
\hline UFI & Initial high selectivity to olefins & UZM-5 & 6.9 & 350 & 0.7 & $30 / 45 / 18$ & 420 & + & Very fast deactivation \\
\hline
\end{tabular}

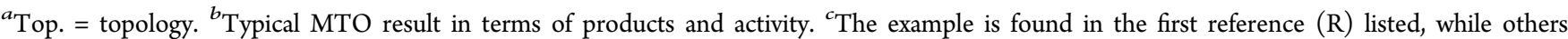
mentioned are illustrative works of MTO with this framework. The table is by no means complete, and different behaviors can be encountered in different conditions. ${ }^{d}$ Always in Brønsted acidic $\mathrm{H}^{+}$form. ${ }^{e}$ Selectivity for individual alkenes, from chosen reference, at one point in time, where the sum of alkenes is highest and at full (or highest reported) conversion. - indicates C4 was not reported separately. ${ }^{f}$ Performance relative vs all entries, ranked from n.a. (no MTO activity) over + (few olefins, fast deactivation) to ++++ (excellent MTO). Material synthesis drawbacks (or ease) not taken into account. ${ }^{g}$ For this industrial benchmark, a range of different olefin ratios can be achieved, depending on conditions, and the value shown is not binding. Propylene selectivities of over $80 \%$ are claimed. The $\mathrm{Si} / \mathrm{Al}$ of this catalyst is in fact the $\mathrm{Si} /(\mathrm{Si}+\mathrm{P}+\mathrm{Al})$ ratio. ${ }^{h} \mathrm{~A}$ lower $\mathrm{Si} / \mathrm{Al}$ is needed there. ${ }^{i}$ Steamed materials: their $\mathrm{Si} / \mathrm{Al}$ ratio considering only framework-Al obtained by correcting low bulk ratio with the Al-tetrahedral fraction in MAS NMR. ${ }^{j}$ Theoretical value.

3.4.2. Overview and Specifics of Small-Pore Zeolite MTO. Aside from ZSM-5, most of the MTO research has focused on small-pore SAPO-34. Here, we limit our discussion to small-pore aluminosilicates, where the MTO literature is less abundant. SSZ-13 (CHA) was one of the first zeolites tested in this category, as patented by Santilli and Zones. ${ }^{409,410}$ On average, compared to SAPOs, zeolites are more strongly acidic and have a higher hydrothermal stability. Katada et al. published a detailed comparison of the acidic properties of small-pore cage-based zeolites with different topologies in comparison to SAPO's (not in an MTO study, but still informative). ${ }^{411}$ Bleken et al. studied the effect of acid strength for this reaction, comparing SAPO-34 and SSZ-13 $(\mathrm{Si} / \mathrm{Al}=11) .{ }^{412}$ Keeping acid density and crystal size constant, and probing strength with CO-IR, a more active MTO chemistry (olefin production but also aromatics production and thus deactivation) was found for the aluminosilicate at the same temperature. Reaction paths and intermediates were similar, demonstrating topology matters more in this respect, although ethylene to propylene ratios were a bit higher for SSZ-13. Due to the higher activity, aluminosilicates can work at lower (optimal) temperature.
Ethylene to propylene ratios usually also increase with temperature, and this is understood from the prevalent dualcycle mechanism and the kinetic competition between (and activation barriers of) aromatic and olefinic cycles (C2/C3 olefin ratios are said to be also influenced by shape-selectivity originating from differences in diffusivity ${ }^{102}$ ). For MTO, the stronger acidity of aluminosilicates is thus not needed per se. The hydrothermal stability can be important for having longer catalysts lifetimes and an overall lower solid use per olefin generated. Given the industrial mode of MTO, often in fluidized bed with regeneration loops at low to intermediate coking levels, this could be important.

The MTO reaction on small-pore cage containing zeolites is a prime example of reaction intermediate confinement, as the cage traps the large hydrocarbon pool's polymethylbenzene intermediates, allowing only the escape of $\mathrm{C} 1-\mathrm{C} 4$ compounds (and a limited fraction of longer linear alkanes/alkenes) and mostly ethylene, propylene, and some butylenes (incl. butadiene). The ratio of ethylene:propylene:butylenes (aside from the mentioned condition dependence) can thus depend on topology-specific changes as well as on the size and shape of 
the cage that can allow different hydrocarbon pool species. Care should be taken, when interpreting topology-dependent selectivities, that the conditions used are comparable (i.e., particle size, T, methanol turnover level, coking level, conversion). $8 \mathrm{MR}$ zeolites without cages have also been assessed, generally without success. ${ }^{413}$ Table 10 lists a comprehensive overview of (all) tested 8MR aluminosilicate zeolite frameworks for the MTO reaction. Typical catalytic data for each framework are supplemented both with relative grading and (dis)advantages. Note that Table 10 does not intend to credit first results reported for a given framework but aims to compile data with the most similar operating conditions.

Aside from the following comparison between small-pore zeolites and their structure-activity relations, work dedicated to understanding the mechanism of MTO in SSZ-13 (using one material with fixed properties) and other aluminosilicates has been reported. Such conditional (e.g., cofeeding, water addition, ...) and kinetic studies ${ }^{414}$ are not detailed here.

3.4.3. Key Structure-Activity Relations in ZeoliteCatalyzed MTO. 3.4.3.1. Topology and the Presence of Cages. From the body of MTO literature, it is obvious that topology is the decisive factor for both activity (selectivity) and deactivation. Based on the information provided in Table 10 and comparing across different reports, it is clear that sufficiently sized-cages are needed when MTO is targeted in small-pore zeolites. Zero MTO activity was found for the 1D ESV and MTF zeolites (very small cage) in a recent study, and the main product in these dense materials is DME. Although MTF showed no olefins, a minor amount, possibly due to impurities, was detected in earlier work (both in Table 10). In comparison to small-pore SAPO zeotypes, ${ }^{422,423}$ and large pore zeolites (ZSM-5: MFI, MEL, TON, BEA, ...), ${ }^{424}$ relatively few studies have narrowed in on the role of cage dimensions in comparative studies for small-pore zeolites. Although parallels between SAPOs and zeolites with the same structure in terms of product distribution have been drawn (e.g., SSZ-13 above, or for AEI: SSZ-39 $9^{179}$ and SAPO- $18^{425}$ ), direct zeolite-zeotype comparisons remain difficult.

The size and the shape of the cage, as well as their connectivity, are decisive in MTO as they:

(i) determine the nature (size and reactivity) of the hydrocarbon pool species that can be included and, derived thereof, MTO activity and $\mathrm{C} 2 / \mathrm{C} 3 / \mathrm{C} 4$ olefin product distribution;

(ii) are linked to acid site density (protons per cage);

(iii) determine deactivation routes through the molecular sizes of accumulating carbonaceous deposits, a.k.a. coke. These originate from species in the pool that are not active toward olefin expulsion anymore (or from reactions at external surface areas).

It is clear that confinement effects and the number of acid sites confined within one cage are crucial in this complex chemistry. With a focus on cage dimensions, CHA, AFX, and LEV (SSZ-17) zeolites were compared by Bhawe et al. at similar $\mathrm{Si} / \mathrm{Al}$ ratios (16) and crystal sizes. The selectivity toward ethylene increased with a decrease in cage size (LEV being the smallest and largest ethylene producer). AFX, with huge aftcavity (Figure 7, 15.1 T/1000 $\AA^{3}$ ), showed the worst performance in terms of both activity ( $53 \%$ of conversion at WHSV $=1.3$ ) and lifetime. Studying the organic species on partially and fully coked AFX samples showed that initially large organic species (phenanthrenes, anthracenes) form on the zeolite, while smaller species later occupy the remaining free cage volume. In contrast, for LEV and CHA zeolites (density of 15.9 and $15.1 \mathrm{~T} / 1000 \AA^{3}$, respectively) at partial coking, the size of the organics at maximum propylene selectivity correlated with the cages size (C2-benzenes for LEV, C3-C4-benzenes for CHA), while heavier carbonaceous species are only encountered later, at full coking. The average molecular weight of the hydrocarbon pool in this case continues to increase. For AFX, the average weight stayed more or less constant during deactivation. This suggests that materials with too large cages can deactivate faster and differently, based on the initial formation of large species right from the start, which could cause pore blockages. Recently, SFW was used for the first time in MTO, and compared to CHA and AFX because of their structural relation (see Figure 10, the SFW-cage is a $c$-axis expanded version of the AFX-cage). ${ }^{419}$ SFW produced equal amounts of C2 and C3 olefins and little butylenes (Table 10), as did AFX in this study (33/33/8 for AFX with $\mathrm{Si} / \mathrm{Al}=14.7$, similar to the tabulated value from another study). Product selectivity and deactivation for the elongated cages are very similar, as is the cage diameter and $8 \mathrm{MR}$ windows. Compared to $\mathrm{CHA}$, larger cages more readily produce organics that lead to faster deactivation.

Park et al. compared LTA (UZM-9, 14.2 T/1000 $\AA^{3}$ ), UFI (15.2 T/1000 $\AA^{3}$ ), and ERI (UZM-12, (16.2 T/1000 $\AA^{3}$ ) zeolites at $350{ }^{\circ} \mathrm{C}$ (Table 10) vs SAPO-34. ${ }^{420}$ UFI and LTA (lta-cage) showed propylene as main product, supplemented with both ethylene and medium amounts of butylenes, while ERI produced more or less $1 / 1 \mathrm{C} 2 / \mathrm{C} 3$ and a few $\mathrm{C} 4$ olefins. The ERI-zeolite tested by Kang et al. showed a somewhat higher ethylene/propylene ratio at peak olefin yield (50/23/5 for a $\mathrm{Si} / \mathrm{Al}=5.7) .{ }^{419}$ These materials with high Al-content $(\mathrm{Si} /$ $\mathrm{Al}=5-7$ ) gave a fast deactivation by coking, as evidenced from anthracene and phenanthrene molecules (quickly) present in the LTA and UFI cage and alkylated naphthalenes in ERI. These large polycyclic aromatics are typical dead-end coke species for this reaction and lead to pore-filling and cage blocking and thus active site and catalyst deactivation. CHA, on the other hand, with a smaller cage (Figure 7), allows the formation of multialkylbenzenes (active hydrocarbon pool species) but suppresses the formation of polycyclic aromatics, at least initially. However, since the UFI, ERI, and LTA materials tested all had very high acid site densities, deactivation paths could be different for Al-deficient materials. Since Boal et al. recently discovered an easy route to high-silica LTA (14.2 $\mathrm{T} / 1000 \AA^{3}$ ) zeolites, the MTO performance of these materials was especially interesting. As seen in Table 10, a $\mathrm{Si} / \mathrm{Al}=42$ LTA-zeolite (synthesis: Table 7, entry 11) showed low C2 + C3 olefin selectivities but a large fraction of butylenes and C5C6 molecules. Also, as a fast deactivation was noticed, it seems clear that the large lta-cavity of LTA favors the formation of higher-carbon number products and thus also likely easy deactivation by larger carbonaceous coking species (rather than being caused (only) by high Al-content in UZM-9). The selectivity toward butylenes was also clear in the SAPO version of LTA. $^{422}$ Table 10 suggests that zeolites UFI, KFI, and RHO, all containing the same lta-cage (although little differences exist, caused by the different connection mode), also show olefin distributions in favor of larger products, like LTA, although, comparing across different conditions and $\mathrm{Si} / \mathrm{Al}$ ratios is difficult. 

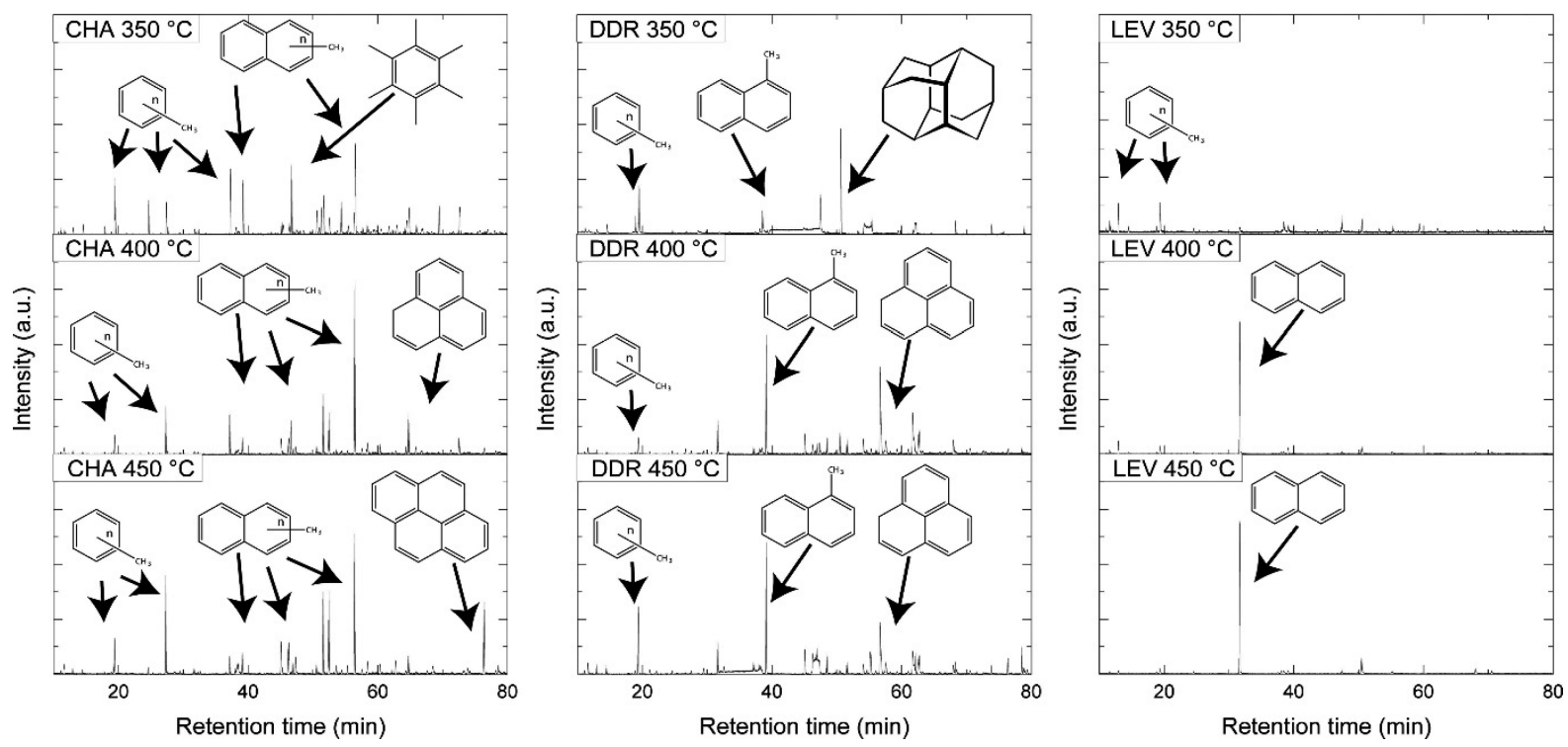

Figure 35. Coke analysis via GC-MS of soluble species in dichloromethane after HF-mediated breakdown of the zeolite in left: CHA (SSZ-13, Si/Al 60); middle: DDR (Sigma-1, Si/Al 50); and right: LEV ( $\mathrm{Si} / \mathrm{Al} \mathrm{30)}$. Reproduced with permission from Goetze et al. ${ }^{418}$ (ACS Author Choice open access).

An interesting case is the dense zeolite DDR with relatively small cages $\left(17.9 \mathrm{~T} / 1000 \AA^{3}\right)$, accessible only in $2 \mathrm{D}$ by ellipsoidal windows $(3.6 \AA \times 4.4 \AA)$. Compared to CHA (15.1 $\mathrm{T} / 1000 \AA^{3}$ ), for instance, this is a dense material, as CHA has $3.8 \AA \times 3.8 \AA$ pores, accessing the cage in 3D. Olson et al. indeed noticed a much faster diffusion of propane and propylene in CHA than in DDR- zeolites. ${ }^{110}$ Thus, apart from the size and shape of the cavity, the accessibility, determined by the dimensionality (1D-2D-3D) of the pore system and the shape of the $8 \mathrm{MR}$ windows, may matter as well. DDR produces virtually no saturated alkanes, as well as high amounts of C2 and C3 olefins (Table 10). ${ }^{246,417}$ In light of costly separation of alkanes from alkenes (e.g., propane from propylene), this could be interesting. Gascon and co-workers studied DDR by looking at the two different methods of making this zeolite (Sigma-1 and ZSM-58). ZSM-58 produced up to $80 \%$ of olefins at $400{ }^{\circ} \mathrm{C}$ (Table 10), while for Sigma-1, up to $90 \%$ of $\mathrm{C} 2+\mathrm{C} 3$ olefins can be yielded at $450{ }^{\circ} \mathrm{C}$ (not in table). As commonly encountered, the ethylene-to-propylene ratio depends on the temperature, e.g., for Sigma-1, going from 0.5 at $380{ }^{\circ} \mathrm{C}$ to 1.6 at $475{ }^{\circ} \mathrm{C}(\mathrm{Si} / \mathrm{Al}=58)$. The ratio also partially depends on catalyst morphology and composition.

A detailed study on the deactivation of zeolite using three different topologies, CHA, LEV (Nu-3), and DDR (Sigma-1), has been published by Goetze et al. $^{418}$ As seen in Figure 35, $\mathrm{CHA}$ coke species exist of methylated benzenes, methylated naphthalenes, and pyrene, while for DDR, 1-methylnaphthalene is mainly found, supplemented with diamantane after the 350 ${ }^{\circ} \mathrm{C}$ reaction. This molecule resembles the OSDA used for Sigma-1 (1-adamantlyamine, see section 2.3.4) but was confirmed to not come from the remains of the synthesis. LEV coke species consist mainly of naphthalene (and methylbenzenes at low $\mathrm{T}$ ), since larger species likely do not fit. An operando-UV-vis study further tried to distinguish the different species between the induction, active, and deactivation periods and at different temperatures. For an in-depth study of deactivation in MTO, with a focus on active intermediate, the reader is referred to the review by Olsbye et al., where SSZ-13 is also covered. ${ }^{426}$
Dusselier et al. studied MTO with SSZ-39 (AEI) noting high C3 and C4 selectivities and about $85 \%$ of olefins at full conversion. ${ }^{179}$ Schmidt et al. reported a new route to $\mathrm{RTH}$, assessing MTO performance in the process, and documenting around $70 \%$ of $\mathrm{C} 3+\mathrm{C} 4$ olefins (Table 10). ${ }^{169}$ Given the fact that the cage of RTH $\left(16.6 \mathrm{~T}\right.$ atoms/1000 $\left.\AA^{3}\right)$ is somewhat smaller than that of AEI $\left(15.1 \mathrm{~T} / 1000 \AA^{3}\right)$, these selectivities are intriguing, as they are not straightforwardly explained by the "large cage, large products" observations over for instance LTA $\left(14.2 \mathrm{~T} / 1000 \AA^{3}\right)$. A more detailed study on the origin of this selectivity is due, although parallels to SAPO-18 (AEI) vs SAPO-34 suggest that indeed the shape of the cage is important, the AEI cage being more basket-shaped and wider at the bottom than the more symmetric CHA cavity. ${ }^{425,427,428}$ SSZ-39 is a very interesting catalyst for MTO, but steaming was needed for optimal performance (section 3.4.3.2). No SAPO versions of RTH exist. Computational chemistry could be useful in this regard but so far has mainly focused on ZSM-5 and SAPO-34.

Sastre computationally screened a series of relevant cages (all found in Table 10), for the methylation of hexamethylbenzene ( $\mathrm{HMB})$, as a model reaction for successive methylation of a hydrocarbon pool species (before olefin expulsion), and for reactions leading to the formation of coke. ${ }^{429}$ In $\mathrm{RTH}, \mathrm{LEV}$, and AEI cavities it was found that it is impossible to host a linear $\mathrm{O}-\mathrm{C}\left(\mathrm{H}_{3}\right) \cdots \mathrm{C}(\mathrm{HMB})$ angle, required by the planar methyl group of methanol interacting with $\mathrm{HMB}$ (Figure 36). In other cavities, larger $\mathrm{O}-\mathrm{C}-\mathrm{C}$ angles (more linear) can be achieved, indicating this reaction to be more likely there. Whether this can be linked to active behavior or deactivation kinetics remains an open question.

Additional discussion on the impact of cavities (in light of the recent work of Kang et al.) taking in consideration other parameters such as $\mathrm{Si} / \mathrm{Al}$ ratio, is found in section 3.4.4 (also featuring zeolite ITE, found in Table 10).

3.4.3.2. Si/Al Ratio and the Presence of Paired Al. It seems that the inherent selectivity in terms of $\mathrm{C} 2 / \mathrm{C} 3 / \mathrm{C} 4$ ratio of a cage-containing MTO-active zeolite, at a fixed temperature and assessed at maximum $\mathrm{C} 3+\mathrm{C} 2$ olefins production, is not 

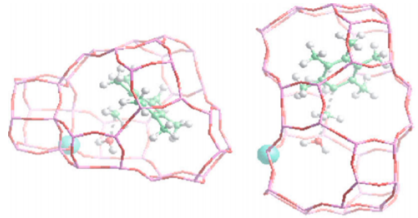

$\mathrm{AFX}$

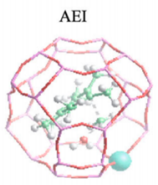

LEV

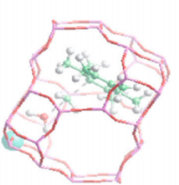

CHA

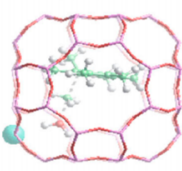

RHO

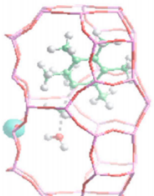

ERI

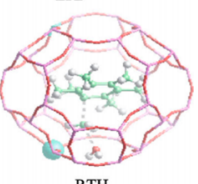

RTH
Figure 36. Cages of small-pore zeolites filled with the HMBmethylation transition state (green $=\mathrm{C}$, red $=\mathrm{O}$, white $=\mathrm{H}$, purple $=\mathrm{Si}$ ). For AEI, LEV, and RTH, the $\mathrm{O}-\mathrm{C}-\mathrm{C}$ angle is $150^{\circ}, 125{ }^{\circ}$ and $156,^{\circ}$ respectively, while larger values, closer to linear, are found for others. The $\mathrm{Al}$-atom close to the Brønsted acid site where methanol interacts is highlighted in blue. Reproduced with permission from ref 429. Copyright 2016 Springer.

strongly dependent on the $\mathrm{Si} / \mathrm{Al}$ ratio (for example: double entries in Table 10 for RHO, LEV, RTH at the same temperature, or for CHA in Figure 37 ). However, this does not mean transient behavior in olefin selectivities is absent, and often ethylene yields tend to rise during the time on stream. The Si/Al dependent behavior in MTO can be described for a couple of small-pore zeolites, where synthetic access to a diverse range of $\mathrm{Si} / \mathrm{Al}$ ratios exists (cf. Table 3) or from dealumination studies based on steaming.

Synthetic access has allowed for the investigation of the effects of Si/Al ratio with CHA (from 2.3 up to 67), ${ }^{201} \mathrm{RTH}$ $(\mathrm{Si} / \mathrm{Al}=17,29,59),{ }^{169} \mathrm{LTA}(\mathrm{Si} / \mathrm{Al}=12,33,38$, and 42 ; although it is more difficult to draw conclusions here), ${ }^{135}$ and $\operatorname{DDR}(\mathrm{Si} / \mathrm{Al}=32,55,107,198),{ }^{417}$ all made via the use of OSDA in hydroxide media, with the exception LTA (HF). Deimund et al. studied CHA thoroughly, concluding that lower $\mathrm{Si} / \mathrm{Al}$ ratios lead to drastically shorter catalytic lifetimes (e.g., less than $2 \mathrm{~h}$ for $\mathrm{Si} / \mathrm{Al}=17$ to more than $5 \mathrm{~h}$ for $\mathrm{Si} / \mathrm{Al}=55$ ) as well as significant transient ethylene selectivity and high light alkane initial selectivities (see A in Figure 37). The higher Si/Al ratio materials resembled the output of SAPO-34. The lifetime effect was also noticed before by Tatsumi and co-workers, ${ }^{201}$ but not the alkanes (perhaps also reaction condition related). The effects of the $\mathrm{Si} / \mathrm{Al}$ (transient nature, alkane production initially) were ascribed to the paired $\mathrm{Al}$ site content, that is increasingly present as the $\mathrm{Si} / \mathrm{Al}$ ratio drops. $\mathrm{Cu}^{2+}$ titration confirmed the paired $\mathrm{Al}$-site content along a theoretical line for "d6r only" zeolites (section 2.3.3.5 and Figure 16) ${ }^{430}$ and was plotted with the initial propane selectivity (B in Figure 37 ). In light of $\mathrm{Al}$-site density per cage, a $\mathrm{Si} / \mathrm{Al}$ ratio of 11 would translate to approximately 1 acid site per cage. Given that one cage consists of $36 \mathrm{~T}$ atoms, each shared over three cages in $\mathrm{CHA}$, and that pairing, inducing alkanes, assumes at least 2 per cage locally, it is clear that the optimal acid site density for MTO is less than 1 per cage for CHA. In the RTH series, higher initial alkane production was also encountered for lower $\mathrm{Si} / \mathrm{Al}$ materials.

Kumita et al. found an optimum MTO performance at $\mathrm{Si} / \mathrm{Al}$ $=55\left(400{ }^{\circ} \mathrm{C}\right)$ for ZSM-58 of the DDR topology, more or less corresponding to 1 acid site per cage. Less aluminum resulted in prompt deactivation, while more aluminum did not help either. ${ }^{417}$ However, Sigma-1, the other DDR zeolite made with a different organic (Figure 17), showed a reverse trend at 450 ${ }^{\circ} \mathrm{C}$. There, more methanol converted over the materials with the least amount of $\mathrm{Al}(\mathrm{Si} / \mathrm{Al}=158$ and 208 vs 60, for similar crystal sizes), and also the yield to ethylene increased, while propylene decreased. Interestingly, the $\mathrm{C} 2 / \mathrm{C} 3$ olefin ratio changes from 0.7 to 1.3 for $\mathrm{Si} / \mathrm{Al}$ ratios varying from 60 to 208, thus demonstrating a zeolite where acid site density influences olefin ratios. Also, for Sigma-1, the acid strength was varying with the $\mathrm{Al}$ content and, with that, the nature of some coke species. Truly exceptional in this series of DDR-zeolites is the very low $\mathrm{Al}$-content (e.g., $\mathrm{Si} / \mathrm{Al}=158$ ) that was able to still perform MTO. The differences between Sigma-1 and ZSM-58 are likely explained by the not-so constant particle sizes in the ZSM-58 series (section 3.4.3.3). What remains puzzling is why for the same $\mathrm{Si} / \mathrm{Al}$ ratio, ZSM-58 converts up to $3 \times$ more methanol before deactivation than Sigma-1. ${ }^{246}$

For some small-pore zeolite (Table 3), synthetic access to a wide range of $\mathrm{Si} / \mathrm{Al}$ ratios is not possible. However, using organic-free methods of zeolite production, $\mathrm{CHA}, \mathrm{RHO}$, and KFI materials with low $\mathrm{Si} / \mathrm{Al}$ ratios were subjected to steaming studies by $\mathrm{Ji}$ et al. ${ }^{22,267}$ For CHA (OSDA-free: $\mathrm{Si} / \mathrm{Al}=2.4$, Table 5, Entry 2) remarkable improvements were obtained. When steaming temperature and partial pressure are optimized and an additional acid washing step is incorporated, the time to deactivation at $400{ }^{\circ} \mathrm{C}$ MTO for instance increased from $1.3 \mathrm{~g}$ of methanol per $\mathrm{g}$ of catalyst to 5.0 (for a sample steamed at $600{ }^{\circ} \mathrm{C}$ and acid washed with a $0.1 \mathrm{M} \mathrm{HCl}$ solution). The same sample was able to produce $71 \%$ of olefins at full conversion at $450{ }^{\circ} \mathrm{C}$ with a time to deactivation of $9 \mathrm{~g} \cdot \mathrm{g}^{-1}$. The $\mathrm{Si} / \mathrm{Al}$ ratio only considering the framework $\mathrm{Al}$ (MAS NMR) of this treated $\mathrm{CHA}$ increased to 12 . For RHO and KFI, the steamed samples
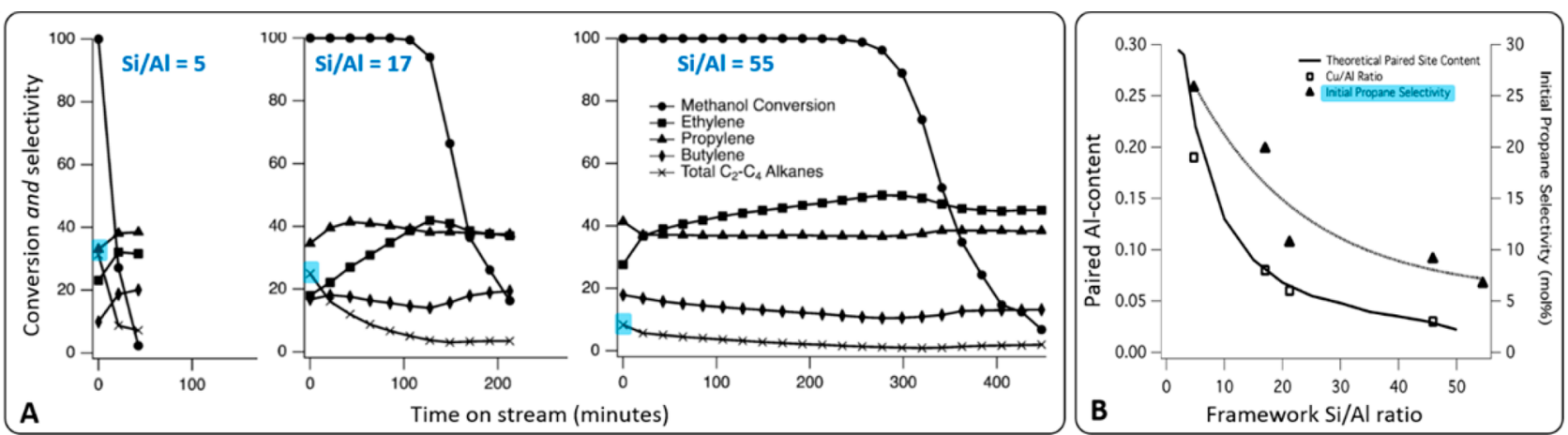

Figure 37. (A) MTO behavior for different $\mathrm{Si} / \mathrm{Al}$ in SSZ-13; (B) paired $\mathrm{Al}$ site content (fraction of framework $\mathrm{Al}$ ) and initial propane selectivity as a function of $\mathrm{Si} / \mathrm{Al}$ ratio. Based on data and plots in ref 416. Copyright 2016 American Chemical Society. WHSV: $1.3 \mathrm{~h}^{-1}, 400{ }^{\circ} \mathrm{C}$. 

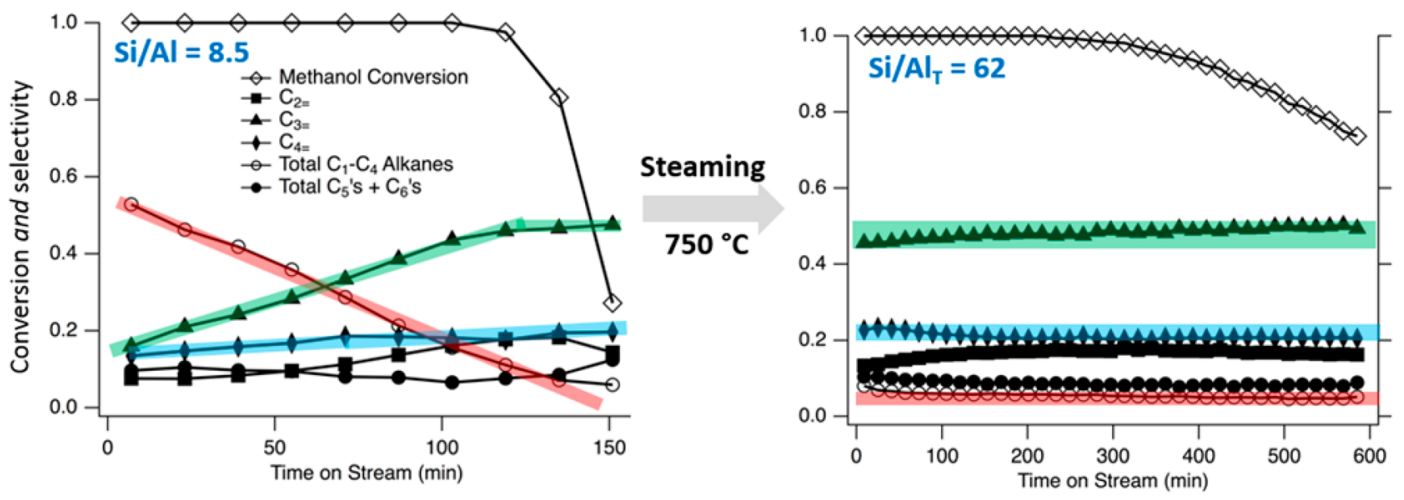

Figure 38. MTO performance of SSZ-39 (AEI) before and after steaming at $750{ }^{\circ} \mathrm{C}$ in its $\mathrm{NH}_{4}$-form. WHSV: $1.3 \mathrm{~h}^{-1}, 400{ }^{\circ} \mathrm{C}$. Red: alkanes, green: propylene, blue: butylene. Based on data and plots in ref 179. Copyright 2015 American Chemical Society.

showed increased lifetimes and olefin selectivities, but the conversion over the materials was never prolonged beyond $2 \mathrm{~h}$ on stream. Interestingly, steaming also created some mesoporosity, also thought to contribute to the increase in lifetime, by allowing better access to the micropores. Phosphite treatment of the external surfaces, to block acid sites locally, was found not to influence the inherent $\mathrm{C} 2 / \mathrm{C} 3 / \mathrm{C} 4$ olefin ratios, but it prolonged the lifetime further of steamed $\mathrm{RHO}$ and KFI zeolites. Likely, acid sites in mesopores made by steaming can also serve as sites for coke deposition.

Remarkable steaming improvements were also noted for SSZ-39. ${ }^{179}$ This zeolite is difficult to access in high $\mathrm{Si} / \mathrm{Al}$ ratios from synthesis (section 2.3.1, most materials around $\mathrm{Si} / \mathrm{Al}=5-$ 10). The $\mathrm{Si} / \mathrm{Al}=8.5$ material (easily accessed) shows quite mediocre MTO performance, characterized by fast deactivation, transient olefin selectivities, and high initial alkane production (Figure 38, left). After steaming at $750{ }^{\circ} \mathrm{C}$, however, a superior MTO catalyst was obtained, showing extraordinary lifetime, few alkanes, and a stable, high olefin production (85\%, Figure 38, right). Extra-framework $\mathrm{Al}$ in this case is still present inside the zeolite particles, but no lowering of the micropore volumes was found in $\mathrm{N}_{2}$-physisorption. The tetrahedral $\mathrm{Si} / \mathrm{Al}_{\mathrm{T}}$ ratio based on combining the bulk value and tetrahedral Al-fraction from Al-MAS NMR was calculated to be 62 (or lower if the steaming temperature was lower). This result is consistent with the crucial role of acid site density in the cages. The steamed SSZ39 catalyst converted over $11 \mathrm{~g} \cdot \mathrm{g}^{-1}$, and the experiment was halted before full deactivation.

3.4.3.3. Crystal Size. Crystal sizes can vary a lot from synthesis, and as documented in section 2, numerous researchers have targeted smaller crystals in their protocols with the aim of improving mass transport issues and, perhaps, coking problems in catalytic applications.

$\mathrm{Li}$ et al. compared the nanosized CHA zeolites obtained by $\mathrm{CTAB}$ addition (section 2.3.3) and noticed a remarkable conversion capacity increase from 4.2 to $10.4 \mathrm{~g} \cdot \mathrm{g}^{-1}$ when going from the standard, $1.5-2.5 \mu \mathrm{m}$ crystals, to the $50-200 \mathrm{~nm}$ nanocrystals (WHSV $0.8 \mathrm{~h}^{-1}, 350{ }^{\circ} \mathrm{C}$ ). ${ }^{208}$ Interestingly, the $\mathrm{C} 2 / \mathrm{C} 3$ ratio also increased for the nanosized samples. This was explained by the lower contribution of hydrogen transfer reactions, causing lower deactivation in the aromatic pool.

Yarulina et al., in their DDR study, also reported on the effect of crystal sizes for Sigma-1 (DDR) with $\mathrm{Si} / \mathrm{Al}$ ratio of 158, i.e., $0.4,2.4$, and $4.6 \mu \mathrm{m}$. Again, smaller crystals were able to convert more methanol, up to $3.6 \mathrm{~g}$ of methanol per $\mathrm{g}$ of catalysts, more than medium $\left(2.3 \mathrm{~g} \cdot \mathrm{g}^{-1}\right)$ or large-size crystals $\left(1.6 \mathrm{~g} \cdot \mathrm{g}^{-1}\right){ }^{246}$
The ethylene yield also dropped with increasing crystal sizes, while C3 and C4-olefins remained constant.

Finally, Martín et al. compared the small SSZ-39 crystals of about 40-50 nm, obtained from IZC (section 2.3.1, Table 4), to a larger SSZ-39 catalyst of $0.2-0.4 \mu \mathrm{m}$; both with $\mathrm{Si} / \mathrm{Al}$ around 8.5. ${ }^{188}$ The latter value is similar to the one shown in Figure 38, while the particle sizes are clearly smaller: around 0.5-1 $\mu \mathrm{m}$ was used in the work of Dusselier et al., and these values were apparently unaffected by steaming. Methanol conversion dipped below 50\% after 540 and $940 \mathrm{~min}$ on stream, for the large and nanocrystals, respectively (after a throughput of $7.2 \mathrm{~g} \cdot \mathrm{g}^{-1}$ and $\left.12.5 \mathrm{~g} \cdot \mathrm{g}^{-1}\right)$. Comparing throughputs with data in Figure 38 is difficult, as a different WHSV and temperature $\left(0.8 \mathrm{~h}^{-1}\right.$ and $\left.350{ }^{\circ} \mathrm{C}\right)$ were used for the nano-SSZ-39 study (although selectivities were in good agreement). ${ }^{179,188}$

3.4.3.4. Other Parameters: Seeding and Defects, Mesopores and Hierarchy. Gascon and co-workers reported an interesting comparison between DDR zeolites, Sigma-1 and ZSM-58, made with and without seeding syntheses. ${ }^{245}$ Seeding is known to speed up zeolite synthesis, either by speeding up nucleation or by core-shell growth around the seed crystals. Faster zeolite crystallization leads to framework imperfections, and this possibly affects MTO performance. Seeding ZSM-58 and Sigma-1 gave nanoparticles with average sizes of $100 \mathrm{~nm}$ in DLS, while direct hydrothermal synthesis yielded disks (12-15 $\mu \mathrm{m}$, Sigma-1) or spheres (0.5-1.6 $\mu \mathrm{m}, \mathrm{ZSM}-58)$. The lifetime at $450{ }^{\circ} \mathrm{C}$ was not linked to sizes in this case, in contrast to the discussion in the above section, and the larger crystals, made without seeds, often performed better. An SSZ-13 benchmark confirmed this. Characterization showed that the main difference between the seeded and the nonseeded zeolites was the large amount of defects, i.e., internal silanols and silanol nests, in seeded materials. It appears that one reason why seeded zeolites deactivate much faster is that the defects accelerate the formation of internal coke and that the positive effect on lifetime of particle size can thus be overridden in seeded small crystals. Finally, confirmation was found in an SSZ-13 zeolite with improved lifetime, after it was subjected to a postsynthetic defect-healing with $\mathrm{NH}_{4} \mathrm{~F}$, a method reported by Valtchev et al. ${ }^{431}$ This defect-induced impact on MTO is a crucial observation, as too often seeded zeolite catalysts are used without benchmarking the effect of their defects.

A large subfield of zeolite catalysis involves material hierarchy, aiming at enhanced mass transport via mesoporous access to microporous active sites. ${ }^{24,307,432}$ Olsbye and co- 
workers reported a desilication study of SSZ-13 with $\mathrm{Si} / \mathrm{Al}=$ 14, with $\mathrm{NaOH}$, for MTO. Mesopores were created at the expense of micropores. The methanol throughput significantly decreased for the mesoporous version and was said to originate from lower surface areas and acidity, while no evidence for larger coke species was found. Possibly, Lewis acidity, created in the mesoporous zeolite also catalyzed the aging of the hydrocarbon pool. ${ }^{433}$

Interestingly, the dual-template SSZ-13 reported by Hensen et al. (section 2.3.3), with micropores similar to the classic SSZ$13\left(0.21 \mathrm{~cm}^{-3} \cdot \mathrm{g}^{-1}\right)$ and containing about the same amount of mesopore volume, outperformed the nonmesoporous version in MTO: the lifetime, at WHSV of $0.8 \mathrm{~h}^{-1}$ and $350{ }^{\circ} \mathrm{C}$, more than doubled. ${ }^{218}$ This was said to come from a more efficient use of the micropore space, by an increase of the surface to volume ratio. These observations are in line with those of the Corma group regarding nanosized SSZ-13. A detailed follow-up study by the Hensen group showed that the increase of access needs to be balanced by an increase in the rate of coke formation. $^{219}$

The interesting bimodal microporous SSZ-13 derived from adding $\mathrm{NaF}$ in hydroxide media was tested in MTO and also gave a longer lifetime. The effect was more pronounced if the $\mathrm{F} / \mathrm{Si}$ ratio in the synthesis was higher ( 0.1 vs $0.05 \mathrm{~F}: \mathrm{Si}){ }^{434}$ The spatial coke distribution was visualized and showed that throughout the entire spent crystal, aromatics were found, versus mainly at the outer rim for the classic SSZ-13. Access again improved performance here, clearly, although the effects of defects in the F-rich conditions (given for example healing with $\mathrm{NH}_{4} \mathrm{~F}$ in the work of Yarulina et al. for DDR and CHA) should be investigated as well. The Hensen group further combined the mesoporogen approach with the bimodal micropores, and the trimodal material outperformed both other approaches. ${ }^{221}$ Confocal microscopy of spent catalysts, in the middle of single crystals, shows the much higher degree of utilization of the crystal, when the bimodal micropores or, in addition to that, mesopores are present (Figure 39). The trimodal catalyst does not light up with exposure from the 488 $\mathrm{nm}$ laser (Figure 39c), which is indicative of polymethylated naphthalenes. Likely for this faster catalyst, these species have already converted into bulkier multiring aromatics. The additional porosity clearly enhances the utilization of the crystals, said to originate from faster transport of methanol. The total methanol conversion capacity for the trimodal SSZ-13 resides in the range of $16-20 \mathrm{~g} \cdot \mathrm{g}^{-1}$, versus only $6.8 \mathrm{~g} \cdot \mathrm{g}^{-1}$ for the classic or $12.5 \mathrm{~g} \cdot \mathrm{g}^{-1}$ for the bimodal microporous version. $^{221}$

Selzer et al. investigated hierarchical DDR zeolites for MTO, made by desilication of a ZSM-58 material with $\mathrm{Si} / \mathrm{Al}=48$ using $\mathrm{NaOH}$ in the presence of TEA. Higher product yields and longer lifetimes were noted for the mesopore-containing zeolites, which also featured lower $\mathrm{Si} / \mathrm{Al}$ ratios. The benign effect of the mesopores was attributed to the increased acidity (although previous DDR work above found less Al to work better) and faster adsorption/desorption kinetics, the latter retarding coke formation. ${ }^{435}$

3.4.4. Overarching Analysis of Small-Pore Zeolite Cavities for MTO. Very recently, Kang et al. presented an interesting MTO study, arguably the most comprehensive set to date, comparing 11 framework topologies, as well as some interesting intergrowths (LEV/ERI: SSZ-105 and CHA/GME: SSZ-99) and an 8MR-zeolite with an unreported topology and an interesting, large cage (SSZ-27). ${ }^{419}$ The testing of ITE (cage

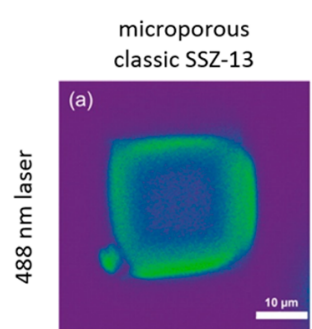

bimodal microporous SSZ-13
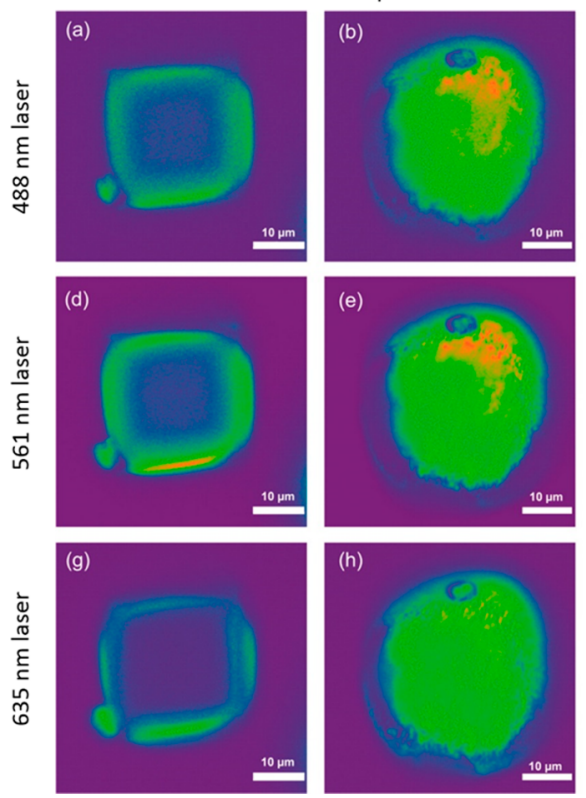

trimodal porous SSZ-13
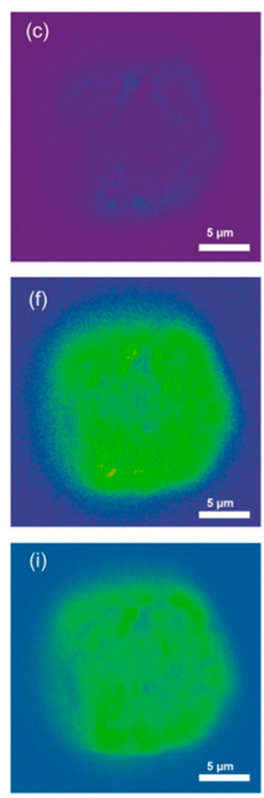

Figure 39. Confocal fluorescence microscopy images of different modal porous crystals collected after the MTO reaction. Images were taken in the middle plane of single crystals and are shown in false colors. The visualization of the coke species is done with different lasers. Adapted with permission from ref 221. Copyright 2016 American Chemical Society.

in Figure 5) and SSZ-27 (both having pentasil subunits as is also the case for DDR) shows that ITE produces double the amount of propylene versus ethylene (Table 10), while SSZ-27 deactivates quickly, likely due to its tortuous nature (not in IZA database so far).

This study visually confirms (Figure 40, left) and generalizes the correlation that the initial alkane production-higher at low $\mathrm{Si} / \mathrm{Al}$-noticed for CHA (Figure 37 above) is present for numerous structures. It also appears that the longer a single cage dimension, the more propane is formed, and this is linked to faster deactivation. Implications from these results are that more symmetrical cages are better, as one longer dimension diminishes lifetime. Also, the number of frameworks tested at the same conditions allows for the identification of four classes of behavior in terms of olefins selectivity (Figure 40, right):

(I) equal $\mathrm{C} 2$ and $\mathrm{C} 3$ olefins with low $\mathrm{C} 4$ olefins (CHA, AFX, SFW)

(II) more C2 than C3 olefins with low C4 olefins (LEV, ERI)

(III) less $\mathrm{C} 2$ than $\mathrm{C} 3$ olefins with $\mathrm{C} 4$ olefins equal to $\mathrm{C} 2$ olefins (AEI, RTH, DDR, ITE)

(IV) equal C2, C3, and C4 olefins (LTA, RHO)

The fact that pentasil units are found in DDR versus only d6r units in AEI but that they, sort of, behave the same indicates that such structural features are not the dominant reason for high propylene selectivities. The IV class, with very large but symmetrical cages, compared to cages that are only large in one dimension (SFW and AFX) reveals that not only size but also shape is crucial. ${ }^{419}$

3.4.5. Conclusions of Small-Pore Cage-Based ZeoliteCatalyzed MTO. When designing small-pore, cage-based zeolites for MTO, the following should be considered: 

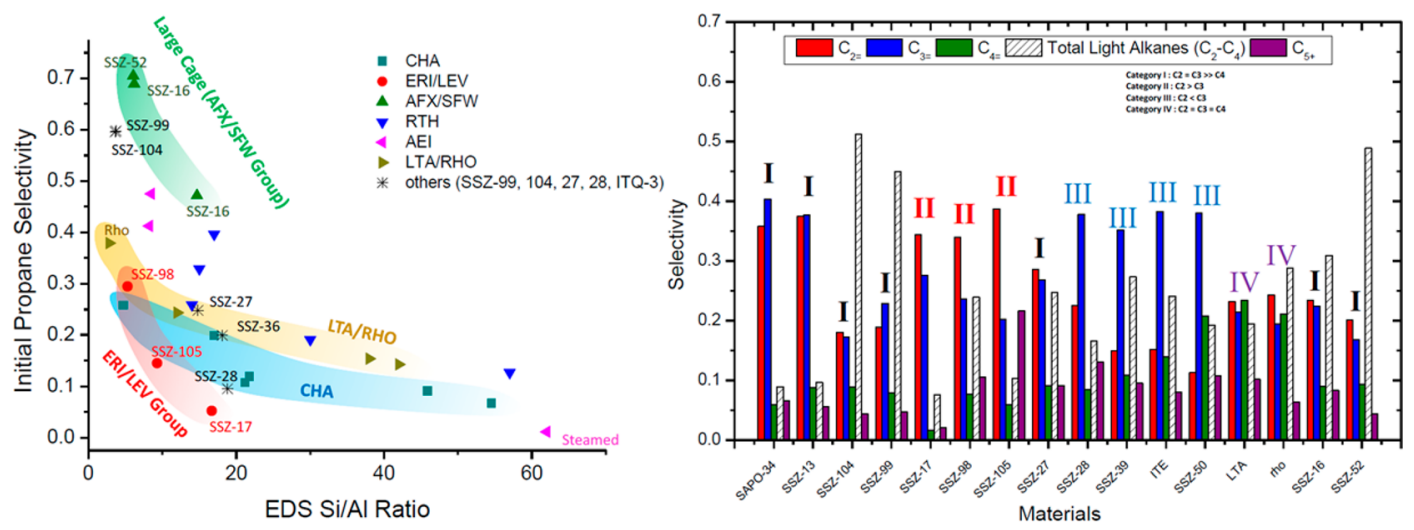

Figure 40. Left: initial propane selectivity after $<10 \mathrm{~min}$ on stream as a function of the tetrahedral $\mathrm{Si} / \mathrm{Al}$ ratio as measured by energy-dispersive $\mathrm{X}$-ray spectroscopy for a number of zeolites and intergrowths. Right: averaged product selectivities for conversions in the range of $98-100 \%$ for of a range of zeolites compared to SAPO-34. Four classes I-IV of behavior are indicated and explained in the text. Both plots reproduced with permission from Kang et al., ref 419 Copyright 2018 Wiley. Conditions of MTO reaction: $400{ }^{\circ} \mathrm{C}$, WHSV $1.3 \mathrm{~h}^{-1}$, 10\% methanol in inerts. SSZ-28 (DDR type); SSZ98 (ERI-type), SSZ-99, 104, and 105 are intergrowths or with stacking faults.

- have large enough cages to allow hydrocarbon pool species to form (e.g., not MTF)

- do not have too large of a cage (even a single dimension of the cage) for fast coking or accumulation of "dead" hydrocarbon pool species (e.g., too large: AFX), and if large, it seems better to have a symmetric one.

- there are four types of behavior in terms of olefin selectivity observed thus far, for different cages

- have a high number of cages per $\mathrm{nm}^{3}$ of solid (low T-site density is an indicator here, although large cages also lower this)

- have a 3D channel structure for optimal diffusion of reactants and products

- have at most one active site per cage

- avoid low $\mathrm{Si} / \mathrm{Al}$ ratios, as these element ratios favor high alkane production (Figure 40)

- minimize particle size and avoiding silanol defects

Thus, a conceptualized, ideal cage would be one that just barely can host the right hydrocarbon pool species needed, but not the coke precursors or e.g. bicyclic aromatics. At this time, although trends are increasingly unraveled, it is not yet clear how to design a crystalline structure to purposefully control the light olefin selectivities to any of the desired products (cf. AEI vs RTH vs DDR). A unifying concept to link the nature of light olefin production to the structure is thus still at large.

3.4.6. Olefin Generation from Ethanol or Ethylene Conversions: ETO and ETP. In addition to MTO, the ethanol-to-olefins process (ETO) is also well-known. Ethylene can be formed via simple dehydration, e.g. shown with $8 \mathrm{MR}$ zeolite ETL at $200{ }^{\circ} \mathrm{C},{ }^{77}$ but the mechanisms of olefin generation in ETO are more complex as higher olefins are also formed and multiple routes can be at work, e.g., identified in ZSM-5 by Galvita and co-workers. ${ }^{436}$ Also, the often considered crucial first $\mathrm{C}-\mathrm{C}$ bond's formation present in $\mathrm{MTO}$ is absent with ETO. ETO could be interesting when considering biobased ethanol, if sustainably sourced availability arises. Another common reaction in this context is the ethanol to butadiene conversion, ${ }^{437}$ requiring different chemistries, e.g., combining dehydrogenation and aldol condensation, often performed on nonporous oxides, or Lewis acidic large pore zeolites. ${ }^{438}$ ETO has been investigated mainly with ZSM-5 and SAPO- $34,{ }^{439}$ but also with zeolites SSZ-13 and MTF.
Tatsumi and co-workers studied the conversion of ethanol at $350{ }^{\circ} \mathrm{C}$ on H-SSZ-13 and H-MTF. While the CHA-type material yielded $25 \%$ of ethylene, $40 \%$ of propylene as well as some alkanes, MTF only led to $90 \%$ of ethylene, likely due to the small cage, and some diethyl ether. ${ }^{440}$ Itakura et al. assessed their SSZ-13 sample made via IZC using BTMA (Table 5, Figure 14), in ETO chemistry, at $400{ }^{\circ} \mathrm{C}$. At their conditions and full conversion, initial yields of 55, 35, and 3\% of ethylene, propylene, and butylenes were obtained. ${ }^{216}$ Itakura went on to study ETO on their materials in greater depth, and they found an interesting relation for the $\mathrm{Si} / \mathrm{Al}$ of the SSZ-13 zeolites, showing a maximum of $47 \%$ of propylene for $\mathrm{Si} / \mathrm{Al}=15$ (Figure 41). ${ }^{224}$ This behavior is related to the oligomerization ability of ethylene on acid sites. ${ }^{439}$

Inoue et al. also tested their LEV-zeolite made by IZC with choline hydroxide (Table 6, Entry 13) in the conversion of ethanol to olefins, at $400{ }^{\circ} \mathrm{C}$, with $36 \%$ of ethylene and $35 \%$ of propylene obtained initially (resembling those values in Table

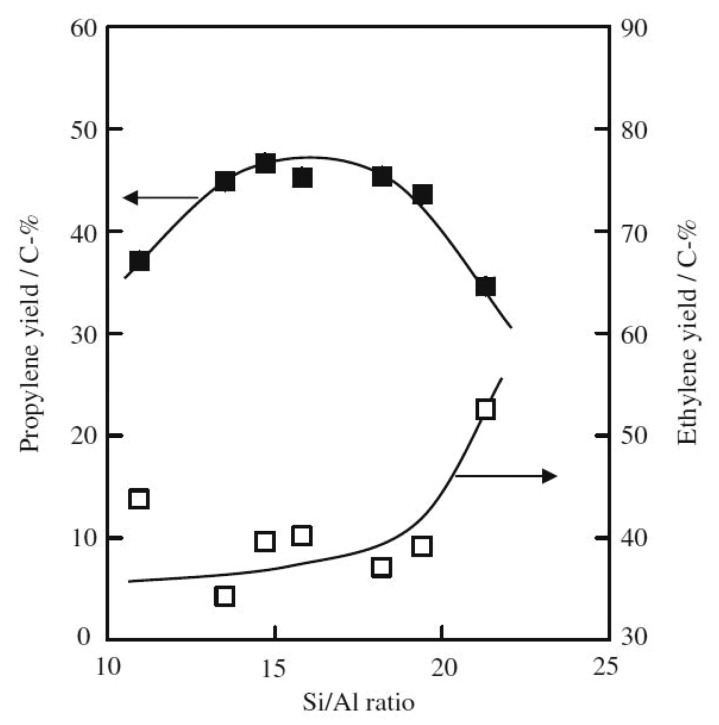

Figure 41. ETO at $400{ }^{\circ} \mathrm{C}$ on H-SSZ-13 showing different propylene and ethylene yields in function of different $\mathrm{Si} / \mathrm{Al}$ ratios obtained from IZC with BTMA. Reproduced with permission from ref 224. Copyright 2011 Elsevier. 


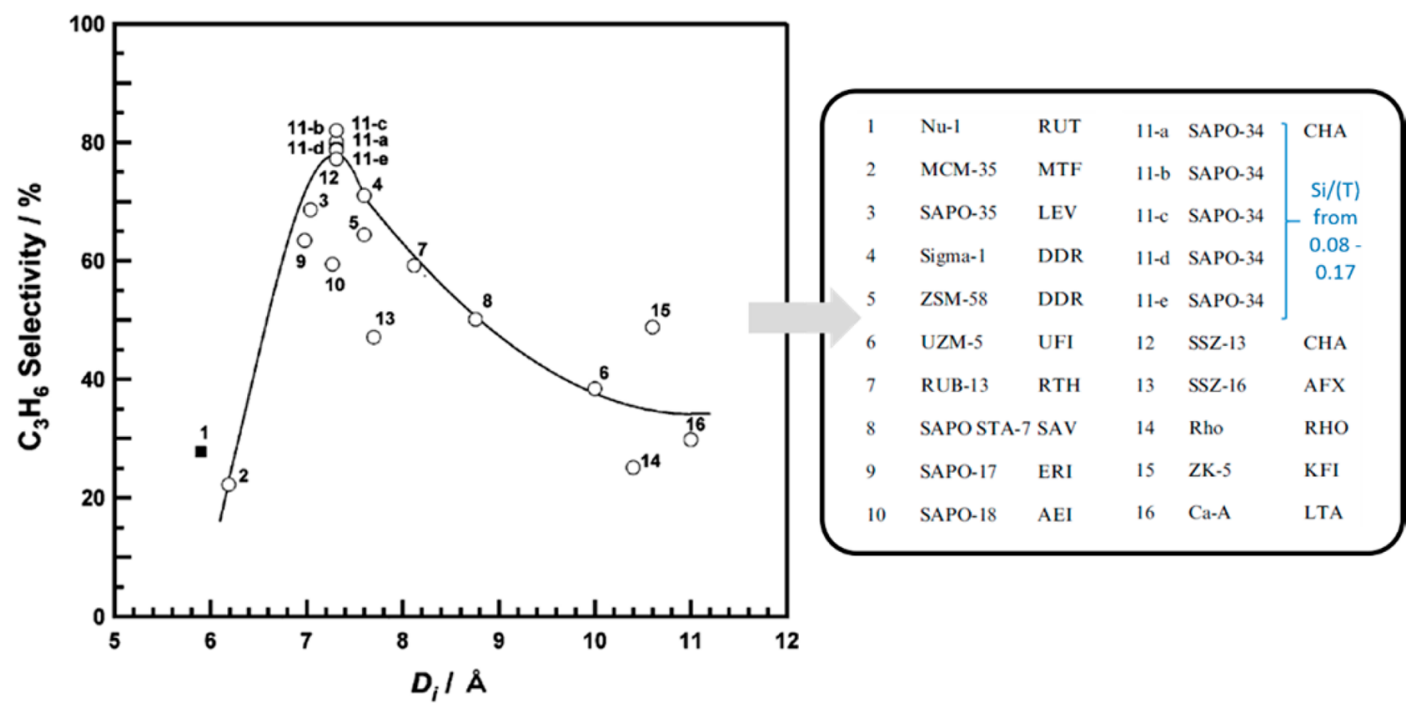

Figure 42. ETP on different $8 \mathrm{MR}$ topologies, with a focus on propylene selectivity, plotted as a function of $\mathrm{D}_{\mathrm{i}}$, diameter of the maximum included sphere in the framework (Foster et $\mathrm{al}^{444}$ ) $\mathrm{D}_{\mathrm{i}}$ is proportional to pore volume. Adapted from Koyama et al., ref 442 with permission of the PCCP Owner Societies.

10 for MTO). When coke starts forming, the selectivity to ethylene goes to $100 \%$. $^{284}$

Another reaction of interest, especially in the light of cheap ethylene from gas-fired steam crackers, e.g., in the US, ${ }^{441}$ is the conversion of ethylene to propylene (ETP, see Figure 2). Tatsumi and co-workers assessed ethylene feedstocks in their MTF-CHA comparison and found that while MTF was largely inactive, CHA converted $68 \%$ of ethylene into mainly propylene, with a $34 \%$ yield, and with some propane. ${ }^{440}$ When the coke content increased, the activity decreased, but the selectivity to C3 olefin increased. This is explained by the decreased hydrogen transfer reaction at high coking levels. Baba and co-workers reported a thorough study on the conversion of ethylene to propylene, ${ }^{42}$ as well as the conversion of butylene, ${ }^{443}$ with a focus on the effects of pore volume and topology. The study is a nice example of a dedicated effort to find topology-effects in catalysis. They suggested that in ETP, the propylene selectivity depends on the pore volume of the zeolite, rather than on classic pore size-sieving effects. ${ }^{442}$ Excellent propylene selectivities from, for example ethylene and pentene cracking, can be obtained based on selecting the right pore volume, that can accommodate the volume of an olefin and/or its carbenium ion. Figure 42 shows data that demonstrate a clear maximum for $8 \mathrm{MR}$ zeolites tested (also includes SAPO-data) for $\mathrm{D}_{\mathrm{i}}$ values (diameter of the maximum included sphere) around 7-7.6 A.

Interpretation aside $\left(D_{i}\right.$, cage size, sieving, hydrocarbon pool?, ...), the screening showed that CHA, DDR, ERI, and LEV (the usual suspects in MTO, viz. Table 10) attained propylene selectivities over $60 \%$ and clear superiority versus large-cage LTA, KFI, and RHO (although $\mathrm{Si} / \mathrm{Al}$ values did not always allow fair comparison).

Finally, Hunger and co-workers investigated the mechanism of ETP in detail over SSZ-13, and they noted a longer lifetime after dealumination, caused by a reduced coke formation at lower acid density. ${ }^{445}$ Also, the nanosized LEV zeolites by IZC, made with $N, N$-dimethylpiperidinium, were briefly assessed for the ethylene conversion at $400{ }^{\circ} \mathrm{C}$. The $35 \mathrm{~nm}$ crystals $(\mathrm{Si} / \mathrm{Al}=$ 10) displayed a better lifetime than a zeolite with $220 \mathrm{~nm}$ sized crystals. ETP was also studied in the case of IZC-derived CHA zeolites. $^{446}$

\subsection{Methylamine Synthesis}

3.5.1. Introduction to Zeolite-Catalyzed Methylamine Synthesis. Methylamines are crucial chemicals in many industrial processes. They are not only intermediates for amine-functionalized chemicals (pesticides, solvents, ...) but also have their own uses (water treatment). The Brønsted acidcatalyzed amination of methanol yields a thermodynamically controlled product profile, with trimethylamines (TrMA) being most abundant, followed by dimethylamine (DMA) and monomethylamine (MMA, structures, see Figure 2). For example, at the relevant $400{ }^{\circ} \mathrm{C}$ and for a $1 / 1 \mathrm{MeOH} / \mathrm{NH}_{3}$ feed, $62 \%$ of TrMA is predicted, versus only 17 and $21 \%$ of MMA and DMA, respectively, at $99 \% \mathrm{MeOH}$ conversion. From an application point-of-view, however, DMA and then MMA are the most important. ${ }^{447}$ Typically, a gas-phase process contacts methanol and ammonia at elevated temperature over a dehydrating catalyst, mostly run in an adiabatic plug flow reactor containing a fixed catalyst bed. In order to avoid TrMA formation (favored), H-MOR zeolites have been applied commercially for a while. ${ }^{448}$ The reader is referred to a thorough review in the field (dated, but the field does not expand during the last years), listing a large number of zeolites tested, and even individual data tables for small-pore RHO, CHA, KFI, and LTA. ${ }^{47}$

3.5.2. Small-Pore Zeolites for Methylamine Synthesis from Methanol and Ammonia. Generally, the acidic zeolite should hinder (the formation or) escape of TrMA $(3.9 \times 5.4 \times$ $6.1 \AA)$ from the pores, while still allowing DMA $(3.9 \times 4.7 \times$ $6.0 \AA)$ and MMA $(3.7 \times 3.9 \times 4.4 \AA)$ to form. ${ }^{164}$ Hong et al. tested a range of different small-pore zeolites in identical conditions, i.e., $\mathrm{H}$-form at $400{ }^{\circ} \mathrm{C}$. Similar and high conversions were attained for UFI, CHA, AFX, and RHO (Table 11), allowing fair comparison of the selectivities. For LEV, MTF, and DDR, however, lower conversions were found. The selectivity of UFI-zeolite is clearly the worst, and $>60 \%$ of TrMA is formed, versus for example only $8 \%$ for the Rho benchmark. The results can be rationalized on pore size effects given the larger diameter of the $8 \mathrm{MR}$ in UFI (the reader is 
Table 11. A List of the Different 8MR-Framework Zeolites Tested for Methanol Conversion in the Presence of Ammonia with Conversion (X), Selectivities (S), and Conditions

\begin{tabular}{|c|c|c|c|c|c|c|c|c|}
\hline Top. ${ }^{a}$ & Material $^{b}$ & $\mathrm{Si} / \mathrm{Al}$ & $\mathrm{T} / \mathrm{WHSV}\left({ }^{\circ} \mathrm{C} / \mathbf{h}^{-1}\right)$ & $\mathrm{X}_{\mathrm{MeOH}}(\%)$ & $\mathrm{D}_{\mathrm{MMA}}^{f}(\%)$ & $\mathbf{D}_{\mathrm{DMA}}^{f}(\%)$ & $\mathbf{D}_{\text {TrMA }}^{f}(\%)$ & Ref \\
\hline \multirow[t]{2}{*}{ RHO } & Rho & n.r. ${ }^{d}$ & $400 / 4.0$ & 90 & 34 & 53 & 13 & 450 \\
\hline & & 3.9 & $400 / 4.3$ & 88 & 31 & 61 & 8 & 164 \\
\hline AFX & SSZ-16 & 6.1 & $400 / 4.3$ & 89 & 27 & 63 & 11 & 164 \\
\hline \multirow[t]{2}{*}{ CHA } & SSZ-13 & 5.1 & $400 / 1.7$ & 93 & 39 & 49 & 13 & 164 \\
\hline & chabazite & 2.4 & $340 /-^{c}$ & 89 & 46 & 49 & 4 & 451 \\
\hline DDR & Sigma-1 & 16 & $400 / 0.34$ & 64 & 37 & 31 & 31 & 164 \\
\hline ERI & erionite & n.r. ${ }^{e}$ & $380 / 2.71$ & 87 & 26 & 32 & 42 & 447 \\
\hline KFI & ZK-5 & 3 & $400 / 2.0$ & 90 & 26 & 63 & 11 & 450 \\
\hline LEV & levyne & 7.9 & $400 / 0.34$ & 39 & 63 & 22 & 15 & 164 \\
\hline LTA & $5 \mathrm{~A}$ & 1 & $380 / 0.35$ & 99 & 31 & 51 & 19 & 447 \\
\hline MTF & MCM-35 & 29 & $400 / 0.34$ & 70 & 9 & 13 & 78 & 164 \\
\hline UFI & UZM-5 & 6.9 & $400 / 4.3$ & 93 & 17 & 21 & 61 & 164 \\
\hline
\end{tabular}

${ }^{a_{\text {Top. }}}=$ topology. ${ }^{b}$ Often other cations than $\mathrm{H}^{+}$also present. ${ }^{c} \mathrm{~W} / \mathrm{F}: 67 \mathrm{~g} \cdot \mathrm{h} \cdot \mathrm{mol}^{-1} .{ }^{d}$ Likely standard Si/Al for Rho around 3-4. ${ }^{e} \mathrm{Natural}$ mineral, often around 3. ${ }^{J}$ Distribution of methylamine products (C\%). Often, minute amounts of dimethylether are also formed: e.g. for $\mathrm{LEV}, 27 \%$ of $\mathrm{MeOH}$ conversion is to methylamine products, while for SSZ-13, this is $90 \%$.

referred to the online database of the IZA). ${ }^{3}$ Furthermore, the cage volume, and the dimensionality were also suggested to matter, as these could be at the origin of the suboptimal MTF, LEV, and DDR performance. CHA, AFX, and LEV were also compared in both zeolite and SAPO versions, to assess acid strength and densities. However, a $\mathrm{Si} / \mathrm{Al}$ variation within one optimal zeolite has not been performed. Overall, AFX and RHO were found to be the most selective zeolites in that study, and the data in Table 11 show that higher selectivities, with the exception of KFI, are not encountered. KFI was studied thoroughly, by Shannon and co-workers, but found to be less active and stable than RHO. ${ }^{449}$

\subsection{Other Relevant Reactions}

3.6.1. Cracking. Since the beginnings of shape-selectivity $(\text { Weisz })^{452,453}$ all types of zeolites have been tested in reactions involving the cracking of hydrocarbons. In the early days, the focus was mainly placed on natural $8 \mathrm{MR}$ zeolites and LTA, since few synthetic small-pore materials existed. Aside from chabazite, ${ }^{454}$ natural mineral erionite (ERI) was investigated. ${ }^{455}$ Small-pore zeolites offer the advantage in cracking that the intracrystalline $8 \mathrm{MR}$ pores allow discriminating between paraffins ( $n$-alkanes) and larger isoparrafins (branched), e.g., valid in hexane cracking, as the branched isomers do not easily enter (reactant type shape-selectivity). On top of that, Chen et al. noted the cage effect for the first time, when cracking $n$ alkane $\mathrm{C}_{22} \mathrm{H}_{46}$ over erionite and found odd product distributions. Remarkably absent were products with $\mathrm{C} 1-\mathrm{C} 2$, $\mathrm{C} 7-\mathrm{C} 9$ and $>\mathrm{C} 12$ carbon numbers indicating additional effects in addition to classic cracking mechanisms. The missing products undergo secondary cracking, while e.g., C10-C12, fragments were said to be able to cross the cage of ERI (bridging across two $8 \mathrm{MR}$ windows), while diffusing along an $8 \mathrm{MR}$ pore. ${ }^{104} \mathrm{C} 7-\mathrm{C} 9$ fragments were indeed found to have very low diffusivities in ERI, compared to longer or shorted alkanes and are trapped in the zeolite (cages), allowing further cracking to $\mathrm{C} 3-\mathrm{C} 4$ products. ${ }^{456}$ It is worth noting that Barrer had already in the 1950s studied the geometric factors involved in diffusion, by looking at the channels of small-pore natural mineral zeolites of the LEV, CHA, and ERI type. ${ }^{457}$ A detailed cracking study by Weitkamp and co-workers focused on smallpore zeolites and $n$-octane (allowing $\beta$-scission) as the substrate. $^{243}$ LTA, CHA (chabazite), LEV (Nu-3), RHO (Rho), the two types of DDR, and KFI (ZK-5) were used in a fixed-bed setup. Haag-Dessau monomolecular cracking (C1C3 products, few branching) was found to be dominant and more prominent as the pores narrow. Bimolecular cracking products (branched) were also detected, such as isobutane and isobutene. Bimolecular hydrogen transfer is hindered in $8 \mathrm{MR}$ zeolites, leading to more olefins than paraffins, but no pure monomolecular cracking was observed. Selectivities to $\mathrm{C} 1$ and C2 products increased with decreasing pore-window size (e.g., RHO < LTA) and increasing spatial constraint (LEV, DDR). The selectivities of LEV, DDR, and RHO were over $30 \%$ for $\mathrm{C} 1-2$ products, versus only $15-21 \%$ for CHA, KFI, and LTA with larger $8 \mathrm{MR}$ windows (than $\mathrm{RHO}$ ).

Aside from cracking with ERI-zeolites and the zeolite series mentioned above, the hydrocracking of $n$-decane has been reported on $\mathrm{Nu}-6$ zeolite (NSI topology) with $\mathrm{Si} / \mathrm{Al}=45$. It was shown to be an active and selective dewaxing catalyst yielding $76 \%$ of cracking products at $79 \%$ conversion. ${ }^{49}$ Santilli and Zones reported on SSZ-16 (AFX) with Si/Al = 6 for the cracking of hexane and hexadecane in the light of studying shape-selectivity. ${ }^{458}$ While hexane and hexadecane both cracked when fed separately, hexadecane ceased to convert in a 50/50 feedstock mixture. Due to the steric nature of this effect, caused by both the small pore and the presence of hexane, this behavior was denoted as an example of "secondary shapeselectivity".

Yun and Lobo reported propane cracking on H-SSZ-13, and they unearthed a structure-activity relation based on thermal treatment for $\mathrm{Si} / \mathrm{Al}=6$ and 12 materials. ${ }^{459}$ Without treatment, both propane cracking and dehydrogenation reaction rates were similar. Interestingly, after a mild thermal treatment $\left(500{ }^{\circ} \mathrm{C}\right)$, the zeolites started to crack more selectively $(2 \times)$, while the high temperature treatment $\left(550-800{ }^{\circ} \mathrm{C}\right)$ enhanced their dehydrogenation behavior. The authors hinted to the formation of another, new type of active site (not Brønsted) in SSZ-13 after the harsh treatment.

3.6.2. Structure-Activity Relation of Al-Pairing in CHA for Dimethyl Ether Formation. The paired $\mathrm{Al}$ series (Figure 16 and the updated work by Gounder et al.) were used to elaborate an elegant synthesis-structure-activity relation for the Brønsted catalyzed dehydration of methanol to DME. It was seen that the rates were 1 order of magnitude smaller on isolated protons, versus those on acid sites in paired arrangements. Evidence was presented to state that such paired 
protons can access alternate reactions paths that are inaccessible to isolated acid sites. ${ }^{237}$

\section{SUMMARY-OPPORTUNITIES-OUTLOOK}

\subsection{General Summary}

(1) Cundy and Cox disagreed with the tendency that many researchers have to label the hydrothermal synthesis of zeolites as poorly understood or as a kind of alchemical mystery. ${ }^{96}$ The synthesis of new frameworks in the 1960 s, especially LTA in the 8MR group, sparked fundamental studies and revealed a lot about hydrothermal synthesis mechanisms when alkali are used in hydrothermally treated gels. Although some aspects of inorganic cation-directed zeolite synthesis in hydrothermal media remain unexplained, like the effect of concentration (water content) on phase competition and relative growth rates, a great deal of these crystallization pathways have been elucidated to some extent. However, the introduction of OSDAs complicates and expands the conceptual view of zeolite synthesis, as has the use of zeolites as source materials (interzeolite conversion) and the roles of seeding. A proof of this complication is found in the charge density mismatch approach, leading to new 8MR zeolite UFI with common TEA, TMA, and Na combinations. Also, the same OSDA can lead to (a range of) completely different zeolites (e.g., Figure 9: AEI vs GME). This is especially the case when the organics are on the smaller side relative to the intrazeolite pore space, and when the OSDA has numerous conformations in solution. OSDA-based syntheses in fluoride media without aluminum and alkali are simpler systems to rationalize how the OSDA leads to a particular topology. Smaller OSDAs and alkali can also stabilize smaller cages, composite building blocks, or tiles of the framework, besides residing in the main cage of the small-pore zeolite. What structural unit they stabilize at what time in the synthesis process depends on the conditions and inorganics used, and an overarching explanation for these interactions is missing. The most useful $8 \mathrm{MR}$ zeolites from a catalytic point of view feature larger cages with $8 \mathrm{MR}$ access. The larger cage is useful in structure prediction or when optimizing synthetic strategies, as they are the voids mostly filled with OSDA. In the case where OSDAs have a decent but not very tight fit with such cages, the $\mathrm{Si} / \mathrm{Al}$ ratio of the product is hard to control. In that situation, it appears that cage-based, small-pore zeolites are driven toward an optimal $\mathrm{Si} / \mathrm{Al}$ ratio, depending on the overall charge balance (e.g., 1 OSDA cation per cage) and the ease (or difficulty) of building in siloxy defects in the material (section 2.4).

(2) The last 15 years have seen remarkable progress in the synthesis of $8 \mathrm{MR}$ zeolites, and a few are highlighted: the pentamethylimidazolium route to RTH; the IZC route to CHA with TEA; the DM3 $(4 \mathrm{MB})$ or supramolecular assembly route to LTA; the IZC routes to AEI and LEV; control over the Al-pairing in CHA via the Na/ADAM ratio or its particle size via growth-modifiers; the isoreticular series based on RHO; the synthesis of ERI and UFI through charge density mismatch; and last but not least the discoveries of the first 2D 8MR zeolite layer (RTH) and SFW, a zeolite with an 18-layer structure.
(3) The use of OSDAs in hydroxide media is the main route in the synthesis of $8 \mathrm{MR}$ zeolites, although for some zeolites, the use of HF is beneficial, e.g., when $d 4 r$ need stabilization in high-silica composition. In some synthesis, $\mathrm{NaF}$ or $\mathrm{NH}_{4} \mathrm{~F}$ is added to hydroxide-rich synthesis media with interesting results (e.g., IZC of FAU to LEV, Table 6; or the trimodal porous CHA). Interzeolite conversion (not the highly alkaline versions) and charge density mismatch approaches are two successful routes, also with OSDAs, to diversify synthesis routes toward existing frameworks (e.g., TEA for CHA), to attain new $\mathrm{Si} / \mathrm{Al}$ ratios for a given framework (e.g., AEI) or even yield new zeolites (e.g., UFI by OSDA cooperation).

(4) Small-pore zeolites have been used in a range of fundamentally interesting or commercially relevant catalytic reactions. $\mathrm{Cu}-\mathrm{SSZ}-13$ catalysts are now the commercial standard in certain diesel-exhaust cleaning systems, and excellent selectivities, activity, and times-onstream stability have been documented in methanol-toolefins catalysis, e.g., with CHA, AEI, and DDR-zeolites. The higher stability of aluminosilicates versus SAPOs or other zeotypes may be beneficial in the light of longer catalyst's lifetime, especially in repeated reaction/ regeneration catalytic processes, as is the case in commercial MTO (now with SAPO). However, the cost of the aluminosilicate should be competitive. Specifically, for the case of MTO, zeolites seem able to compete in terms of performance, with SAPO-34 but the latter are made with cheap amines, instead of (often) quaternary ammonium OSDAs. The cost of a zeolite is largely determined by the cost of the organic and the synthesis time in a given reactor unit. Some of the OSDAs needed for $8 \mathrm{MR}$ zeolite synthesis are not currently available (e.g., the new benzyl-imidazolium for LTA), while others are commercially accessible at the large scale (TEA, TMA, choline) or in close alignment with industrial precursors (e.g., dimethylpiperidines for AEI). Useful benchmarks for OSDA-cost assessment are the commercial ADAM used in SSZ-13 synthesis for SCR, estimated to cost around 20-30 USD $\cdot \mathrm{kg}^{-1}$ and TEA, at 3-5 USD $\cdot \mathrm{kg}^{-1}$.

(5) The progress in synthesis has led to a more widespread exploration of $8 \mathrm{MR}$ zeolites in heterogeneous catalyzed gas-phase processes. The new routes to AEI, RTH, LTA, and RHO, for example, now give synthetic access to a wider range of $\mathrm{Si} / \mathrm{Al}$ ratios, allowing catalytic tests to be run with a more appropriate acid or active site density. An important example here is the new synthesis route to LTA using DM3(4MB), leading to the discovery of a very efficient SCR catalyst, that at certain conditions, is outperforming $\mathrm{Cu}-\mathrm{SSZ}$-13. Apart from improvements in controlling the Al-content, for selected zeolites, the finetuning of particle sizes, hierarchy, and even some control over the pairing or isolation of $\mathrm{Al}$ has been reported (CHA, Figure 16). This synthetic control over the zeolite properties has led to improvements in catalytic performance of certain $8 \mathrm{MR}$-topologies.

(6) New reactivities for small-pore zeolites can still be found. The partial oxidation of methane to methanol on $\mathrm{Cu}$ centers in SSZ-39 and SSZ-13 was for instance first reported in 2015 (Table 9). The reaction is now mostly performed in a cycle involving methanol extraction and reactivation after every reaction, although catalytic 
processes have been documented, for the first time, in recent years. For this reaction, catalytic development will need to focus on increasing the productivities drastically while synthesis efforts could be directed toward increasing the numbers of active sites per gram of zeolite support.

\subsection{Opportunities in Synthesis and Catalysis}

In no particular order, some opportunities in the synthesis and catalysis with $8 \mathrm{MR}$ zeolites are as follows:

- For some $8 \mathrm{MR}$ frameworks with catalysis-relevant features, access to higher $\mathrm{Si} / \mathrm{Al}$ ratios is lacking. Table 3 provides an extensive overview, although the $\mathrm{Si} / \mathrm{Al}$ limits of AEI (max $25\left(\mathrm{OH}^{-}\right)$), EAB (max. 3), ERI (max. 8 ), KFI (max. 4), and RHO (max. 8) come to mind. This challenge becomes even more formidable if one is to consider a cost-effective synthesis route.

- In this context-e.g., KFI with less $\mathrm{Al}$, or more costeffective routes-the computational prediction of suitable OSDAs for a given lattice, as successfully demonstrated by Deem and co-workers for SFW, STW, and AEI, ${ }^{137,138,185,333}$ should be further explored.

- Given the new OSDA for high-silica LTA, i.e., DM3(4MB), and the proposed mechanism for LTA-synthesis starting with the construction of the large cage; the synthesis of KFI and RHO, with the same $\alpha$-cage differently connected, could be explored with DM3$(4 \mathrm{MB})$ in conditions resembling that of RHO and KFI. A second OSDA to consider for LTA and KFI syntheses is the $\mathrm{Cs}^{+}-18$-crown-6-ether complex reported for RHO.

- The forty-four existing $8 \mathrm{MR}$ zeolites (Table 1) are part of the $8 \mathrm{MR}$ molecular sieve family totaling seventy-six zeotypes. There are thus thirty-two small-pore frameworks that are, so far, unattainable in zeolite composition. Four of these are pure-silicates (Table 2), while the remaining ones usually are (metallo)aluminophosphates. Some of these structures could be highly unique catalysts when access to their zeolite counterpart is found. One such example is the SAV topology $\left(\mathrm{MgAlPO}_{4}\right){ }^{271}$ a 3D framework with large, unusual cages, that can be exclusively built from d6r units, and that is closely related to KFI.

- The control of the pairing or isolation of $\mathrm{Al}$ sites in CHA could be expanded to other frameworks relevant in catalysis with an abundance in 6MR (LEV, AEI, KFI) and perhaps even 8MR zeolites with 5MR (RTH, DDR). Such control can undoubtedly lead to catalytic insights and new synthesis-structure-activity relationships.

- The cage-count approach, detailed for AEI, CHA, and LEV, and discussed in section 2.4, should be applied to other cage-containing zeolites.

- Tables 1 and 3 present more zeolite materials than those used in catalysis, i.e., Table $8,9,10$ or 11 . Given the structure-activity relations detailed above, some candidates could be worthy of investigation, e.g., EAB or PAU for SCR or MTO (provided they can be made with less aluminum or dealuminated) or RHO for the partial oxidation of methane. For the latter, the SCR overview can be useful, as the same metal precursor to the respective active sites is used. SFW and ETL, recent additions to the $8 \mathrm{MR}$ zeolite group, are also relatively unexplored in catalysis.
- The search for alternative MTO catalysts is still ongoing, and significant advantages could be achieved for zeolites that would be more selective to a single olefin, i.e., specific to propylene or ethylene.

- The performance of the steamed AEI in MTO is highly promising, especially when $\mathrm{C} 4$ olefins are valued more than ethylene. The recent improvements in synthetic access to AEI with larger $\mathrm{Si} / \mathrm{Al}$ ratios (Table 3) would be helpful.

- A detailed study of the effects of seeding on defect formation in zeolite synthesis is needed. The work on DDR showed that secondary growth from seeds can lead to materials rife with defects and deteriorated MTO performance. $^{245}$ Although seeding is used a lot as a synthetic tool to enhance nucleation/crystallization rates and phase selectivity, the consequences of their use on catalysis are rarely investigated in comparison to nonseeded materials.

- Fe-containing small-pore zeolites could be more broadly assessed in SCR, and for the low-temperature partial oxidation of methane (with $\mathrm{N}_{2} \mathrm{O}$ activation).

- Although not within the scope of this review, the recent development of siliceous $8 \mathrm{MR}$ zeolites containing Lewis acid framework atoms (e.g., $\mathrm{Sn}^{460}$ and $\mathrm{Ti}^{461}$ in CHA, $\mathrm{Ti}$ in LTA, ${ }^{135} \mathrm{Zn}$ in $\left.\mathrm{AEI}^{462}\right)$ is worth noting. In the context of catalysis (e.g., MTO or methylamine synthesis) such Lewis acidic sites could display unexpected selectivities. $^{18,463,464}$

\subsection{Outlook}

Changes in global energy, carbon (feedstock) and environmental challenges (point-source pollution control) are demanding innovative solutions. Material science and catalytic technology have a large role to play in dealing with the key issues. For instance, feedstocks in the (petro)chemical industry are shifting to a more gaseous nature and with them, the required specifications of catalytic and porous materials. Smallpore zeolites have proven potential in the MTO reactions, as well as in engine pollution control based on NOx removal. The catalytic potential of cage-containing, small-pore $8 \mathrm{MR}$ aluminosilicates is obviously large and growing. Engineering smallpore zeolites to this end and tailoring them to applications is clearly an active component of modern catalytic technology.

The recently increasing interest in using $8 \mathrm{MR}$ zeolites has sparked innovation in the synthesis of these types of materials (small pore zeolites have been ignored for several decades due to the emphasis on medium pore materials like ZSM-5), and a large number of new strategies have been reported recently. In years to come, control over the $\mathrm{Al}$-substitution, both in content and exact location in the framework, will be a topic of research and debate. Structure-activity relations based on active site elucidation (e.g., $\mathrm{Cu}$ in SCR or partial methane oxidation) under working catalytic conditions (operando) will spark further interest in controlling the porous host and the location of its framework charge. The search for a $100 \%$ selective MTO catalyst based on the shape of the cage and its Al-distribution is another example. In SCR, the question of how structure leads to stability remains to be elucidated, and the role of the shape of the cage and the mechanisms of framework protection by active divalent cations are not completely understood. The relation between starting and product zeolite in IZC is puzzling, and the mechanism of these syntheses is clearly different from standard hydrothermal syntheses starting from amorphous 
reagents. The exploitation of IZC for different purposes, not only the synthesis of a given zeolite with $\mathrm{Si} / \mathrm{Al}$ control, but also active-site control (e.g., $\mathrm{Cu}$ in situ) or metal encapsulation is in its early stages of development. Finally, computation has shown that likely, there are framework-dependent, preferred $\mathrm{Al}$ contents and locations for proton-balanced zeolite ( $\mathrm{Si}, \mathrm{Al})$ systems. In future work, such computation will include OSDAs and all other cations present, in order to simulate not only the energetic minima of the framework but also those of the OSDA-framework hybrid (the true product of a synthesis) and its Al-location. In reverse, computation will also play an increasingly larger role in synthesis, via the prediction of feasible OSDAs for a given lattice (e.g., the success with SFW). The charge density mismatch approach as well as the tuning of Al pairing in CHA clearly shows that the role of charged cations, i.e., their nature, quantity, density, and interactions with other charged species (both cations and anionic Al-incorporations), is crucial to the synthesis path followed and, therefore, the end-product, the kinetic construct that is a zeolite. It is expected that the role of the OSDA as a charge center, and not only a space-filler, will be better understood.

\section{AUTHOR INFORMATION}

\section{Corresponding Authors}

*E-mail: michiel.dusselier@kuleuven.be.

*E-mail: mdavis@cheme.caltech.edu.

\section{ORCID 10}

Michiel Dusselier: 0000-0002-3074-2318

Mark E. Davis: 0000-0001-8294-1477

Notes

The authors declare no competing financial interest.

\section{Biographies}

Michiel Dusselier (1986, Kortrijk, Belgium) obtained his Ph.D. degree in Bioscience Engineering (Catalytic Technology, 2013) at KU Leuven under the guidance of Prof. Bert Sels and Prof. Pierre Jacobs, inventing new catalytic routes for bioplastics synthesis. In 2014-15, he did postdoctoral work with Mark Davis at Caltech, studying the synthesis of zeolites and methanol-to-olefins. He is now a tenure-track research professor at the Center for Surface Chemistry and Catalysis of KU Leuven focusing on zeolite synthesis methods and novel zeotype architectures, generally in the context of sustainable chemistry, gas conversion, and functional bioplastics. He has (co)authored ca. 40 peer-reviewed papers and 6 patents, of which one transferred to industry.

Mark E. Davis is the Warren and Katharine Schlinger Professor of Chemical Engineering at the California Institute of Technology. He has over 450 scientific publications, two textbooks, and over 90 US patents. Professor Davis was a founding editor of CaTTech and has been an associate editor of Chemistry of Materials and the AIChE Journal. Professor Davis was the first engineer to win the NSF Alan T. Waterman Award. He was elected in the National Academy of Engineering in 1997, the National Academy of Sciences in 2006, and the National Academy of Medicine in 2011. In 2014, he received the Prince of Asturias Award for Technical and Scientific Research from the King of Spain, and in 2015, he was elected into the National Academy of Inventors.

\section{ACKNOWLEDGMENTS}

M.D. thanks Research Foundation - Flanders (FWO) for funding, KU Leuven BOF for his appointment to Research
Professor, Katrin Boden for general support, and Jong Hun Kang for making some of the 3D framework visualizations. M.E.D. thanks the coauthors of the papers his group has published on the synthesis and catalytic behavior of $8 \mathrm{MR}$ zeolites and Chevron and Dow for funding those investigations.

\section{ABBREVIATIONS}

Abbreviations not found in this list = topology-designating three-letter codes (e.g., AEI), material names (e.g., CIT-9), or specific composite building units (e.g., can (-cage))

$8 \mathrm{MR}=$ eight-member(ed) ring, with members being $\mathrm{T}$ atoms, technically, 16 atoms are in the ring

$\mu \mathrm{mol} \cdot \mathrm{g} \mathrm{cat}^{-1}=\mu \mathrm{mol}$ per gram of catalyst

ADAM $=N, N, N$-trimethyl-1-adamantyl-ammonium

BTMA $=N, N, N$-trimethylbenzylammonium

$\mathrm{CDM}=$ charge density mismatch

$\mathrm{CTAB}=$ hexadecyl trimethylammonium bromide

$\mathrm{CVD}=$ chemical vapor deposition

$\mathrm{d} 6 \mathrm{r}=$ double six-ring (also $\mathrm{d} 4 \mathrm{r}$, d8r exists)

$\mathrm{DABCO}=$ 1,4-diazabicyclo[2.2.2] octane

DEDMA = diethyldimethylammonium

Diquat $=$ diquaternary OSDA

DLS = dynamic light scattering

DM3(4MB) = 1,2-dimethyl-3-(4-methylbenzyl)imidazolium

$\mathrm{DME}=$ dimethyl ether

IZA = International Zeolite Association

IZC = interzeolite conversion

$\mathrm{MeQ}=N$-methylquinuclidium

MMA, DMA, TrMA = mono-, di-, trimethylamine

NMR = nuclear magnetic resonance spectroscopy

OSDA = organic structure directing agent

PDDAC $=$ poly (diallyldimethylammonium chloride $)$

PEIM = polyethylenimine

$\mathrm{PXRD}=$ powder $\mathrm{X}$-ray diffraction

$\mathrm{Si} / \mathrm{Al}=$ molar silicon to aluminum ratio

TEA = tetraethylammonium

TEOS $=$ tetraethylorthosilicate

TEP = tetraethylphosphonium

TGA = thermogravimetric analysis

TMA = tetramethylammonium

T-range $=$ temperature range

\section{REFERENCES}

(1) Barrer, R. M. Zeolites and Their Synthesis. Zeolites 1981, 1, 130140.

(2) Chen, H.-Y. In Urea-Scr Technology for Denox after Treatment of Diesel Exhausts; Nova, I., Tronconi, E., Eds.; Springer New York: New York, NY, 2014.

(3) International Zeolite Association: Structure Commission. Database of Zeolite Structures, http://www.iza-structure.org/.

(4) Zones, S. I. US 4,544,538, 1985.

(5) Dent, L. S.; Smith, J. V. Crystal Structure of Chabazite, a Molecular Sieve. Nature 1958, 181, 1794-1796.

(6) Feng, P.; Bu, X.; Stucky, G. D. Hydrothermal Syntheses and Structural Characterization of Zeolite Analogue Compounds Based on Cobalt Phosphate. Nature 1997, 388, 735-741.

(7) Zanardi, S.; Millini, R.; Frigerio, F.; Belloni, A.; Cruciani, G.; Bellussi, G.; Carati, A.; Rizzo, C.; Montanari, E. Ers-18: A New Member of the Non-Euo-Nes Zeolite Family. Microporous Mesoporous Mater. 2011, 143, 6-13.

(8) Smeets, S.; Xie, D.; McCusker, L. B.; Baerlocher, C.; Zones, S. I.; Thompson, J. A.; Lacheen, H. S.; Huang, H.-M. Ssz-45: A High-Silica Zeolite with Small Pore Openings, Large Cavities, and Unusual Adsorption Properties. Chem. Mater. 2014, 26, 3909-3913. 
(9) Dusselier, M.; Van Wouwe, P.; Dewaele, A.; Jacobs, P. A.; Sels, B. F. Shape-Selective Zeolite Catalysis for Bioplastics Production. Science 2015, 349, 78-80.

(10) Vermeiren, W.; Gilson, J. P. Impact of Zeolites on the Petroleum and Petrochemical Industry. Top. Catal. 2009, 52, 11311161.

(11) Flanigen, E. M.; Broach, R. W.; Wilson, S. T. Zeolites in Industrial Separation and Catalysis; Wiley-VCH Verlag $\mathrm{GmbH} \&$ Co. KGaA, 2010.

(12) Vogt, E. T. C.; Weckhuysen, B. M. Fluid Catalytic Cracking: Recent Developments on the Grand Old Lady of Zeolite Catalysis. Chem. Soc. Rev. 2015, 44, 7342-7370.

(13) Degnan, T. F., Jr The Implications of the Fundamentals of Shape Selectivity for the Development of Catalysts for the Petroleum and Petrochemical Industries. J. Catal. 2003, 216, 32-46.

(14) Freyhardt, C. C.; Tsapatsis, M.; Lobo, R. F.; Balkus, K. J.; Davis, M. E. A High-Silica Zeolite with a 14-Tetrahedral-Atom Pore Opening. Nature 1996, 381, 295-298.

(15) Wagner, P.; Yoshikawa, M.; Tsuji, K.; Davis, M. E.; Lovallo, M.; Taspatsis, M. Cit-5: A High-Silica Zeolite with 14-Ring Pores. Chem. Commun. 1997, 2179-2180.

(16) Kresge, C. T.; Leonowicz, M. E.; Roth, W. J.; Vartuli, J. C.; Beck, J. S. Ordered Mesoporous Molecular Sieves Synthesized by a LiquidCrystal Template Mechanism. Nature 1992, 359, 710.

(17) Jae, J.; Tompsett, G. A.; Foster, A. J.; Hammond, K. D.; Auerbach, S. M.; Lobo, R. F.; Huber, G. W. Investigation into the Shape Selectivity of Zeolite Catalysts for Biomass Conversion. J. Catal. 2011, 279, 257-268.

(18) Ferrini, P.; Dijkmans, J.; De Clercq, R.; Van de Vyver, S.; Dusselier, M.; Jacobs, P. A.; Sels, B. F. Lewis Acid Catalysis on Single Site Sn Centers Incorporated into Silica Hosts. Coord. Chem. Rev. 2017, 343, 220-255.

(19) Dapsens, P. Y.; Mondelli, C.; Perez-Ramirez, J. Design of LewisAcid Centres in Zeolitic Matrices for the Conversion of Renewables. Chem. Soc. Rev. 2015, 44, 7025-7043.

(20) Guo, Q.; Fan, F.; Pidko, E. A.; van der Graaff, W. N. P.; Feng, Z.; Li, C.; Hensen, E. J. M. Highly Active and Recyclable Sn-Mww Zeolite Catalyst for Sugar Conversion to Methyl Lactate and Lactic Acid. ChemSusChem 2013, 6, 1352-1356.

(21) Moliner, M.; Roman-Leshkov, Y.; Davis, M. E. Tin-Containing Zeolites Are Highly Active Catalysts for the Isomerization of Glucose in Water. Proc. Natl. Acad. Sci. U. S. A. 2010, 107, 6164-6168.

(22) Holm, M. S.; Saravanamurugan, S.; Taarning, E. Conversion of Sugars to Lactic Acid Derivatives Using Heterogeneous Zeotype Catalysts. Science 2010, 328, 602-605.

(23) Jacobs, P. A.; Dusselier, M.; Sels, B. F. Will Zeolite-Based Catalysis $\mathrm{Be}$ as Relevant in Future Biorefineries as in Crude Oil Refineries? Angew. Chem., Int. Ed. 2014, 53, 8621-8626.

(24) Ennaert, T.; Van Aelst, J.; Dijkmans, J.; De Clercq, R.; Schutyser, W.; Dusselier, M.; Verboekend, D.; Sels, B. F. Potential and Challenges of Zeolite Chemistry in the Catalytic Conversion of Biomass. Chem. Soc. Rev. 2016, 45, 584-611.

(25) Wulfers, M. J.; Teketel, S.; Ipek, B.; Lobo, R. F. Conversion of Methane to Methanol on Copper-Containing Small-Pore Zeolites and Zeotypes. Chem. Commun. 2015, 51, 4447-4450.

(26) Jiao, F.; Pan, X.; Gong, K.; Chen, Y.; Li, G.; Bao, X. ShapeSelective Zeolites Promote Ethylene Formation from Syngas Via a Ketene Intermediate. Angew. Chem., Int. Ed. 2018, 57, 4692-4694.

(27) Gao, P.; Li, S.; Bu, X.; Dang, S.; Liu, Z.; Wang, H.; Zhong, L.; Qiu, M.; Yang, C.; Cai, J.; et al. Direct Conversion of Co2 into Liquid Fuels with High Selectivity over a Bifunctional Catalyst. Nat. Chem. 2017, 9, 1019-1024.

(28) Lawton, S. L.; Rohrbaugh, W. J. The Framework Topology of Zsm-18, a Novel Zeolite Containing Rings of Three (Si,Al)-O Species. Science 1990, 247, 1319-1322.

(29) Yoshikawa, M.; Wagner, P.; Lovallo, M.; Tsuji, K.; Takewaki, T.; Chen, C.-Y.; Beck, L. W.; Jones, C.; Tsapatsis, M.; Zones, S. I.; et al. Synthesis, Characterization, and Structure Solution of Cit-5, a New,
High-Silica, Extra-Large-Pore Molecular Sieve. J. Phys. Chem. B 1998, 102, 7139-7147.

(30) Burton, A.; Elomari, S.; Chen, C.-Y.; Medrud, R. C.; Chan, I. Y.; Bull, L. M.; Kibby, C.; Harris, T. V.; Zones, S. I.; Vittoratos, E. S. Ssz53 and Ssz-59: Two Novel Extra-Large Pore Zeolites. Chem. - Eur. J. 2003, 9, 5737-5748.

(31) Moliner, M.; Martínez, C.; Corma, A. Synthesis Strategies for Preparing Useful Small Pore Zeolites and Zeotypes for Gas Separations and Catalysis. Chem. Mater. 2014, 26, 246-258.

(32) Chiyoda, O.; Davis, M. E. Adsorption Studies with Gmelinite Zeolites Containing Mono-, Di- and Tri-Valent Cations. Microporous Mesoporous Mater. 2000, 38, 143-149.

(33) Dusselier, M.; Kang, J. H.; Xie, D.; Davis, M. E. Cit-9: A FaultFree Gmelinite Zeolite. Angew. Chem., Int. Ed. 2017, 56, 1347513478 .

(34) Barrer, R. M.; White, E. A. D. 283. The Hydrothermal Chemistry of Silicates. Part I. Synthetic Lithium Aluminosilicates. J. Chem. Soc. 1951, 1267-1278.

(35) Kerr, G. T., US Patent 3459,676, 1969.

(36) Zones, S. I.; Nakagawa, Y.; Evans, S. T.; Lee, G. S. US 5,958,370, 1999.

(37) Corma, A.; Rey, F.; Rius, J.; Sabater, M. J.; Valencia, S. Supramolecular Self-Assembled Molecules as Organic Directing Agent for Synthesis of Zeolites. Nature 2004, 431, 287-290.

(38) Lobo, R. F.; Zones, S. I.; Medrud, R. C. Synthesis and Rietveld Refinement of the Small-Pore Zeolite Ssz-16. Chem. Mater. 1996, 8, 2409-2411.

(39) Zones, S. I., US 4508837, 1985.

(40) Acara, N. A.; Breck, D. W., US3011869 A, 1961.

(41) Barrer, R. M.; White, E. A. D. 286. The Hydrothermal Chemistry of Silicates. Part Ii. Synthetic Crystalline Sodium Aluminosilicates. J. Chem. Soc. 1952, 1561-1571.

(42) Acara, N. A., US3414602 A, 1968

(43) Ikeda, T.; Itabashi, K. Rma-3: Synthesis and Structure of a Novel Rb-Aluminosilicate Zeolite. Chem. Commun. 2005, 2753-2755.

(44) Barrer, R.; Baynham, J. 562. The Hydrothermal Chemistry of the Silicates. Part Vii. Synthetic Potassium Aluminosilicates. J. Chem. Soc. 1956, 2882-2891.

(45) Takeuchi, Y.; Haga, N.; Ito, J. The Crystal Structure of Monoclinic Caal2si2o8: A Case of Monoclinic Structure Closely Simulating Orthorhombic Symmetry. Z. Kristallogr. - Cryst. Mater. 1973, 137, 380-398.

(46) Rubin, M. K., US4820502, 1989.

(47) Rubin, M. K. US4981663 A, 1991

(48) Khodabandeh, S.; Lee, G.; Davis, M. E. Cit-4: The First Synthetic Analogue of Brewsterite. Microporous Mater. 1997, 11, 8795.

(49) Zanardi, S.; Alberti, A.; Cruciani, G.; Corma, A.; Fornés, V.; Brunelli, M. Crystal Structure Determination of Zeolite Nu-6(2) and Its Layered Precursor Nu-6(1). Angew. Chem., Int. Ed. 2004, 43, 49334937.

(50) Hughes, R. W.; Weller, M. T. The Structure of the Cas Type Zeolite, Cs4[Al4si20o48] by High-Resolution Powder Neutron Diffraction 29si Mas and Nmr. Microporous Mesoporous Mater. 2002, 51, 189-196.

(51) Guo, P.; Shin, J.; Greenaway, A. G.; Min, J. G.; Su, J.; Choi, H. J.; Liu, L.; Cox, P. A.; Hong, S. B.; Wright, P. A.; et al. A Zeolite Family with Expanding Structural Complexity and Embedded Isoreticular Structures. Nature 2015, 524, 74-78.

(52) Knight, L. M.; Miller, M. A.; Koster, S. C.; Gatter, M. G.; Benin, A. I.; Willis, R. R.; Lewis, G. J.; Broach, R. W. In Stud. Surf. Sci. Catal.; Xu, Z. G. J., Wenfu, Y., Eds.; Elsevier, 2007; Vol. 170.

(53) Casmer, S. G.; Dhingra, S.; Kresge, C. T. WO2002042208, 2002.

(54) Vaughan, D. E. W.; Strohmaier, K. G. Synthesis of Ecr-18 - a Synthetic Analog of Paulingite. Microporous Mesoporous Mater. 1999, 28, 233-239.

(55) Zones, S. I.; Yuen, L. T.; Miller, S. J. US 6709644, 2004. 
(56) Kuhl, G. H. Synthetic Phillipsite. Am. Mineral. 1969, 54, 16071612 .

(57) Stewart, A.; Johnson, D. W.; Shannon, M. D. In Stud. Surf. Sci. Catal.; Grobet, P. J., Schulz-Ekloff, G., Eds.; Elsevier, 1988; Vol. 37, pp $57-64$.

(58) Valyocsik, E. W. US4698217, 1987.

(59) Robson, H. E.; Shoemaker, D. P.; Ogilvie, R. A.; Manor, P. C. In Molecular Sieves; American Chemical Society, 1973; Vol. 121.

(60) Aiello, R; Barrer, R. M. Hydrothermal Chemistry of Silicates. Part Xiv. Zeolite Crystallisation in Presence of Mixed Bases. J. Chem. Soc. A 1970, 1470-1475.

(61) Meier, W. M.; Groner, M. Zeolite Structure Type Eab: Crystal Structure and Mechanism for the Topotactic Transformation of the Na, Tma Form. J. Solid State Chem. 1981, 37, 204-218.

(62) Lee, G. S.; Zones, S. I. Polymethylated [4.1.1] Octanes Leading to Zeolite Ssz-50. J. Solid State Chem. 2002, 167, 289-298.

(63) Ghobarkar, H.; Schäf, O. Hydrothermal Synthesis and Morphology of Thomsonite and Edingtonite. Cryst. Res. Technol. $1997,32,653-657$.

(64) Sherman, J. D. In Molecular Sieves-II; American Chemical Society, 1977; Vol. 40.

(65) Zones, S.; Burton, A. US7138007, 2006.

(66) Xie, D.; McCusker, L. B.; Baerlocher, C.; Zones, S. I.; Wan, W.; Zou, X. Ssz-52, a Zeolite with an 18-Layer Aluminosilicate Framework Structure Related to That of the Denox Catalyst Cu-Ssz-13. J. Am. Chem. Soc. 2013, 135, 10519-10524.

(67) Ghobarkar, H. The Morphology of Hydrothermally Grown Epistilbite. Cryst. Res. Technol. 1984, 19, 1571-1573.

(68) Khodabandeh, S.; Davis, M. E. Zeolites P1 and L as Precursors for the Preparation of Alkaline-Earth Zeolites. Microporous Mater. 1997, 12, 347-359.

(69) Miller, M. A.; Lewis, G. J.; Moscoso, J. G.; Koster, S.; Modica, F.; Gatter, M. G.; Nemeth, L. T. In Stud. Surf. Sci. Catal.; Xu, G. J. C., Wenfu, Y., Eds.; Elsevier, 2007; Vol. 170, pp 487-492.

(70) Lee, J. H.; Park, M. B.; Lee, J. K.; Min, H.-K.; Song, M. K.; Hong, S. B. Synthesis and Characterization of Eri-Type Uzm-12 Zeolites and Their Methanol-to-Olefin Performance. J. Am. Chem. Soc. 2010, 132, 12971-12982.

(71) Campbell, B. J.; Cheetham, A. K.; Bellussi, G.; Carluccio, L.; Perego, G.; Millini, R.; Cox, D. E. The Synthesis of the New Zeolite, Ers-7, and the Determination of Its Structure by Simulated Annealing and Synchrotron X-Ray Powder Diffraction. Chem. Commun. 1998, $1725-1726$

(72) Park, M. B.; Ahn, N. H.; Broach, R. W.; Nicholas, C. P.; Lewis, G. J.; Hong, S. B. Crystallization Mechanism of Zeolite Uzm-5. Chem. Mater. 2015, 27, 1574-1582.

(73) Blackwell, C. S.; Broach, R. W.; Gatter, M. G.; Holmgren, J. S.; Jan, D.-Y.; Lewis, G. J.; Mezza, B. J.; Mezza, T. M.; Miller, M. A.; Moscoso, J. G.; et al. Open-Framework Materials Synthesized in the Tma+/Tea+ Mixed-Template System: The New Low Si/Al Ratio Zeolites Uzm-4 and Uzm-5. Angew. Chem., Int. Ed. 2003, 42, 17371740.

(74) Baerlocher, C.; Meier, W. The Crystal Structure of Synthetic Zeolite Na-P 1, an Isotype of Gismondine. Z. Kristallogr. 1972, 135, 339-354.

(75) Hawkins, D. B. Zeolite Studies I. Synthesis of Some Alkaline Earth Zeolites. Mater. Res. Bull. 1967, 2, 951-958.

(76) Barrer, R. M.; Marshall, D. J. 86. Hydrothermal Chemistry of Silicates. Part Xii. Synthetic Strontium Aluminosilicates. J. Chem. Soc. 1964, 485-497.

(77) Bae, J.; Cho, J.; Lee, J. H.; Seo, S. M.; Hong, S. B. Eu-12: A Small-Pore, High-Silica Zeolite Containing Sinusoidal Eight-Ring Channels. Angew. Chem., Int. Ed. 2016, 55, 7369-7373.

(78) Cantín, A.; Corma, A.; Leiva, S.; Rey, F.; Rius, J.; Valencia, S. Synthesis and Structure of the Bidimensional Zeolite Itq-32 with Small and Large Pores. J. Am. Chem. Soc. 2005, 127, 11560-11561.

(79) Jordá, J. L.; Rey, F.; Sastre, G.; Valencia, S.; Palomino, M.; Corma, A.; Segura, A.; Errandonea, D.; Lacomba, R.; Manjón, F. J.; et al. Synthesis of a Novel Zeolite through a Pressure-Induced
Reconstructive Phase Transition Process. Angew. Chem., Int. Ed. 2013, 52, 10458-10462.

(80) Valtchev, V.; Paillaud, J. L.; Lefebvre, T.; Le Nouen, D.; Kessler, $\mathrm{H}$. Synthesis and Characterization of Mu-14: An Aluminosilicate Zeolite with Ite-Type Topology. Microporous Mesoporous Mater. 2000, 38, 177-185.

(81) Camblor, M. A.; Corma, A.; Villaescusa, L. A. US 6500404 B1, 2002

(82) Barrett, P. A.; Boix, T.; Puche, M.; Olson, D. H.; Jordan, E.; Koller, H.; Camblor, M. A. Itq-12: A New Microporous Silica Polymorph Potentially Useful for Light Hydrocarbon Separations. Chem. Commun. 2003, 2114-2115.

(83) Yang, X.; Camblor, M. A.; Lee, Y.; Liu, H.; Olson, D. H. Synthesis and Crystal Structure of as-Synthesized and Calcined Pure Silica Zeolite Itq-12. J. Am. Chem. Soc. 2004, 126, 10403-10409.

(84) Marler, B.; Grünewald-Lüke, A.; Gies, H. Decasils, a New Order-Disorder Family of Microporous Silicas. Zeolites 1995, 15, 388399.

(85) Marler, B.; Grünewald-Lüke, A.; Gies, H. Structure Refinement of the as-Synthesized and the Calcined Form of Zeolite Rub-3 (Rte). Microporous Mesoporous Mater. 1998, 26, 49-59.

(86) Grünewald-Lüke, A.; Marler, B.; Gies, H. Synthesis and Characterization of the Microporous Silica Phase Rub-3 (Rte). Microporous Mesoporous Mater. 1998, 26, 37-48.

(87) Robson, H. U.S. Patent 3,720,753, 1973.

(88) Kerr, G. T. Zeolite Zk-5: A New Molecular Sieve. Science 1963, 140,1412 .

(89) Marler, B.; Ströter, N.; Gies, H. The Structure of the New Pure Silica Zeolite Rub-24, Si32o64, Obtained by Topotactic Condensation of the Intercalated Layer Silicate Rub-18. Microporous Mesoporous Mater. 2005, 83, 201-211.

(90) Ikeda, T.; Oumi, Y.; Takeoka, T.; Yokoyama, T.; Sano, T.; Hanaoka, T. Preparation and Crystal Structure of Rub-18 Modified for Synthesis of Zeolite Rwr by Topotactic Conversion. Microporous Mesoporous Mater. 2008, 110, 488-500.

(91) Davis, M. E.; Lobo, R. F. Zeolite and Molecular Sieve Synthesis. Chem. Mater. 1992, 4, 756-768.

(92) Weigel, O.; Steinhoff, E. IX. Die Aufnahme Organischer Flüssigkeitsdämpfe Durch Chabasit. Z. Kristallogr. - Cryst. Mater. 1924, 61, 125.

(93) Tian, P.; Wei, Y.; Ye, M.; Liu, Z. Methanol to Olefins (Mto): From Fundamentals to Commercialization. ACS Catal. 2015, 5, 19221938.

(94) Nedyalkova, R.; Montreuil, C.; Lambert, C.; Olsson, L. Interzeolite Conversion of Fau Type Zeolite into Cha and Its Application in Nh3-Scr. Top. Catal. 2013, 56, 550-557.

(95) Gao, F.; Kwak, J. H.; Szanyi, J.; Peden, C. H. Current Understanding of $\mathrm{Cu}$-Exchanged Chabazite Molecular Sieves for Use as Commercial Diesel Engine Denox Catalysts. Top. Catal. 2013, 56, $1441-1459$

(96) Cundy, C. S.; Cox, P. A. The Hydrothermal Synthesis of Zeolites: History and Development from the Earliest Days to the Present Time. Chem. Rev. 2003, 103, 663-702.

(97) Meng, X.; Xiao, F.-S. Green Routes for Synthesis of Zeolites. Chem. Rev. 2014, 114, 1521-1543.

(98) Li, Y.; Yu, J. New Stories of Zeolite Structures: Their Descriptions, Determinations, Predictions, and Evaluations. Chem. Rev. 2014, 114, 7268-7316.

(99) Snyder, B. E. R.; Bols, M. L.; Schoonheydt, R. A.; Sels, B.; Solomon, E. I. Iron and Copper Active Sites in Zeolites and Their Correlation to Metalloenzymes. Chem. Rev. 2018, 118, 2718-2768.

(100) Beale, A. M.; Gao, F.; Lezcano-Gonzalez, I.; Peden, C. H. F.; Szanyi, J. Recent Advances in Automotive Catalysis for Nox Emission Control by Small-Pore Microporous Materials. Chem. Soc. Rev. 2015, 44, 7371-7405.

(101) Zhang, R.; Liu, N.; Lei, Z.; Chen, B. Selective Transformation of Various Nitrogen-Containing Exhaust Gases toward N2 over Zeolite Catalysts. Chem. Rev. 2016, 116, 3658-3721. 
(102) Barger, P. In Zeolites for Cleaner Technologies; Guisnet, M., Gilson, J.-P., Eds.; Imperial College Press: London, 2002; Vol. 3.

(103) Lambert, C.; Cavataio, G. In Urea-Scr Technology for Denox after Treatment of Diesel Exhausts; Nova, I., Tronconi, E., Eds.; Springer New York: New York, NY, 2014.

(104) Chen, N. Y.; Lucki, S. J.; Mower, E. B. Cage Effect on Product Distribution from Cracking over Crystalline Aluminosilicate Zeolites. J. Catal. 1969, 13, 329-332.

(105) Vanelderen, P.; Hadt, R. G.; Smeets, P. J.; Solomon, E. I.; Schoonheydt, R. A.; Sels, B. F. Cu-Zsm-5: A Biomimetic Inorganic Model for Methane Oxidation. J. Catal. 2011, 284, 157-164.

(106) Groothaert, M. H.; Smeets, P. J.; Sels, B. F.; Jacobs, P. A.; Schoonheydt, R. A. Selective Oxidation of Methane by the Bis(MOxo)Dicopper Core Stabilized on Zsm-5 and Mordenite Zeolites. J. Am. Chem. Soc. 2005, 127, 1394-1395.

(107) Grundner, S.; Markovits, M. A. C.; Li, G.; Tromp, M.; Pidko, E. A.; Hensen, E. J. M.; Jentys, A.; Sanchez-Sanchez, M.; Lercher, J. A. Single-Site Trinuclear Copper Oxygen Clusters in Mordenite for Selective Conversion of Methane to Methanol. Nat. Commun. 2015, 6, 7546

(108) Fruijtier-Pölloth, C. The Safety of Synthetic Zeolites Used in Detergents. Arch. Toxicol. 2009, 83, 23-35.

(109) Eldridge, R. B. Olefin/Paraffin Separation Technology: A Review. Ind. Eng. Chem. Res. 1993, 32, 2208-2212.

(110) Olson, D. H.; Camblor, M. A.; Villaescusa, L. A.; Kuehl, G. H. Light Hydrocarbon Sorption Properties of Pure Silica Si-Cha and Itq-3 and High Silica Zsm-58. Microporous Mesoporous Mater. 2004, 67, 2733.

(111) Olson, D. H., US6488741, 2002.

(112) Remy, T.; Peter, S. A.; Van Tendeloo, L.; Van der Perre, S.; Lorgouilloux, Y.; Kirschhock, C. E. A.; Baron, G. V.; Denayer, J. F. M. Adsorption and Separation of $\mathrm{Co} 2$ on Kfi Zeolites: Effect of Cation Type and $\mathrm{Si} / \mathrm{Al}$ Ratio on Equilibrium and Kinetic Properties. Langmuir 2013, 29, 4998-5012.

(113) Hudson, M. R.; Queen, W. L.; Mason, J. A.; Fickel, D. W.; Lobo, R. F.; Brown, C. M. Unconventional, Highly Selective Co2 Adsorption in Zeolite Ssz-13. J. Am. Chem. Soc. 2012, 134, 1970-1973.

(114) Aoki, K.; Kusakabe, K.; Morooka, S. Gas Permeation Properties of a-Type Zeolite Membrane Formed on Porous Substrate by Hydrothermal Synthesis. J. Membr. Sci. 1998, 141, 197-205.

(115) Huang, A.; Caro, J. Cationic Polymer Used to Capture Zeolite Precursor Particles for the Facile Synthesis of Oriented Zeolite Lta Molecular Sieve Membrane. Chem. Mater. 2010, 22, 4353-4355.

(116) Aoki, K.; Kusakabe, K.; Morooka, S. Separation of Gases with an a-Type Zeolite Membrane. Ind. Eng. Chem. Res. 2000, 39, 22452251.

(117) Davis, M. E. Zeolites from a Materials Chemistry Perspective. Chem. Mater. 2014, 26, 239-245.

(118) Hunt, H. K.; Lew, C. M.; Sun, M.; Yan, Y.; Davis, M. E. PureSilica Lta, Cha, Stt, Itw, and -Svr Thin Films and Powders for Low-K Applications. Microporous Mesoporous Mater. 2010, 130, 49-55.

(119) Mintova, S.; Mo, S.; Bein, T. Humidity Sensing with Ultrathin Lta-Type Molecular Sieve Films Grown on Piezoelectric Devices. Chem. Mater. 2001, 13, 901-905.

(120) Fenwick, O.; Coutino-Gonzalez, E.; Grandjean, D.; Baekelant, W.; Richard, F.; Bonacchi, S.; De Vos, D.; Lievens, P.; Roeffaers, M.; Hofkens, J.; et al. Tuning the Energetics and Tailoring the Optical Properties of Silver Clusters Confined in Zeolites. Nat. Mater. 2016, 15, 1017.

(121) Yokoi, T.; Yoshioka, M.; Imai, H.; Tatsumi, T. Diversification of Rth-Type Zeolite and Its Catalytic Application. Angew. Chem., Int. Ed. 2009, 48, 9884-9887.

(122) Szostak, R. Molecular Sieves: Principles of Synthesis and Identification, 2nd ed.; Blackie Academic and Professional: London, 1998.

(123) Barrer, R. M. Preparation of Synthetic Quartz. Nature 1946, 157, 734 .

(124) Ghobarkar, H.; Franke, W. The Morphology of Analcime. Cryst. Res. Technol. 1986, 21, 1071-1075.
(125) Barrer, R. M. 33. Synthesis of a Zeolitic Mineral with Chabazite-Like Sorptive Properties. J. Chem. Soc. 1948, 127-132.

(126) Barrer, R. M.; Robinson, D. J. The Structures of the SaltBearing Aluminosilicates, Species P and Q. Z. Kristallogr. 1972, 135, 374.

(127) Meier, W. M.; Kokotailo, G. T. The Crystal Structure of Synthetic Zeolite Zk-5. Z. Kristallogr. 1965, 121, 211-219.

(128) Breck, D. W.; Eversole, W. G.; Milton, R. M.; Reed, T. B.; Thomas, T. L. Crystalline Zeolites. I. The Properties of a New Synthetic Zeolite, Type A. J. Am. Chem. Soc. 1956, 78, 5963-5972.

(129) Reed, T. B.; Breck, D. W. Crystalline Zeolites. Ii. Crystal Structure of Synthetic Zeolite, Type A. J. Am. Chem. Soc. 1956, 78, 5972-5977.

(130) Milton, R. M. US2882243 A, 1959.

(131) Barrer, R. M.; Denny, P. J. 201. Hydrothermal Chemistry of the Silicates. Part Ix. Nitrogenous Aluminosilicates. J. Chem. Soc. 1961, 971-982.

(132) Kerr, G. T. Chemistry of Crystalline Aluminosilicates. Ii. The Synthesis and Properties of Zeolite Zk-4. Inorg. Chem. 1966, 5, 15371539.

(133) Paolucci, C.; Parekh, A. A.; Khurana, I.; Di Iorio, J. R.; Li, H.; Albarracin Caballero, J. D.; Shih, A. J.; Anggara, T.; Delgass, W. N.; Miller, J. T.; et al. Catalysis in a Cage: Condition-Dependent Speciation and Dynamics of Exchanged Cu Cations in Ssz-13 Zeolites. J. Am. Chem. Soc. 2016, 138, 6028-6048.

(134) Li, J.; Corma, A.; Yu, J. Synthesis of New Zeolite Structures. Chem. Soc. Rev. 2015, 44, 7112-7127.

(135) Boal, B. W.; Schmidt, J. E.; Deimund, M. A.; Deem, M. W.; Henling, L. M.; Brand, S. K.; Zones, S. I.; Davis, M. E. Facile Synthesis and Catalysis of Pure-Silica and Heteroatom Lta. Chem. Mater. 2015, 27, 7774.

(136) Schmidt, J. E.; Deimund, M. A.; Xie, D.; Davis, M. E. Synthesis of Rth-Type Zeolites Using a Diverse Library of Imidazolium Cations. Chem. Mater. 2015, 27, 3756-3762.

(137) Davis, T. M.; Liu, A. T.; Lew, C. M.; Xie, D.; Benin, A. I.; Elomari, S.; Zones, S. I.; Deem, M. W. Computationally Guided Synthesis of Ssz-52: A Zeolite for Engine Exhaust Clean-Up. Chem. Mater. 2016, 28, 708-711.

(138) Pophale, R.; Daeyaert, F.; Deem, M. W. Computational Prediction of Chemically Synthesizable Organic Structure Directing Agents for Zeolites. J. Mater. Chem. A 2013, 1, 6750-6760.

(139) Barrer, R. M.; Hinds, L.; White, E. A. 299. The Hydrothermal Chemistry of Silicates. Part Iii. Reactions of Analcite and Leucite. J. Chem. Soc. 1953, 1466-1475.

(140) Dwyer, F. G.; Chu, P. Zsm-4 Crystallization Via Faujasite Metamorphosis. J. Catal. 1979, 59, 263-271.

(141) Cundy, C. S.; Cox, P. A. The Hydrothermal Synthesis of Zeolites: Precursors, Intermediates and Reaction Mechanism. Microporous Mesoporous Mater. 2005, 82, 1-78.

(142) Zones, S. I.; Van Nordstrand, R. A. Further Studies on the Conversion of Cubic P Zeolite to High Silica Organozeolites. Zeolites 1988, 8, 409-415.

(143) Zones, S. I.; Van Nordstrand, R. A. Novel Zeolite Transformations: The Template-Mediated Conversion of Cubic P Zeolite to Ssz-13. Zeolites 1988, 8, 166-174.

(144) Zones, S. I. Conversion of Faujasites to High-Silica Chabazite Ssz-13 in the Presence of N,N,N-Trimethyl-1-Adamantammonium Iodide. J. Chem. Soc., Faraday Trans. 1991, 87, 3709-3716.

(145) Sano, T.; Itakura, M.; Sadakane, M. High Potential of Interzeolite Conversion Method for Zeolite Synthesis. J. Jpn. Pet. Inst. 2013, 56, 183-197.

(146) Honda, K.; Itakura, M.; Matsuura, Y.; Onda, A.; Ide, Y.; Sadakane, M.; Sano, T. Role of Structural Similarity between Starting Zeolite and Product Zeolite in the Interzeolite Conversion Process. J. Nanosci. Nanotechnol. 2013, 13, 3020-3026.

(147) Itabashi, K.; Kamimura, Y.; Iyoki, K.; Shimojima, A.; Okubo, T. A Working Hypothesis for Broadening Framework Types of Zeolites in Seed-Assisted Synthesis without Organic Structure-Directing Agent. J. Am. Chem. Soc. 2012, 134, 11542-11549. 
(148) Lewis, G. J.; Miller, M. A.; Moscoso, J. G.; Wilson, B. A.; Knight, L. M.; Wilson, S. T. In Stud. Surf. Sci. Catal.; E. van Steen, I. M. C., Callanan, L. H., Eds.; Elsevier, 2004; Vol. 154, pp 364-372.

(149) Flanigen, E. M.; Patton, R. L. US4073865, 1978.

(150) Camblor, M. A.; Corma, A.; Lightfoot, P.; Villaescusa, L. A.; Wright, P. A. Synthesis and Structure of Itq-3, the First Pure Silica Polymorph with a Two-Dimensional System of Straight Eight-Ring Channels. Angew. Chem., Int. Ed. Engl. 1997, 36, 2659-2661.

(151) Schreyeck, L.; Caullet, P.; Mougenel, J. C.; Guth, J. L.; Marler, B. Prefer: A New Layered (Alumino) Silicate Precursor of Fer-Type Zeolite. Microporous Mater. 1996, 6, 259-271.

(152) Marler, B.; Wang, Y.; Song, J.; Gies, H. Topotactic Condensation of Layer Silicates with Ferrierite-Type Layers Forming Porous Tectosilicates. Dalton Trans. 2014, 43, 10396-10416.

(153) Ikeda, T.; Akiyama, Y.; Oumi, Y.; Kawai, A.; Mizukami, F. The Topotactic Conversion of a Novel Layered Silicate into a New Framework Zeolite. Angew. Chem., Int. Ed. 2004, 43, 4892-4896.

(154) Zhao, Z.; Zhang, W.; Ren, P.; Han, X.; Müller, U.; Yilmaz, B.; Feyen, M.; Gies, H.; Xiao, F.-S.; De Vos, D.; et al. Insights into the Topotactic Conversion Process from Layered Silicate Rub-36 to FerType Zeolite by Layer Reassembly. Chem. Mater. 2013, 25, 840-847. (155) De Baerdemaeker, T.; Feyen, M.; Vanbergen, T.; Müller, U.; Yilmaz, B.; Xiao, F.-S.; Zhang, W.; Yokoi, T.; Bao, X.; De Vos, D. E.; et al. From Layered Zeolite Precursors to Zeolites with a ThreeDimensional Porosity: Textural and Structural Modifications through Alkaline Treatment. Chem. Mater. 2015, 27, 316-326.

(156) Dorset, D. L.; Kennedy, G. J. Crystal Structure of Mcm-65: An Alternative Linkage of Ferrierite Layers. J. Phys. Chem. B 2004, 108, 15216-15222.

(157) Martínez-Franco, R.; Paris, C.; Martínez-Triguero, J.; Moliner, M.; Corma, A. Direct Synthesis of the Aluminosilicate Form of the Small Pore Cdo Zeolite with Novel Osdas and the Expanded Polymorphs. Microporous Mesoporous Mater. 2017, 246, 147-157.

(158) De Baerdemaeker, T.; Gies, H.; Yilmaz, B.; Muller, U.; Feyen, M.; Xiao, F.-S.; Zhang, W.; Yokoi, T.; Bao, X.; De Vos, D. E. A New Class of Solid Lewis Acid Catalysts Based on Interlayer Expansion of Layered Silicates of the Rub-36 Type with Heteroatoms. J. Mater. Chem. A 2014, 2, 9709-9717.

(159) Bhawe, Y.; Moliner-Marin, M.; Lunn, J. D.; Liu, Y.; Malek, A.; Davis, M. Effect of Cage Size on the Selective Conversion of Methanol to Light Olefins. ACS Catal. 2012, 2, 2490-2495.

(160) Barrett, P. A.; Díaz-Cabañas, M.-J.; Camblor, M. A. Crystal Structure of Zeolite Mcm-35 (Mtf). Chem. Mater. 1999, 11, 29192927.

(161) Whittam, T. V., US4397825, 1983.

(162) Diaz-Cabanas, M.-J.; Barrett, P. A. Synthesis and Structure of Pure Sio2 Chabazite: The Sio2 Polymorph with the Lowest Framework Density. Chem. Commun. 1998, 1881-1882.

(163) Doherty, H. G.; Plank, C. J.; Rosinski, E. J., US4247416 1981.

(164) Jeon, H.-Y.; Shin, C.-H.; Jung, H. J.; Hong, S. B. Catalytic Evaluation of Small-Pore Molecular Sieves with Different Framework Topologies for the Synthesis of Methylamines. Appl. Catal., A 2006, 305, $70-78$.

(165) Kim, D. J.; Shin, C.-H.; Hong, S. B. Synthesis and Characterization of a Gallosilicate Analog of Zeolite Paulingite. Microporous Mesoporous Mater. 2005, 83, 319-325.

(166) Cichocki, A. Hydrothermal Synthesis of Zeolites in the Na2oK2o-Al2o3-Sio2-H2o System. Part 1. The Effect of the Silicon Module and of the Alkali Glass Corrosion. Zeolites 1991, 11, 758-766.

(167) Robson, H.; Lillerud, K. P. Verified Syntheses of Zeolitic Materials, 2nd Revised ed..; Elsevier, 2001.

(168) Kecht, J.; Mintova, S.; Bein, T. Nanosized Edi-Type Molecular Sieve. Microporous Mesoporous Mater. 2008, 116, 258-266.

(169) Schmidt, J. E.; Deimund, M. A.; Davis, M. E. Facile Preparation of Aluminosilicate Rth across a Wide Composition Range Using a New Organic Structure-Directing Agent. Chem. Mater. 2014, 26, 7099-7105.

(170) Occelli, M. L.; Innes, R. A.; Pollack, S. S.; Sanders, J. V. Quaternary Ammonium Cation Effects on the Crystallization of
Offretite-Erionite Type Zeolites: Part 1. Synthesis and Catalytic Properties. Zeolites 1987, 7, 265-271.

(171) Jan, D. Y.; Lewis, G. J.; Mezza, T. M.; Moscoso, J. G.; Patton, R. L.; Koljack, M. P.; Tota, P. V. In Stud. Surf. Sci. Catal.; E. van Steen, M. C., Callanan, L. H., Eds.; Elsevier, 2004; Vol. 154, pp 1332-1340. (172) Jo, D.; Ryu, T.; Park, G. T.; Kim, P. S.; Kim, C. H.; Nam, I.-S.; Hong, S. B. Synthesis of High-Silica Lta and Ufi Zeolites and Nh3-Scr Performance of Their Copper-Exchanged Form. ACS Catal. 2016, 6, 2443-2447.

(173) Kim, C.; Hwang, S.-J.; Burton, A. W.; Zones, S. I. A Case Study of Divergent Structure Directing Effects of Geometric Isomers: The Discovery of a New Structure Directing Agent for an All-Silica Rth Zeolite Prepared in Fluoride Media. Microporous Mesoporous Mater. 2008, 116, 227-232.

(174) Schmidt, J. E.; Xie, D.; Davis, M. E. Synthesis of the Rth-Type Layer: The First Small-Pore, Two Dimensional Layered Zeolite Precursor. Chem. Sci. 2015, 6, 5955-5963.

(175) Lee, G. S.; Zones, S. I., US6254849, 2001.

(176) First, E. L.; Gounaris, C. E.; Wei, J.; Floudas, C. A. Computational Characterization of Zeolite Porous Networks: An Automated Approach. Phys. Chem. Chem. Phys. 2011, 13, 1733917358.

(177) Simmen, A.; McCusker, L. B.; Baerlocher, C.; Meier, W. M. The Structure Determination and Rietveld Refinement of the Aluminophosphate AlPO4-18. Zeolites 1991, 11, 654-661.

(178) Wagner, P.; Nakagawa, Y.; Lee, G. S.; Davis, M. E.; Elomari, S.; Medrud, R. C.; Zones, S. I. Guest/Host Relationships in the Synthesis of the Novel Cage-Based Zeolites Ssz-35, Ssz-36, and Ssz-39. J. Am. Chem. Soc. 2000, 122, 263-273.

(179) Dusselier, M.; Deimund, M. A.; Schmidt, J. E.; Davis, M. E. Methanol-to-Olefins Catalysis with Hydrothermally Treated Zeolite Ssz-39. ACS Catal. 2015, 5, 6078-6085.

(180) Cao, G.; Strohmaier, K. G.; Li, H.; Guram, A. S.; Saxton, R. J.; Muraoka, M. T.; Yoder, J. C.; Yaccatu, K. WO2005063624A1, 2005.

(181) Moliner, M.; Franch, C.; Palomares, E.; Grill, M.; Corma, A. $\mathrm{Cu}-\mathrm{Ssz}-39$, an Active and Hydrothermally Stable Catalyst for the Selective Catalytic Reduction of Nox. Chem. Commun. 2012, 48, 8264-8266.

(182) Maruo, T.; Yamanaka, N.; Tsunoji, N.; Sadakane, M.; Sano, T. Facile Synthesis of Aei Zeolites by Hydrothermal Conversion of Fau Zeolites in the Presence of Tetraethylphosphonium Cations. Chem. Lett. 2014, 43, 302-304.

(183) Sonoda, T.; Maruo, T.; Yamasaki, Y.; Tsunoji, N.; Takamitsu, Y.; Sadakane, M.; Sano, T. Synthesis of High-Silica Aei Zeolites with Enhanced Thermal Stability by Hydrothermal Conversion of Fau Zeolites, and Their Activity in the Selective Catalytic Reduction of Nox with Nh3. J. Mater. Chem. A 2015, 3, 857-865.

(184) Dusselier, M.; Schmidt, J. E.; Moulton, R.; Haymore, B.; Hellums, M.; Davis, M. E. Influence of Organic Structure Directing Agent Isomer Distribution on the Synthesis of Ssz-39. Chem. Mater. 2015, 27, 2695-2702.

(185) Schmidt, J. E.; Deem, M.; Lew, C.; Davis, T. ComputationallyGuided Synthesis of the 8-Ring Zeolite Aei. Top. Catal. 2015, 58, 410-415.

(186) Martín, N.; Boruntea, C. R.; Moliner, M.; Corma, A. Efficient Synthesis of the Cu-Ssz-39 Catalyst for Denox Applications. Chem. Commun. 2015, 51, 11030-11033.

(187) Kakiuchi, Y.; Yamasaki, Y.; Tsunoji, N.; Takamitsu, Y.; Sadakane, M.; Sano, T. One-Pot Synthesis of Phosphorus-Modified Aei Zeolites Derived by the Dual-Template Method as a Durable Catalyst with Enhanced Thermal/Hydrothermal Stability for Selective Catalytic Reduction of Nox by Nh3. Chem. Lett. 2016, 45, 122-124. (188) Martín, N.; Li, Z.; Martinez-Triguero, J.; Yu, J.; Moliner, M.; Corma, A. Nanocrystalline Ssz-39 Zeolite as an Efficient Catalyst for the Methanol-to-Olefin (Mto) Process. Chem. Commun. 2016, 52, 6072-6075.

(189) Nakazawa, N.; Inagaki, S.; Kubota, Y. Direct Hydrothermal Synthesis of High-Silica Ssz-39 Zeolite with Small Particle Size. Chem. Lett. 2016, 45, 919-921. 
(190) Zones, S. I.; Burton, A. W.; Lee, G. S.; Olmstead, M. M. A Study of Piperidinium Structure-Directing Agents in the Synthesis of Silica Molecular Sieves under Fluoride-Based Conditions. J. Am. Chem. Soc. 2007, 129, 9066-9079.

(191) Ransom, R.; Coote, J.; Moulton, R.; Gao, F.; Shantz, D. F. Synthesis and Growth Kinetics of Zeolite Ssz-39. Ind. Eng. Chem. Res. 2017, 56, 4350-4356.

(192) Burton, A. W.; Lee, G. S.; Zones, S. I. Phase Selectivity in the Syntheses of Cage-Based Zeolite Structures: An Investigation of Thermodynamic Interactions between Zeolite Hosts and Structure Directing Agents by Molecular Modeling. Microporous Mesoporous Mater. 2006, 90, 129-144.

(193) Imai, H.; Hayashida, N.; Yokoi, T.; Tatsumi, T. Direct Crystallization of Cha-Type Zeolite from Amorphous Aluminosilicate Gel by Seed-Assisted Method in the Absence of Organic-StructureDirecting Agents. Microporous Mesoporous Mater. 2014, 196, 341-348.

(194) Archer, R. H.; Zones, S. I.; Davis, M. E. Imidazolium Structure Directing Agents in Zeolite Synthesis: Exploring Guest/Host Relationships in the Synthesis of Ssz-70. Microporous Mesoporous Mater. 2010, 130, 255-265.

(195) Lee, S.-H.; Shin, C.-H.; Choi, G. J.; Park, T.-J.; Nam, I.-S.; Han, B.; Hong, S. B. Zeolite Synthesis in the Presence of Flexible Diquaternary Alkylammonium Ions (C2h5) $3 \mathrm{n}+(\mathrm{Ch} 2) \mathrm{Nn}+(\mathrm{C} 2 \mathrm{~h} 5) 3$ with $\mathrm{N}=3-10$ as Structure-Directing Agents. Microporous Mesoporous Mater. 2003, 60, 237-249.

(196) Fickel, D. W.; Lobo, R. F. Copper Coordination in Cu-Ssz-13 and $\mathrm{Cu}-\mathrm{Ssz}-16$ Investigated by Variable-Temperature Xrd. J. Phys. Chem. C 2010, 114, 1633-1640.

(197) Hrabanek, P.; Zikanova, A.; Supinkova, T.; Drahokoupil, J.; Fila, V.; Lhotka, M.; Dragounova, H.; Laufek, F.; Brabec, L.; Jirka, I.; et al. Static in-Situ Hydrothermal Synthesis of Small Pore Zeolite Ssz16 (Afx) Using Heated and Pre-Aged Synthesis Mixtures. Microporous Mesoporous Mater. 2016, 228, 107-115.

(198) Martín, N.; Paris, C.; Vennestrøm, P. N. R.; Thøgersen, J. R.; Moliner, M.; Corma, A. Cage-Based Small-Pore Catalysts for Nh3-Scr Prepared by Combining Bulky Organic Structure Directing Agents with Modified Zeolites as Reagents. Appl. Catal., B 2017, 217, 125136.

(199) Bourgogne, M.; Guth, J. L.; Wey, R. US 4503024, 1985.

(200) Liu, B.; Zheng, Y.; Hu, N.; Gui, T.; Li, Y.; Zhang, F.; Zhou, R.; Chen, X.; Kita, H. Synthesis of Low-Silica Cha Zeolite Chabazite in Fluoride Media without Organic Structural Directing Agents and Zeolites. Microporous Mesoporous Mater. 2014, 196, 270-276.

(201) Zhu, Q.; Kondo, J. N.; Ohnuma, R.; Kubota, Y.; Yamaguchi, M.; Tatsumi, T. The Study of Methanol-to-Olefin over Proton Type Aluminosilicate Cha Zeolites. Microporous Mesoporous Mater. 2008, $112,153-161$.

(202) Eilertsen, E. A.; Nilsen, M. H.; Wendelbo, R.; Olsbye, U.; Lillerud, K. P. In Stud. Surf. Sci. Catal.; Antoine Gédéon, P. M., Florence, B., Eds.; Elsevier, 2008; Vol. 174A, pp 265-268.

(203) Camblor, M. A.; Villaescusa, L. A.; Díaz-Cabañas, M. J. Synthesis of All-Silica and High-Silica Molecular Sieves in Fluoride Media. Top. Catal. 1999, 9, 59-76.

(204) Villaescusa, L. A.; Bull, I.; Wheatley, P. S.; Lightfoot, P.; Morris, R. E. The Location of Fluoride and Organic Guests in 'as-Made' Pure Silica Zeolites Fer and Cha. J. Mater. Chem. 2003, 13, 1978-1982.

(205) Eilertsen, E. A.; Arstad, B.; Svelle, S.; Lillerud, K. P. Single Parameter Synthesis of High Silica Cha Zeolites from Fluoride Media. Microporous Mesoporous Mater. 2012, 153, 94-99.

(206) Bohström, Z.; Arstad, B.; Lillerud, K. P. Preparation of High Silica Chabazite with Controllable Particle Size. Microporous Mesoporous Mater. 2014, 195, 294-302.

(207) Kumar, M.; Luo, H.; Román-Leshkov, Y.; Rimer, J. D. Ssz-13 Crystallization by Particle Attachment and Deterministic Pathways to Crystal Size Control. J. Am. Chem. Soc. 2015, 137, 13007-13017.

(208) Li, Z.; Navarro, M. T.; Martinez-Triguero, J.; Yu, J.; Corma, A. Synthesis of Nano-Ssz-13 and Its Application in the Reaction of Methanol to Olefins. Catal. Sci. Technol. 2016, 6, 5856-5863.
(209) Zhu, X.; Kosinov, N.; Hofmann, J. P.; Mezari, B.; Qian, Q.; Rohling, R.; Weckhuysen, B. M.; Ruiz-Martinez, J.; Hensen, E. J. M. Fluoride-Assisted Synthesis of Bimodal Microporous Ssz-13 Zeolite. Chem. Commun. 2016, 52, 3227-3230.

(210) Liu, Z.; Wakihara, T.; Oshima, K.; Nishioka, D.; Hotta, Y.; Elangovan, S. P.; Yanaba, Y.; Yoshikawa, T.; Chaikittisilp, W.; Matsuo, T.; et al. Widening Synthesis Bottlenecks: Realization of Ultrafast and Continuous-Flow Synthesis of High-Silica Zeolite Ssz-13 for Nox Removal. Angew. Chem., Int. Ed. 2015, 54, 5683-5687.

(211) Cao, G.; Mertens, M. M.; Guram, A. S.; Li, H.; Yoder, J. C. US7754187, 2010.

(212) Wang, X.; Wu, Q.; Chen, C.; Pan, S.; Zhang, W.; Meng, X.; Maurer, S.; Feyen, M.; Muller, U.; Xiao, F.-S. Atom-Economical Synthesis of a High Silica Cha Zeolite Using a Solvent-Free Route. Chem. Commun. 2015, 51, 16920-16923.

(213) Ren, L.; Zhu, L.; Yang, C.; Chen, Y.; Sun, Q.; Zhang, H.; Li, C.; Nawaz, F.; Meng, X.; Xiao, F.-S. Designed Copper-Amine Complex as an Efficient Template for One-Pot Synthesis of Cu-Ssz-13 Zeolite with Excellent Activity for Selective Catalytic Reduction of Nox by Nh3. Chem. Commun. 2011, 47, 9789-9791.

(214) Martínez-Franco, R.; Moliner, M.; Thogersen, J. R.; Corma, A. Efficient One-Pot Preparation of Cu-Ssz-13 Materials Using Cooperative Osdas for Their Catalytic Application in the Scr of Nox. ChemCatChem 2013, 5, 3316-3323.

(215) Zones, S. I. US8007763, 2011.

(216) Itakura, M.; Inoue, T.; Takahashi, A.; Fujitani, T.; Oumi, Y.; Sano, T. Synthesis of High-Silica Cha Zeolite from Fau Zeolite in the Presence of Benzyltrimethylammonium Hydroxide. Chem. Lett. 2008, 37, 908-909.

(217) Xu, R.; Zhang, R.; Liu, N.; Chen, B.; Zhang Qiao, S. Template Design and Economical Strategy for the Synthesis of Ssz-13 (ChaType) Zeolite as an Excellent Catalyst for the Selective Catalytic Reduction of Nox by Ammonia. Chem CatChem 2015, 7, 3792-3792. (218) Wu, L.; Degirmenci, V.; Magusin, P. C. M. M.; Szyja, B. M.; Hensen, E. J. M. Dual Template Synthesis of a Highly Mesoporous Ssz-13 Zeolite with Improved Stability in the Methanol-to-Olefins Reaction. Chem. Commun. 2012, 48, 9492-9494.

(219) Wu, L.; Degirmenci, V.; Magusin, P. C. M. M.; Lousberg, N. J. H. G. M.; Hensen, E. J. M. Mesoporous Ssz-13 Zeolite Prepared by a Dual-Template Method with Improved Performance in the Methanolto-Olefins Reaction. J. Catal. 2013, 298, 27-40.

(220) Choi, M.; Na, K.; Kim, J.; Sakamoto, Y.; Terasaki, O.; Ryoo, R. Stable Single-Unit-Cell Nanosheets of Zeolite Mfi as Active and LongLived Catalysts. Nature 2009, 461, 246-249.

(221) Zhu, X.; Hofmann, J. P.; Mezari, B.; Kosinov, N.; Wu, L.; Qian, Q.; Weckhuysen, B. M.; Asahina, S.; Ruiz-Martínez, J.; Hensen, E. J. M. Trimodal Porous Hierarchical Ssz-13 Zeolite with Improved Catalytic Performance in the Methanol-to-Olefins Reaction. ACS Catal. 2016, 6, 2163-2177.

(222) Ji, Y.; Deimund, M. A.; Bhawe, Y.; Davis, M. E. Organic-Free Synthesis of Cha-Type Zeolite Catalysts for the Methanol-to-Olefins Reaction. ACS Catal. 2015, 5, 4456-4465.

(223) Van Tendeloo, L.; Gobechiya, E.; Breynaert, E.; Martens, J. A.; Kirschhock, C. E. A. Alkaline Cations Directing the Transformation of Fau Zeolites into Five Different Framework Types. Chem. Commun. 2013, 49, 11737-11739.

(224) Itakura, M.; Goto, I.; Takahashi, A.; Fujitani, T.; Ide, Y.; Sadakane, M.; Sano, T. Synthesis of High-Silica Cha Type Zeolite by Interzeolite Conversion of Fau Type Zeolite in the Presence of Seed Crystals. Microporous Mesoporous Mater. 2011, 144, 91-96.

(225) Takata, T.; Tsunoji, N.; Takamitsu, Y.; Sadakane, M.; Sano, T. Nanosized Cha Zeolites with High Thermal and Hydrothermal Stability Derived from the Hydrothermal Conversion of Fau Zeolite. Microporous Mesoporous Mater. 2016, 225, 524-533.

(226) Martín, N.; Moliner, M.; Corma, A. High Yield Synthesis of High-Silica Chabazite by Combining the Role of Zeolite Precursors and Tetraethylammonium. Scr of Nox. Chem. Commun. 2015, 51, 9965-9968. 
(227) Goto, I.; Itakura, M.; Shibata, S.; Honda, K.; Ide, Y.; Sadakane, M.; Sano, T. Transformation of Lev-Type Zeolite into Less Dense Cha-Type Zeolite. Microporous Mesoporous Mater. 2012, 158, 117122.

(228) Goel, S.; Zones, S. I.; Iglesia, E. Synthesis of Zeolites Via Interzeolite Transformations without Organic Structure-Directing Agents. Chem. Mater. 2015, 27, 2056-2066.

(229) Yamanaka, N.; Itakura, M.; Kiyozumi, Y.; Ide, Y.; Sadakane, M.; Sano, T. Acid Stability Evaluation of Cha-Type Zeolites Synthesized by Interzeolite Conversion of Fau-Type Zeolite and Their Membrane Application for Dehydration of Acetic Acid Aqueous Solution. Microporous Mesoporous Mater. 2012, 158, 141-147.

(230) Barthomeuf, D. Topology and Maximum Content of Isolated Species (Al, Ga, Fe, B, Si, ...) in a Zeolitic Framework. An Approach to Acid Catalysis. J. Phys. Chem. 1993, 97, 10092-10096.

(231) Bates, S. A.; Verma, A. A.; Paolucci, C.; Parekh, A. A.; Anggara, T.; Yezerets, A.; Schneider, W. F.; Miller, J. T.; Delgass, W. N.; Ribeiro, F. H. Identification of the Active Cu Site in Standard Selective Catalytic Reduction with Ammonia on Cu-Ssz-13. J. Catal. 2014, 312, 87-97.

(232) Akporiaye, D. E.; Dahl, I. M.; Mostad, H. B.; Wendelbo, R. Aluminum Distribution in Chabazite: An Experimental and Computational Study. J. Phys. Chem. 1996, 100, 4148-4153.

(233) Di Iorio, J. R.; Gounder, R. Controlling the Isolation and Pairing of Aluminum in Chabazite Zeolites Using Mixtures of Organic and Inorganic Structure-Directing Agents. Chem. Mater. 2016, 28, 2236-2247.

(234) Dědeček, J.; Sobalík, Z.; Wichterlová, B. Siting and Distribution of Framework Aluminium Atoms in Silicon-Rich Zeolites and Impact on Catalysis. Catal. Rev.: Sci. Eng. 2012, 54, 135-223.

(235) Dedecek, J.; Kaucky, D.; Wichterlova, B.; Gonsiorova, O. Co2+ Ions as Probes of Al Distribution in the Framework of Zeolites. Zsm-5 Study. Phys. Chem. Chem. Phys. 2002, 4, 5406-5413.

(236) Sazama, P.; Tabor, E.; Klein, P.; Wichterlova, B.; Sklenak, S.; Mokrzycki, L.; Pashkkova, V.; Ogura, M.; Dedecek, J. Al-Rich Beta Zeolites. Distribution of Al Atoms in the Framework and Related Protonic and Metal-Ion Species. J. Catal. 2016, 333, 102-114.

(237) Di Iorio, J. R.; Nimlos, C. T.; Gounder, R. Introducing Catalytic Diversity into Single-Site Chabazite Zeolites of Fixed Composition Via Synthetic Control of Active Site Proximity. ACS Catal. 2017, 7, 6663-6674.

(238) Bialek, R.; Meier, W. M.; Davis, M.; Annen, M. J. The Synthesis and Structure of Ssz-24, the Silica Analog of AlPO4-5. Zeolites 1991, 11, 438-442.

(239) Gies, H. Studies on Clathrasils. Ix. Crystal Structure of DecaDodecasil 3r, the Missing Link between Zeolites and Clathrasils. Z. Kristallogr. - Cryst. Mater. 1986, 175, 93-104.

(240) Himeno, S.; Tomita, T.; Suzuki, K.; Yoshida, S. Characterization and Selectivity for Methane and Carbon Dioxide Adsorption on the All-Silica Dd3r Zeolite. Microporous Mesoporous Mater. 2007, 98, 62-69.

(241) Zhu, W.; Kapteijn, F.; Moulijn, J. A.; den Exter, M. C.; Jansen, J. C. Shape Selectivity in Adsorption on the All-Silica Dd3r. Langmuir 2000, 16, 3322-3329.

(242) Kuhn, J.; Gascon, J.; Gross, J.; Kapteijn, F. Detemplation of Ddr Type Zeolites by Ozonication. Microporous Mesoporous Mater. 2009, 120, 12-18.

(243) Altwasser, S.; Welker, C.; Traa, Y.; Weitkamp, J. Catalytic Cracking of N-Octane on Small-Pore Zeolites. Microporous Mesoporous Mater. 2005, 83, 345-356.

(244) Fickel, D. W.; D’Addio, E.; Lauterbach, J. A.; Lobo, R. F. The Ammonia Selective Catalytic Reduction Activity of Copper-Exchanged Small-Pore Zeolites. Appl. Catal., B 2011, 102, 441-448.

(245) Yarulina, I.; Dikhtiarenko, A.; Kapteijn, F.; Gascon, J. Consequences of Secondary Zeolite Growth on Catalytic Performance in Dmto Studied over Ddr and Cha. Catal. Sci. Technol. 2017, 7, 300309.

(246) Yarulina, I.; Goetze, J.; Gucuyener, C.; van Thiel, L.; Dikhtiarenko, A.; Ruiz-Martinez, J.; Weckhuysen, B. M.; Gascon, J.;
Kapteijn, F. Methanol-to-Olefins Process over Zeolite Catalysts with Ddr Topology: Effect of Composition and Structural Defects on Catalytic Performance. Catal. Sci. Technol. 2016, 6, 2663-2678.

(247) Lillerud, K. P.; Raeder, J. H. On the Synthesis of ErioniteOffretite Intergrowth Zeolites. Zeolites 1986, 6, 474-483.

(248) Rubin, M. K.; Rosinksi, E. J. US3699139 1972.

(249) Sanders, J. V.; Occelli, M. L.; Innes, R. A.; Pollack, S. S. In Stud. Surf. Sci. Catal.; Y. Murakami, A. I., Ward, J. W., Eds.; Elsevier, 1986; Vol. 28, pp 429-436.

(250) Miller, M.; Lewis, G.; Gisselquist, J.; Moscoso, J.; Patton, R. US20060073094, 2006.

(251) Xie, D.; Lew, C. M. US Patent 9663380, 2017.

(252) Barrer, R. M.; Bultitude, F. W.; Kerr, I. S. 294. Some Properties of, and a Structural Scheme for, the Harmotome Zeolites. J. Chem. Soc. 1959, 1521-1528.

(253) Hansen, S.; Håkansson, U.; Landa-Canovas, A. R.; Falth, L. On the Crystal Chemistry of Nap Zeolites. Zeolites 1993, 13, 276-280.

(254) Brown, G. T.; Osinga, T. J.; Parkington, M. J.; Steel, A. T. EP0384070, 1995.

(255) Carr, S. W.; Gore, B.; Anderson, M. W. 29si27al and 1h SolidState Nmr Study of the Surface of Zeolite Map. Chem. Mater. 1997, 9, 1927-1932.

(256) Baerlocher, C.; Meier, W. M. Synthese Und Kristallstruktur Von Tetramethylammonium-Gismondin. Helv. Chim. Acta 1970, 53, $1285-1293$.

(257) Albert, B. R.; Cheetham, A. K.; Adams, C. J. Investigations on P Zeolites: Synthesis and Structure of the Gismondine Analogue, Highly Crystalline Low-Silica Cap. Microporous Mesoporous Mater. 1998, 21, 127-132.

(258) Albert, B. R.; Cheetham, A. K.; Stuart, J. A.; Adams, C. J. Investigations on P Zeolites: Synthesis, Characterisation, and Structure of Highly Crystalline Low-Silica Nap. Microporous Mesoporous Mater. 1998, 21, 133-142.

(259) Rees, L. V. C.; Chandrasekhar, S. Hydrothermal Reaction of Kaolinite in Presence Offluoride Ions at $\mathrm{Ph}<1$. Zeolites 1993, 13, 534-541.

(260) Subotić, B.; Šmit, I.; Madžija, O.; Sekovanić, L. Kinetic Study of the Transformation of Zeolite a into Zeolite P. Zeolites 1982, 2, $135-142$.

(261) Huo, Z.; Xu, X.; Lü, Z.; Song, J.; He, M.; Li, Z.; Wang, Q.; Yan, L. Synthesis of Zeolite Nap with Controllable Morphologies. Microporous Mesoporous Mater. 2012, 158, 137-140.

(262) Aldahri, T.; Behin, J.; Kazemian, H.; Rohani, S. Synthesis of Zeolite Na-P from Coal Fly Ash by Thermo-Sonochemical Treatment. Fuel 2016, 182, 494-501.

(263) Behin, J.; Kazemian, H.; Rohani, S. Sonochemical Synthesis of Zeolite Nap from Clinoptilolite. Ultrason. Sonochem. 2016, 28, 400408.

(264) Sharma, P.; Yeo, J.-g.; Han, M. H.; Cho, C. H. Knobby Surfaced, Mesoporous, Single-Phase Gis-Nap1 Zeolite Microsphere Synthesis and Characterization for $\mathrm{H} 2$ Gas Adsorption. J. Mater. Chem. A 2013, 1, 2602-2612.

(265) Goel, S.; Wu, Z.; Zones, S. I.; Iglesia, E. Synthesis and Catalytic Properties of Metal Clusters Encapsulated within Small-Pore (Sod, Gis, Ana) Zeolites. J. Am. Chem. Soc. 2012, 134, 17688-17695.

(266) Kerr, G. T. US3247195 A, 1966.

(267) Ji, Y.; Birmingham, J.; Deimund, M. A.; Brand, S. K.; Davis, M. E. Steam-Dealuminated, Osda-Free Rho and Kfi-Type Zeolites as Catalysts for the Methanol-to-Olefins Reaction. Microporous Mesoporous Mater. 2016, 232, 126-137.

(268) Verduijn, J. P. US4994249 A, 1991.

(269) Barrer, R. M.; Sieber, W. Hydrothermal Chemistry of Silicates. Part 21. Zeolites from Reaction of Lithium and Caesium Ions with Tetramethylammonium Aluminosilicate Solutions. J. Chem. Soc., Dalton Trans. 1977, 1020-1026.

(270) Lillerud, K. P.; Akporiaye, D. In Stud. Surf. Sci. Catal.; J. Weitkamp, H. G. K. H. P., Hölderich, W., Eds.; Elsevier, 1994; Vol. 84, pp 543-550. 
(271) Wright, P. A.; Maple, M. J.; Slawin, A. M. Z.; Patinec, V.; Aitken, R. A.; Welsh, S.; Cox, P. A. Cation-Directed Syntheses of Novel Zeolite-Like Metalloaluminophosphates Sta-6 and Sta-7 in the Presence of Azamacrocycle Templates. J. Chem. Soc., Dalton Trans. 2000, 1243-1248.

(272) Short, G. D.; Whittam, T. V., EP0040016 1981.

(273) Casci, J. L.; Whittam, T. V. In Stud. Surf. Sci. Catal.; B. Držaj, S. H., Pejovnik, S., Eds.; Elsevier, 1985; Vol. 24, pp 623-630.

(274) Stewart, A. EP0255770, 1992.

(275) Tuoto, C. V.; Regina, A.; Nagy, J. B.; Nastro, A. Influence of the Sio2/Al2o3 Ratio on the Synthesis and Physicochemical Characteristics of Levyne-Type Zeolite. Microporous Mesoporous Mater. 1998, 20, 247-257.

(276) Thompson, R. W. In Molecular Sieves; Springer Berlin Heidelberg: Berlin, Heidelberg, 1998; Vol. 1: Synthesis.

(277) Koller, H.; Lobo, R. F.; Burkett, S. L.; Davis, M. E. Sio-*..Hosi Hydrogen Bonds in as-Synthesized High-Silica Zeolites. J. Phys. Chem. 1995, 99, 12588-12596.

(278) Chan, I. Y.; Zones, S. I. Analytical Electron Microscopy (Aem) of Cubic P Zeolite to Nu-3 Zeolite Transformation. Zeolites 1989, 9, $3-11$.

(279) Caullet, P.; Delmotte, L.; Faust, A. C.; Guth, J. L. Synthesis of Lev-Type Zeolite from Aqueous Nonalkaline Fluoride Aluminosilicate Gels. Zeolites 1995, 15, 139-147.

(280) Kuehl, G. H. US4495303, 1985.

(281) Yamamoto, K.; Ikeda, T.; Onodera, M.; Muramatsu, A.; Mizukami, F.; Wang, Y.; Gies, H. Synthesis and Structure Analysis of Rub-50, an Lev-Type Aluminosilicate Zeolite. Microporous Mesoporous Mater. 2010, 128, 150-157.

(282) Xu, H.; Li, J.; Xu, J.; Wang, J.; Deng, F.; Li, J.; Dong, J. Synthesis and Properties of a Zeolite Lev Analogue from the SystemNa2o-Al2o3-Sio2-N,N-Dimethylpiperidine Chloride-H2o. Catal. Today 2009, 148, 6-11.

(283) Han, B.; Lee, S.-H.; Shin, C.-H.; Cox, P. A.; Hong, S. B. Zeolite Synthesis Using Flexible Diquaternary Alkylammonium Ions (Cnh2n $+1) 2 \mathrm{hn}+(\mathrm{Ch} 2) 5 \mathrm{n}+\mathrm{H}(\mathrm{Cnh} 2 \mathrm{n}+1) 2$ with $\mathrm{N}=1-5$ as StructureDirecting Agents. Chem. Mater. 2005, 17, 477-486.

(284) Inoue, T.; Itakura, M.; Jon, H.; Oumi, Y.; Takahashi, A.; Fujitani, T.; Sano, T. Synthesis of Lev Zeolite by Interzeolite Conversion Method and Its Catalytic Performance in Ethanol to Olefins Reaction. Microporous Mesoporous Mater. 2009, 122, 149-154.

(285) Shibata, S.; Itakura, M.; Ide, Y.; Sadakane, M.; Sano, T. FauLev Interzeolite Conversion in Fluoride Media. Microporous Mesoporous Mater. 2011, 138, 32-39.

(286) Yashiki, A.; Honda, K.; Fujimoto, A.; Shibata, S.; Ide, Y.; Sadakane, M.; Sano, T. Hydrothermal Conversion of Fau Zeolite into Lev Zeolite in the Presence of Non-Calcined Seed Crystals. J. Cryst. Growth 2011, 325, 96-100.

(287) Zhang, H.; Yang, C.; Zhu, L.; Meng, X.; Yilmaz, B.; Müller, U.; Feyen, M.; Xiao, F.-S. Organotemplate-Free and Seed-Directed Synthesis of Levyne Zeolite. Microporous Mesoporous Mater. 2012, $155,1-7$.

(288) Funase, N.; Tanigawa, T.; Yamasaki, Y.; Tsunoji, N.; Sadakane, M.; Sano, T. Thermally Stable Nanosized Lev Zeolites Synthesized by Hydrothermal Conversion of Fau Zeolites in the Presence of N,NDimethylpiperidinium Cations. J. Mater. Chem. A 2017, 5, 1924519254.

(289) Valyocsik, E. W. EP0143642, 1985.

(290) Conato, M. T.; Oleksiak, M. D.; Peter McGrail, B.; Motkuri, R. K.; Rimer, J. D. Framework Stabilization of Si-Rich Lta Zeolite Prepared in Organic-Free Media. Chem. Commun. 2015, 51, 269-272. (291) Wadlinger, R. L.; Rosinksi, E. J.; Plank, C. J. US3375205, 1962.

(292) Kuehl, G. H. High-Silica Analogs of Zeolite a Containing Intercalated Phosphate. Inorg. Chem. 1971, 10, 2488-2495.

(293) Moscoso, J. G.; Lewis, G. J.; Gisselquist, J. L.; Miller, M. A.; Rohde, L. M. US6713041, 2004.

(294) Bouizi, Y.; Paillaud, J.-L.; Simon, L.; Valtchev, V. Seeded Synthesis of Very High Silica Zeolite A. Chem. Mater. 2007, 19, 652654.
(295) Moteki, T.; Lobo, R. F. A General Method for Aluminum Incorporation into High-Silica Zeolites Prepared in Fluoride Media. Chem. Mater. 2016, 28, 638-649.

(296) Choi, M.; Wu, Z.; Iglesia, E. Mercaptosilane-Assisted Synthesis of Metal Clusters within Zeolites and Catalytic Consequences of Encapsulation. J. Am. Chem. Soc. 2010, 132, 9129-9137.

(297) Park, M. B.; Jo, D.; Jeon, H. C.; Nicholas, C. P.; Lewis, G. J.; Hong, S. B. Zeolite Synthesis from a Charge Density Perspective: The Charge Density Mismatch Synthesis of Uzm-5 and Uzm-9. Chem. Mater. 2014, 26, 6684-6694.

(298) Park, M. B.; Lee, Y.; Zheng, A.; Xiao, F.-S.; Nicholas, C. P.; Lewis, G. J.; Hong, S. B. Formation Pathway for Lta Zeolite Crystals Synthesized Via a Charge Density Mismatch Approach. J. Am. Chem. Soc. 2013, 135, 2248-2255.

(299) Mintova, S.; Olson, N. H.; Valtchev, V.; Bein, T. Mechanism of Zeolite a Nanocrystal Growth from Colloids at Room Temperature. Science 1999, 283, 958-960.

(300) Huang, A.; Weidenthaler, C.; Caro, J. Facile and Reproducible Synthesis of Itq-29 Zeolite by Using Kryptofix 222 as the Structure Directing Agent. Microporous Mesoporous Mater. 2010, 130, 352-356. (301) Fayad, E. J.; Bats, N.; Kirschhock, C. E. A.; Rebours, B.; Quoineaud, A.-A.; Martens, J. A. A Rational Approach to the Ionothermal Synthesis of an Alpo4Molecular Sieve with an Lta-Type Framework. Angew. Chem., Int. Ed. 2010, 49, 4585-4588.

(302) Schmidt, J. E.; Zones, S. I.; Xie, D.; Davis, M. E. The Synthesis of Aluminophosphate and Germanosilicate Lta Using a Triquaternary Structure Directing Agent. Microporous Mesoporous Mater. 2014, 200, $132-139$.

(303) Maldonado, M.; Oleksiak, M. D.; Chinta, S.; Rimer, J. D. Controlling Crystal Polymorphism in Organic-Free Synthesis of NaZeolites. J. Am. Chem. Soc. 2013, 135, 2641-2652.

(304) Oleksiak, M. D.; Soltis, J. A.; Conato, M. T.; Penn, R. L.; Rimer, J. D. Nucleation of Fau and Lta Zeolites from Heterogeneous Aluminosilicate Precursors. Chem. Mater. 2016, 28, 4906-4916.

(305) Zhu, G.; Qiu, S.; Yu, J.; Sakamoto, Y.; Xiao, F.; Xu, R.; Terasaki, O. Synthesis and Characterization of High-Quality Zeolite Lta and Fau Single Nanocrystals. Chem. Mater. 1998, 10, 1483-1486.

(306) Verboekend, D.; Keller, T. C.; Mitchell, S.; Pérez-Ramírez, J. Hierarchical Fau- and Lta-Type Zeolites by Post-Synthetic Design: A New Generation of Highly Efficient Base Catalysts. Adv. Funct. Mater. 2013, 23, 1923-1934.

(307) Verboekend, D.; Perez-Ramirez, J. Design of Hierarchical Zeolite Catalysts by Desilication. Catal. Sci. Technol. 2011, 1, 879-890.

(308) Xiao, F.-S.; Wang, L.; Yin, C.; Lin, K.; Di, Y.; Li, J.; Xu, R.; Su, D. S.; Schlögl, R.; Yokoi, T.; et al. Catalytic Properties of Hierarchical Mesoporous Zeolites Templated with a Mixture of Small Organic Ammonium Salts and Mesoscale Cationic Polymers. Angew. Chem. 2006, 118, 3162-3165.

(309) Choi, M.; Cho, H. S.; Srivastava, R.; Venkatesan, C.; Choi, D.H.; Ryoo, R. Amphiphilic Organosilane-Directed Synthesis of Crystalline Zeolite with Tunable Mesoporosity. Nat. Mater. 2006, 5, 718-723.

(310) Cho, K.; Cho, H. S.; de Ménorval, L.-C.; Ryoo, R. Generation of Mesoporosity in Lta Zeolites by Organosilane Surfactant for Rapid Molecular Transport in Catalytic Application. Chem. Mater. 2009, 21, $5664-5673$.

(311) Hasan, F.; Singh, R.; Li, G.; Zhao, D.; Webley, P. A. Direct Synthesis of Hierarchical Lta Zeolite Via a Low Crystallization and Growth Rate Technique in Presence of Cetyltrimethylammonium Bromide. J. Colloid Interface Sci. 2012, 382, 1-12.

(312) Chen, H.; Wydra, J.; Zhang, X.; Lee, P.-S.; Wang, Z.; Fan, W.; Tsapatsis, M. Hydrothermal Synthesis of Zeolites with ThreeDimensionally Ordered Mesoporous-Imprinted Structure. J. Am. Chem. Soc. 2011, 133, 12390-12393.

(313) Serrano, D. P.; Aguado, J.; Escola, J. M.; Rodríguez, J. M.; Peral, Á. Hierarchical Zeolites with Enhanced Textural and Catalytic Properties Synthesized from Organofunctionalized Seeds. Chem. Mater. 2006, 18, 2462-2464. 
(314) Xue, Z.; Ma, J.; Hao, W.; Bai, X.; Kang, Y.; Liu, J.; Li, R. Synthesis and Characterization of Ordered Mesoporous Zeolite Lta with High Ion Exchange Ability. J. Mater. Chem. 2012, 22, 2532-2538.

(315) Hasan, F.; Singh, R.; Webley, P. A. Formation of Lta Zeolite Crystals with Multi-Hollow Polycrystalline Core-Shell Structure Via Aggregation-Recrystallization Route in Presence of Emulsion Droplets. Microporous Mesoporous Mater. 2012, 160, 75-84.

(316) Schwieger, W.; Machoke, A. G.; Weissenberger, T.; Inayat, A.; Selvam, T.; Klumpp, M.; Inayat, A. Hierarchy Concepts: Classification and Preparation Strategies for Zeolite Containing Materials with Hierarchical Porosity. Chem. Soc. Rev. 2016, 45, 3353-3376.

(317) Serrano, D. P.; Escola, J. M.; Pizarro, P. Synthesis Strategies in the Search for Hierarchical Zeolites. Chem. Soc. Rev. 2013, 42, 40044035.

(318) Na, K.; Choi, M.; Ryoo, R. Recent Advances in the Synthesis of Hierarchically Nanoporous Zeolites. Microporous Mesoporous Mater. 2013, 166, 3-19.

(319) Wu, Z.; Goel, S.; Choi, M.; Iglesia, E. Hydrothermal Synthesis of Lta-Encapsulated Metal Clusters and Consequences for Catalyst Stability, Reactivity, and Selectivity. J. Catal. 2014, 311, 458-468.

(320) Davis, M. E.; Saldarriaga, C.; Rossin, J. A. Synthesis and Catalysis of Transition Metal-Containing Zeolite A. J. Catal. 1987, 103, 520-523.

(321) Wu, J. C. S.; Goodwin, J. G.; Davis, M. Zeolite a-Supported Ru Catalysts. J. Catal. 1990, 125, 488-500.

(322) Rossin, J. A.; Davis, M. E. Synthesis of Rhodium Zeolite A. J. Chem. Soc., Chem. Commun. 1986, 234-236.

(323) Frilette, V. J.; Maatman, R. W. US3373109, 1968.

(324) Jo, D.; Lim, J. B.; Ryu, T.; Nam, I.-S.; Camblor, M. A.; Hong, S. B. Unseeded Hydroxide-Mediated Synthesis and Co2 Adsorption Properties of an Aluminosilicate Zeolite with the Rth Topology. J. Mater. Chem. A 2015, 3, 19322-19329.

(325) Robson, H. E. US patent 3904738, 1975.

(326) Burkett, S. L.; Davis, M. E. Structure-Directing Effects in the Crown Ether-Mediated Syntheses of Fau and Emt Zeolites. Microporous Mater. 1993, 1, 265-282.

(327) Chatelain, T.; Patarin, J.; Fousson, E.; Soulard, M.; Guth, J. L.; Schulz, P. Synthesis and Characterization of High-Silica Zeolite Rho Prepared in the Presence of 18-Crown-6 Ether as Organic Template. Microporous Mater. 1995, 4, 231-238.

(328) Wright, P. A.; Morris, R. E.; Wheatley, P. S. Synthesis of Microporous Materials Using Macrocycles as Structure Directing Agents. Dalton Trans. 2007, 5359-5368.

(329) Liu, S.; Zhang, P.; Meng, X.; Liang, D.; Xiao, N.; Xiao, F.-S. Cesium-Free Synthesis of Aluminosilicate Rho Zeolite in the Presence of Cationic Polymer. Microporous Mesoporous Mater. 2010, 132, 352356.

(330) Ke, Q.; Sun, T.; Cheng, H.; Chen, H.; Liu, X.; Wei, X.; Wang, S. Targeted Synthesis of Ultrastable High-Silica Rho Zeolite through Alkali Metal-Crown Ether Interaction. Chem. - Asian J. 2017, 12, 1043-1047.

(331) Min, J. G.; Choi, H. J.; Shin, J.; Hong, S. B. Crystallization Mechanism of a Family of Embedded Isoreticular Zeolites. J. Phys. Chem. C 2017, 121, 16342-16350.

(332) Yoshioka, M.; Yokoi, T.; Liu, M.; Imai, H.; Inagaki, S.; Tatsumi, T. Preparation of Rth-Type Zeolites with the Amount and/or Kind of Organic Structure-Directing Agents (Osda): Are Osdas Indispensable for the Crystallization? Microporous Mesoporous Mater. 2012, 153, 70-78.

(333) Schmidt, J. E.; Deem, M. W.; Davis, M. E. Synthesis of a Specified, Silica Molecular Sieve by Using Computationally Predicted Organic Structure-Directing Agents. Angew. Chem. 2014, 126, 85128514.

(334) Schmidt, J. E.; Xie, D.; Davis, M. E. High-Silica, HeulanditeType Zeolites Prepared by Direct Synthesis and Topotactic Condensation. J. Mater. Chem. A 2015, 3, 12890-12897.

(335) Muraoka, K.; Chaikittisilp, W.; Okubo, T. Energy Analysis of Aluminosilicate Zeolites with Comprehensive Ranges of Framework
Topologies, Chemical Compositions, and Aluminum Distributions. J. Am. Chem. Soc. 2016, 138, 6184-6193.

(336) Kubota, Y.; Helmkamp, M. M.; Zones, S. I.; Davis, M. E. Properties of Organic Cations That Lead to the Structure-Direction of High-Silica Molecular Sieves. Microporous Mater. 1996, 6, 213-229.

(337) Lobo, R. F.; Zones, S. I.; Davis, M. E. Structure-Direction in Zeolite Synthesis. J. Inclusion Phenom. 1995, 21, 47-78.

(338) Davis, M. E.; Saldarriaga, C. Synthesis of Gmelinite and Zsm12 Zeolites with a Polymer Template. J. Chem. Soc., Chem. Commun. 1988, 920-921.

(339) Willhammar, T.; Sun, J.; Wan, W.; Oleynikov, P.; Zhang, D.; Zou, X.; Moliner, M.; Gonzalez, J.; Martínez, C.; Rey, F.; et al. Structure and Catalytic Properties of the Most Complex Intergrown Zeolite Itq-39 Determined by Electron Crystallography. Nat. Chem. 2012, 4, 188-194.

(340) Ahn, S. H.; Lee, H.; Hong, S. B. Crystallization Mechanism of Cage-Based, Small-Pore Molecular Sieves: A Case Study of Cha and Lev Structures. Chem. Mater. 2017, 29, 5583-5590.

(341) Tolborg, S.; Sádaba, I.; Osmundsen, C. M.; Fristrup, P.; Holm, M. S.; Taarning, E. Tin-Containing Silicates: Alkali Salts Improve Methyl Lactate Yield from Sugars. ChemSusChem 2015, 8, 613-617.

(342) Iwamoto, M.; Furukawa, H.; Mine, Y.; Uemura, F.; Mikuriya, S.-i.; Kagawa, S. Copper(Ii) Ion-Exchanged Zsm-5 Zeolites as Highly Active Catalysts for Direct and Continuous Decomposition of Nitrogen Monoxide. J. Chem. Soc., Chem. Commun. 1986, 1272-1273.

(343) Brandenberger, S.; Kröcher, O.; Tissler, A.; Althoff, R. The State of the Art in Selective Catalytic Reduction of Nox by Ammonia Using Metal-Exchanged Zeolite Catalysts. Catal. Rev.: Sci. Eng. 2008, 50, 492-531.

(344) Paolucci, C.; Di Iorio, J. R.; Ribeiro, F. H.; Gounder, R.; Schneider, W. F. In Adv. Catal.; Song, C., Ed.; Academic Press, 2016; Vol. 59.

(345) Bull, I.; Boorse, R. S.; Jaglowski, W. M.; Koermer, G. S.; Moini, A.; Patchett, J. A.; Xue, W. M.; Burk, P.; Dettling, J. C.; Caudle, M. T. US Patent 20080226545, 2008.

(346) Andersen, P. J.; Bailie, J. E.; Casci, J. L.; Chen, H. Y.; Fedeyko, J. M.; Foo, R. K. S.; Rajaram, R. R. WO Patent 2008132452, 2008.

(347) Cavataio, G.; Jen, H.-W.; Warner, J. R.; Girard, J. W.; Kim, J. Y.; Lambert, C. K. Enhanced Durability of a $\mathrm{Cu} /$ Zeolite Based Scr Catalyst. SAE Int. J. Fuels Lubr. 2009, 1, 477-487.

(348) Kwak, J. H.; Tonkyn, R. G.; Kim, D. H.; Szanyi, J.; Peden, C. H. F. Excellent Activity and Selectivity of Cu-Ssz-13 in the Selective Catalytic Reduction of Nox with Nh3. J. Catal. 2010, 275, 187-190.

(349) Paolucci, C.; Verma, A. A.; Bates, S. A.; Kispersky, V. F.; Miller, J. T.; Gounder, R.; Delgass, W. N.; Ribeiro, F. H.; Schneider, W. F. Isolation of the Copper Redox Steps in the Standard Selective Catalytic Reduction on Cu-Ssz-13. Angew. Chem., Int. Ed. 2014, 53, 11828-11833.

(350) Borfecchia, E.; Lomachenko, K. A.; Giordanino, F.; Falsig, H.; Beato, P.; Soldatov, A. V.; Bordiga, S.; Lamberti, C. Revisiting the Nature of $\mathrm{Cu}$ Sites in the Activated Cu-Ssz-13 Catalyst for Scr Reaction. Chem. Sci. 2015, 6, 548-563.

(351) Lomachenko, K. A.; Borfecchia, E.; Negri, C.; Berlier, G.; Lamberti, C.; Beato, P.; Falsig, H.; Bordiga, S. The Cu-Cha Denox Catalyst in Action: Temperature-Dependent Nh3-Assisted Selective Catalytic Reduction Monitored by Operando Xas and Xes. J. Am. Chem. Soc. 2016, 138, 12025-12028.

(352) Beale, A. M.; Lezcano-Gonzalez, I.; Slawinksi, W. A.; Wragg, D. $\mathrm{S}$. Correlation between $\mathrm{Cu}$ Ion Migration Behaviour and Denox Activity in Cu-Ssz-13 for the Standard Nh3-Scr Reaction. Chem. Commun. 2016, 52, 6170-6173.

(353) Andersen, C. W.; Borfecchia, E.; Bremholm, M.; Jørgensen, M. R. V.; Vennestrøm, P. N. R.; Lamberti, C.; Lundegaard, L. F.; Iversen, B. B. Redox-Driven Migration of Copper Ions in the $\mathrm{Cu}$-Cha Zeolite as Shown by the in Situ Pxrd/Xanes Technique. Angew. Chem. 2017, 129, 10503-10508.

(354) Gao, F.; Mei, D.; Wang, Y.; Szanyi, J.; Peden, C. H. F. Selective Catalytic Reduction over $\mathrm{Cu} / \mathrm{Ssz}-13$ : Linking Homo- and Heterogeneous Catalysis. J. Am. Chem. Soc. 2017, 139, 4935-4942. 
(355) Paolucci, C.; Khurana, I.; Parekh, A. A.; Li, S.; Shih, A. J.; Li, H.; Di Iorio, J. R.; Albarracin-Caballero, J. D.; Yezerets, A.; Miller, J. T.et al. Dynamic Multinuclear Sites Formed by Mobilized Copper Ions in Nox Selective Catalytic Reduction. Science 2017, 357, 89810.1126/ science.aan 5630

(356) Gao, F.; Wang, Y.; Kollár, M.; Washton, N. M.; Szanyi, J.; Peden, C. H. F. A Comparative Kinetics Study between Cu/Ssz-13 and Fe/Ssz-13 Scr Catalysts. Catal. Today 2015, 258 (Part 2), 347-358.

(357) Gao, F.; Kollár, M.; Kukkadapu, R. K.; Washton, N. M.; Wang, Y.; Szanyi, J.; Peden, C. H. F. Fe/Ssz-13 as an Nh3-Scr Catalyst: A Reaction Kinetics and Ftir/Mössbauer Spectroscopic Study. Appl. Catal., B 2015, 164, 407-419.

(358) Martín, N.; Vennestrøm, P. N. R.; Thøgersen, J. R.; Moliner, M.; Corma, A. Iron-Containing Ssz-39 (Aei) Zeolite: An Active and Stable High-Temperature Nh3-Scr Catalyst. ChemCatChem 2017, 9, 1754-1757.

(359) Kim, J.; Cho, S. J.; Kim, D. H. Facile Synthesis of Kfi-Type Zeolite and Its Application to Selective Catalytic Reduction of Nox with Nh3. ACS Catal. 2017, 7, 6070-6081.

(360) Bull, I.; Müller, U. US Patent 20120014865, 2015.

(361) Blakeman, P. G.; Burkholder, E. M.; Chen, H.-Y.; Collier, J. E.; Fedeyko, J. M.; Jobson, H.; Rajaram, R. R. The Role of Pore Size on the Thermal Stability of Zeolite Supported Cu Scr Catalysts. Catal. Today 2014, 231, 56-63.

(362) Prodinger, S.; Derewinski, M. A.; Wang, Y.; Washton, N. M.; Walter, E. D.; Szanyi, J.; Gao, F.; Wang, Y.; Peden, C. H. F. SubMicron $\mathrm{Cu} / \mathrm{Ssz}-13$ : Synthesis and Application as Selective Catalytic Reduction (Scr) Catalysts. Appl. Catal., B 2017, 201, 461-469.

(363) Albarracin-Caballero, J. D.; Khurana, I.; Di Iorio, J. R.; Shih, A. J.; Schmidt, J. E.; Dusselier, M.; Davis, M. E.; Yezerets, A.; Miller, J. T.; Ribeiro, F. H.; et al. Structural and Kinetic Changes to Small-Pore CuZeolites after Hydrothermal Aging Treatments and Selective Catalytic Reduction of Nox with Ammonia. React. Chem. Eng. 2017, 2, 168179.

(364) Ryu, T.; Ahn, N. H.; Seo, S.; Cho, J.; Kim, H.; Jo, D.; Park, G. T.; Kim, P. S.; Kim, C. H.; Bruce, E. L.; et al. Fully Copper-Exchanged High-Silica Lta Zeolites as Unrivaled Hydrothermally Stable Nh3-Scr Catalysts. Angew. Chem. 2017, 129, 3304-3308.

(365) Ahn, N. H.; Ryu, T.; Kang, Y.; Kim, H.; Shin, J.; Nam, I.-S.; Hong, S. B. The Origin of an Unexpected Increase in Nh3-Scr Activity of Aged Cu-Lta Catalysts. ACS Catal. 2017, 7, 6781-6785.

(366) Reichinger, M.; Maletz, G.; Eisert, K. US Patent 20130089494, 2013

(367) Kovarik, L.; Washton, N. M.; Kukkadapu, R.; Devaraj, A.; Wang, A.; Wang, Y.; Szanyi, J.; Peden, C. H. F.; Gao, F. Transformation of Active Sites in Fe/Ssz-13 Scr Catalysts During Hydrothermal Aging: A Spectroscopic, Microscopic, and Kinetics Study. ACS Catal. 2017, 7, 2458-2470.

(368) Gao, F.; Zheng, Y.; Kukkadapu, R. K.; Wang, Y.; Walter, E. D.; Schwenzer, B.; Szanyi, J.; Peden, C. H. F. Iron Loading Effects in Fe/ Ssz-13 Nh3-Scr Catalysts: Nature of the Fe Ions and StructureFunction Relationships. ACS Catal. 2016, 6, 2939-2954.

(369) Kwak, J. H.; Tran, D.; Szanyi, J.; Peden, C. H. F.; Lee, J. H. The Effect of Copper Loading on the Selective Catalytic Reduction of Nitric Oxide by Ammonia over Cu-Ssz-13. Catal. Lett. 2012, 142, 295-301.

(370) Deka, U.; Lezcano-Gonzalez, I.; Warrender, S. J.; Lorena Picone, A.; Wright, P. A.; Weckhuysen, B. M.; Beale, A. M. Changing Active Sites in $\mathrm{Cu}-$ Cha Catalysts: Denox Selectivity as a Function of the Preparation Method. Microporous Mesoporous Mater. 2013, 166, 144-152.

(371) Wang, D.; Gao, F.; Peden, C. H. F.; Li, J.; Kamasamudram, K.; Epling, W. S. Selective Catalytic Reduction of Nox with Nh3 over a Cu-Ssz-13 Catalyst Prepared by a Solid-State Ion-Exchange Method. ChemCatChem 2014, 6, 1579-1583.

(372) Xie, L.; Liu, F.; Ren, L.; Shi, X.; Xiao, F.-S.; He, H. Excellent Performance of One-Pot Synthesized Cu-Ssz-13 Catalyst for the Selective Catalytic Reduction of Nox with Nh3. Environ. Sci. Technol. 2014, 48, 566-572.
(373) Yamada, H.; Iida, T.; Liu, Z.; Naraki, Y.; Ohara, K.; Kohara, S.; Okubo, T.; Wakihara, T. Downsizing Afx Zeolite Crystals to Nanoscale by a Postmilling Recrystallization Method. Cryst. Growth Des. 2016, 16, 3389-3394.

(374) Oord, R.; ten Have, I. C.; Arends, J. M.; Hendriks, F. C.; Schmidt, J.; Lezcano-Gonzalez, I.; Weckhuysen, B. M. Enhanced Activity of Desilicated Cu-Ssz-13 for the Selective Catalytic Reduction of Nox and Its Comparison with Steamed Cu-Ssz-13. Catal. Sci. Technol. 2017, 7, 3851-3862.

(375) Pannov, G. I.; Sobolev, V. I.; Kharitonov, A. S. The Role of Iron in N2o Decomposition on Zsm-5 Zeolite and Reactivity of the Surface Oxygen Formed. J. Mol. Catal. 1990, 61, 85-97.

(376) Snyder, B. E. R.; Vanelderen, P.; Bols, M. L.; Hallaert, S. D.; Böttger, L. H.; Ungur, L.; Pierloot, K.; Schoonheydt, R. A.; Sels, B. F.; Solomon, E. I. The Active Site of Low-Temperature Methane Hydroxylation in Iron-Containing Zeolites. Nature 2016, 536, 317321.

(377) Woertink, J. S.; Smeets, P. J.; Groothaert, M. H.; Vance, M. A.; Sels, B. F.; Schoonheydt, R. A.; Solomon, E. I. A [Cu2o]2+ Core in $\mathrm{Cu}-Z s m-5$, the Active Site in the Oxidation of Methane to Methanol. Proc. Natl. Acad. Sci. U. S. A. 2009, 106, 18908-18913.

(378) Smeets, P. J.; Hadt, R. G.; Woertink, J. S.; Vanelderen, P.; Schoonheydt, R. A.; Sels, B. F.; Solomon, E. I. Oxygen Precursor to the Reactive Intermediate in Methanol Synthesis by Cu-Zsm-5. J. Am. Chem. Soc. 2010, 132, 14736-14738.

(379) Vanelderen, P.; Snyder, B. E. R.; Tsai, M.-L.; Hadt, R. G.; Vancauwenbergh, J.; Coussens, O.; Schoonheydt, R. A.; Sels, B. F.; Solomon, E. I. Spectroscopic Definition of the Copper Active Sites in Mordenite: Selective Methane Oxidation. J. Am. Chem. Soc. 2015, 137, 6383-6392.

(380) Vanelderen, P.; Vancauwenbergh, J.; Sels, B. F.; Schoonheydt, R. A. Coordination Chemistry and Reactivity of Copper in Zeolites. Coord. Chem. Rev. 2013, 257, 483-494.

(381) Hammond, C.; Conrad, S.; Hermans, I. Oxidative Methane Upgrading. ChemSusChem 2012, 5, 1668-1686.

(382) Tomkins, P.; Mansouri, A.; Bozbag, S. E.; Krumeich, F.; Park, M. B.; Alayon, E. M. C.; Ranocchiari, M.; van Bokhoven, J. A. Isothermal Cyclic Conversion of Methane into Methanol over Copper-Exchanged Zeolite at Low Temperature. Angew. Chem. 2016, 128, 5557-5561.

(383) Sushkevich, V. L.; Palagin, D.; Ranocchiari, M.; van Bokhoven, J. A. Selective Anaerobic Oxidation of Methane Enables Direct Synthesis of Methanol. Science 2017, 356, 523-527.

(384) Narsimhan, K.; Iyoki, K.; Dinh, K.; Román-Leshkov, Y. Catalytic Oxidation of Methane into Methanol over CopperExchanged Zeolites with Oxygen at Low Temperature. ACS Cent. Sci. 2016, 2, 424-429.

(385) Hammond, C.; Forde, M. M.; Rahim, A.; Hasbi, M.; Thetford, A.; He, Q.; Jenkins, R. L.; Dimitratos, N.; Lopez-Sanchez, J. A.; Dummer, N. F. Direct Catalytic Conversion of Methane to Methanol in an Aqueous Medium by Using Copper-Promoted Fe-Zsm-5. Angew. Chem., Int. Ed. 2012, 51, 5129-5133.

(386) Ravi, M.; Ranocchiari, M.; van Bokhoven, J. A. A Critical Assessment of the Direct Catalytic Oxidation of Methane to Methanol. Angew. Chem., Int. Ed. 2017, 56, 16464-16483.

(387) Park, M. B.; Ahn, S. H.; Mansouri, A.; Ranocchiari, M.; van Bokhoven, J. A. Comparative Study of Diverse Copper Zeolites for the Conversion of Methane into Methanol. ChemCatChem 2017, 9, 3705-3713.

(388) Ipek, B.; Lobo, R. F. Catalytic Conversion of Methane to Methanol on Cu-Ssz-13 Using N2o as Oxidant. Chem. Commun. 2016, 52, 13401-13404.

(389) Pappas, D. K.; Borfecchia, E.; Dyballa, M.; Pankin, I.; Lomachenko, K. A.; Martini, A.; Signorile, M.; Teketel, S.; Arstad, B.; Berlier, G.; et al. Methane to Methanol: Structure-Activity Relationships for Cu-Cha. J. Am. Chem. Soc. 2017, 139, 14961-14975.

(390) Ipek, B.; Wulfers, M. J.; Kim, H.; Göltl, F.; Hermans, I.; Smith,

J. P.; Booksh, K. S.; Brown, C. M.; Lobo, R. F. Formation of 
[Cu2o2]2+ and [Cu2o]2+ toward C-H Bond Activation in Cu-Ssz-13 and Cu-Ssz-39. ACS Catal. 2017, 7, 4291-4303.

(391) Kulkarni, A. R.; Zhao, Z.-J.; Siahrostami, S.; Nørskov, J. K.; Studt, F. Monocopper Active Site for Partial Methane Oxidation in Cu-Exchanged 8mr Zeolites. ACS Catal. 2016, 6, 6531-6536.

(392) Chang, C. D.; Lang, W. H.; Silvestri, A. J. US4062905, 1977. (393) Chang, C. D.; Silvestri, A. J. The Conversion of Methanol and Other O-Compounds to Hydrocarbons over Zeolite Catalysts. J. Catal. 1977, 47, 249-259.

(394) Olsbye, U.; Svelle, S.; Bjørgen, M.; Beato, P.; Janssens, T. V. W.; Joensen, F.; Bordiga, S.; Lillerud, K. P. Conversion of Methanol to Hydrocarbons: How Zeolite Cavity and Pore Size Controls Product Selectivity. Angew. Chem., Int. Ed. 2012, 51, 5810-5831.

(395) Olah, G. A.; Goeppert, A.; Prakash, G. S. Beyond Oil and Gas: The Methanol Economy; John Wiley \& Sons, 2011.

(396) Olah, G. A. Beyond Oil and Gas: The Methanol Economy. Angew. Chem., Int. Ed. 2005, 44, 2636-2639.

(397) Stöcker, M. Methanol-to-Hydrocarbons: Catalytic Materials and Their Behavior. Microporous Mesoporous Mater. 1999, 29, 3-48.

(398) Chen, D.; Moljord, K.; Holmen, A. A Methanol to Olefins Review: Diffusion, Coke Formation and Deactivation on Sapo Type Catalysts. Microporous Mesoporous Mater. 2012, 164, 239-250.

(399) Haw, J. F.; Song, W.; Marcus, D. M.; Nicholas, J. B. The Mechanism of Methanol to Hydrocarbon Catalysis. Acc. Chem. Res. 2003, 36, 317-326.

(400) Song, W.; Wei, Y.; Liu, Z. In Zeolites in Sustainable Chemistry: Synthesis, Characterization and Catalytic Applications; Xiao, F.-S., Meng, X., Eds.; Springer Berlin Heidelberg: Berlin, Heidelberg, 2016.

(401) Dahl, I. M.; Kolboe, S. On the Reaction Mechanism for Propene Formation in the Mto Reaction over Sapo-34. Catal. Lett. 1993, 20, 329-336.

(402) Bjørgen, M.; Svelle, S.; Joensen, F.; Nerlov, J.; Kolboe, S.; Bonino, F.; Palumbo, L.; Bordiga, S.; Olsbye, U. Conversion of Methanol to Hydrocarbons over Zeolite H-Zsm-5: On the Origin of the Olefinic Species. J. Catal. 2007, 249, 195-207.

(403) Zhang, M.; Xu, S.; Wei, Y.; Li, J.; Wang, J.; Zhang, W.; Gao, S.; Liu, Z. Changing the Balance of the Mto Reaction Dual-Cycle Mechanism: Reactions over Zsm-5 with Varying Contact Times. Chin. J. Catal. 2016, 37, 1413-1422.

(404) Wu, X.; Xu, S.; Zhang, W.; Huang, J.; Li, J.; Yu, B.; Wei, Y.; Liu, Z. Direct Mechanism of the First Carbon-Carbon Bond Formation in the Methanol-to-Hydrocarbons Process. Angew. Chem., Int. Ed. 2017, 56, 9039-9043.

(405) Liu, Y.; Müller, S.; Berger, D.; Jelic, J.; Reuter, K.; Tonigold, M.; Sanchez-Sanchez, M.; Lercher, J. A. Formation Mechanism of the First Carbon-Carbon Bond and the First Olefin in the Methanol Conversion into Hydrocarbons. Angew. Chem., Int. Ed. 2016, 55, $5723-5726$.

(406) Chowdhury, A. D.; Houben, K.; Whiting, G. T.; Mokhtar, M.; Asiri, A. M.; Al-Thabaiti, S. A.; Basahel, S. N.; Baldus, M.; Weckhuysen, B. M. Initial Carbon-Carbon Bond Formation During the Early Stages of the Methanol-to-Olefin Process Proven by ZeoliteTrapped Acetate and Methyl Acetate. Angew. Chem., Int. Ed. 2016, 55, $15840-15845$

(407) Müller, S.; Liu, Y.; Kirchberger, F. M.; Tonigold, M.; SanchezSanchez, M.; Lercher, J. A. Hydrogen Transfer Pathways During Zeolite Catalyzed Methanol Conversion to Hydrocarbons. J. Am. Chem. Soc. 2016, 138, 15994-16003.

(408) Nesterenko, N.; Aguilhon, J.; Bodart, P.; Minoux, D.; Dath, J. P. In Zeolites and Zeolite-Like Materials; Kustov, L. M., Ed.; Elsevier: Amsterdam, 2016.

(409) Santilli, D. S.; Zones, S. I. US4496786, 1985.

(410) Yuen, L.-T.; Zones, S. I.; Harris, T. V.; Gallegos, E. J.; Auroux, A. Product Selectivity in Methanol to Hydrocarbon Conversion for Isostructural Compositions of $\mathrm{Afi}$ and Cha Molecular Sieves. Microporous Mater. 1994, 2, 105-117.

(411) Katada, N.; Nouno, K.; Lee, J. K.; Shin, J.; Hong, S. B.; Niwa, M. Acidic Properties of Cage-Based, Small-Pore Zeolites with
Different Framework Topologies and Their Silicoaluminophosphate Analogues. J. Phys. Chem. C 2011, 115, 22505-22513.

(412) Bleken, F.; Bjørgen, M.; Palumbo, L.; Bordiga, S.; Svelle, S.; Lillerud, K.-P.; Olsbye, U. The Effect of Acid Strength on the Conversion of Methanol to Olefins over Acidic Microporous Catalysts with the Cha Topology. Top. Catal. 2009, 52, 218-228.

(413) Deimund, M.; Schmidt, J.; Davis, M. Effect of Pore and Cage Size on the Formation of Aromatic Intermediates During the Methanol-to-Olefins Reaction. Top. Catal. 2015, 58, 1-8.

(414) Hwang, A.; Kumar, M.; Rimer, J. D.; Bhan, A. Implications of Methanol Disproportionation on Catalyst Lifetime for Methanol-toOlefins Conversion by Hssz-13. J. Catal. 2017, 346, 154-160.

(415) Zhu, Q.; Kondo, J. N.; Tatsumi, T.; Inagaki, S.; Ohnuma, R.; Kubota, Y.; Shimodaira, Y.; Kobayashi, H.; Domen, K. A Comparative Study of Methanol to Olefin over Cha and Mtf Zeolites. J. Phys. Chem. C 2007, 111, 5409-5415.

(416) Deimund, M. A.; Harrison, L.; Lunn, J. D.; Liu, Y.; Malek, A.; Shayib, R.; Davis, M. E. Effect of Heteroatom Concentration in Ssz-13 on the Methanol-to-Olefins Reaction. ACS Catal. 2016, 6, 542-550.

(417) Kumita, Y.; Gascon, J.; Stavitski, E.; Moulijn, J. A.; Kapteijn, F. Shape Selective Methanol to Olefins over Highly Thermostable Ddr Catalysts. Appl. Catal., A 2011, 391, 234-243.

(418) Goetze, J.; Meirer, F.; Yarulina, I.; Gascon, J.; Kapteijn, F.; Ruiz-Martínez, J.; Weckhuysen, B. M. Insights into the Activity and Deactivation of the Methanol-to-Olefins Process over Different SmallPore Zeolites as Studied with Operando Uv-Vis Spectroscopy. ACS Catal. 2017, 7, 4033-4046.

(419) Kang, J. H.; Walter, R.; Xie, D.; Davis, T.; Chen, C.-Y.; Davis, M. E.; Zones, S. I. Further Studies on How the Nature of Zeolite Cavities That Are Bounded by Small Pores Influences the Conversion of Methanol to Light Olefins. ChemPhysChem 2018, 19, 412-419.

(420) Park, J. W.; Lee, J. Y.; Kim, K. S.; Hong, S. B.; Seo, G. Effects of Cage Shape and Size of 8-Membered Ring Molecular Sieves on Their Deactivation in Methanol-to-Olefin (Mto) Reactions. Appl. Catal., A 2008, 339, 36-44.

(421) Masih, D.; Imai, H.; Yokoi, T.; Kondo, J. N.; Tatsumi, T. Methanol Conversion to Lower Olefins over Rho Type Zeolite. Catal. Commun. 2013, 37, 1-4.

(422) Li, J.; Wei, Y.; Chen, J.; Xu, S.; Tian, P.; Yang, X.; Li, B.; Wang, J.; Liu, Z. Cavity Controls the Selectivity: Insights of Confinement Effects on Mto Reaction. ACS Catal. 2015, 5, 661-665.

(423) Chen, J.; Li, J.; Wei, Y.; Yuan, C.; Li, B.; Xu, S.; Zhou, Y.; Wang, J.; Zhang, M.; Liu, Z. Spatial Confinement Effects of Cage-Type Sapo Molecular Sieves on Product Distribution and Coke Formation in Methanol-to-Olefin Reaction. Catal. Commun. 2014, 46, 36-40.

(424) Cui, Z.-M.; Liu, Q.; Song, W.-G.; Wan, L.-J. Insights into the Mechanism of Methanol-to-Olefin Conversion at Zeolites with Systematically Selected Framework Structures. Angew. Chem., Int. Ed. 2006, 45, 6512-6515.

(425) Chen, J.; Li, J.; Yuan, C.; Xu, S.; Wei, Y.; Wang, Q.; Zhou, Y.; Wang, J.; Zhang, M.; He, Y.; et al. Elucidating the Olefin Formation Mechanism in the Methanol to Olefin Reaction over Alpo-18 and Sapo-18. Catal. Sci. Technol. 2014, 4, 3268-3277.

(426) Olsbye, U.; Svelle, S.; Lillerud, K. P.; Wei, Z. H.; Chen, Y. Y.; Li, J. F.; Wang, J. G.; Fan, W. B. The Formation and Degradation of Active Species During Methanol Conversion over Protonated Zeotype Catalysts. Chem. Soc. Rev. 2015, 44, 7155-7176.

(427) Smith, R. L.; Svelle, S.; Del Campo, P.; Fuglerud, T.; Arstad, B.; Lind, A.; Chavan, S.; Attfield, M. P.; Akporiaye, D.; Anderson, M. W. Cha/Aei Intergrowth Materials as Catalysts for the Methanol-toOlefins Process. Appl. Catal., A 2015, 505, 1-7.

(428) Marcus, D. M.; Song, W.; Ng, L. L.; Haw, J. F. Aromatic Hydrocarbon Formation in Hsapo-18 Catalysts: Cage Topology and Acid Site Density. Langmuir 2002, 18, 8386-8391.

(429) Sastre, G. Confinement Effects in Methanol to Olefins Catalysed by Zeolites: A Computational Review. Front. Chem. Sci. Eng. 2016, 10, 76-89.

(430) Bates, S. A.; Delgass, W. N.; Ribeiro, F. H.; Miller, J. T.; Gounder, R. Methods for Nh3 Titration of Brønsted Acid Sites in Cu- 
Zeolites That Catalyze the Selective Catalytic Reduction of Nox with Nh3. J. Catal. 2014, 312, 26-36.

(431) Qin, Z.; Lakiss, L.; Tosheva, L.; Gilson, J.-P.; Vicente, A.; Fernandez, C.; Valtchev, V. Comparative Study of Nano-Zsm-5 Catalysts Synthesized in Oh- and F- Media. Adv. Funct. Mater. 2014, 24, 257-264.

(432) Verboekend, D.; Nuttens, N.; Locus, R.; Van Aelst, J.; Verolme, P.; Groen, J. C.; Perez-Ramirez, J.; Sels, B. F. Synthesis, Characterisation, and Catalytic Evaluation of Hierarchical Faujasite Zeolites: Milestones, Challenges, and Future Directions. Chem. Soc. Rev. 2016, 45, 3331-3352.

(433) Sommer, L.; Mores, D.; Svelle, S.; Stöcker, M.; Weckhuysen, B. M.; Olsbye, U. Mesopore Formation in Zeolite H-Ssz-13 by Desilication with Naoh. Microporous Mesoporous Mater. 2010, 132, 384-394.

(434) Zhu, X.; Kosinov, N.; Hofmann, J. P.; Mezari, B.; Qian, Q.; Rohling, R.; Weckhuysen, B. M.; Ruiz-Martinez, J.; Hensen, E. J. M. Fluoride-Assisted Synthesis of Bimodal Microporous Ssz-13 Zeolite. Chem. Commun. 2016, 52, 3227-3230.

(435) Selzer, C.; Biemelt, T.; Werner, A.; Kaskel, S. Hierarchical Zeolite Zsm-58 as Shape Selective Catalyst for Methanol-to-Olefins Reaction. Microporous Mesoporous Mater. 2018, 261, 51-57.

(436) Van der Borght, K.; Batchu, R.; Galvita, V. V.; Alexopoulos, K.; Reyniers, M.-F.; Thybaut, J. W.; Marin, G. B. Insights into the Reaction Mechanism of Ethanol Conversion into Hydrocarbons on $\mathrm{H}-$ Zsm-5. Angew. Chem. 2016, 128, 13009-13013.

(437) Makshina, E. V.; Dusselier, M.; Janssens, W.; Degreve, J.; Jacobs, P. A.; Sels, B. F. Review of Old Chemistry and New Catalytic Advances in the on-Purpose Synthesis of Butadiene. Chem. Soc. Rev. 2014, 43, 7917-7953.

(438) Sushkevich, V. L.; Palagin, D.; Ivanova, I. I. With Open Arms: Open Sites of Zrbea Zeolite Facilitate Selective Synthesis of Butadiene from Ethanol. ACS Catal. 2015, 5, 4833-4836.

(439) Oikawa, H.; Shibata, Y.; Inazu, K.; Iwase, Y.; Murai, K.; Hyodo, S.; Kobayashi, G.; Baba, T. Highly Selective Conversion of Ethene to Propene over Sapo-34 as a Solid Acid Catalyst. Appl. Catal., A 2006, $312,181-185$.

(440) Zhu, Q.; Kondo, J.; Inagaki, S.; Tatsumi, T. Catalytic Activities of Alcohol Transformations over 8-Ring Zeolites. Top. Catal. 2009, 52, $1272-1280$.

(441) Bruijnincx, P. C. A.; Weckhuysen, B. M. Shale Gas Revolution: An Opportunity for the Production of Biobased Chemicals? Angew. Chem., Int. Ed. 2013, 52, 11980-11987.

(442) Koyama, T. R.; Hayashi, Y.; Horie, H.; Kawauchi, S.; Matsumoto, A.; Iwase, Y.; Sakamoto, Y.; Miyaji, A.; Motokura, K.; Baba, T. Key Role of the Pore Volume of Zeolite for Selective Production of Propylene from Olefins. Phys. Chem. Chem. Phys. 2010, $12,2541-2554$.

(443) Iwase, Y.; Sakamoto, Y.; Shiga, A.; Miyaji, A.; Motokura, K.; Koyama, T.-r.; Baba, T. Shape-Selective Catalysis Determined by the Volume of a Zeolite Cavity and the Reaction Mechanism for Propylene Production by the Conversion of Butene Using a ProtonExchanged Zeolite. J. Phys. Chem. C 2012, 116, 5182-5196.

(444) Foster, M. D.; Rivin, I.; Treacy, M. M. J.; Delgado Friedrichs, O. A Geometric Solution to the Largest-Free-Sphere Problem in Zeolite Frameworks. Microporous Mesoporous Mater. 2006, 90, 32-38. (445) Dai, W.; Sun, X.; Tang, B.; Wu, G.; Li, L.; Guan, N.; Hunger, $\mathrm{M}$. Verifying the Mechanism of the Ethene-to-Propene Conversion on Zeolite H-Ssz-13. J. Catal. 2014, 314, 10-20.

(446) Jun, J.-W.; Khan, N. A.; Seo, P. W.; Kim, C.-U.; Kim, H. J.; Jhung, S. H. Conversion of Y into Ssz-13 Zeolites and Ethylene-toPropylene Reactions over the Obtained Ssz-13 Zeolites. Chem. Eng. J. (Amsterdam, Neth.) 2016, 303, 667-674.

(447) Corbin, D. R.; Schwarz, S.; Sonnichsen, G. C. Methylamines Synthesis: A Review. Catal. Today 1997, 37, 71-102.

(448) Sasaki, Y.; Fukatsu, M. Selective Catalysts for the Production of Nitrogen-Containing Compounds. Catal. Surv. Jpn. 1998, 2, 199-205.
(449) Shannon, R. D.; Keane, M.; Abrams, L.; Staley, R. H.; Gier, T. E.; Sonnichsen, G. C. Selective Synthesis of Dimethylamine over Small-Pore Zeolites. J. Catal. 1989, 115, 79-85.

(450) Keane, M.; Sonnichsen, G. C.; Abrams, L.; Corbin, D. R.; Gier, T. E.; Shannon, R. D. Selective Synthesis of Dimethylamine over Small Pore Zeolites. Appl. Catal. 1987, 32, 361-366.

(451) Ilao, M. C.; Yamamoto, H.; Segawa, K. Shape-Selective Methylamine Synthesis over Small-Pore Zeolite Catalysts. J. Catal. 1996, 161, 20-30.

(452) Weisz, P. B. Molecular Shape Selective Catalysis. Pure Appl. Chem. 1980, 52, 2091-2103.

(453) Weisz, P. B.; Frilette, V. J. Intracrystalline and MolecularShape-Selective Catalysis by Zeolite Salts. J. Phys. Chem. 1960, 64, 382-382.

(454) Miale, J. N.; Chen, N. Y.; Weisz, P. B. Catalysis by Crystalline Aluminosilicates: Iv. Attainable Catalytic Cracking Rate Constants, and Superactivity. J. Catal. 1966, 6, 278-287.

(455) Chen, N. Y.; Garwood, W. E. Some Catalytic Properties of Zsm-5, a New Shape Selective Zeolite. J. Catal. 1978, 52, 453-458.

(456) Gorring, R. L. Diffusion of Normal Paraffins in Zeolite T: Occurrence of Window Effect. J. Catal. 1973, 31, 13-26.

(457) Barrer, R. M.; Kerr, I. S. Intracrystalline Channels in Levynite and Some Related Zeolites. Trans. Faraday Soc. 1959, 55, 1915-1923.

(458) Santilli, D. S.; Zones, S. I. Secondary Shape Selectivity in Zeolite Catalysis. Catal. Lett. 1990, 7, 383-387.

(459) Yun, J. H.; Lobo, R. F. Effects of Temperature Pretreatment on Propane Cracking over H-Ssz-13 Zeolites. Catal. Sci. Technol. 2015, 5, 264-273.

(460) Harris, J. W.; Liao, W.-C.; Di Iorio, J. R.; Henry, A. M.; Ong, T.-C.; Comas-Vives, A.; Copéret, C.; Gounder, R. Molecular Structure and Confining Environment of Sn Sites in Single-Site Chabazite Zeolites. Chem. Mater. 2017, 29, 8824-8837.

(461) Kunitake, Y.; Takata, T.; Yamasaki, Y.; Yamanaka, N.; Tsunoji, N.; Takamitsu, Y.; Sadakane, M.; Sano, T. Synthesis of Titanated Chabazite with Enhanced Thermal Stability by Hydrothermal Conversion of Titanated Faujasite. Microporous Mesoporous Mater. 2015, 215, 58-66.

(462) Dusselier, M.; Davis, M. E. US20160243531 A1, 2016.

(463) Roman-Leshkov, Y.; Davis, M. E. Activation of CarbonylContaining Molecules with Solid Lewis Acids in Aqueous Media. ACS Catal. 2011, 1, 1566-1580.

(464) Orazov, M.; Davis, M. E. Catalysis by Framework Zinc in Silica-Based Molecular Sieves. Chem. Sci. 2016, 7, 2264-2274.

(465) Barrett, P. A.; et al. Synthesis of a merlinoite-type zeolite with an enhanced $\mathrm{Si} / \mathrm{Al}$ ratioviapore filling with tetraethylammonium cations. J. Mater. Chem. 1998, 8, 2263-2268. 